\title{
ESTUDO EXPERIMENTAL EM UMA CENTRIFUGA DE PLASMA INICIADA POR ARCO NO VÁCUO
}

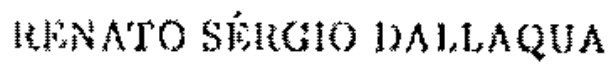 \\ TESE DE DOUTORADO
}

Orientador: Prof. Dr. RICARDo MAGNUS O. GALVÃo
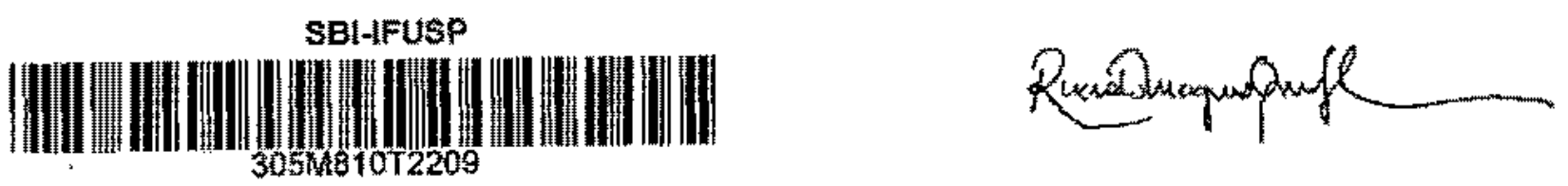

Banca Examinadora:

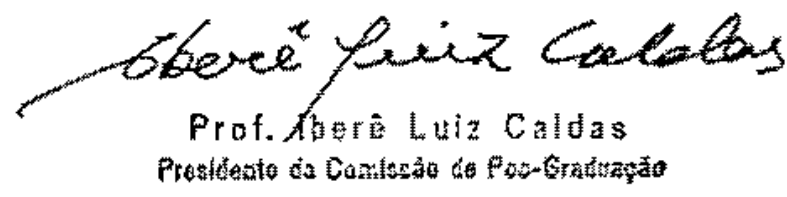

- Dr. Antonio de Pádua Brito Serbeto Instituto de Fisica - Universidade.Federal Fluminense

- Dr. Hugo Franco

Instituto de Fisica - Universidade de Sầ Paulo

- Dr. Mário Veda

Instituto Nacional de Pesquisas Espaciajs

- Dr. Ruy Pepe da Silva

Instituto de Fisica - Universitide de Săo Paulo

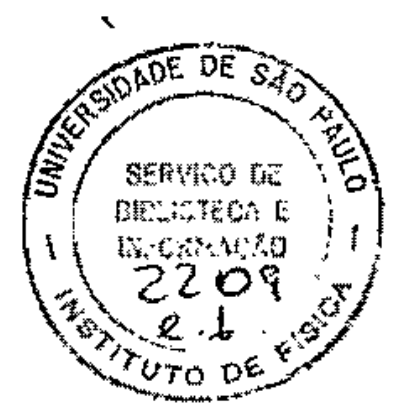

UNIVERSIDADE DE SAO PAULO

INSTITUTO DE FISICA 


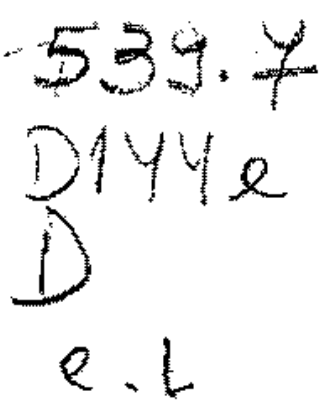

\section{FICHA CATALOGRÁFICA}

Preparada pelo Serviço de Biblioteca e Informaçăo do Instituto de Física da Universidade de Sāo Paulo

\section{Dallaqua, Renato Sërgio}

Estudo experimental em uma centrífuga de plasma iniciada por arco no vácuo. São Paulo, 1994

Tese (Doutorado) - Universidade de Săo Paulo. Ins tituto de Física. Departamento de Fisica Nuciear.

Área de Concentração: Física Nuclear.

Orientador: Prof. Dr. Ricardo Magnus Osório Galvăo.

Unitermos: 1. Centrifuga de plasma; 2. Separação isotópica; 3. Descarga em arco no vácuo; 4..1sotópicos no vácuo. 


\title{
ESTUDO EXPERIMENTAL EM UMA CENTRÍFUGA DE PLASMA INICIADA POR ARCO NO VÁCUO
}

\author{
RENATO SÉRGIO DALLAQUA \\ ORIENTADOR PROF.RICARDO MAGNUS O. GALVÄO
}

TESE DE DOUTORADO

UNIVERSIDADE DE SĀO PAULO

INSTITUTO DE FÍSICA 


\section{AGRADECIMENTOS}

Ao Prof. Ricardo M.O.Galvão pela orientaça e estímulo sempre dados para que o trabalho fosse desenvalvido.

Aos Drs. G.O.Ludwig e A.Montes que possibilitaram os recursos e condiçôs tăcaicas necessarias para o desenvolvimento do projeto centrífuga de plasma.

Ao Dr. Edson Del Bosco que iniciou o projeto junto ao LAP/INPE em 1981 a a qual me juntei em 1982. Durante estes anos todos a cooperação mútua tornou possível vencer muitos obstáculos apresentados no desenvolvimento deste experimento.

Ao Dr.Rui Pepe da Silva que ceden gentilmente os esquemas do circnito de varredura para ser montado no LAP/INPE, viabilizando a obtençäo de muitos dos dados apresentados neste trabalho.

Ao Dr.\$.W.Simpson que sugeriu o estudo da influểncia de gases restiduais nos parametros da centrifuga de plasma (Capitulo 4) e sua participaçäo ativa na obtençäo e análise dos dados.

A Beatria J.Rojas pela datilografia e a Patricia R.P.Barreto pela diagramaçāo deste trabalho. Aos colegas pesquisadores, técnicos e estudantes do LAP/INPE do IFUSP pelo estimulo e ajuda que me foram dadas para a realizaçäo deste trabalho. 


\section{RESUMO}

Na decada de 80 houve um aumento na utilização de isótopos estáveís em fŕsiç muclear, medicina nuclear, ciências biomédicas, geociências etc e, as previsöes indicam para um crescimento no consumo destes isótopos nas próximas decadas. Dentro deste quadro nowas zaétodos de separação isotópica foram propostos e desenvolvidos, entre eles, a centrifuga de plasma iniciada por arco no vácuo. Este trabalho mostza os resultados experimentais obtidos na centrifuga de plasma iniciada por atco no vácno desenvolvida no l,AP/WNPE desde 1981. Inicialmente é feita uma descriçẳo da descarga em areo no văcuo, que é a fonte de plasma desta centrífuga $e$, com as medidas realizadas, uma caracterizaçäo completa do plasma pode ser obtida. Os resultados teóricos obtidos de un rnodelo de fluido para coluria de plasma em rotação sắo comparados com os obtidos experimentalmente e, algumas limitaçoes deste separador isotópico sẫo mencionadas. Os efeitos de gases residuais nos parâmetros do plasma desta centrifuga foram estudados e, os resultados mostraram que o melhor desempenho deste separador ocorre na ausência de gases na câmara de vácuo. Dos resultados experimentais obtítos fol feito um estudo comparativo entre os diferentes métodó de supara̧̧äo isotópica e, observaçôes conclusivas foram possíveis sobre a viabilidade de uma centrifuga de plasma iniciada por arco no vácuo como um dispositivo para a separaçณ̄o de isótopos estáveís. 


\begin{abstract}
In the 80 's, an increase in the utilization of stable isotopes in the nuclear physics, muclear medicine, biomedical science, geoscience has been observed. The previsions indicate that the consumption of these isotopes in the early future will be even higher. Within this pitture new methods of isotope separation were proposed and developed, arnong them, the vacuum are plasma centrifuge. This work shows the experimental results obtained in the vacuun arc plasma centrifuge developed at LAP/WNPE since 1981. Initially we describe the vacum arc discharge which is the plasma source in this device. The measurements performed provide a full characterization of the plasma. The experimental result were compared with that ones expected using an MHD model for a rotating plasma column. The limitations of this isotopie separator are discussed. The effects of residual gases in the plasma parameters of the vacuum are plasma centrifuge were studied and the results shown that the best performance oecurs in the absence of gases in the vacutun chamber. The experimental results obtained were used to make a comparative study between different methods of isotope separation and conclusive remarks were achieved about the viability of a vacuum are plasma centrifuge as a device for stable istotope separation.
\end{abstract}


Dedico a Beatriz e Fernanda Beatriz pelo apoio compreensẵo dada durante a realizaçäo deste traballo. 


\section{Conteúdo}

INTRODUCÂA

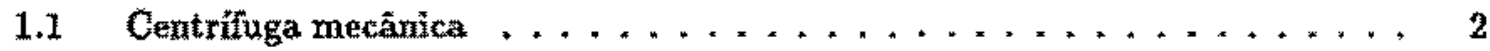

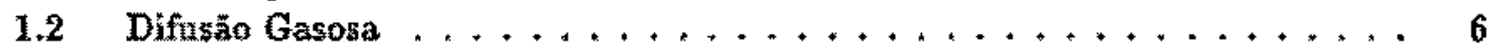

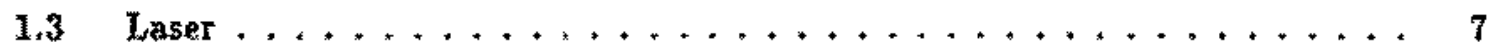

1.4 Ressonância ton ciclotronica ................... 8

I.5 Calutrons ............................. 10

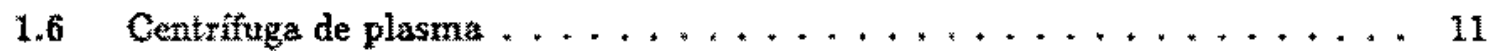

1.7 Centrufuga de plasma iniciada por arco no wácuo ........... 12

2 DESCARGA EM ARCO NO VACUO

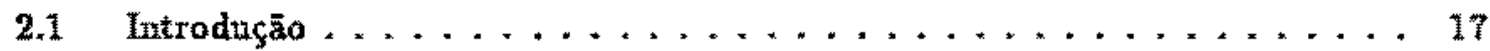

2.2 Descarga em arco no vắcuo. ....................... 18

2.2.1 Modelo para ponto luminoso quase-estacionărio ou térmico (Tipo 2) 29

2.2.2 Emissão explosiva de elátrons e pontos luminosos năo estacionários-

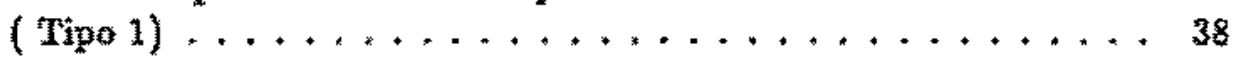

2.2.3 Método das regiöes de existência dos pontos luminosos . . . . . . 41

2.2 .4 Efeitos do campo magnético sobre a descarga em arco no vắcuo . . 41

2.3 Impedancia do plasma a circuito formador de pulso construído . . . . 47

2.4 Tensäo de arco, erosăo e consumo de energia para a produçăo dos íons . . . 55

2.5 Velocidade axial de deriva, temperatura de elétrons, densidade de partículas carregadas e potencial de plasma $\ldots \ldots \ldots \ldots \ldots \ldots \ldots \ldots$

2.5 .1 velocidade axial de derivs $\ldots \ldots \ldots \ldots \ldots$

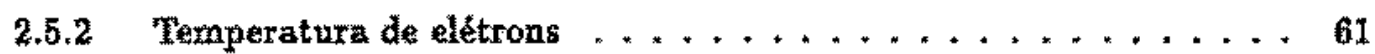

2.5.3 Densidade de partículas carregadas $\ldots \ldots \ldots \ldots \ldots \ldots$

2.5 .4 Potencial de plasm .....................66 6

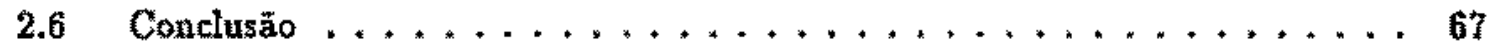

3 DESCRIÇO MAGNETOHIDRODINAMICA PARA A COHUNA DE PLASMA E OS RESULTADOS EXPERIMENTAIS T0

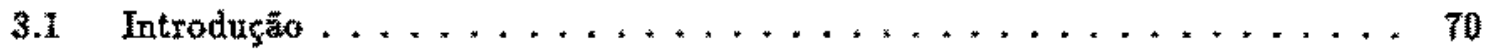

3.2 Descriçấo física da coluna de plasma em rotaçăo . . . . . . . . . 70

3.3 Modelo de fluido para a coluna de plasma emo rotaçăo .......... 73

3.3.1 Campo elétrico radial e potencial de plasma ou espacial ...... 79

\$.3.2 Densidade de particulas carregadas ............... 80

3.3 .3 Velocidade angular $\ldots \ldots \ldots \ldots \ldots$

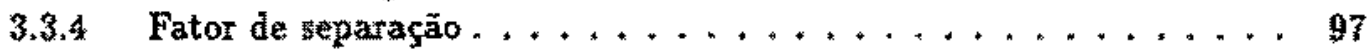

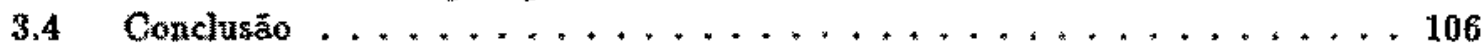

4 EFEITOS DE GASES RESIDUAIS NOS PARAMETROS DA CENTRIFUGA DE PLASMA INICIADA POR ARCO NO VÁCUO

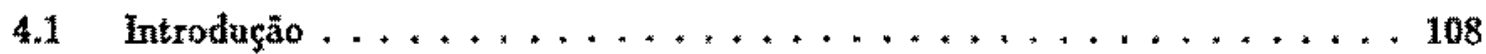

4.2 Infuência de gases residuais nos parâmetros: temperatura de elétrons, densidade de partículas carregadas, velocidade angular e no fator de separaçäo. 108 
4.2.1 Efeitos de gases resituais na temperatura de elétıons . . . . . . 109

4.2.2 Efeitos de gases residuais na densidade de partículas carregadas . . 111

4.2.3 Efeitos dos gases residuais na velocidade angular . . . . . . . . 112

4.2 .4 Efeitos de gases residuals no fator de stparação. . . . . . . . . 121

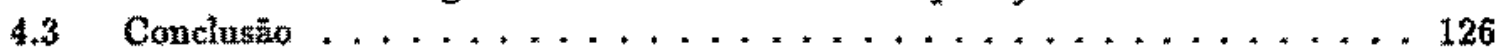

5 ESTUDO COMPARATTVO ENTRE OS DIVERSOS MÉTODOS DE SEPARAGÄO ISOTÓPICA APRESENTADOS

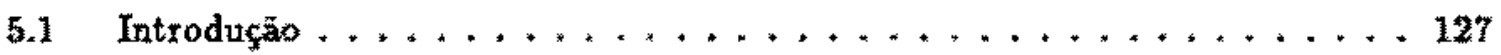

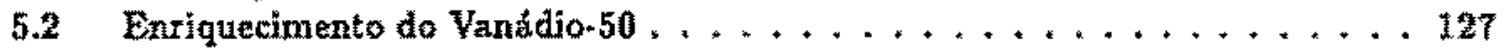

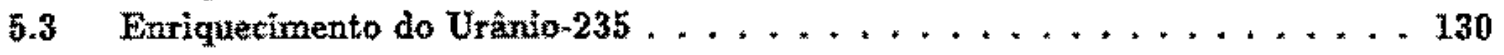

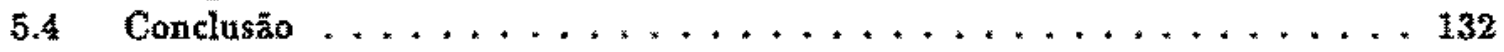

6 CONCLUSĀO 


\section{Lista de Figuras}

1.1 Esquema da centrifuga meeanica. $\ldots \ldots \ldots \ldots \ldots \ldots$

1.2 Perfil radial da densidade dos ísótopos numo centrífuga gasosa. . . . . . 4

1.3 Principio de funcionamento da difusäo gasosa. . . . . . . . . .

1.4 Esquema para separaçăo isotópica utilizando laser. . . . . . . . . . 8

1.5 Princípio de funcionarnento da ressonância fon ciclotröníca. . . . . . . . . 9

1.6 Esquema de funcionamento do Calutron. . . $\ldots \ldots \ldots \ldots \ldots$

1.7 Esquema de uma centrifuga de plasma. . . . . . . . . . . 12

1.8 Esquema do experimento centrífuga de plasma iniciada por arco no vácuo (PCEN) desenvolvida no $\mathrm{WAP} /$ INPE. . . . . . . . . . . . . 14

2.1 Pulso típico de corrente de arco $\left(I_{a}\right)$ e da tensão de arco $\left(U_{a}\right)$ para catodo de magnésio e campo magnético axial do 0,1T, obtido na PCEN. . . . . 19

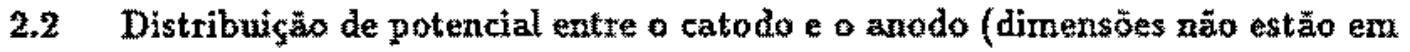

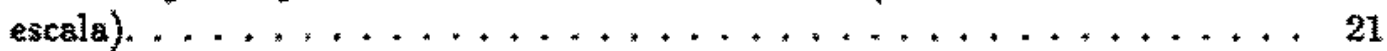

2.3 Origem das partículas num arco difuso. . . . . . . . . . . . 23

2.4 Número médio de pontos lumincosos em funçăo da corrente de arco para cinco materiais[21]. .......................... 24

2.5 Distribuiçäo da densidade de corrente te íons origimada de um ponto luminoso. 27

2.6 Energia dos íns por unidade de carga como funçäo da corrente de arco para

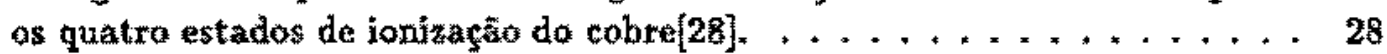

2.7 a) Descriçāo do ponto luminoso quase-estacionário. b) Perfil do potencial elétrico entre o catodo e onodo. ................... 34

2.8 Potencial elétrico tipo corcova na regiäo $2[28] \ldots \ldots \ldots$

2.9 Modelo da emissä́o explosiva de elétrons para os pontos luminosos. . . . . 40

2.10 Diagrama de existencia para os pontos luminosos no catodo de cobre as processos dominantes de ganho e perda de energia ns auperficie do catodo $(\mathrm{A}=\mathrm{aquecimeato}, \mathrm{D}=$ desaquecimento $)[56,57] \ldots \ldots \ldots \ldots \ldots$

2.11 a) Disposiçäo dos campos na PCEN. b) Modos da instabilidade de dobra. . 43

2.12 Distribuiçẫo angnlar da cotrente de fons com o campo magnético axial aplicado, $I_{i}$ e corrente de íns por unidade de ángulo sólido[59]. . . . . . 44

2.13 Expansäo do plasma a partir da cratera a) sem e b) com campo magnético tangencial $\left(B_{T}\right)$ á superficie do catodo[60]. $\ldots \ldots \ldots \ldots, \ldots \ldots$

2.14 Pulso de corrente ne PCEN antes de $1989 \ldots \ldots \ldots \ldots \ldots \ldots$

2.15 Esquema do circuito formador de pulso ou linha de transmissäo LC. . . . . 48

2.16 Formas de onda da corrente na carga conforme a relaçäo entre $Z_{0}$ e $z_{p} \ldots \ldots 49$

2.17 Esquema do circuito formador de pulso levando em conta a resistência série e paralelo do capacitor e a resistência série do indutor. . . . . . . 50

2.18 Diagrama para obtençäo das equaçöes de Kirchhoff para o circuito formador de pulso. . . . . . . . . . . . . . . . . . 51

2.19 Forma final do circuito formador de pulso. . . . . . . . . . 53

2.20 Pulsos da corrente de arco e do campo magnétíco axial. . . . . . . . . 54

2.21 a) Taxa de erosâo como funçäo da corrente de arco $I_{a}\left(B_{*}=0,1 T\right)$ e b) como funçăo do campo magnético $B_{2}\left(I_{\mathrm{a}}=1,5 k, 4\right)[66] \ldots \ldots \ldots$ 
2.22 Porcentagem de fons de magnésio transmitidos atravês da grade como função do campo magnético[ 60$]. \ldots \ldots \ldots \ldots \ldots \ldots \ldots$. . . . . .

2.23 Estquema para aquisiçăo análise des curva caracteristícs da sonda de Langmuir. 60

2.24 Temperatura de elétrons versus corrente de arco para os catodos de $\mathrm{C}, \mathrm{Mg}$ e Cd. ................................ 61

2.25 Temperatura de elétrons como funçằo do campo magnético axial com $l_{a}=$ $1,5 k$ A para os catodos $\mathrm{C}, \mathrm{Mg}$ e Cd. . . . . . . . . . . .

2.26 Corrente de saturaçắo de ions para os catodos $\mathrm{C}, \mathrm{Mg}$ e $\mathrm{Cd}$ como funçấ da corrente de arco $\left(B_{z}=0,1 T\right.$ e $\left.=0\right) \ldots \ldots \ldots \ldots$

2.27 Densidade de ions $C^{+}$versus o campo magnético axial $\left(I_{a}=1,1 k A, r=0\right)$.

3.1 a) Velocidades de deriva resultantes na direçäo azimutal para os elêtrons $\left(u_{\varphi \varphi}\right)$ e íons $\left(u_{i \varphi}\right)$ e a densidade de corrente $J_{\varphi}$. b) Diagrama esquenática das forças atuando na coluna de plasma $\left(\vec{F}_{C}=\right.$ força centrifuga, $\vec{F}_{y}=\overrightarrow{J_{i 0}} \times$ $\vec{B}$ e $\vec{F}=-\nabla p) \ldots \ldots \ldots \ldots \ldots \ldots$

3.2 Perfil radial da temperatura de elétrons para os plasmat de carbono e magnésio $\operatorname{com} l_{a}=1, y_{k} A_{1}, B_{x}=0,1 T^{k}$ e $t=8 \mathrm{~ms} \ldots \ldots \ldots \ldots$

3.3 a) Perfil temporal da densidade de partículas carregadas. b) Perfil temporal da temperatura de elétrons, para carbono e magnésio com $I_{a}=1,5 k A$, $B_{x}=0,1 T$ e $r=0 \ldots \ldots \ldots \ldots \ldots \ldots \ldots$

3.4 Perfil radial do potencial flutuante de glasma para plasma de carbono $\left(I_{\mathrm{a}}=1,5 \mathrm{k}, B_{\mathrm{z}}=0,1 T_{\mathrm{e}} \mathrm{i}=8 \mathrm{~ms}\right) \ldots \ldots \ldots \ldots$

3.5 Perfil radial do potencial fiutuante e de plasma para plasma de magnésio $\left(I_{n}=1,5 k, A_{1} B_{z}=0,1 T\right.$ e $\left.t=8 m s\right) . \ldots \ldots \ldots . \ldots \ldots$

3.6 Perfil radial da densidade de ions para o plastna de arbono. . . . . . . 83

3.7 Perfil radial da densidade de ínz para o plasma de magnésio . . . . . . 84

3.8 Esquema para medir a velocidade angular utilizando-se duas sondas. ... . 86

3.9 Sinaís do poteneial flutuante apresentados pelas sondas durante o pulso de

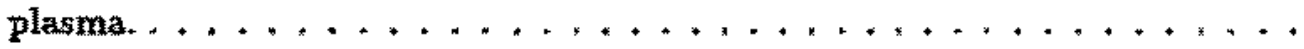

3.10 Sinais da Fig. 3,9 expandidos em torno to tempo da descarga $t=12,5 \mathrm{~ms}$, .

3.11 Perfil temporal da velocidade angular no plasma de magnésio com $I_{a}=$ $1,5 k A_{1} B_{2}=0,1 T$ e $r=15 \mathrm{~mm} \ldots \ldots \ldots \ldots$

3.12 Perfil radial da yelocidade angular para uma coluna de plasma de magnésio.

3.13 Flututaços apresentadas pelas sondas para o raio $x=30 \mathrm{~mm} . \ldots \ldots \ldots$

3.14 Flutuaçōes apresentadas pelas sondas para o rajo $\mathrm{r}=40 \mathrm{~mm} . \ldots \ldots \ldots$

3.15 Sinats da Figura 3.13 expandidos em torno do tempo $t=12,5 \mathrm{~ms} . \ldots \ldots$

3.16 Velocidade angular em fungäo do campo magnético axial para os plasmas de magnésio, zinco, cádmio e chumbo para $r=20 \mathrm{~mm}$ cam $Y_{a}=0,9 k A$ (valor de pico) [77].

3.17 Duas possibilidades para as oscilaçōes apresentadas pelas sondas a) coluna estacionária e a onda viajando ao redor da coluna $\mathrm{e}$ b) a coluna girando e a anda "travads" sobre coluna. . . . . . . . . . . . . . 96

3.18 Sinal do pulso de corrente do espectrômetro de massa para uma massa fuxa. 99

3.19 Especiro de rnassa obtido e o melhor ajuste aos pontos experimentais, $\mathrm{r}=$

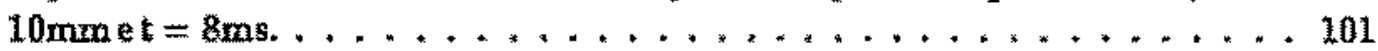

3.20 Fator de separaçấo como funçäo do tempo, $r=10 \mathrm{~mm} . \ldots \ldots \ldots \ldots$

3.21 Perfil radial para o valor médio do fator de separaçăo tomado entre os instantes $t=4 \mathrm{~ms}$ e $t=14 \mathrm{~ms}$ da descarga para o isötopo $\mathrm{Mg}-25, \mathrm{O}-$ dados experimentais. ............................. 104

3.22 Perfil radial para valor médio do fator de separação tomado entre os instantes $t=4 \mathrm{~ms}$ e $t=14 \mathrm{~ms}$ para o isótopo $\mathrm{Mg}$-26, $\mathrm{O}$. dados experimentais. 105

3.23 Fator de separaçăo como funçăo do campo magnétíco, para plasma de magnésio com $I_{a}=l_{2} 7 k A$ (valor de pico) e $r=40 \mathrm{~mm}[79] \ldots \ldots \ldots$ 
4.1 Evoluçăo temporal da temperatura de elétrons quando são introduzidos separadamente os gases hidrogento, hélio argönio na descarga $(r=0)$. A linha tracejada e o valor médio dos pontos experimentzís na condiçäo de vácuo

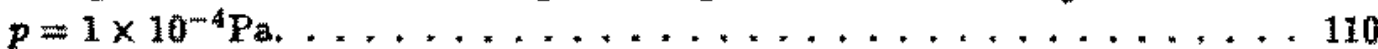

4.2 Temperatura de elétrons como funça da pressăo do hidrogénio como gás residual nos instantes $1=2,8$ e 12 mos da descarga $(r=0)$.

4.3 Corrente de saturaç⿳⺈冂大 de jous como funçäo do tempo da descarga al com găs hidrogënio na cắrnara; b) com gấs hélio. A linha tracejada é o valor médio dos pontos experiment ats na condiçăo de vácuo $p=1 \times 10^{-4} \mathrm{P}_{3} \ldots \ldots \ldots 113$

4.4 Corrente de saturạ̧ăo de ions versus pressäo do gás hidrogêno para dois instanteg da descarga. . . . . . . . . . . . . . . . . 114

4.5 Padrăo de oscilaçăo do potencial flutuante apresentado pelas sondas com argonio a pressão $p_{A \varepsilon}=5 \times 10^{-2} P_{a, r}=15 \mathrm{~mm} \ldots \ldots \ldots 115$

4.6 Sinaïs da Fig.4.5 expardidos em torno do tempo $t=12,5 \mathrm{~ms}$ da descarga. . . 116

4.7 Sinas apresentados pelas sondes para $\mathrm{z}=40 \mathrm{~mm}$ e $\mathrm{F}=1 \times 10^{-4} \mathrm{~Pa}$, expandi-

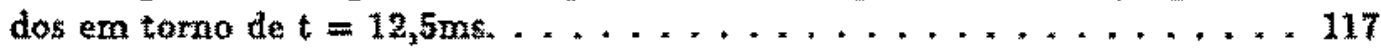

4.8 Sinais apresentados pelas sondas para $=40 \mathrm{~mm}$ e $\mathrm{p}=5 \times 10^{-2} \mathrm{~Pa}_{\text {, expandi- }}$

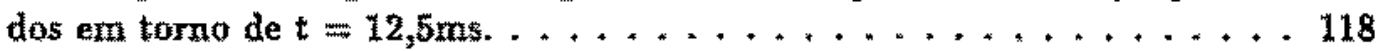

4.9 Evaluçằo temporal da velocidade angular com a introduçäo dos gases: a) hidrogênio; b) hellio e c) argônio. A linha tracejada é o valor médio dos pontos experimentais na condiçăo de vácuo $p=1 \times 10^{-4} \mathrm{~Pa} \ldots \ldots \ldots .119$

4.10 Velocidade angular como funçüo da pressẫo para três intstantes da descarga: a) $t=2,5 \mathrm{~ms} ;$ b) $t=7,5 \mathrm{~ms}$ e c) $t=12,5 \mathrm{~ms}$. A linha tracejada é valor obtido para a velocidade angular na condiçăo de vácuo $p=1 \times 10-4 \mathrm{P}_{\mathrm{a}} . \ldots 120$

4.11 Perfil radial da valocidade angular com aresença de gás residual, $p=$ $1 \times 10^{-4} P_{a}$ (vácuo), $P=1 \times 10^{-1} P a\left(H_{2}\right) p=5 \times 10^{-2} P a($ Ar) no instante

4,12 Evoluçăo temporal do fator de separaçäo com hidrog enio ma pressăo $p=$

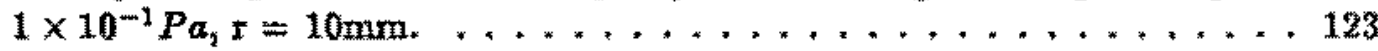

4.13 Fator de separaçấo para o isótopo ${ }^{25} \mathrm{Mg}$ tomado entre os instantes $\mathrm{t}=4$ mos $\mathrm{e} t=14 \mathrm{~ms}$ da descarga para várias posiçốt radiais nas pressôtet: $\mathrm{O} p=$ $1 \times 10^{-4} \mathrm{~Pa}$ (vácuo $) \mathrm{A} \mathrm{p}=1 \times 10^{-1} \mathrm{~Pa}\left(\mathrm{H}_{\mathrm{a}}\right) . \ldots \ldots \ldots \ldots \ldots$

4.14 Fator de separação para o isótopo ${ }^{76} \mathrm{Mg}$ tomado entre os instantes $t=4 \mathrm{~ms}$ e $=14$ ms da destarga para várias posiçöes radiais nas pressōes: $O p=$

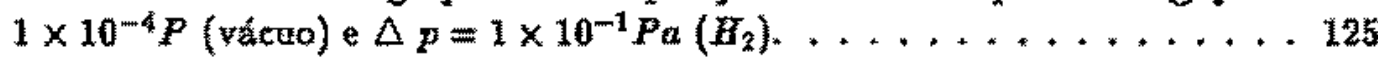




\section{Lista de Tabelas}

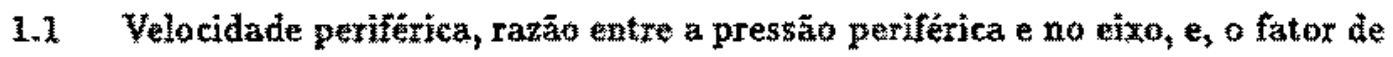
separação para o gás $U F_{\mathrm{G}}$ com $\mathbf{T}=\mathbf{3 1 0 \mathrm { K }} \ldots \ldots \ldots \ldots \ldots$

1.2 Tensão de cisalhamento, densidade e velocidade periférita máxima suportada

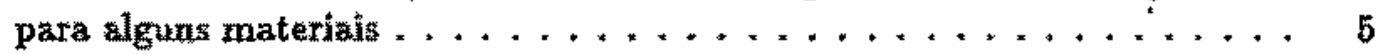

1.3 Comparaçāo entre dois experimentos utilizando ressonancia fon-ciclotrönica 9

1.4 Consumo de energia para enxiquecer $1 \mathrm{~g}$ de vanádio-50 por quatro métodos diferentes ................................ 11

1.5 Experimento com centrifuga de plasma parcialmente ionizado ...... 13

2.1 Densidade de corrente de elétrons emitidos pelo catodo $\left(A / m^{2}\right) \ldots \ldots 2$

2.2 Velocidade média do ponto luminoso $(\mathrm{m} / \mathrm{s})$ para trés instantes da descarga

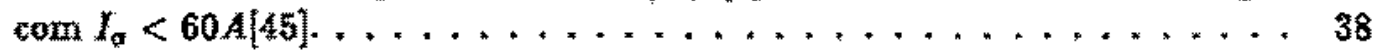

2.3 Inpedância (ern mn) para os plasmas de magnésio, zinco, cádmio e chumbo 52

2.4 Parämetros para a descarga em arco no vácuo na PCEN para oito catodos diferentes, corn corrente de arco de $1,5 \mathrm{kA}$ e campo magnético axial de 0,1T. 67 


\section{CAPÍTULO 1}

\section{INTRODUÇÃO}

Neste trabalho é dado continuidade a estudo da separacăo isotópica numa centrifugza de plasma iniciadz por arco no vácuo, experimento este que teve inf́lo em 1981 no Laboratório Associado de Plasma do Instituto Nacional de Pesqựas Espaciais.

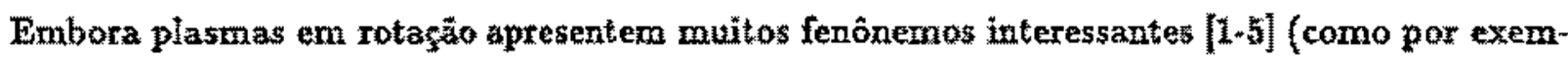
plo: ondas de deriva, efeitos devilo à força de Coriolis, e ete.), com aplicaçöes espaciais, os experimentos em laboratório tem dado atençăo especial à separaçäo isotópica esta é a ênfase dada so presente trabalho.

Atualmente há um erescimento no uso de isótopos em áreas tais como: energia nuelear, agrím cultura, medicina nuclear, ciências biomédicas, química, fisicica nuclear ete. Com relaçắa ì geraçằ de energia, utiliza-se o isótopo uränio-235 enriquecido a 2-3\% corn consumo de centenas a milhares de tondadas por ano. Como exemplo, uma usina nuclear de 1000MW (6,6 TWh/ano, aproximadamente a energia consumida por Paris em um ano), consumirá 27 toneladas de uränio (2.3\% de enriquecimento, reator PWR) ou 160 toneladas de urànio natural. Difusä̃o gasosa, no passado, e, presentemente, ocorrendo um aumento na utìlizaçẳo da centrífuga mecânica (ou gasosa), săo os métodos comercialmente usados gara obtençäo do urảnio-235 enriquecido.

Üm quadro completamente diferente é apresentado no uso de isŏtopos estávels na ắrea de pesquisa. Neste caso ha mas de 200 isỏtopos utilizados com quantidades variando de algamas $\mathrm{mg}$ a milhares de mg com aplicaçôes mứto variadas, tornando impossiviel sintetizá.las em poucas linhas [6]. Estes isótopos sắo obtidos a um custo elevado em aparelhos chamados Ca- 
lutrons, no Oak llidge National Laboratory. De particular interesse sāo as pesquisas em medicina nuclear/ciências biomédicas, onde o desenvolvimento de um tratamento ou medicamento de uzo corrente terá um grande retorno social e financeiro. Havendo um crescimento no constumo de isótopos estáveís ocorrerá uma procura a novos métodos de separaçäo ísotópica de custos maits bainos.

Com o objetivo de se introduzir slguns parâmetros e de se descrever os príncípios fisicos de funcionamento, assim como discutir suas linitaçôs, sete métodos de separaçầo de isótopos šeräo analìsados resumidamente, a saber: centrifuga mecânica, difusāo gasosă, laser, ressonäncia ion ciclotrônica, calutrons, centrifuga de plasma e centrífuga de plasma inieiada por arto no vắcươ.

\subsection{Centrifuga mecânica}

O principio de funcionamento de uma centrifuga mecànica é como segue. Inicialmente os isótopos numa forma gasosa (por exemplo: gás $\mathrm{UF}_{6}\left({ }^{3 a s} \mathrm{UF}_{6}{ }^{238} \mathrm{UF}_{6}\right)$ ), a uma pressão da ordem de 100 Torr ( densidade $10^{23}-10^{24} \mathrm{~m}^{-3}$ ), estâo contidos em um cilindro de raio típico $\sim 0,1 \mathrm{~m}$ e cerca de 1ma de comprimento, como mostrado na Figura 1.1. O cilindro é colocado em rotaçảo zo redor do seu eixo com velocidade angular $\omega_{1}$, assim, $_{\text {, }}$ forças vistosas colocam o gás dentro do cilindro em rotação. A força centrifuga faz com que as espécies mais pesadas se desloquem para a periferia do cilindro, ocorrendo entāo, uma separaçāo dos isốtopos na direçăo radial.

Para uraa mistura isotérmica de dois isótopos, com densidades $\mathrm{n}_{1_{3}} \mathrm{n}_{2} ;$ massas $\mathrm{M}_{1}, \mathrm{M}_{2}$ e temperatura $\mathrm{T}$, o movimento do gás no estado estacionário é uma rotaçāo de corpo rígido, com cornponentes de velocidades $\mathbf{u}_{y}=0, \mathbf{u}_{\varphi}=\omega r$ e $u_{z}=0$, e as equaçöes que descrevem o sistema são a equaşầ de estado e o componente radial da equação de movimento, dadas por

$$
\begin{aligned}
p_{j} & =n_{j} k_{B} T \\
\frac{d p_{j}}{d} & =n_{j} M_{j} z^{2} r_{3}
\end{aligned}
$$




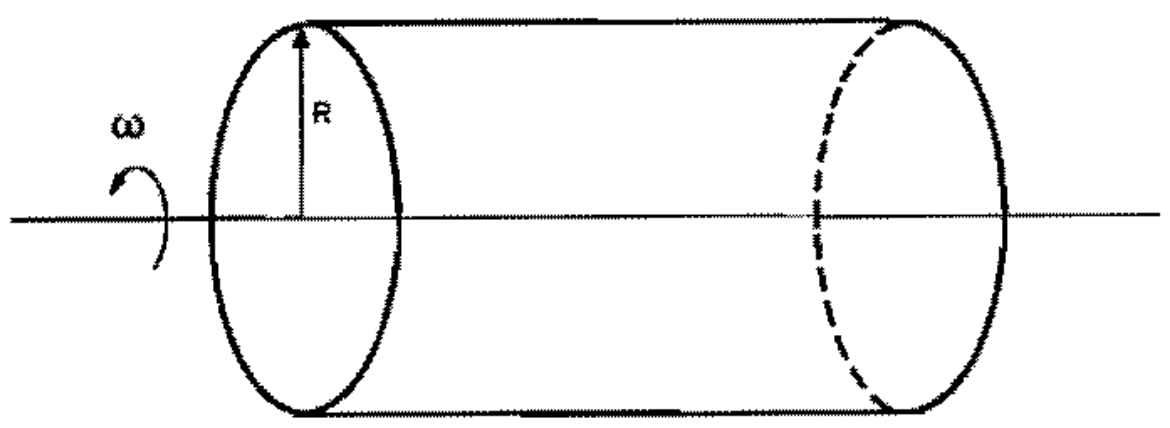

Figura 1.1. Esquema da centriffuga mecểnica.

onde $p$ é a pressäo, $\omega$ a velocidade argular e $k_{B}$ a constante de Boltzmann $(\mathrm{j}=1,2)$.

Substituindo (1.1) em (1.2) obtếrn-se

$$
\frac{d n_{j}}{n_{j}}=\frac{M_{j}}{k_{n}{ }^{2}} \omega^{2} r d r
$$

Integrando (1.3) entre o eixo $(r=0)$ e a parede $(r=R)$ resulta em

$$
\frac{n_{j}(n)}{n_{j}(0)}=\exp \left[\frac{M_{j} \omega^{2} n^{2}}{2 k_{B} T}\right]
$$

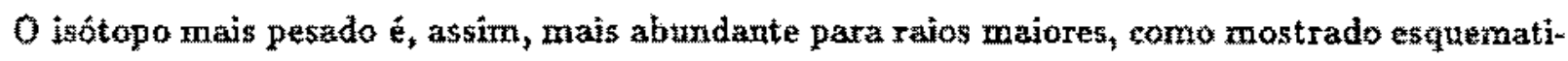
camente na Figura 1,2.

O fator de separaçắo, $\alpha$, é definido por

$$
\alpha=\frac{\left(n_{1} / n_{2}\right)_{R}}{\left(n_{1} / n_{2}\right)_{0}}=\exp \left[\frac{\left(M_{1}-M_{2}\right) \omega^{2} R^{2}}{2 k_{B} T}\right]
$$




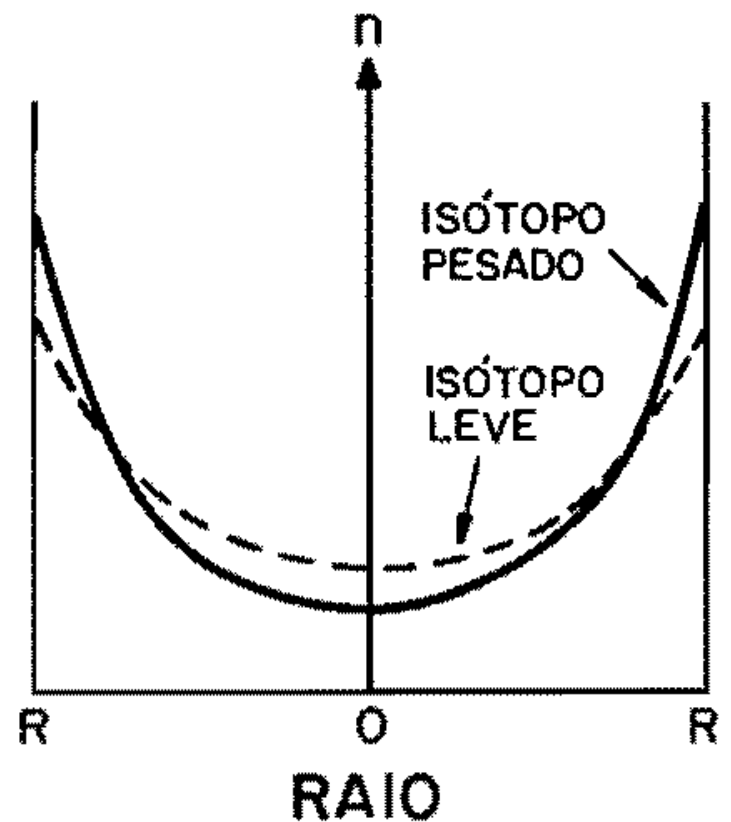

Figura 1.2. Perfil radial da densidade dos isótopos numa centrínga gasosa.

Obtendo-se alta velocidade periferica $\left(u_{\psi}=\omega R\right)$ e baixa temperatura ofator de separação serả alto. A ternperatura típica dos gases na centrifuga mecănica e $310 \mathrm{~K}(0,03 \mathrm{eV})$. A velocidade periférica está lìmitada pela zesesistência mecäniea do material utilizado na construçāo da cāmara cilindrica. Para yer o problema da resistência mecănica do material é melhor reescrełer a equaçào (1.4) em termos ds pressão no eixo e na periferia tendo-se entä̌o

$$
\frac{p_{j}(R)}{p_{j}(0)}=\exp \left(\frac{M_{j} w^{2} R^{2}}{2 k_{B} T}\right)
$$

A Tabela 1.1 apresenta os valores obtidos da razzo $p_{j}(R) / p_{j}(0)$ e do fator de separaçă para diferentes velocidades periférica, para o gás $U F_{6}$ a $310 \mathrm{~K}$.

A. Tabela 1.2 apresentu dados para alguns materiais [7].

Observa-te da Tabela 1.2 a existência de materiais que suportam altas velocidades periféricas, o que entäo resultaria, em um fator de separação alto. A Tabela 1.1 mostra que neste caso a 
Tabela 1.1. Velocidade periférica, razäo entre a presstöo periférica e no eixo, e, o fator de separaçüo para o gás $U F_{6}$ com $T=310 \mathrm{~K}$

\begin{tabular}{|c|c|c|}
\hline Velocidade periférica $(\mathrm{m} / \mathrm{s})$ & Razắn $p_{j}(R) / p_{j}(0)$ & $a$ \\
\hline 400 & $5,5 \times 10^{4}$ & 1,0975 \\
500 & $2,5 \times 10^{7}$ & 1,156 \\
600 & $4,6 \times 10^{10}$ & 1,233 \\
700 & $3,3 \times 10^{14}$ & 1,329 \\
\hline
\end{tabular}

Tabela 1.2. Tensāo de cisalhamento, densídade e velocidade perifrérica máxíma suportads pars alguns nateriais

\begin{tabular}{|c|c|c|c|}
\hline Material & Tensz̃ $\left(10^{6} \mathrm{P}\right)$ & Densidade $\left(\mathrm{g} / \mathrm{cm}^{3}\right)$ & Veloc.Máxima $(\mathrm{m} / \mathrm{s})$ \\
\hline Kevlar & 1500 & 1,3 & 1100 \\
Liga de Al & 500 & 2,8 & 425 \\
Liga de Ti & 900 & 4,6 & 440 \\
Fibra de Vidro & 700 & 1,9 & 600 \\
Aço Alta Tensāo & 1700 & 8,0 & 455 \\
Fibra de Carbono & 1600 & 1,55 & 950 \\
\hline
\end{tabular}

diferença entre a pressão na periferia e no centro seria enorme. Este fato coloca pelo menos duas limitaçöes, a saber:

- a enorme diferença de pressão pode levar o gás a se cristalizar na periferia $\mathrm{e}_{3}$ assim, centrifuga mecãnica estă linitada a elementos que formam gases de alta pressão de vapor:

- esta diferença de pressüo pode levar o găs a estar em dois regines diferentes (molecular a turbulento), podendo entäo surgir instabilidades hidrodinamicas.

Estas limîtaçōes implicam que a velocidade periférica deve ser baixa o que diminue $\alpha$, A centrífuga gasosa tern a grande vantagem do fuxo molar ser grande, implicando em uma grande quantidade de material processado. Para se obter fator de separaçâo alto, utilizama-se cen* tenas ou até milhares (dependendo do enriquecimento desejado) de separadores em arranjos șéte/paralelo, significando um elevado investimento de capital na implantaçäo de uma uxina de enriquecimento isotópico.

Uma vez que tum método de separação isotópica texha a sua comprovaçắo científica, o próximo passo ê provar sua viabilidade conōmica, comparando-se corn outros métodos já existentes. Para se fazer tal comparaçāo é comumente utilizada (principalmente para o enxiquecimento do 
urânio) a funçāo valor definida por U=F.V(N) onde F 6 a razão temporal de fiuxo molsur de material e $V(N)$ é o potencial separativo ( $N=$ fraçäo molar do isótopo)[7,cap.2]. A unidade de tal funçăo é a unidade de trabalho separativo (SWU) com dimensão de massa; assim kgSWU è unidade usual. Para a centrífuga gasosa o valor máximo para a funçăo valor é dada pela expressäa

$$
U_{\max }=\frac{\pi}{2} p_{0} D \|(\alpha-1)^{2}
$$

onde $p_{0}=\mathrm{nM}$ a densidade, $\mathrm{D}$ o coeficiente de difusuro e lo comprimento do cilindro.

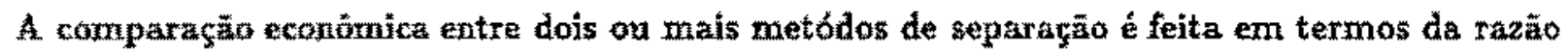
poténcia consumida ( $k$ Wh) por unidade de trabalho separativo, onde se busca o menor valor para esta razão. Parz a centrífuga gasosa tem-se $\sim 250 \mathrm{kWh} / \mathrm{kgSWU}$ (para a separaçäo do urânio). Embora esta razäo seja a mais comum, é possivel encontrar na literatura outras comparaçồ como por exemplo o consumo de energia (Joules) para a realizaça da separaçăo isotópica.

\subsection{Difusäo Gasosa}

Neste caso, o processo fisico de separaçāo se deve à diferença na difusāo através de um orificio por gases diferentes conforme mostrado na Figura 1.3.

Se $p_{b}$ for desprezável o fator de separação é dado por $[7$, cap.3 3$]$

$$
\alpha=\sqrt{\frac{M_{2}}{M_{3}}}
$$

Os seguintes resultados sä obtidos para $\alpha: \alpha\left[{ }^{238} \mathrm{UF}_{6},{ }^{235} \mathrm{UF}_{6}\right]=1,00429 ; \alpha\left[{ }^{22} \mathrm{~N}_{e},{ }^{20} \mathrm{~N}_{e}\right]=1,0488 \mathrm{e}$ $\alpha\left[^{40} \mathrm{Ar},{ }^{36} \mathrm{Ar}\right]=1,0541$. Normalmente $p_{b}$ näo é desprezível (há urn refluxo), o que significa que $\alpha$ é menor que o obtido da expressäo (1.8), por exemplo $\alpha=1,002$ para $\mathrm{VE}_{6}, 0$ custo da difusāo gasosa é $\sim 2500 \mathrm{kWh} / \mathrm{kgSWU}$, ou saja, cerca de 10 vezes maior que o da centrifuga mecănica. 


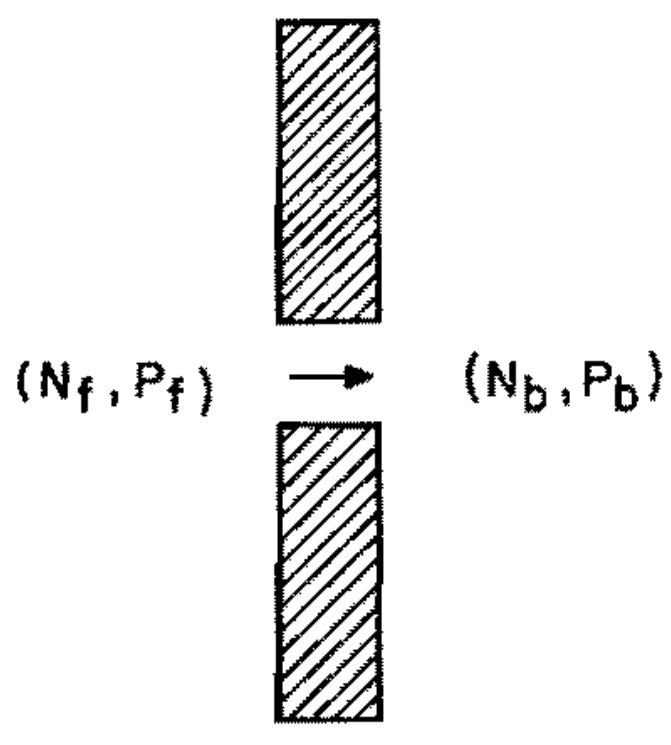

Figurs 1.3. Principio de funcionamento da difusăo gasasa.

\subsection{Laser}

O princípio de funcionamento è sintonizar a radiaçäo coerente numa determinada transiçẳo do espectro do elemento (ou alguma molécula do elemento) que se queira fazer a separaçäo isotópica

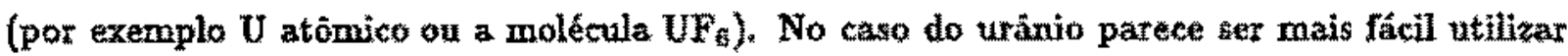
o átomo do que a molécula UF, $O$ esquema para o caso atömico está mostratio na Figura 1.4. Un flamento de uränio é aquecido a uma temperatura de $\sim 2500 K$ e, sobre o vapor de urănio assin produzido, incidem dois feixes de laser, sendo que um deles está bem sintonizado (excitaçăo seletiva) numa das transịçôes do ${ }^{235} \mathrm{U}$ ao passo que o outro laser ioniza somente estes átomos já excitados. Os ions sẫo entāo coletados numa placa coletora com polarização negativa.

As duas limitaçōes deste procetsto são:

- se a densidade for alta haver muitas colisōes entre os íons o que degradará o enriquecimento e desse modo a densidade deve ser mantida abaixo de $10^{1 \mathrm{r}} \mathrm{m}^{-3}$;

- um laser que está sintonizado para separar determinado isótopo de um elemento näo estará apto para separar outwo isótopo deste rnesmo elemento e nem de outro elemento. 


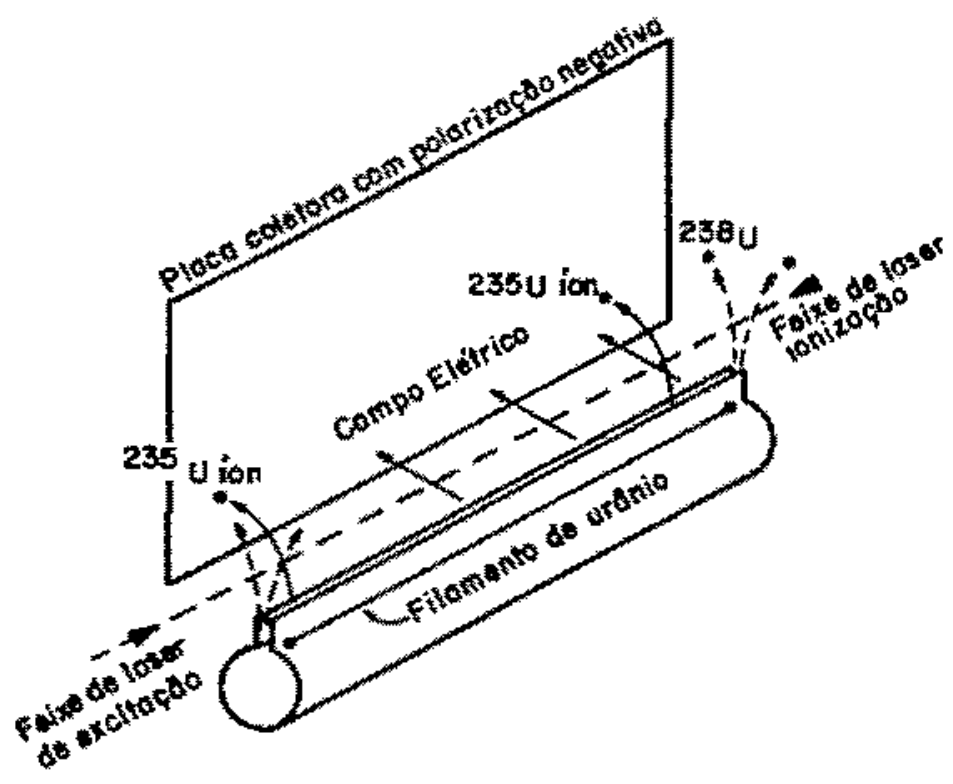

Figura 1.4. Esquema para separą̧ấo isotópica utilizando laser.

Apesar destas linnitaģôes há um grande investimento neste métod̆o jấ que obtém-se un alto enriquecimento a um baixo custo.

\subsection{Ressonância íon ciclotrônica}

A separaçăo se dá pela diferença no movirnento de dois ions de massas $\mathrm{m}_{1}$ e $\mathrm{m}_{2}$ sujeitos a um campo magnético estätico e uniforme na direçăo axial e, um campo elétrico oscilante perpendicular ao campo magnětico como mostrado na Figura 1.5. É necessătio ter alta uniformídade do campo magnético, e por causs das colisōes entre os jons, a densidade e limitada a $10^{16}-10^{18}$ $\mathrm{m}^{-3}$ mas o fator de separaçä̌ $\dot{e}$ alto [8].

A. Tabela 1.3 mostra alguns parametros de dois experimentos deste tipo de separador.

Alguns efeitos coletivos do plasma (colisōes, instabilidades, amortecimento Landau) limitam a operaçāo deste método de separaçã̃o. 


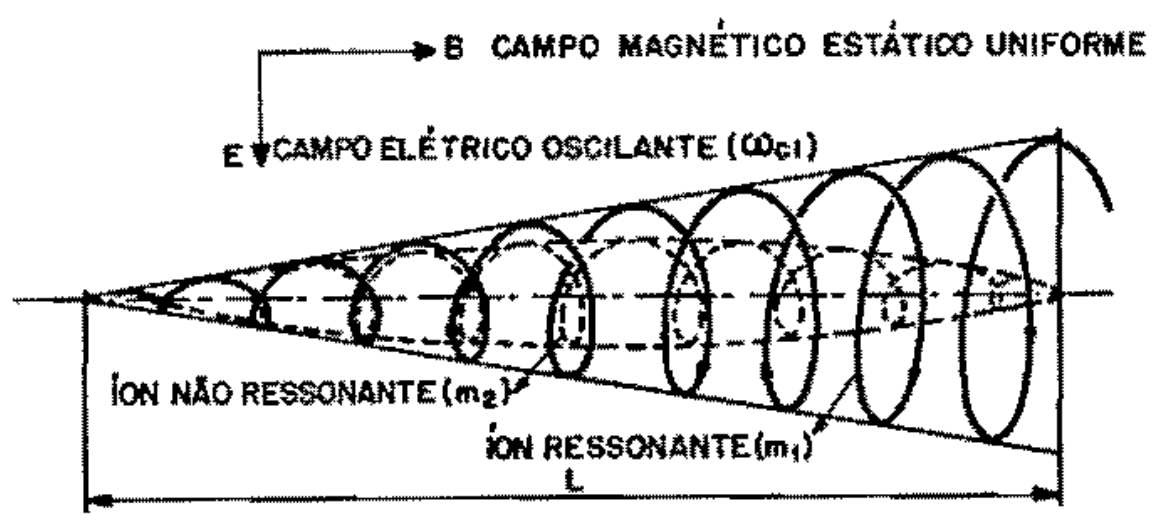

Figura 1.5. Princípio de funcionamento da ressonảncia ion ciclotrổitca.

Tabela 1.3. Comparaçüo entre dois experimentos ntilizando ressonảntia foncielotrônica.

\begin{tabular}{|c|c|c|}
\hline Parâmetro & FRIC(CEA) & PPM(THW) \\
\hline$B_{m e \pm}(T)$ & 3 & 2 \\
\hline$\triangle \mathrm{B} / \mathrm{B}$ & $\pm 5 \times 10^{-3}$ & $\pm 10^{-3}$ \\
\hline$(m)$ & 0,3 & 1 \\
\hline $\mathrm{L}(\mathrm{m})$ & 2 & 5 \\
\hline$w_{\mathrm{a}}(G H z)$ & $10-18$ & 28 \\
\hline$P_{* t_{\mathrm{si}}}$ & $\sim 1,5 \mathrm{KW}$ & w100KW \\
\hline$n\left(m^{-3}\right)$ & $10^{16}-10^{18}$ & $10^{17}-10^{18}$ \\
\hline$T_{i}(\mathrm{eV})$ & $0,4-2,0$ & $1-2$ \\
\hline Gás/Metal & $\mathrm{Kr}, \mathrm{Ar} / \mathrm{Mo}, \mathrm{Ni}_{3} \mathrm{Cr}$ & $\mathrm{A}=\mathrm{Ni}, \mathrm{Cu}, \mathrm{U}$ \\
\hline Metal & $\mathrm{Ca}, \mathrm{Ba}, \mathrm{Cd}$ & $\mathrm{U}, \mathrm{Pb}, \mathrm{In}$ \\
\hline$\alpha$ & $133(\mathrm{Ca}) ; 8,5(\mathrm{Ba}) ; 7,5(\mathrm{Cr})$ & $20(\mathrm{Ni})$ \\
\hline
\end{tabular}




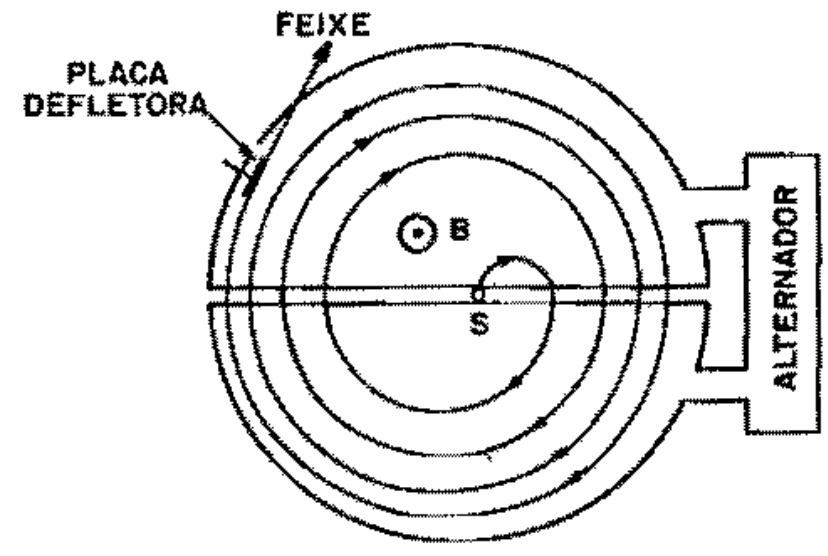

Figura 1.6. Esqquema de funcionamento do Calutron.

\subsection{Calutrons}

O princípio do Calutron (Calutron=California University Cyclotzon) ê o cíclotron, conforme mostrado na Fig. 1.6 .

Os fons produzidos na fonte $\mathrm{S}$ sāo aceleradas e entram numb regiäo entre duas peças de cobre separadas por ums pequena distância. Este conjunto estå imerso num campo magnétíco produzido por um eletro-imä cuja direçăo aponta para fora do plano da figura. Entre as duas peças de cobre é aplicado um campo elétrico oscilante com frequència $\nu_{0}$ e, se o ́on encontrar o campo elétrïco sempre na condiçäo de aceleraçäo o seu rajo de gíro aumentará até o feixe ser extraido para um rajo determinado.

Para separaçăo isotópica deve-se, entāo, fazer com que a frequência ciclotrônica do ion seja igual à frequéncia de oscilaçăo do campo elétrico,

$$
\nu_{c}=\nu_{0}=\frac{q B}{2 \pi m_{i}}
$$

Somente o ion que estiver sintonizado serä coletado. O feixe de fons obtido é de baixa intensidade 
e o mattodo é conveniente para separar pequenas quantidades de material, como é o caso de isótopos estáveis usados em pesquisa. A Tabela 1.4 mostra a estimativa do consumo de energia para separar $1 \mathrm{~g}$ de vanádio-50 por quatro métodos de separaçăo isotópica, com o enriquecínento dado na tabela.

Tabela 1.4. Consumo de energia para enriqueser 1g de vanúdio-50 por quatro métodos diferentes

\begin{tabular}{|c|c|c|}
\hline Separador & Consumo de Energia & Enriquecimento (\%) \\
\hline Calutron & $\sim 4,4 T J$ & 36 \\
Laser (Vapor Atómico) & $18-138 \mathrm{MJ}$ & 10 \\
Centrífuga Mecanica & $\sim 36 \mathrm{MJ}$ & 10 \\
Ressonância Ion Ciclotrônica & $<360 \mathrm{MJ}$ & 10 \\
\hline
\end{tabular}

Como pode ser visto desta tabela se houver um crescimento na demanda de isótopos estáveis será atrativo desenvolver métodos alternativos no Calutron para enriquecimento isotópico.

\subsection{Centrífuga de plasma}

Obserya-se da expressāo (1.5), para o fator de separaçăo, que tendo um meto de se aumentar w sem aumentar muito a temperatura obter-se-ia a maiores. Este objetivo é alcançado utilizandose um plasma onde a força eletromagnética $(\vec{J} \times \vec{B})$ pöe a coluna em rotação, näo havendo desse modo nexhurna parte mecänica em movimexto. A Figura 1.7 mostra o esquema de uma tal centrifuga em que um plasma é crído dentro de uma câmara cilíndrica com um campo magnético axial. A densidade (e portanto o fluxo molar) é menor que o da centrifuga mecânica mas o fator de separaçāo maíor pode compensar.

As pesquisas com centrifuga de plasma seguiram duas linhas distintas. primeira foi utillizar um plasma parcialmente ionizado (ionizaçấ $\sim 10 \%$ ) preenchendo toda a câmara e a segunda a de se utilizar uma coluna de plasma completamente ionizado circundada por um gás nentro Esta segunda alternativa dá velocidades periféricas maiores mas a gasto energético é maior, o que no cômputo geral prova ser a grimeira alternatiza a maís atrativa. Neste caso a relaçäo entre a velocidade periférica máxima, corrente de plasma(1), campo magnêtico(B) e a viscosidade( $\mu)$ devido às colìsöes entre partículas neutras ế 


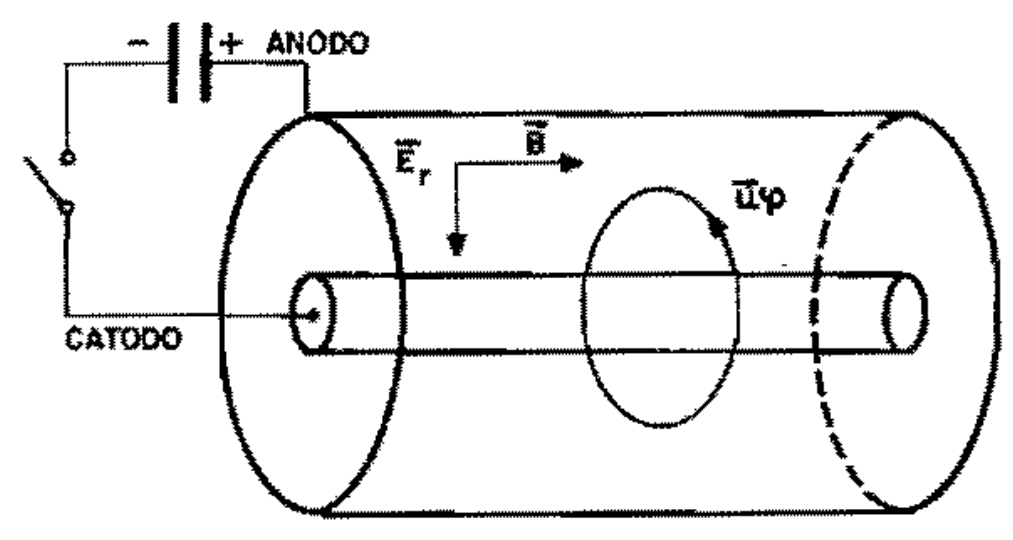

Figura 1.7. Esquema de uma centrifuga de plasma.

$$
u_{\varphi} \propto \frac{I B}{H}
$$

Embora, a príncípio, seja possível obter alta velocidade periférica, os resultados experimentaís [9-10] mostraram que esta estava limitada, assim chamada, velocidade crítica de Alfién ( $\left.u_{4}\right)$. Alfvén propôs que, quando a velocidade relativa entre un gás nentro e um plasma magnetizado atingix o valor $\sqrt{2 e V_{i} / M}\left(V_{i} \equiv\right.$ potencial de ionizaçăo do gás) ocorrerá um grande atumento na taxa de ionizaģăo do gás. Qualquer potència adicional, entäo colocada no plasma, irá produgir mais tonizaçăo ao in̛és de sumentar a velocidade pesifexica. Além desta limitaçăa, a interaçăo com particulas neutras gera turbulência e uma mistura dos isotópos o que díminue ainda mais o fator de separaçäo. A Tabela 1.5 apresenta os dados do experimento realizado por B.W.James e. S. Wimpson $[11]$.

\subsection{Centrifuga de plasma iniciada por arco no vácuo}

Cormo foi salientado na seçăo anterior a presença de partículas neutras inviabiližou a centrifuga de plasras, Em 1981, Krishnan et al [12] propuseram uma nova centrifuga de plasma que utiliza um plasma altamente ionizado gerado por uma descarga em arco no văcuo, A Figura 1.8 mostra o esquerna da centrifuga te plasma iniciada por arco no vácuo, PCEN, desemvalvida no INPE 
Tabela 1,5. Experimento com centrifuga de plasma parcialmente lonizado

\begin{tabular}{|c|c|}
\hline Parametro & Valor \\
\hline comprimento da câmara cilindrica & $0,36 \pi n$ \\
\hline rajo da cämuara & $0,11 \mathrm{~m}$ \\
\hline gás utilizado & neönio $\left({ }^{20} N e{ }^{22} N e\right)$ \\
\hline pressão & $\sim$ ITorr \\
\hline grau de lonizaçâo & $15 \%$ \\
\hline densidade & $5 \times 10^{2 n}-5 \times 10^{21} m^{-3}$ \\
\hline temperatura & $0,3-0,5 \mathrm{eV}$ \\
\hline campo magnatico & $\leq 2,0 \mathrm{~T}$ \\
\hline velocídade periférica & $7 \times 10^{3} \mathrm{~m} / \mathrm{s}$ \\
\hline fator de separaçăo & 1,10 \\
\hline
\end{tabular}

em seu estágio atual.

A descrição deste experimento é como segue. Uma cămara de aço inoxidável de comprimento $1,05 \mathrm{~m}$ e $0,22 \mathrm{~m}$ de diärnetro é evacuada a uma pressāo de $1 \times 10^{-1}$ Pa por umá bomba difusora. Dentro desta camara e numa das extremidades estāo o catodo, polarizado por urn circuito formator de pulso am tensão típica de $100 \mathrm{~V}$ e o anodo, que é uma grade de fungsténio aterrada colocada a $0,06 \mathrm{~m}$ do catodo. O catodo formará o plasma no qual será estudado a separaçăo isotópica ou entre elementos.As bobinas magnẻticas produzem um campo magnético pulıado na direçào axial com valor mảximo de $1,0 \mathrm{~T}$, mas, experimentalmente verifica-se uma melhor operação do experimento com valores entre 0,1-0,2T. Para se fechar o circuito entre o catodo o anodo utiliza.se a radiaçăo $(10,6 \mathrm{um})$ proveniente de um laser de $\mathrm{CO}_{2}$ pulsado de 30MW. O pulso de corrente (tipicamente 1-3kA) gerado por essa descarga em arco tern urna duraçäo de $\sim 16$ ms sendo $\sim 14 \mathrm{~ms}$ praticamente constante. $O$ pulso de corrente é obtido qukndo o campo rragnético é máximo. A interaçăo entre a corrente de plasma e campo magnêtíco (força $\vec{J} \times \vec{B})$, coloca a coluna de plasma en rotaçāo e o campo magnético guia esta caluna atế autra extremidade, onde sầo feitas as medidas dos vários parămetros do plasma e do fator de enriquecimento.

O pulso de corrente obtido na PCEN é mủto reprodutivel, com variaçă $<3 \%$ na amplìude, na forma na duragăo do pulso. No entanto, na medida dos parâmetros temperatura de elétrons; densidade e fator de separaçä̀ aparecen flutwaçöes de até $30 \%$ de pulso para pulso. Para minì mizat o eleito das flutuaçöes, cada ponto experimental apresentado neste trabalho é o resultado da média de pelo menos cinco pulses a barra de erro refiete o desvio dessa médía. 


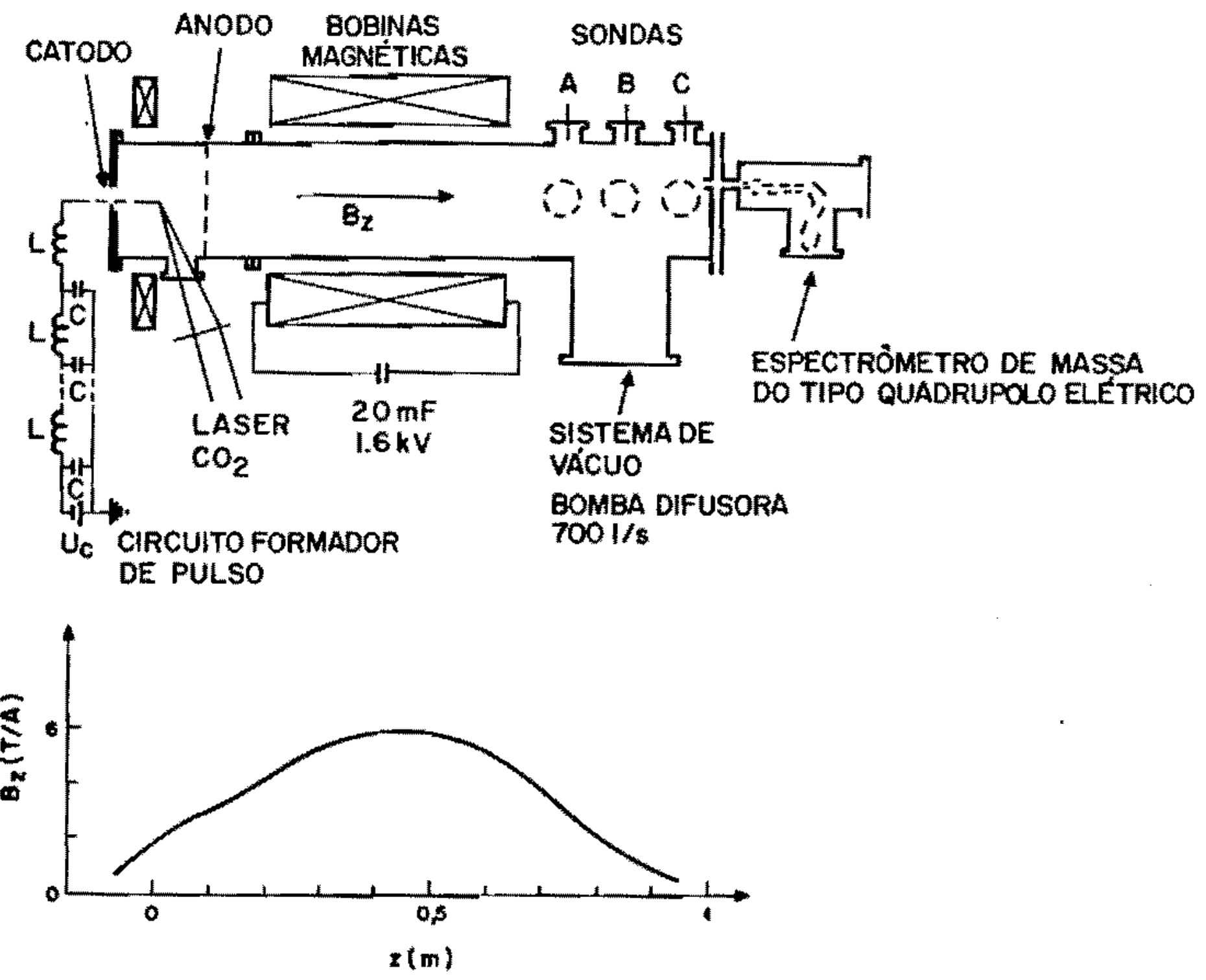

Figura 1.8. Esquema do experimento centrífuga de plasma iniciada por arco no vacno (PCEN) desenvolvida no LAP/LNPE. 
Nos capítulos que se seguem tem-se?

Capítulo 2 - Aprestnta-se urna descriçäo fistita da descarga ena arco no vắcuo, que é a fonte de íns da PCEN. Baseando-se nesta descriçâo do arco e com os parãnetros: corrente de arco; carnpo magnêtéco; anodo utilizado e ternpo de äuraçăo da descarga foi possivel defizir o tipo e o modelo de arco neste experimento. Este capítulo apresenta os resultados das medidas efetuadas de vários parâmetros a saber: impedäncia do plasma, ternperatura de elétrons, velocidade axial de deriva, densidade de particulas carregadas, tensäo de arco, erosāo e, a partì destes, a energia consumida pars a produçäo de cada ion. De particular importântia, fơ a medida da impedäncia do plasma para o projeto de um circuito formador de pulso com casamento de impedancias, o que possiblitou a obtençäo de um pulso de corrente de plasma praticamente constante por $\sim 1 \frac{4}{4}$ mns. Este pulso permititu o estudo da variação temporal de vários parămetros na PCEN.

Capitulo 3 - Os resultados teóricos obtidos a partir das equaçồes MHD aplicadas a coluna de plasma em rotą̧a para o perfil radial da densidade de partículas carregadas, potencial de plasma, fator de separaçäo e valor teórico para a velocidade angular são confrontados com os resultados expetinnentais obtidos. Na aplicą̧ăo das equaçōes MHD, algumas aproximaçöes sāo feitas e justificadas com base nas medidas experimentais efetusdas e da destrigăo da descarga em arco apresentada. Estes resultados teóricos/experimentais permitiram uma boa descriçäo física da coluna de plasma em rotaçäo.

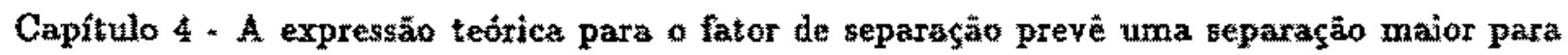
temperaturas menores, Com o intúto de abaixar a temperatura do plasma os gases hidrogeño, hélio e argönio foram introluzidos na cămara de vácuo até a pressāo de $10^{-1} \mathrm{~Pa}$. A medida da temperatura revelou um decréscimó com a introduçăo de gases residuais mas foram obser

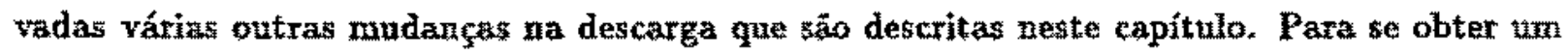
diagnóstíco completo os parämetros: densidade de partículas carregadas, velocidade angular e fator de separaçǟo também foram medidos nestas noyas condiçồs.

Capitulo 5 - É feito um estudo comparativo entre os diversos métodos de separaçäo isotópica apresentados e, a eentrifuga de plasma iniciada por arco no vácuo. 0 estudo foi realizado para a separaçãa dos isótopos Vanădio-50 e Ũuãnia-235. 
Capitulu 6 . É a contelusão do presente trabalho. Os principais zesultados obtidos sầo relatados, e tambérn apresentado uma perspectiva para trabalhos futuros no dispositivo PCEN. 


\section{CAPÍtULO 2}

\section{DESCARGA EM ARCO NO VÁCUO}

\subsection{Introdução}

Neste capítulo a atenção está voltada para a fonte de plasma da centrífuga de plasma. Como visto na introduçāo, o ideal é ter alta densidade, alto fator de separaçāo e baixo consumo de energia. No caso da centrífuga de plasma a presença de átomos neutros é indesejável. Assim, as características desejáveis de uma fonte de ions são:

- produção de um plasma completamente ionizado e envolto por vácuo;

- alta densidade $\left(\mathrm{n} \geq 10^{20} \mathrm{~m}^{-3}\right)$;

- bajxa temperatura $(\mathrm{T}<\mathrm{leV}$ );

- baixo consumo de energia para produzir o plasma;

- versatilidade na produçāo de plasma de metais, ligas e gases;

- estabilidade, isto é, baira flutuação nos parâmetros, e

- reprodutibilidade.

No que segue será dada uma descrição das principais características da descarga em arco no vácuo e os resultados das medidas efetuadas da impedância do plasma, tensāo de arco, erosāo do catodo, consumo de energia para produçāo dos íons, velocidade axial de deriva, temperatura de elétrons, densidade de partículas carregadas e avaliação do grau de ionização do plasma gerado nessa descarga. 


\subsection{Descarga em arco no vácuo}

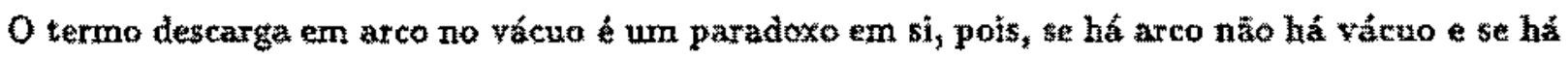
vácuo nẫo há arco. Por descarga em arco no yácuo entende-ste um arco sustentado unicamente pelo material originado dos eletrodos (catodo e anodo) num meio que é o vácuo. Dentro desta categoria de arco, interesse é pelo arco difuso, no qual todo material tem origern no catodo, ou seja, o anodo é passivo, lsto coloca um limite na corrente de arco $\left(I_{a}\right)$ que para anodo de tungsténio é $\mathrm{I}_{\alpha}<10 \mathrm{kA}$. No caso da $\mathrm{PCEN}$ este critério é plenamente satisfếto, pois $\mathrm{I}_{0} \approx 1-3 \mathrm{kA}$ $[13,14,15]$

Como foi descrito na introdução, no caso da PCEN tem-se dois eletrodos separados por uma distancia aproximada de $60 \mathrm{~mm}$ sendo que o catodo é polarizado ama tensăo tápica de $\sim 100$ V e o anodo é uma grade de tungstènio (aterrada), estando estes dentro de uma cămara de váczo a uma pressão de $\sim 1 \times 10^{-4} \mathrm{~Pa}$. Nestas circunstancias deve laver um agente que feche o círcuito entre o catodo o anodo, e este agente plasma formado por un laser incidindo sobre o catodo. Para isto, fol construido um laser de $\mathrm{CO}_{2}$ com energia $\sim 3 \mathrm{~J}$, largura de pulso de 100 ns (30 MW de potencia) e comprimento de onda de $10,6 \mu \mathrm{m}$ [16]. Este pulso de laser focalizado numa áce de $\sim 1 \mathrm{~mm}^{2}$ na superície do catodo o que resulta (desprezando perdas) em $\sim 3 \times 10^{27} \mathrm{~W} / \mathbf{m}^{2}$. Um laser de 50MW [17] incidindo sobre um alvo de cobre produz um plasma com densidade $\sim 10^{16}=10^{20} \mathrm{~m}^{-3}$; expandindo-se com uma velocidade $\sim 5 \times 10^{4} \mathrm{~m} / \mathrm{s}, \mathrm{e}, \mathrm{assim}$, numa distância de $60 \mathrm{~mm}$ o arco se formará en cerca de $1 \mu \mathrm{s}_{\text {, o }}$ que é desprezível perto dos $\approx$ 16 ms de duxaçāo da descarga principal. A Figura 2.1 mostra um pulso típico de corrente da tensāo entre o catodo e anodá (tensão inicial no catodo $U_{6}$, tensāo de arco $U_{a}$ ) para catodo de magnésio e campo magnetético axial de 0,1T, obtido na PCEN.

A incidência do laser nāo implica necessariamente que a descarga em arco se formará. Deve haver na superficie do catodo alta temperatura campo elétrico suficienternente alto para ocorrer a emissāo das partícula: (elétrons, ions, vapor metâlico), que sustentarn a descarga em sequuência ¿̀ incidência do laser.

Da Figura 2.1 pode-se observar que a tensāo que mantérn o arco bajxa ( $\sim 35 \mathrm{~V})$, e isto, é característico de arcos em gera (näo só de arcos difusos). Se a corrente de $\sim 1$, 5k A (mostrada 


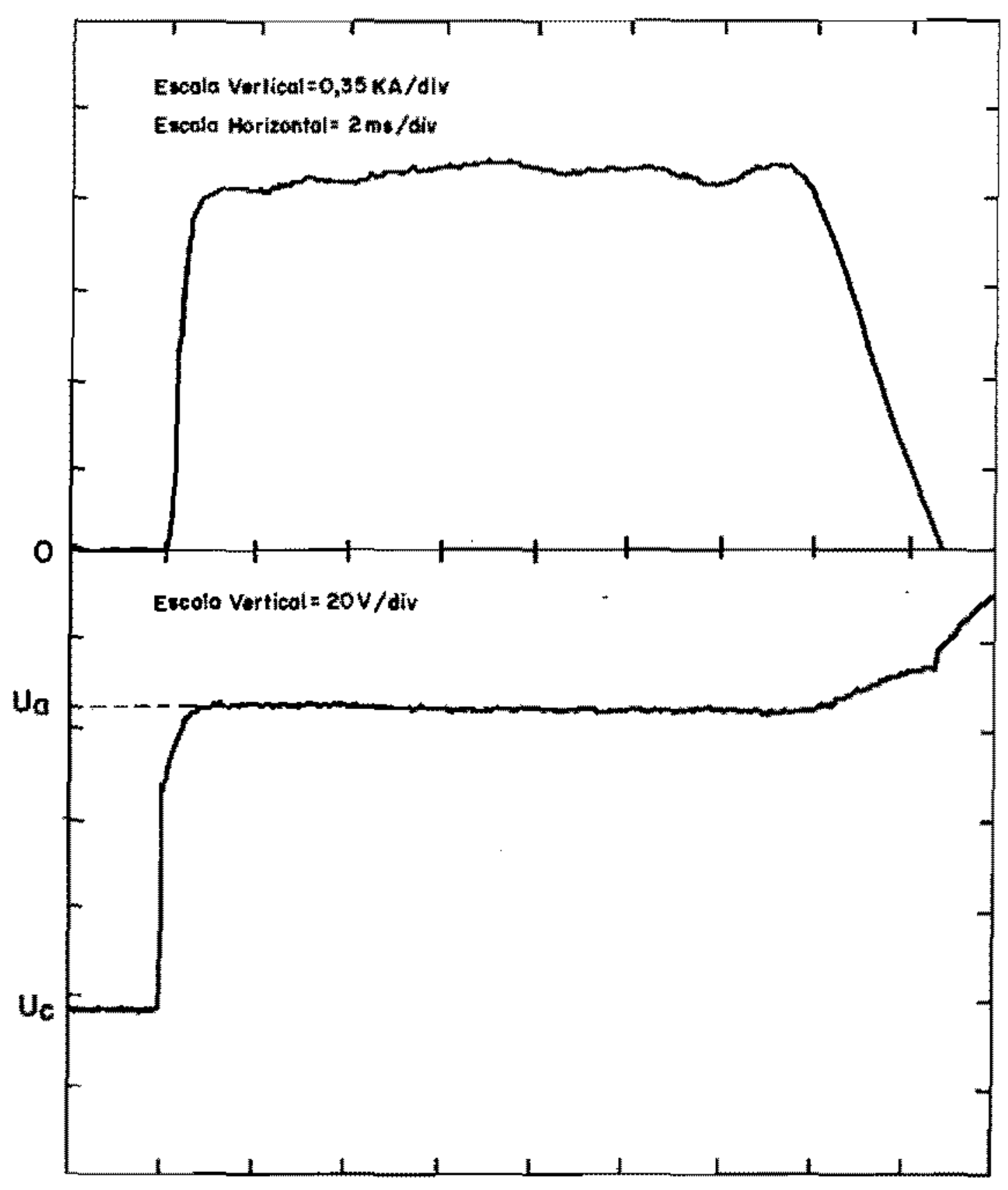

Figura 2.1. Pulso tipico de corrente de arco $\left(I_{a}\right)$ e da tensão de arco $\left(U_{a}\right)$ para catodo de magnésio e campo magnético axial de $0,1 \mathrm{~T}$, obtido na PCEN. 
na Fig. 2.1) fosse transportada somente por elétrons, fsto é, nä́o houvesse neutralização de cargas, $\operatorname{com} \mathrm{L}=60 \mathrm{~mm}$ (distãncia entre catodo e anodo) e $\mathrm{A}_{c} \simeq 7,5 \times 10^{-3} \mathrm{~m}^{2}$ (area estimada para o transporte de cargas), obtérn-se da equaçäo de Child

$$
U_{a}=\left[\frac{a I_{\sigma} L^{2}}{\varepsilon_{0} A_{\epsilon}} \sqrt{\frac{m_{e}}{2 e}}\right]
$$

o valor $\mathrm{U}_{\mathrm{a}} \simeq 200 \mathrm{~K}$. Mesmo para uma neutralizaçă de $99 \%$ dos elćtrons é obtido um valor $\mathrm{U}_{\mathrm{a}}$ muito superior aos $35 \mathrm{~V}$.

O significado destr anallise é o seguinte: praticamente todo o espaço entre o catodo anodo é preenchido por um plasma onde a condiçăo de neutralidade é satisfeita. Desse modo quase toda variaçäo de potencial ocorre mưto próxima dos eletrodos, sendo que a maíor variaçào acontece junto so catodo numa distancia avaliada em ${ }^{-8} 10^{-8}+10^{-9} \mathrm{~m}$ o que resulta em um campo eletrico de $\sim 10^{9} \cdot 10^{10} \mathrm{~V} / \mathrm{m}$ (para uma variaçăo de $10 \mathrm{~V}$ no potencial). A Figura 2.2 resume esquematicamente estas idélas.

Os fons que se movimentam para o anodo (contrário ao campo elétrico!) a fixa de neutralizar os elêtrons, são gerados a uma distância $\sim 10^{-\frac{k}{s}}-10^{-8} \mathrm{~m}$ do catodo por colisóes entre o vapor metálico e os elétrons ambos oriundos ào catodo. Para uma densidade de corrente Jo2 $\times$ $10^{5} \mathrm{~A} / \mathrm{m}^{2}\left(I_{a} \sim 1,5 \mathrm{kA}, \mathrm{A}_{c} \sim 7,5 \times 10^{-3} \mathrm{~m}^{2}\right)$ deve haver uma alta emissão tanto de elétrons quanto de vapor metálico, $e_{2}$ isto, é possível somente para uma temperatura altá no catodo 12000 . $3000 \mathrm{~K})$.

A energia no arco pode ser avaliada aproximadamente por

$$
\Delta E=I_{a} U_{a} \Delta t_{*}
$$

onde com $\mathrm{I}_{\alpha} \sim 1,5 \mathrm{kA}, \mathrm{U}_{\mathrm{a}} \sim 35 \mathrm{~V}$ e $\Delta \mathrm{t} \sim 16 \mathrm{~ms}$ obtém-se $\sim 800 \mathrm{~J}$ sendo que cerca de $30 \%$ (240J) desta energía é dissipada no catoda [18].

A variaçăo da temperatura no catodo en cada disparo pode ser obtida da expressäo 


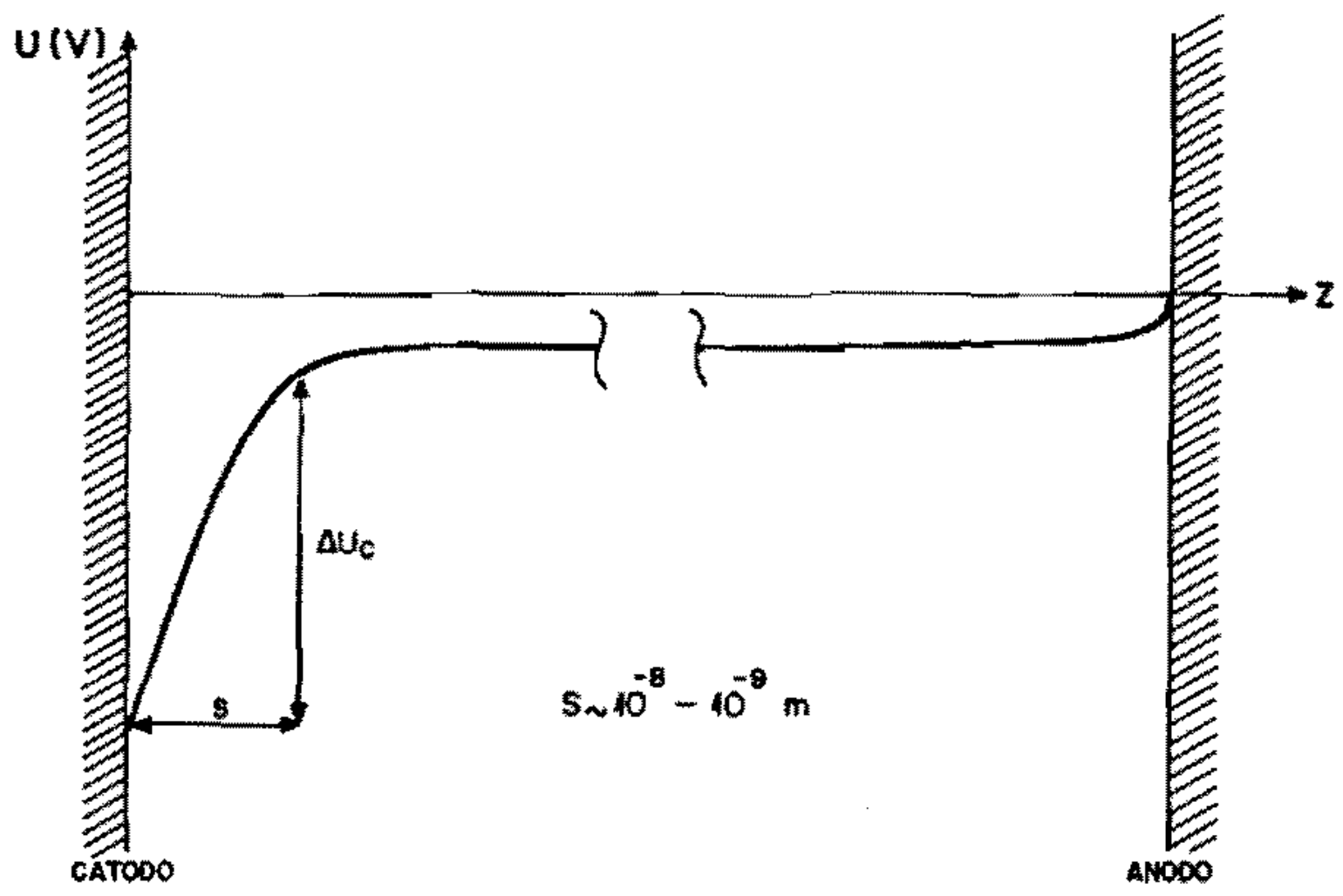

Figura 2.2. Distribuiçăo de potencial entre o catodo e 0 anodo (dimensöes năo estäo em escala). 
Tabela 2,1 . Densidade de corrente de elétrons emitidos pelo catodo $\left(A / \mathrm{m}^{2}\right)$

\begin{tabular}{|c|c|c|}
\hline Tipo de emissăo & $E=2 \times 10^{9} \mathrm{~V} / \mathrm{m}$ & $E=5 \times 10^{9} \mathrm{~V} / \mathrm{m}$ \\
\hline Termolónico & $2,2 \times 10^{1}(2000 \mathrm{~K})$ & $2,2 \times 10^{1}$ \\
& $3,0 \times 10^{4}(3000 \mathrm{~K})$ & \\
\hline Schottly & $4,2 \times 10^{5}(2000 \mathrm{~K})$ & $1,2 \times 10^{8}$ \\
& $2,1 \times 10^{8}(3000 \mathrm{~K})$ & $9,7 \times 10^{9}$ \\
\hline Por efeito de campo & $4,7 \times 10^{0}$ & $3,9 \times 10^{9}$ \\
& $4,7 \times 10^{0}$ & $3,9 \times 10^{9}$ \\
\hline
\end{tabular}

$$
\Delta E=m c \Delta T
$$

onde para o catodo de magnésio utilizado m $\sim 5 g, c=1020 \mathrm{~J} \cdot \mathrm{K}^{-1} \mathrm{~kg}^{-1}$ e $\Delta \mathrm{E} * 240 \mathrm{~J}$ resulta em $\Delta T \sim 50 \mathrm{~K}$, wan aumento insignificante na temperatura.

A emissāo de eletrons pelo catodo pode ocorrer por três efeitos:

- Emissăo pelo efeito de temperatura elevada (emissão termoiônica);

- Emissão pelo efeito combinado de temperatura e campo elétrico intenso (Schottky), e

- Pelo efeito de campo intenso.

A Tabela 2.1 fornece os valores da densidade de corrente du emissão de elétrons para estes três casos com duas temperaturas diferentes e supendo uma funçä̌ de trabalho $\phi=4,5 \mathrm{eV}[19]$.

No cálculo da elevação da temperatura fơ suposto que toda s energia estava distribúdáa sobre o catodo ou que a emissão de corrente ocorresse sobre toda superficie do catodo. A realidade é bem diferente disto, como já tinha sido observado por Starkera 1903. A emissão de elëtrons e vapor metalico ocorre em pequenos pontos luminosos (fenomeno comum a todos os tipos de arco) sobre a superficie com área $\sim 10^{-7}-10^{-11} \mathrm{~m}^{2}$. Nestes pontos luminosos a temperatura alcançavalores suficiente para a emissāo de elétrons e vapor metálico( $\left.\mathrm{T}_{\mathrm{c}} \geq 3000 \mathrm{~K}\right)$, apresentando densidades de corrente de $10^{8}-10^{13} \mathrm{~A} / \mathrm{m}^{2}$. Estes pontos luminosos se movimentam aleatoriamente sobre a supertície com velocidades atingindo atế $\sim 30 \mathrm{~m} / \mathrm{s}$. A quantidede de pontos luminosos na superfície depende do valor da corrente e das propriedzdes térmicas do catodo. A Figura 2.3 mostra esquematicamente a presença destes pequenos pontos luminosos sobre superfície do 


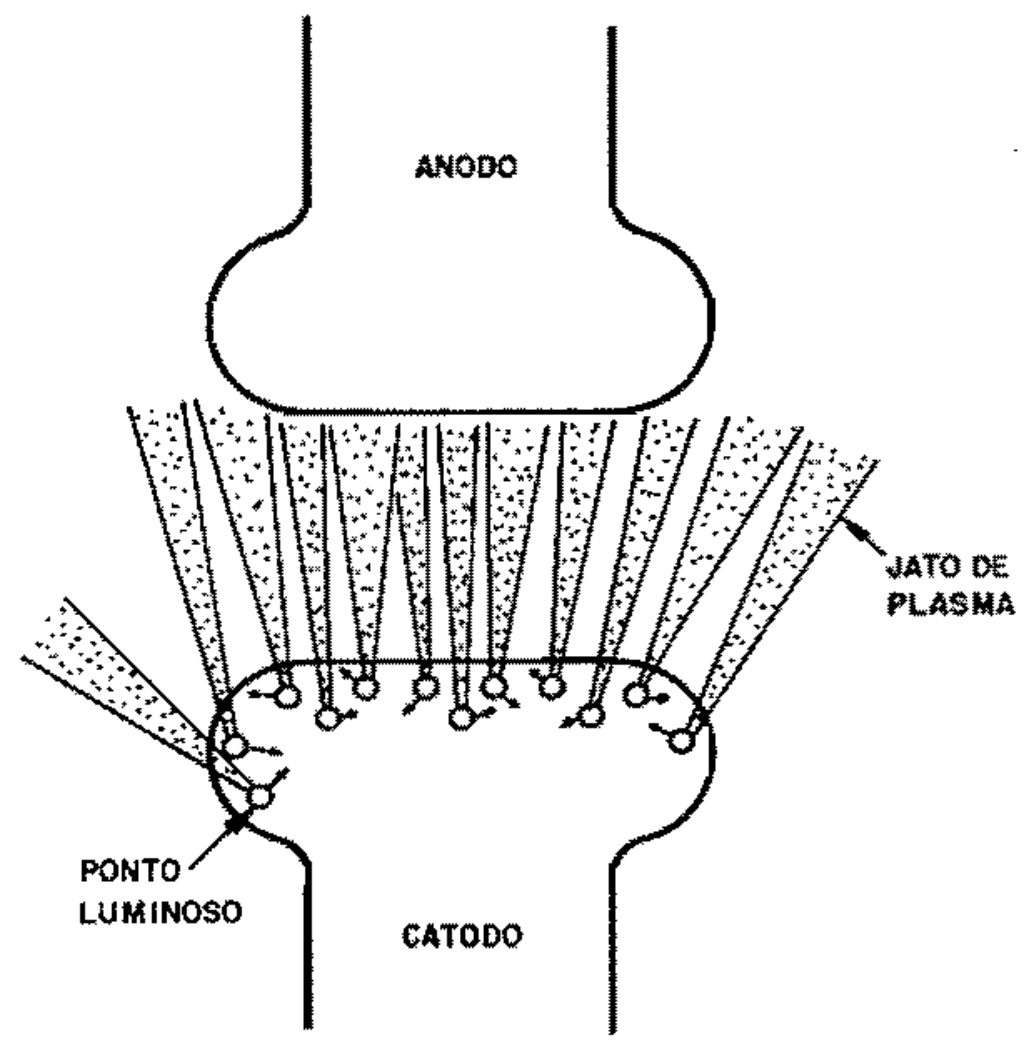

Figura 2.3. Origern das partículas num arco difüso.

catodo $e_{\xi}$ o jato de plasma resultante atingindo o anodo. Uma fotografia da opera̧̧ăo de um arco onde se vê claramente os pontos luminosos sobre a superfïcie do catodo o jato de plasma pode ser visto na referência [20].

Estes pontos luminosos tem um tempo de vide de $\approx 10^{-3}-10^{-9} s$ e seu compartamento é altamente dinămico; eles aparecem, desaparecem e podem reaparecer em outro lugar e assim pode-se somente falar no número médio $(\bar{n})$ dos mesmos durante a descarga. Há uma corrente máxima, dependendo do material do catodo, que o ponto luminoso pode transportar. Para correntes acima desse valor máximo ocorre a divisäo do ponto luminoso. A Figura 2.4 mostza a dependência do número médio de pontos luminosos presentes com a corrente de arco e o material do catodo [21].

Os dados aprezentados para estes pontos luminosos (por exemplo, a densidade de corrente) dif̂rem as veres em vărias ordens de grandeza. Isto em grande parte reflete o desconhecimento 


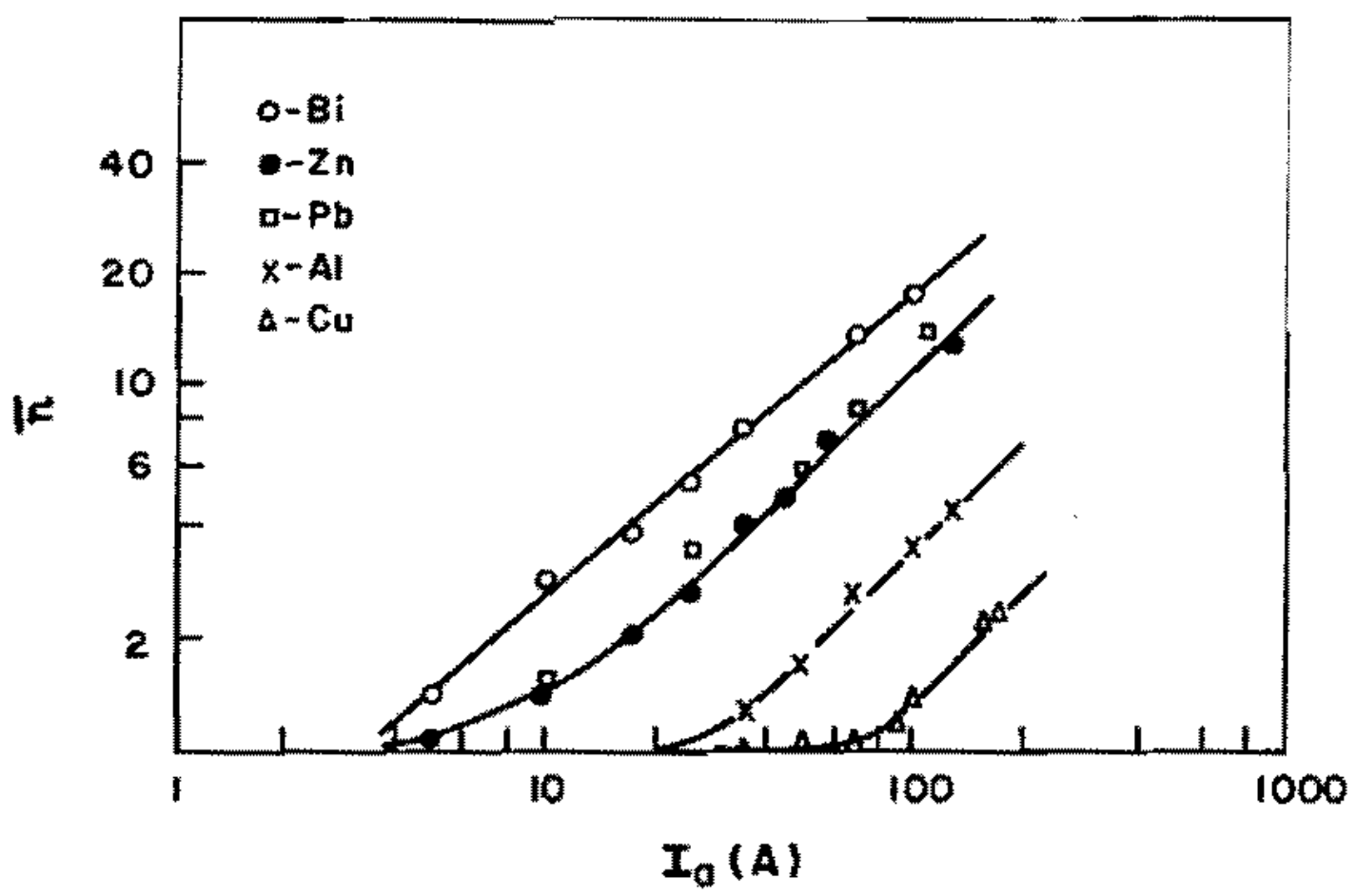

Figura 2.4. Número médio de pontos luminosos em funģăo da corrente de arco para cinco materiais[21]. 
dos fenomenos que ocorrem na superficie do catodo e no plasma adjacente a esta superfície. Embora arcos sejam estudados a maỉs de um século, năo thá no momento nenhum modelo que descreva completamente todos os complexos fenómenos que estä́o ocorrendo e os modelos existentes tern gerado muita controvérsia e levado a tấo distintas previsöes do: paränetros.

As principais dificuldades para o entendimento do arco sä̊:

- O plasma depende do catodo (suprimento dos elétrons e vapor metalíco) para a sua existência e o catodo depende do plasma (suprimento de energia e campo elétríco) para a emissäo de elétrons e vapor metalico. Desse modo a superfície do catodo o plasma adjacente são interdependentes formando os pontos luminosos. A descriçăo dos fenômenos que ocorrem nesta regiäo (un volume muyt to menor que $1 \mathrm{~mm}^{3} !$ ) envolve: eletrodinânica, termodinämica, hidrodinämica, estado sólido e fistca de plasma. O plasma pxóximo ao catodo tern uma densidade de elétrons $n_{e} \sim 10^{23}-10^{25} \mathrm{~m}^{-3}$ e temperatura de elétrons $T_{t} \geq 1 \mathrm{eV}$, embora alguns postulem $n_{e} \sim 10^{26}-10^{28} \mathrm{~m}^{-3}$. Para um valor tấo alto de densidade tem-se $g=1 / n \lambda_{b}^{3} \gg 1$, o que torna o plasma náo ideal.

- Na superficie do catodo tem-se $\mathbf{T}_{\varepsilon} \geq 3000 \mathrm{~K}, \mathrm{E} \sim 10^{9}-10^{10} \mathrm{~V} / \mathrm{m}$ e $\mathbf{p}=\mathbf{n k} \mathrm{k}_{B} \mathrm{~T} \sim 0, \mathbf{1}-100$ atm. Muitas propriedades térmicas dos materiais tais como calor latente de evaporaç̄ōo, fusằo, calor específico e também os efeitos nos niveis de energia de Fermi săo destconhecidos nestas condiçôes.

- As condiçōes da superficie do catodo tem uma grande influêneia nos parämetros dos pontos luminosos. Gases absorvidos pelo catodo, bxidos formados mesmo para uma pressäo de $10^{-6} \mathrm{~Pa}_{1}$ presenga de impurezas e rugosidade da superficie (mesmo uma superficie bem poHa apresenta quando observăa num microscópio eletrónico de yarredura protuberâncias

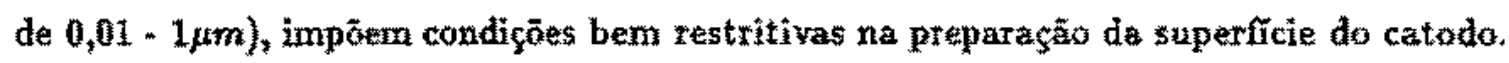
A prớpria operaçẩo do arco tem um efeito de limpeza, principalmente a degaseificaçăo da superficie. Por isto, neste trabalho, todos os dados foram obtidos depais de $10-50$ pulsos com a firalidade de condicionarnento da superficie es catodos tinham uma puxeza maior que $99,95 \%$, a excessão do carbono que embora puro tinha ura índice de pureza desconhecida. Por outro lado, uma superfieie que de ínicio estava bem polida depois de alguns puisos já apresentava uma rugosidade perceptível a olho nú. 
- Os mêtodos de medida devem tez uma resoluçấo pacial de $\sim$ lum e temporal de $\sim 1 n s$. Um dos principajs parâmetros é densidade de corrente transportada pelos pontos luminosos durante a sua existência. Por exemplo, para $I_{\alpha} \sim 1,5 \mathrm{kA}$ e $\bar{\pi} \sim 20$ tem-se 75A por ponto luminoso, mas é necessário saber a área destes para se obter a densidade e ai reside algumas controyếrsias [22]. Dois métodos são usados nestas medidas; o método autográfíco e o das fotografias de alta velocidade. No método autográfico os traços deixados (crateras) pelo arco săo medidos. No método das fotografias de alta velocidade säo analisadas as dimensōes dos pontos luminosos durante a operaçāo do arco.

No método autográfico supöe-se que a cratera surgíu devĩdo a emissäo da corrente e, para um diâmetro $\mathrm{d}_{\varepsilon} \sim 10 \mu \mathrm{m}\left(\mathrm{A}_{\mathrm{s}} \sim 10^{-10} \mathrm{~m}^{2}\right)$ obtémmse $\mathrm{j}>10^{11} \mathrm{~A} / \mathrm{m}^{2}$. Para alguns, a relação da dimensão da cratera com o da emissäo de corrente nāo é corteto, como exernplos, a cratera pode ter sido produzida pelos íns do plasma atíngindo a supeticie do catodo ou pela propagação de ondas termoelásticas.

método de fotografias de alta velocidade fornece $A, \sim 10^{-6} \mathrm{~m}^{2}$ e assim $\mathrm{j} \leq 10^{10} \mathrm{~A} / \mathrm{m}^{2}$. A critica a este método é a de que foras excitados podem escapar da regiäo transportando a cortente, tesultando, então, numa área maior para o ponto luminoso com a consequente red̆uçżo da densidade de corrente.

Todos os modelos de arco propostos (que em última análise referem-se sos pontos luminosos) devem explicar alguns fatos experimentajs como os listados abaixo (somente os que estäo diretamente relacionados com o presente trabalho).

Tensão de arco - A tensão de arco é baixa estando no intervalo $\sim 10$. $50 \mathrm{~V}$ dependendo do material do catodo, corrente de arco, campo magnético aplicado e da distâneía dos eletrodos. Materiais com alta temperatura de ebuliçāo (ex: $\mathrm{Zx}_{3} \mathrm{Mo}, \mathrm{Ta}, \mathrm{W}$ ) são os que apresentam maior tensäo de arco $[23,24]$.

Corrente de ions $\left(\mathrm{H}_{i}\right) \cdot$ A corrente de fons longe da regia do catodo $\left(\mathrm{z}>10^{-2} \mathrm{~m}\right)$ é $5 \cdot 12 \%$ da corrente de arco [25]. A densidade de corrente de ions de urn ponto luminoso tem uma dependência corn a distância $z$ do catodo $(\mathrm{z}>1 \mathrm{~mm})$ a com $o$ àngulo $\theta$, onde $\theta$ é a angulo relativo a normal ao catodo dada por 


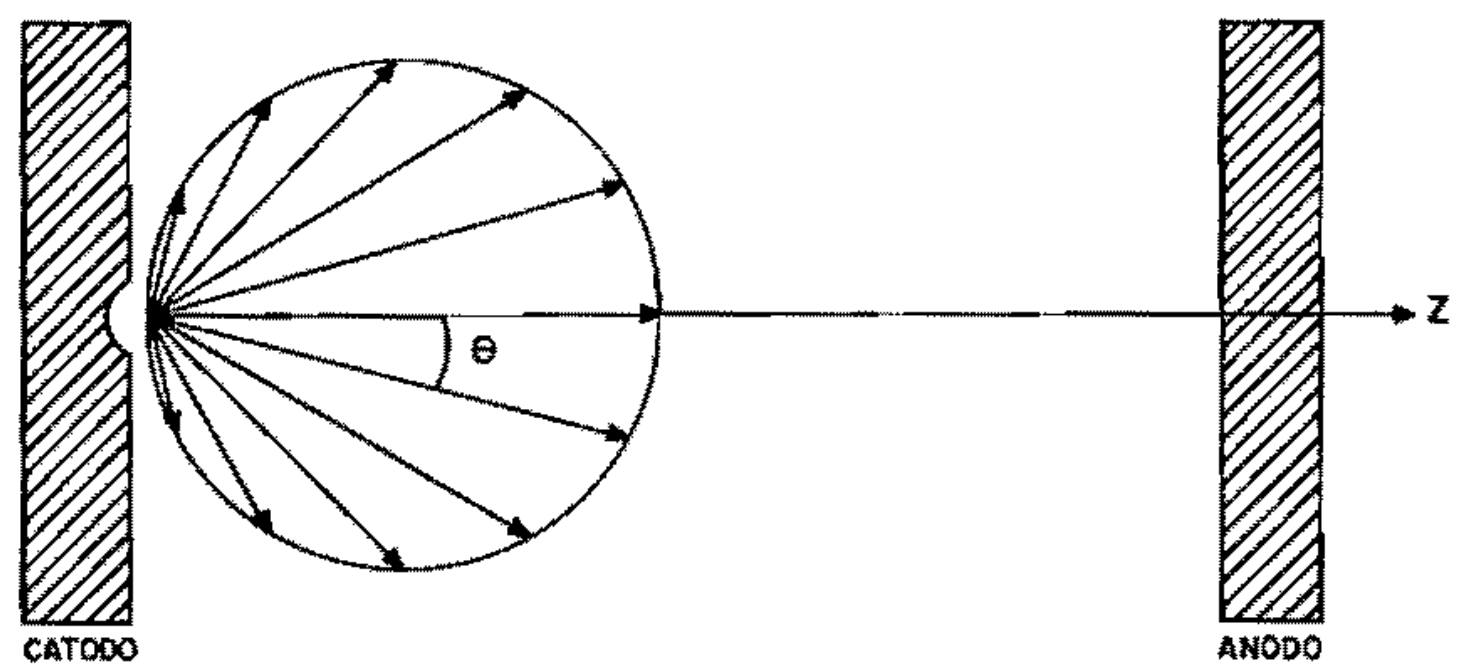

Figura 2.5. Distribuiçẵo da densidade de corrente de íns originada de um ponto luminoso,

$$
\begin{array}{r}
\dot{j}_{i}=e I_{a} z^{-2} \cos \theta\left(0 \leq \theta<\frac{\pi}{2}\right) \\
j_{i}=d I_{a} z^{-2}\left(\theta=\frac{\pi}{2}\right)
\end{array}
$$

onde $c$ e $d$ sāo constantes $(\mathrm{d} \sim 0,1 \mathrm{c})[54]$.

A Figura 2.5 mostra a distribựçâo da densidade de corrente de fons de um ponto luminoso.

Carga dos lons ( $q_{i}$ ) * A descarga em arco no văcuo é rica na produçäo de ions de cargat múltiplas $\left(q_{i}=\mathrm{Ze}, \mathrm{z}=1,2,3 \ldots\right)$. Os materiais com alta temperatura de ebuliçă̄o [26] apresentarn um $\bar{Z}$ mais alto. Por exemplo, para $W$ a seguinte composiçẫo iônica é obtida $q=1(2 \%) ; z=2$ $(23 \%) ; z=3(43 \%) ; Z=4(26 \%) ; Z=5(5 \%)$ e $Z=6(1 \%)$ resu西anto em $\bar{Z}=3,1$. Materiats como zinco, cádmio chumbo apresentam $\bar{Z} \leq 1$, e para o carbono $Z=1$. A condição de neutralidade na descarga em arco no vámo é escrita como $n_{e}=n_{i}=\sum z_{2} Z$.

Energia dos fons $\left(\mathrm{E}_{i}\right)$ - Os fons se movimentam para o anodo (contrátrio ao campo elétrico) com energia cinética de 10 a $150 \mathrm{eV}$ (velocidades de deriva na direçäo axial de $\sim 10^{3}+10^{4} \mathrm{~m} / \mathrm{m}$ ) acima da energia $Z_{e} V_{a}[27,28,29]$. Assim, deve haver um mecanismo muito eficiente de transferência de energia para os ions próximo ad catodo. A energia por unidade de carga $\left(\mathrm{V}_{Z}=\mathrm{E}_{Z} / \mathrm{z}_{\mathrm{z}}\right)$ decresce 


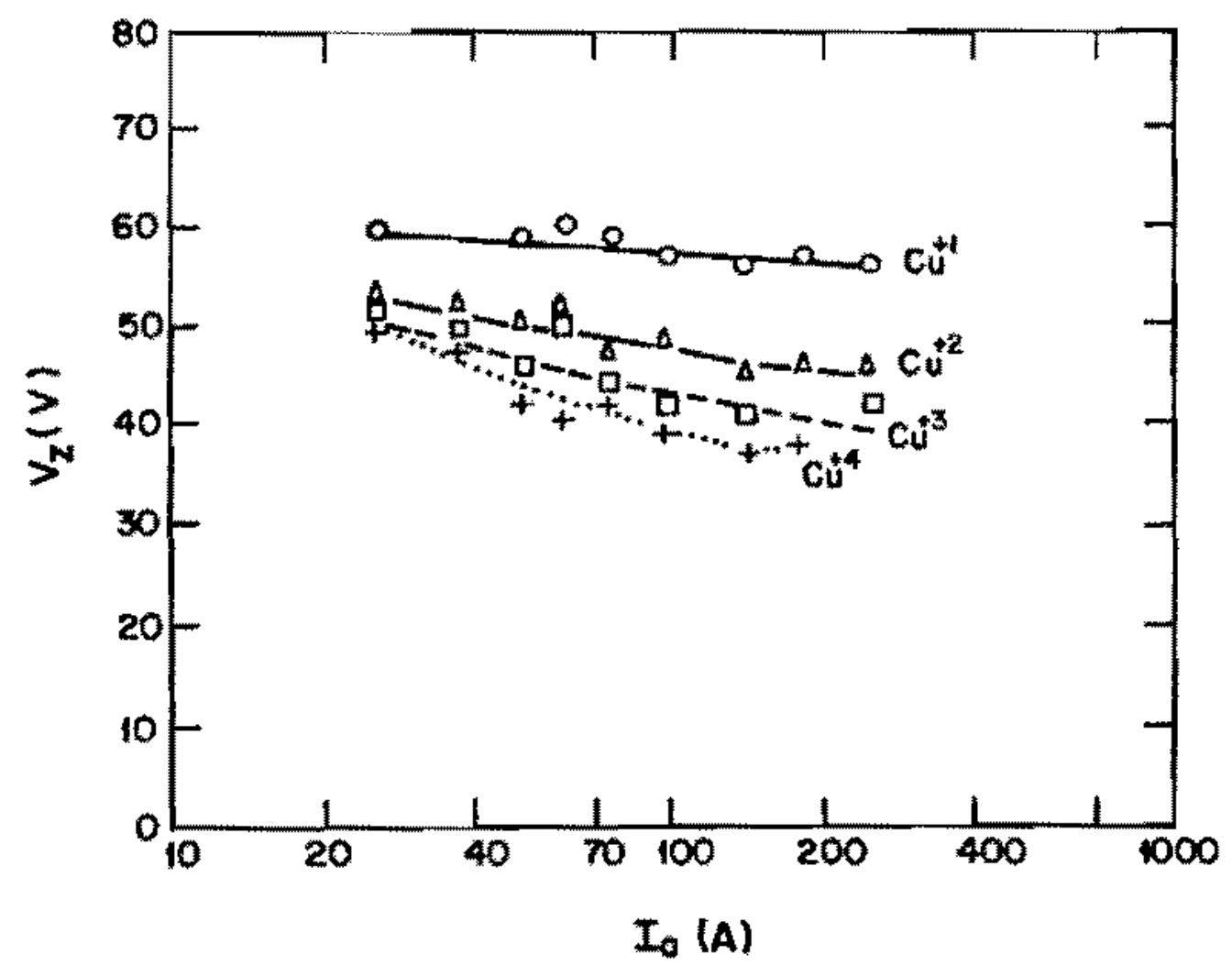

Figura 2.6. Energia dos lons por wnidade de carga como funçăo da corrente de arco para os quatro estados de ionização do cobre[28].

com a corrente de arco e, para uma dada corrente, estados de lonizaçä̌ mais altos possuem energia menor. A Figura 2.6 mostra dados experimentais referentes a energia dos íons[28].

Grau de ionizaçăo $(\gamma)-0$ grau de ionizaçäo $(\gamma)$ varia de $\gamma=0,1-1,0$. Para o magnésío tem-se $y=0,8-1,0$ an passo que para zinco, cádmio chumbo $\gamma \sim 0,10 * 0,25[27,30]$.

Atualmente há basicamente três grupos de opiniōes sobre os pontos luminosos:

A primeira é a de que estes pontos luminosos operam por causa de uma sequência repetïda de emissăo explosiva de elétrons e nenhuma mudança acorre durante a descarga. Nesta concep̧̧äo a densidade de corrente é $\mathrm{j}>10^{11} \mathrm{~A} / \mathrm{m}^{2}$ e o tempo de vida $5-10 \mathrm{~ns}$.

A segunda ê que existem dois tipos de pontos luminosos: os de emissão explosiva de elétrons e 
os térmicos (ou quase estacionárín),

A terceira $e^{2}$ a de que dois tipos de pontos luminosos existem; un quase-estacionário (Tipo 2) com tempo de vida de wims e outro nāo estacionário com tempo de vida de a transiçäo entre um tipo e outro depende dos parâmetros da descarga e do naterial do catodo. Neste modelo a emissäo explosiva com densidade de corrente elevada $\left(\geq 10^{11} \mathrm{~A} / \mathrm{m}^{2}\right)$ ocorre somente nos instantes iniciais do ponto luminoso Tipo 1 ( $t<10$ ns) e, na maior parte do tempo de vida $(\sim 10 \mu)$ a densidade de corrente tem um valor $<10^{10} \mathrm{~A} / \mathrm{m}^{2}$. Estas opiniôtes seräo sintetizadas a seguir.

\subsubsection{Modelo para ponto luminoso quase-estacionário ou térmico (Tipo 2)}

Este o modelo mais simples e se aplica a pontos luminosos que se deslocam com velocidades de $\sim 0,1-1 \mathrm{~m} / \mathrm{s}$ sobre a superficie do catoda. Estes pontos luminosos tem a tendência de se agruparem com tipicamente 10 deles em cada grupo, não sendo claro o que leva a este

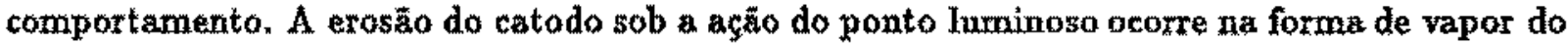
metal, elétrons e na forma de macropartículas com diämetro $<100$ am ejetadas com velocidades de $\sim 10-500 \mathrm{~m} / \mathrm{s}$. Pontos luminosos do Tipo 2 säo os que apresentam a maior erosāo e também crateras de dimensöes maiores, diâtretro $\mathrm{d}_{\mathrm{k}}>10 \mathrm{\mu m}$, ocorrendo aproximadamente a emissăo de 10 elétrons para cada átomo emitido na forma de vapor[31].

O modeIo quase-estacionário exvolve as seguintes aproximaçöes: s) catodo com uma superñicie plana e lisa; b) una superficie limpa, isto é, sem gases tbsorvidos, impurezas e óxidos; c) somente pontos luminosos citculares; d) parâmetros constantes deatro do ponto luminoso; e) omíssāo dos processos fora dos pontos luminosos; f) nenhum movimento e g) condizpäes de estado estacionário (nenhuma dependência temporal dos parâtnetros).

Os seguintes parânetros e a dependència ext te eles descrevem esta situaçăo[32]:

- a densidade de corrente de elétrons, $j_{e}$ de emissăbo por efeito de campo e temperatura (emissǟo Schottky com corregōes quắnticas [33]) 


$$
j_{e}=j_{e}\left(T_{c}, E_{c}\right)
$$

onde $\mathrm{T}_{t}$ a a temperatura e $\mathrm{E}_{\text {; }}$ o campo elétrico na superî́cie do catodo.

- a densidade de potência, $Q_{e}$, na superfície do catodo

$$
Q_{t}=Q_{d}\left(\dot{j}_{i}, j_{\varepsilon}, \mathrm{A} U_{a,}, T_{\varepsilon}, E_{c 4} j_{0}\right)
$$

onde, $\mathfrak{j}_{i}$ é a densidade de corrente de íns, jo é a densidade do fluxo de ătomos evaporados e $\Delta U_{c}$ é a variaçäo do potencjal.

- temperatura do catodo $\mathrm{T}_{c}$ obtida da solução da equaçüo de conduçăo de calor

$$
T_{c}=T_{c}\left(Q_{e}, a, j\right)
$$

onde a é a raio do ponto luminoso e $j=j_{i}+j_{e}$.

- o campo elétrico obtido da equaţăa de Poisson

$$
E_{c}=E_{i}\left(j_{i 1} j_{c}, \Delta U_{c}, T_{p 8} n_{c}, E_{p}\right)
$$

onde $\mathrm{T}_{p}$ é a temperatura do plasma, $\mathrm{E}_{p}$ campo elétrico no plasma e $\mathrm{n}_{e}$ é a densidade de eletrons do plasma.

- a corrente total do ponto luminoso

$$
I=I(j, a)
$$

- a densidade do fluxo de átomos evaporados

$$
j_{0}=j_{0}\left(p_{v}\left(T_{c}\right), T_{c}\right)
$$

onde $p_{*}$ é a pressắ de vapor.

* - balanço de energila do plasma 


$$
Q_{p}=Q_{p}\left(j_{i}, j_{c}, \Delta U_{c}, T_{p}, j_{0}, T_{c}, a_{,} n_{c y} \gamma\right)
$$

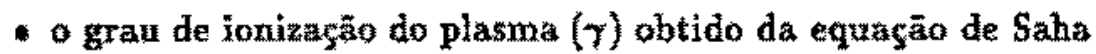

$$
\gamma=\gamma\left(p_{w 2}, T_{p}\right)
$$

- a temperatura do plasma $\mathrm{T}_{\mathrm{y}}$

$$
T_{p}=T_{p}\left(Q_{p}, \hat{j}_{p}, v_{p}, p_{t}\right)
$$

onde $\mathrm{j}_{p}$ densidade de corrente do plasms e $\psi_{p}$ é a velocidade de expansäo do plasma.

- a densidade de corrente de íns para o catodo

$$
j_{i}=j_{i}\left(\gamma_{1} n_{e_{i}}, T_{p}, E_{p}\right)
$$

Eistas relaçōes devem ser suplementadas por outras equaçôes tais como, conservaçăo de partículas, momento, equaģäo de estado etcr, $\mathrm{e}$ às vezes relações exupíricas também säo nsadas. Isto tudo demonstra a dificuldate em se obter uma descriçāo do arco mesmo nesta sìtuaçāo matút simples pois, ế praticamente impossivel resolver todas estas equaçöes sirmultaneamente para obter todos os parâmetros, Outra dificuldade ocorre devido ao desconhecimento do efeito de campo intenso, alta pressä̉o e temperatuxa sobre alguns parâmetros e também qual a relação funcional que deve ser utillizada nestas condịçöes. Por exemplo, na densidade do fluxo de átomos evaporados, relaçăo (2.10), a pressâso de vapor é dependente da temperatura do catodo para $T_{e} \sim 3000-5000 \mathrm{~K}$ ha um graude desconhecimento de $p_{v}\left(T_{t}\right)$.

Com todas estas dificuldades, alguns métodos säo utilizados para uma descriçẩo aproximada dos pontos luminosos quase-estacionărios; três exemplos podem ser citados:

- nāo utilizar todas as equaçöes, ocorrendo neste caso o perigo de que muitos parãmetros 
podem ficar en aberto e, com uma escolha conveniente destes, resultado final pode se ajustar bern aos dados experimentuás dando a falsa impressäo de exatidäo do tratamento;

- substituição de algumas equaçöes por xelaçōes empíricas, mas estas relaçōes podem valer para determinado grupo de materiais e năo para outros grupos, e

- substituição de algumas das relaçồes por inequaşồ, isto é, dando limites superior ou inferior para determinados paränetros. Estes diferentes modos de atacar o problema de pontos luminosos quase-estacionário levam a resultados bem distintos dos parâmetros para o catodo de cobre [32].

A seguinte descriçăo fisica é de aceiłaçăo geral para os pontos luminosos quase-estacionários, com a Figura 2.7 mostrando a situaçäo e os parămetros th́picos (as dimensồs não estäo em escala).

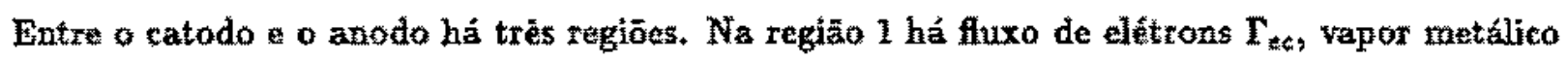
$\Gamma_{6}$, racropartículas $\Gamma_{m p}$ e lons $\Gamma_{i c}$ vindos da regiäo 2 (contrário ao fluxo de elétrons). Forma-se nessa regižo uma bainha livre de colisöes com predominäncis de íons ocorrendo assim uma queda de potencial $\Delta U_{c}(\sim 10 \cdot 50 \mathrm{~V})$; a largura dessa bainha é da ordera do livre caminho médio dos fons $m 10^{-8} \mathrm{~m}$. Desse modo, existe nesta regiāo urn campo elétrico de $\sim 10^{s} \mathrm{~V} / \mathrm{m}$ que acelera os fons que entram nesta regiāo para a superficie do catodo es elekrons para a regiño 2 . Os h́ons atingindo a superficie do catodo cedem a energia ganha no campo e jumtamente com a enengia devido ao aquecimento resistivo pala emissễo de clétrons elevam a temperatura do catodo para 3000 - 5000K. O campo intenso abaixa e estreita a barreira de potencial do metal e a temperatura elevada sumenta o número de elétrons acima do nível de Fermi, ocortendo, entäa, a triissăo de elétrons pelo éeito térmico. Com a temperatura elevada ocorre a emissão de vapor metálico da superficie.

Na regiäo 2 tem-se am quase-equilibrio onde ocorrem colisöes, ionizzçäo e recombinaçäo. Os elétrons entrando nesta regiāo com uma energia $\sim 10$ - 50 eV sãa termalizados a uma témperatura $\mathrm{T}_{t} \rightarrow 1-5 \mathrm{eV}$ e depois desta terrnalizaça poden entrar por difusão na regiāo 1 onde são acelerados e atingem $O$ catodo, fechando se 0 ciclo. Os parämetros típicos desta regiāo säo: densidade de vapor metálico $\mathrm{n}_{\mu} \times 10^{24}-10^{2 \mathrm{C}_{\mathrm{m}}} \mathrm{3}^{-3}$; densidade de ions $\simeq$ densidade de elétrons $\mathrm{n}_{i} \simeq \mathrm{n}_{E} \sim 10^{23} \cdot 10^{25} \mathrm{~m}^{-3}$ e a latgura desta região é xo 
1 - $100 \mu \mathrm{m}$. Um plasma nestas condiçôes näo pode estar em equiliorio ( $p>1$ atm) mas expande-se $\operatorname{com}$ a densidade caindo com $z^{-2}$ [34], dando origem a um plasma em equilibrio (região 3) que ocupa praticamente toda a regiāo entre os eletrodos. Neste plasma $n_{i}=n_{e} \leq 10^{21} \mathrm{mn}^{-3}, \mathrm{~T}_{e}<$ $5 \mathrm{eV}$ e a temperatura dit fons năo deve ser muito diferente da temperatura le elétrons $[35,36]$. Por outro lado, os fons tern uma energia cinética de $\sim 10$ - 100 eV resultando numa velocidade de deriva $u_{i *} \sim 10^{3} \cdot 10^{4} \mathrm{~m} / \mathrm{s}$ dirigida para o anodo.

O seguinte balanço dos diversos fluxos resulta [37]:

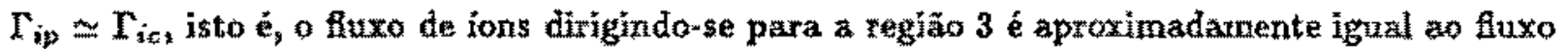
dirigindo-se para o catodo.

$\Gamma_{m p}$ e fuxo de macropartículas tendo uma maior concentraçăo num ângulo $\vartheta \sim 20 \cdot 30^{\circ} \mathrm{da}$ superficie do catodo.

Fis é o fluxo de fons atingindo a câmara de vácuo. No caso da PCEN há um campo magnético axial fazendo com que $\Gamma_{i n} \simeq 0,0$ que resulta em $\Gamma_{j p} \simeq \Gamma_{i A}\left(\Gamma_{i A}\right.$ o fluxo de ions se dirigindo para o anoto).

$\Gamma_{c p}, \Gamma_{i p}-\hat{A}$ razäo entre $u_{i x}$ e a velocidade termica dos tons $u_{i T}$ e $u_{i x} / u_{i T} \cong 5-10$ o que quet dizer que os fons formam um fiuxo dirigido para o anodo. Por outro lado, para os elétrons esta razão é 1 es elétrons formam um fluxo térmico dirigindo-se para o anodo. A corrente de fons é $\mathrm{I}_{i} \simeq(0,05-0,12) \mathrm{I}_{a}$ e a de elétrons $\mathrm{L}_{c} \simeq(1,05-1,12) \mathrm{L}_{\alpha}$.

Corno já salientado anteriormente, os ions na regiäo 3 tem uraa energia cinética $E_{;}$w $10-150$ eV (ou velocidades $u_{i x} \sim 10^{3}-10^{4} \mathrm{~m} / \mathrm{s}$ ) e há uma multiplicidade de estados de ionização. Estes

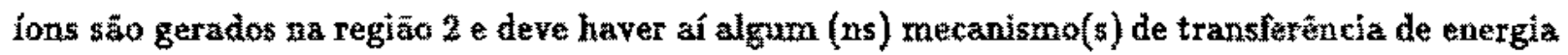
para as mesmos. Alguns dos possíveis mecanismos de transferềncia de energia, embora nenhum deles explique todos os fatos experimentais, sāo:

- Perfil do potencial elétrico perto do catodo (regiäo 2) [27,28]

O perfil de potencial elëtrico nesta regiāo seria modificado como segue. Na região 2 ocorre a ionização do vapor metálico pelos elétrons; produrindo assim um aumento acentuado na 
a)

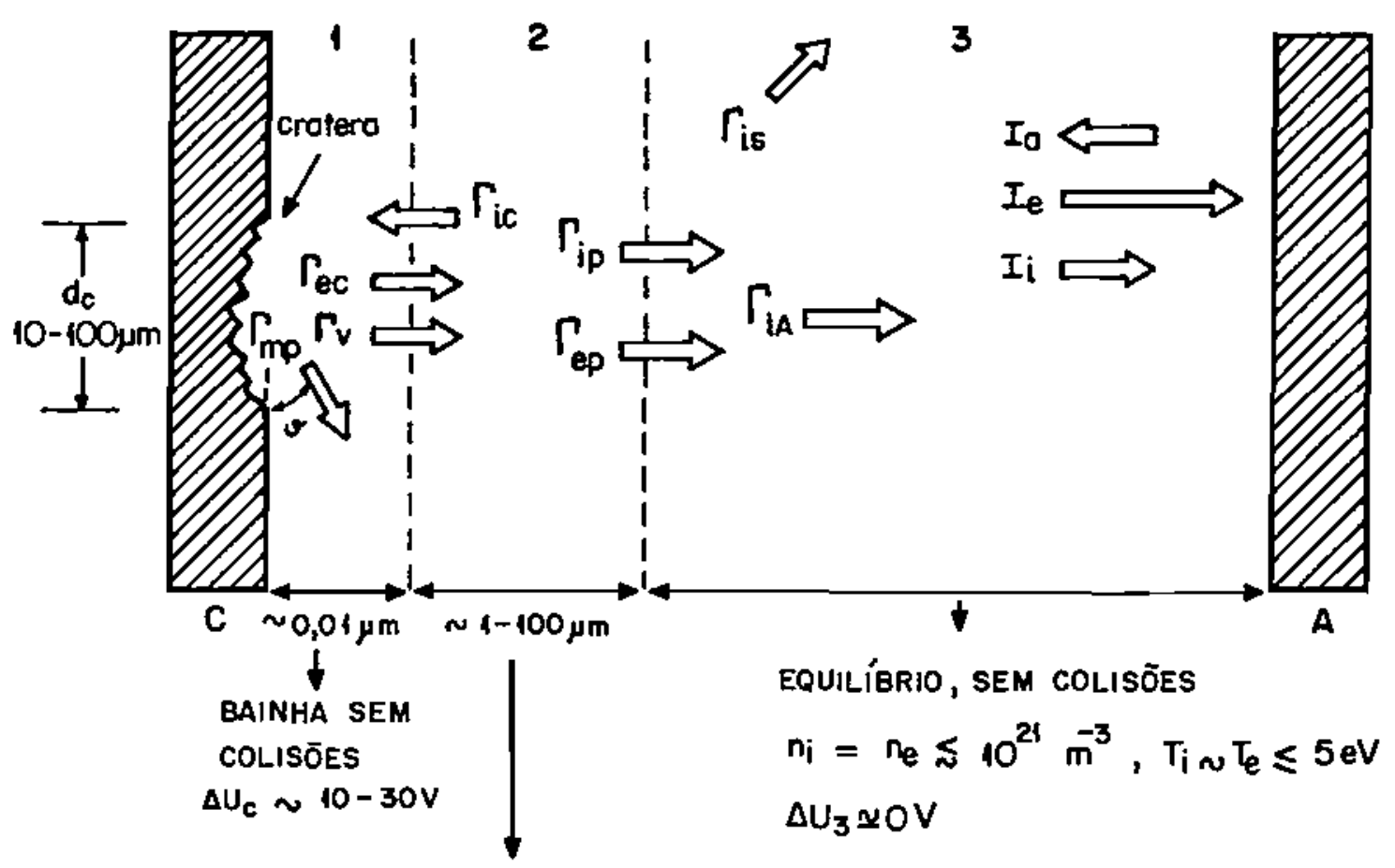

QUASE EQUILÍBRIO COLISÕES, NONIZAÇǑES

RECOMBINACAO

$n_{i} \simeq n_{0} \sim 10^{23}-40^{25} \mathrm{~m}^{-3}$

$\Delta U_{2}<5 \mathrm{~V}$

b)

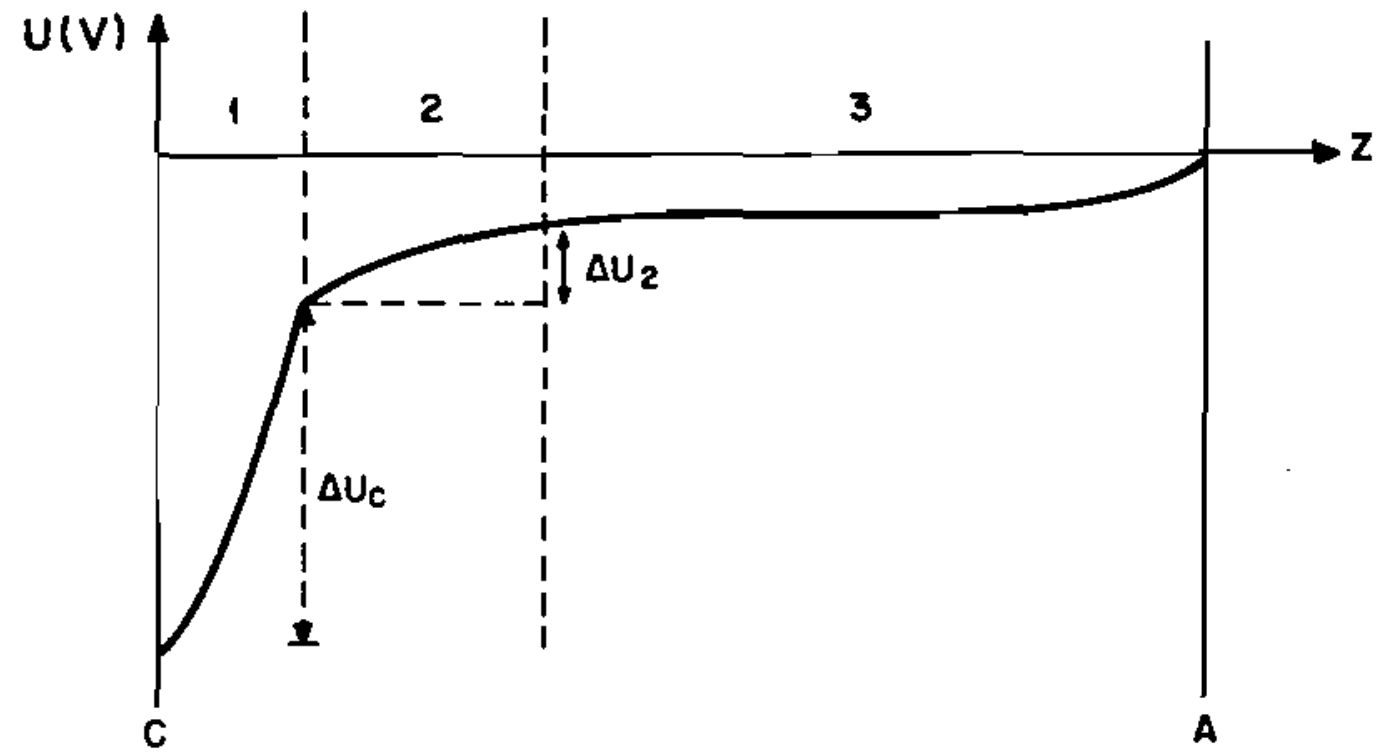

Figura 2.7. a) Descrição do ponto luminoso quase-estacionário. b) Perfil do potencial elétrico entre o catodo e o anodo. 
densidade local de jons. A razazo de produçāo de ions rapidarnente atinge um mấximo e entäo decae com a distancia do catodo por dois motivos:

- porque os elétrons cederam parte de sua energia para a ionizagäo não tendo assim mais energia para novas ionizações, $e$

- \$densidade de vapor metálico decresceu devido a conversäo para ́́ons e pelo efeito geométrico devido a expansäo que ocorreu nesța regiào. Pelo menos um elétron té produzido na ionizaçäo, e, assim, a densidade de elétrons também deveria ser máxima mas, isto näo ocorre porque $1_{e T}>u_{i z}$ es elétrons deixam esta regiäo mais rapidamente ficando wn excesso de cargas positivas para trấs dando origem a um máximo no potencial. Com o crescimento deste potencial os elétron sắo retardados e os tons acelerados e um estado estacionário é atingido no qual os fluxes de cargas pesâtivas e negativas säo iguais, processo controlado por difusāo ambipolar. No estado estacionario, nowos ions să produzidos neste potencial devem entāo possuir energias tăo elevadas quanto o potencial onde foram criados, possfbilitando a existëncia de lóns com cargas $q_{i}=\mathrm{Ze}(\mathrm{Z}=1,2 \ldots)$. A Figura 2.8 mostra este potencial modificado (tipo corcova) para regiāo 2 (comparar com a Fig. 2.7b).

Un tal perfil de potencial é dificil de se obter tanto experimentalmente (a largura desta regiäo é $\times 1-100 \mu \mathrm{m}$ ), como através de uma formulaçäo matemática.

\section{- Dinämica dos gases $[38,39,40]$}

Os íns ganham energia tanto por colisöes com o fluxo de elétrons de alta velocidade (há uma transferência de energia do fluxo de elétrons para o fluxo de ions), como através da expansāo do plasma (há uma conversão da energia térmícs para a energì dínigida).

A conservaçâo de energia fornece a relaçẵo

$$
Q \frac{t_{z}^{2}}{2}=I_{a}\left(U_{a}-\Delta U_{c}\right)
$$

onde $\mathrm{G}$ é a erosäo de material por unidade de tempo $(\mathrm{kg} / \mathrm{s})$, $\mathrm{u}_{x}$ é a veloctdade de expansão do plasma e $\Delta \mathrm{U}_{2}=\mathrm{U}_{a}-\Delta \mathrm{U}_{c}$ é a varią̧äo de potencíal na regiào 2. Os dados obtidos na PCEN com magnésio foram $u_{z}=1 \times 10^{4} \mathrm{~m} / \mathrm{s}, \mathrm{G} \sim 4 \times 10^{-5} \mathrm{~kg} / \mathrm{s}, \mathrm{I}_{a}=1,5 \mathrm{kA}$ tesultando eII $\Delta U_{2} \sim$ IV. Assim, nāo hă uma grande variação do potencial na regiäo 2 se o ganho de energía dos ions vem da dinâmica dos gases. 


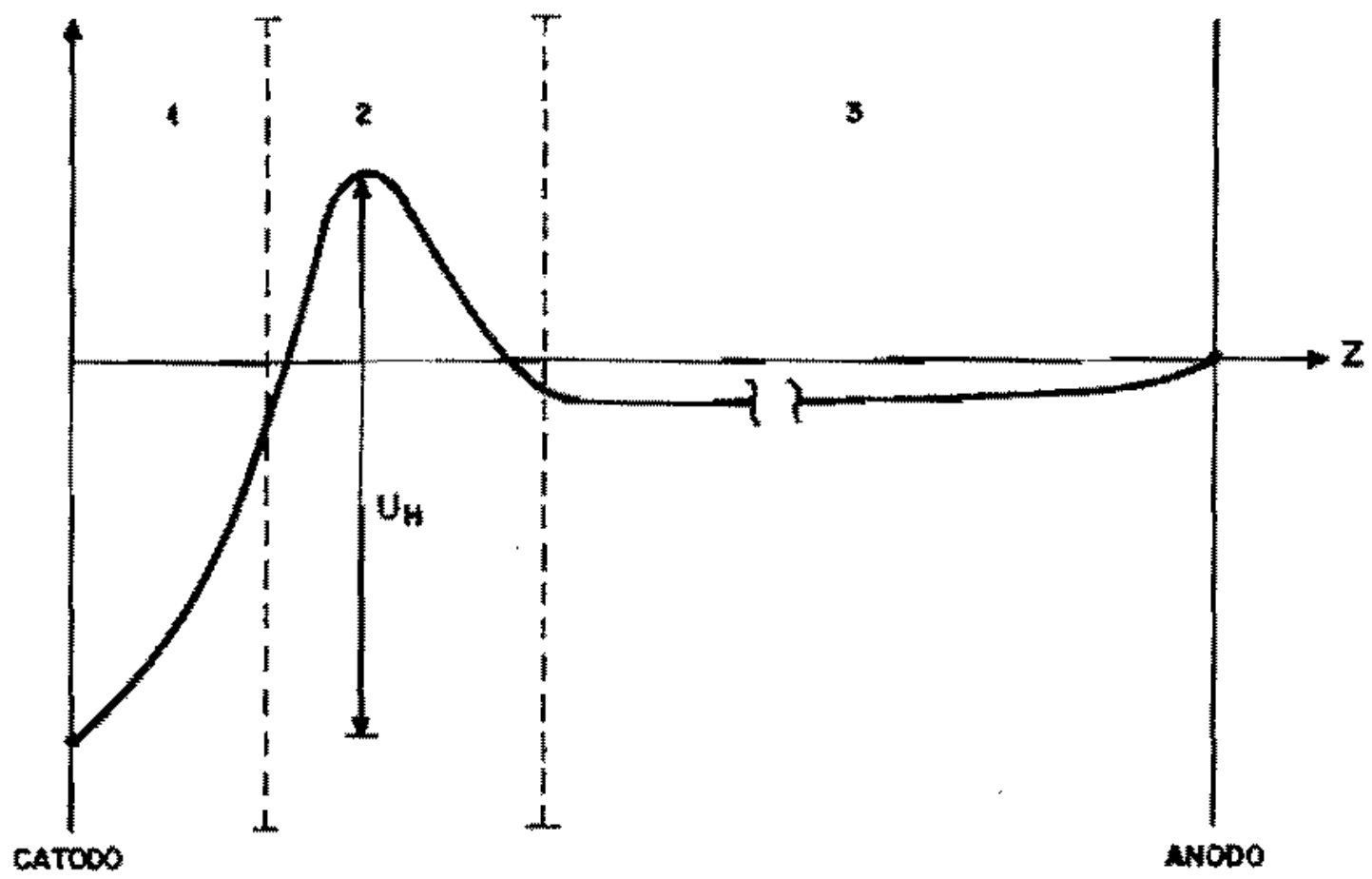

Figura 2.8. Potencial elêtrico tipo corcova na regiäo 2[28]. 
- Efeito combinado $[41,42]$

Neste caso os três efeitos estäo presentes; potencial tipo corcova, efeito de colisöes e gradiente de pressāon. Para un plasma năo isotérnico com $T_{i}<T_{n}, \sim 60 \%$ da energia dos fons vem colisôes, $\sim 30 \%$ do campo elétrico $€ * 10 \%$ do gradiente de pressão. Para um plasma isotérmico $\sim 45 \%$ vem das colisöes, $\sim 20 \%$ do campo elétrico e $\sim 35 \%$ do gradiente de pressấ.

- Irstabilidade de Buneman [43]

A condição para esta instabilidade surgir é que a velocidade de deriva relativa entre os elétrons es íons seja maior ou igual à velocidade térmica dos elétrons

$$
u \equiv\left|u_{e z}-\vec{u}_{i z}\right| \geq u_{\varepsilon T}=\sqrt{\frac{T_{\varepsilon}}{m_{\varepsilon}}}
$$

Da relaçäa $=\mathrm{n}_{e} \mathrm{u}$, com $\mathrm{n}_{e} \sim 10^{24} \mathrm{~m}^{-3}, \mathrm{j} \leq 10^{12} \mathrm{~A} / \mathrm{m}^{2}, \mathrm{~T}_{e} \sim 1-3 \mathrm{eV}$ obtém-se os valores $u>2 \times 10^{6} \mathrm{~m} / \mathrm{s}$ e $u_{e T} \sim(4-7) \times 10^{5} \mathrm{~m} / \mathrm{s}$ ou seja $u>u_{e} T$. Esta instabilidade produz o arraste elétron-íon necessário para acelerar os lons (como $u_{\varepsilon d} \gg u_{i z}$ o fluxo de alétrons é como um vento incidindo sobre os ions) no ponto em que a transferència de montento dos elétrons para os íns via colisöes coulombiantos seja pequena. A seguinte relação é obtida entre a energia do ion com carga $\mathrm{Ze}$ e $\mathrm{a}$ do estado $\mathrm{Z}=1$

$$
E_{Z}=Z^{\frac{1}{b}} E_{1}
$$

ou

$$
V_{z}=z^{-\frac{2}{8}} V_{1}
$$

A energia por unidade de carga diminue para 2 maiores como mostrado na Fig. 2.6 .

- Aceleraçăa eletrodinämica dos tons [44]

Os dados experimentais sugerem que uma força $F \propto i_{\text {(a) }}^{2}$ (onde $i_{a}$ e a corrente transportada pelo ponto luminosol pode atuat na aceleração dos íons. Uma força com tal dependència com a corrente deve ser de natureza eletromagnética. Partindo da força de Ampere entre dois elementos de corrente com $i_{y}=100 \mathrm{~A}$ e cratera com diämetro de $10 / \mathrm{m}$ o seguinte resultado foi obtido: 
Tabela 2.2. Velocidade média do ponto luminoso $(\mathrm{m} / \mathrm{s})$ para trés instantes da descarga $\operatorname{com} I_{a}<60 A[45]$.

\begin{tabular}{|c|c|c|c|}
\hline Metal & $t_{1}=0,1 m s$ & $t_{2}=1 \mathrm{~ms}$ & $t_{3}=10 \mathrm{~ms}$ \\
\hline Cu & 3,2 & 1,0 & 0,32 \\
Cd & 2,8 & 0,89 & 0,28 \\
Al & 4,7 & 1,5 & 0,47 \\
Mo & 3,4 & 1,1 & 0,34 \\
\hline
\end{tabular}

$$
\begin{aligned}
& \int_{a}^{b} n_{i} F d z=6,1 \times 10^{9} \frac{J}{m^{3}} \\
& \frac{1}{2} n_{i} m_{j} z_{z}^{2}=6,1 \times 10^{9} \frac{J}{m^{3}}
\end{aligned}
$$

onde $a=10^{-8} \mathrm{~m}$ e $b=10^{-5} \mathrm{~m}$. Para catodo de cobre $e \mathrm{n}_{i}=(3-6) \times 10^{26} \mathrm{~m}^{-3}$ obtém-se $w_{z}=(1,4-2) \times 10^{4} \mathrm{~m} / \mathrm{s}_{z}$ estando em contordância com os resultados experimentais para a velocidade de expansäo do plasma de cobre.

\subsubsection{Cimistäo explosiva de elêtrons e pontos luminosos näo estacionários- ( Tipo 1)}

Agora atenç⿳亠丷厂犬 $1 \mathrm{~m} / \mathrm{s}$ sobre a superficie do catodo; velocidad de até $\sim 30 \mathrm{ma} / \mathrm{s}$ podem ser encontradas. característico do Tipo 1 uma taxa de erosăo pequena, diâmetro da cratera $<10 \mu \mathrm{m}$ e ocorre preferencialmente para baixas correntes de arco $(<100 \mathrm{~A})$, onde o número de pontos luminosos é pequeno. Em superficies contaminadas (gases absorvidos, óxidos, dielétrico), irregulares e para materiais refratários $(\mathrm{Mo}, \mathrm{Ta}, \mathrm{W})$ este é ponto luminoso comumente encontrado.

Durante a descarga a velocidade do ponto luminoso decresce e pode chegar a velocidades abaixo de $1 \mathrm{~m} / \mathrm{s}$ ocorrendo assim uma transiçäo do Tipo 1 para o Tipo 2, conforme mostrado na Tabela $2.2[45]$.

Para explicar este tipo de ponto luminoso é muito utilizado o conceito da emissäo explosiva de elétrons, un fenômeno que ocorre na ruptura em vácuo entre eletrodos em forma de pontas onde campos elétricos intensos de $\sim 10^{10} \mathrm{~V} / \mathrm{m}$ estäo presentes (emissẵo por eféto de campo), gerando densidades de correntes altas $\sim 10^{13} \mathrm{~A} / \mathrm{m}^{2}[46,47]$. Normalmente os pulsos sằ de curta duraçăo 
$\tau_{p}<1 \mu$, baixa corrente $I_{a}<100 \mathrm{~A}$, e tensāo aplicada entre os eletrodos säo de dezenas a centenas de $\mathbf{k V}$.

O desenvolvimento deste processo está indicado na Figura $2.9[48,49,50,51,52]$. Uma microir regularidade (1) existe na superficie onde o campo elétrico se concentra $\left(\sim 10^{10} \mathrm{~V} / \mathrm{m}\right)$. Esta microirregularidade pode existir tanto numa buperficie bem polida como pode ser produzids pelo plasma inicisl que fechou o areo (criado pelo laser na PCEN). Este campo elétrico intenso dá origem z uma densidade de corrente de $\sim 10^{13} \mathrm{~A} / \mathrm{m}^{2} \mathrm{e}_{3}$ a passagem desta corrente por esta irregularidade dissipa muita energia (por efelto Joule) elevando a temperatura neța regiāo para $\mathrm{f}_{t}>5000 \mathrm{~K}$. Uma temperatura täo elevada, juntamezte com uma pressäo $\mathrm{p}>10 \mathrm{~atm}$, leva a uma transiçäo da fase sólida para a liquida (2). Junto corn o fluxo de elétrons da emissäo explosiva (3) forma-se um plasma (nżo ideal) de densidade muito alta $10^{26} \cdot 10^{28} \mathrm{~m}^{-3} \mathrm{e} \mathrm{T}_{e} \sim 5 \mathrm{eV}$ (4). A pressão exercida por este plasma (5) deforma a superficie como indicado na figura formando uma cratera com $\mathrm{d}_{e}<10 \mu \mathrm{m}$. Este plasma tem um comprimento Debye $\lambda_{D} \sim 15 \mathrm{~A}$ a distância entre as partículas è $\mathrm{d} \sim(1 / n)^{(1 / 3)} \sim 30$, um plasma colisional, nāo havendo a possibilidade da formaçäo de uma bainha junto à superfície do catodo. A queda de potencial ocorre ao longo de todo o plasma quase metálico pelo fiuxo de correate através deste plasma $(\vec{J}=\vec{E})$. A velocidade de expansāo deste plasma pode ser calculada da expressāo [48].

$$
u_{x}=\sqrt{4 \varepsilon_{*} s\left[\frac{\gamma}{\gamma-1}\right]}
$$

onde $\gamma$ é o expoente adiabătico( $(\gamma=1,24$ para plasms $), \epsilon_{z}$ é a energia específica de sublimaçäo $(\mathrm{J} / \mathrm{kg})$ e $\delta$ é fator de superaquecimento. Para catodo de cobre $\epsilon_{3}=5,34 \times 10^{6} \mathrm{~J} / \mathrm{kg}$ e $\delta=3,8$ resultando em $\mathrm{u}_{z}=2 \times 10^{4} \mathrm{~m} / \mathrm{s}$.

Na periferia da cratera há a ejeção de macropartículas (6) e a formaçäo de uma nova microirregularidade (7). Da etapa (1) atě a (7) houve um crescimento na ărea de emissăo, diminuindo a densidade de corrente e a temperatura. Näo havendo mais as condigöes de existencia da

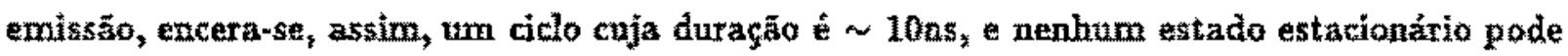
ocorrer neste modelo. O novo ciclo de emisssäo explosiva pode ocorrer na microirregularidade surgida ou se deslocar para um outro ponto com melhores condiçōes para a emiszäo. Como tanto a formaçăo de novas mieroitregularidades como as que jả existiam estäo dispostas de uma 

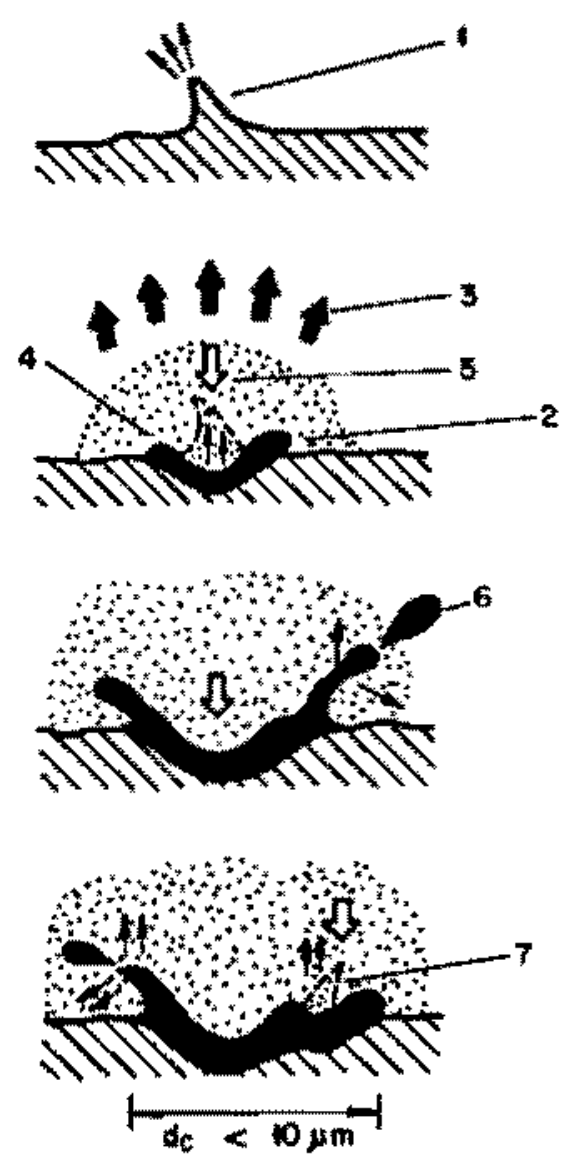

Figura 2.9. Modelo da emissāo explosiva de elétrons para os pontos luminosos.

maneira aleatónia sobre a superneie, este modelo explica o fato de que o movinento dos pontos huminosos ser aleatório.

Jấ foi salientado anteriormente que as opiniöes se dividem sobre a origern dos pontos luminosos e, há argumentaçöes fisicas fayorâtueis tanto a um quanto a outro grupo $[22,52,53,54,55]$. Por exemplo(da relação $J=\sigma E)$, para transportar uma densidade de corrente $\mathrm{j}>10^{11} \mathrm{~A} / \mathrm{m}^{2}$ seria necessatio $\mathrm{AU}_{\varepsilon}>100 \mathrm{~V}$, se a condutividade fot calculada pelo modelo Sptizer-Harm $\left(\sigma_{a}\right)$, um valor mutto maior que o experimental $(10-50 \mathrm{~V})$, essim entäoj $\leq 10^{10} \mathrm{~A} / \mathrm{m}^{2}$. A argumentaçäo dos que defendem $\mathrm{j} \geq 10^{11} \mathrm{~A} / \mathrm{m}^{2}$ e a de que o plasma é näo ideal $\left(\mathrm{n}_{\mathrm{s}}>10^{2 \mathrm{~g}} \mathrm{~m}^{-3}\right) \mathrm{e}_{\mathrm{q}}$ o cálculo da condutividade deve levar isto em conta, dando um valor de $\sigma \sim 10 \times 100 \%$, o que resulta em $\Delta \mathrm{U}_{c} \sim 10-50 \mathrm{~V}$.

O desenvolvimento de um modelo para o estado não-estacionário é muito complexo e a descrição 
fisica está longe de um consenso para os pontos luminosos Tipo 1.

\subsubsection{Método das regiốes de existência dos pontos luminosos}

Un outro método (pouco utilizado, apresentado aqui só para completar a exposị̧äo sobre arcos) para resolver as equaçōes (2.5) * (2.14) consiste em substituix parte destas equaçōes que säo raủto complicadas ou năo muito conhecidas por inequaçöes apropriadas. Com este método obtern-se no plano $T_{c}-\mathrm{j}$ a regiäo (ou regiồt luminosos só podern existir dentro desta(s) regiăo(äes) que delimitam os valores da temperatura do catodo e densidade de corrente. A Figura 2.10 apresenta um tal diagrama para o catodo de cobre $[56,57]$.

Nesta figura pode ser vista a existência de duas regiöes, uma com $T_{s}$ e $j$ menores (modo 0 ) e outra onde $T_{c}$ e jā̃o mais elevados (modo 1). Na figura também podem ser vistos os processos dominantes de ganho e perda de energia que ocorrem na superficie do catodo. $O$ aquecimento Nottingham (ou efeito Nottingham) ocorre do fato de que a energia média transportada pelos elétrons de conđụ̧ão do interior do catodo para a superfície de emissäo é diferente da energia média transportada pelón elétrons emitidos.

\subsubsection{Efeitos do campo magnêtico sobre a descarga em arco no vácuo}

Agora seräo vistos alguns efếtó que surgem com a aplicação de um campo magnétíco externo - do campo magnético produrido pela corrente de arco.

0 campo magnético $\left(B_{\varphi}\right)$ produzido pela corrente de arco $x_{6} \sim 1$, WA para tama coluna de plasma

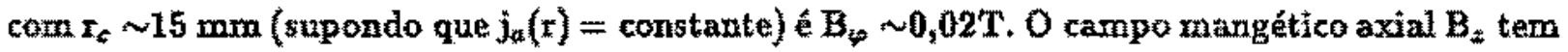
um efeito estabilizador no $5 r e$, , onde para campo baixo aparecem muitas flutuaçöes no pulso de corrente. A Figura 2.11 mostra a disposiçäo dos campos que esta sujeita a instabilidade de dobra [58].

A coluna é estabilizada por um campo axial crítico dado pelo limite de Kruskal - Shafranoq 


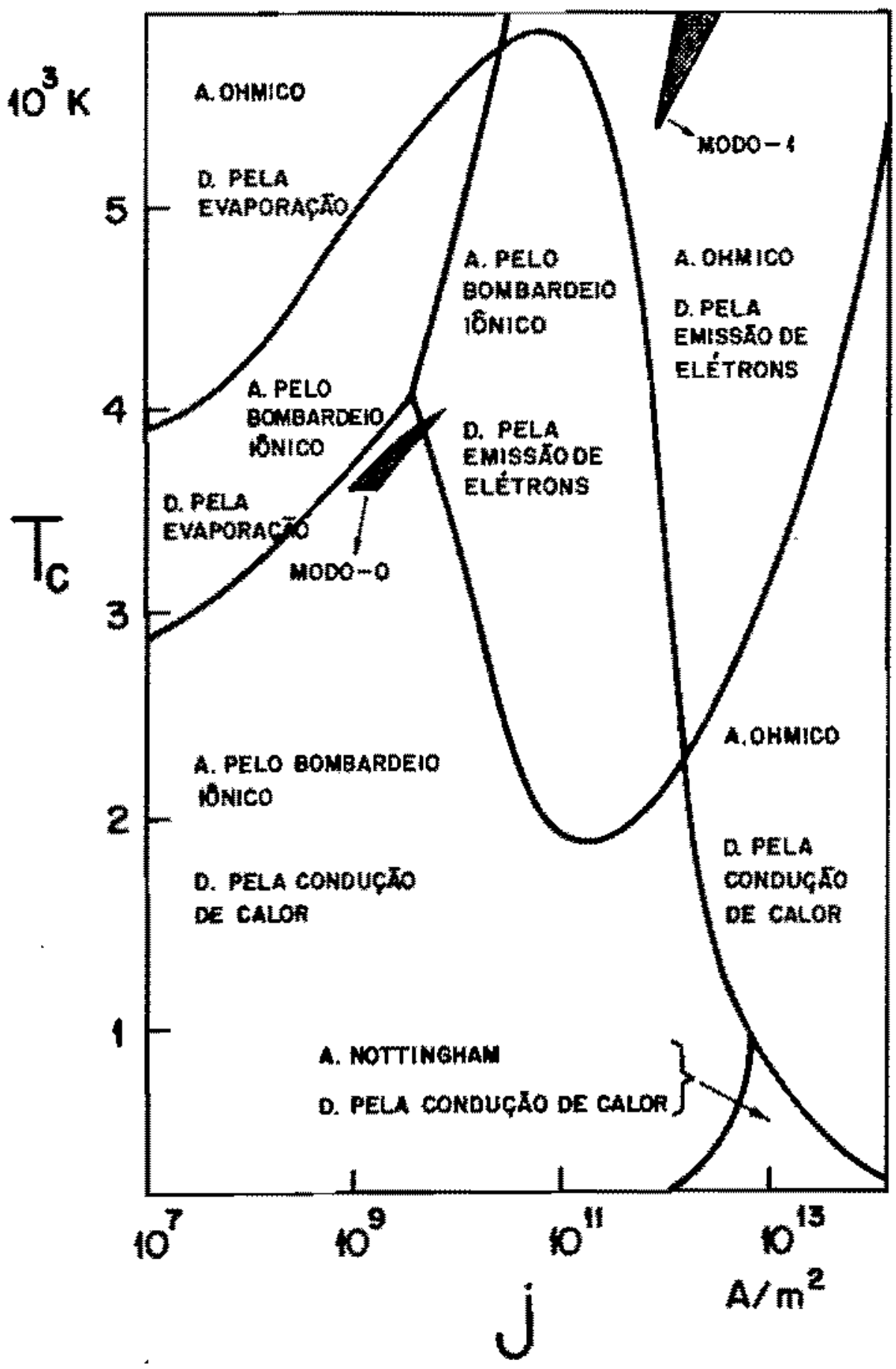

Figura 2.10. Diagrama de existência para os pontos luminosos no catodo de cobre e os processos dominantes de ganho e perda de energia na superficie do catodo $(\mathrm{A}=\mathrm{aqueciment}, \mathrm{D}=$ desaquecimento $)[56,57]$. 


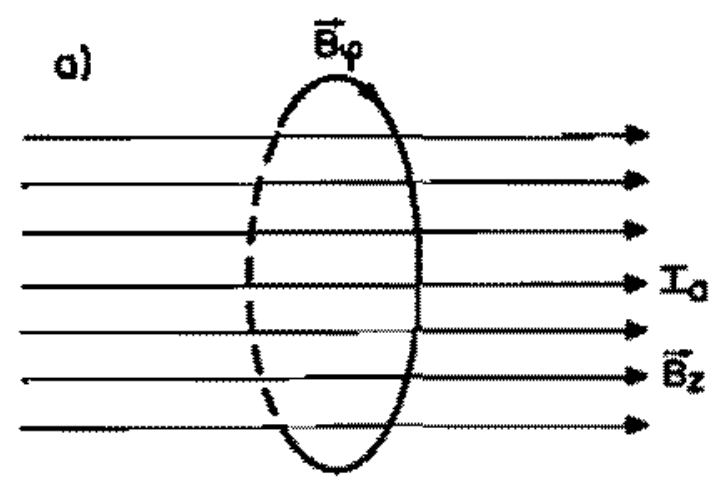

b)

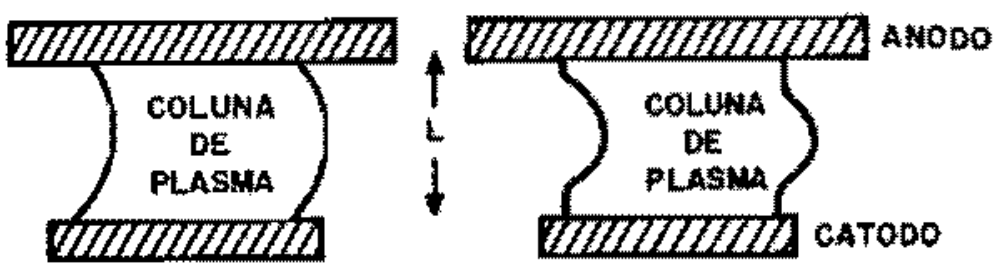

Figura 2.11. a) Disposiçăo dos campos na PCEN. b) Modos da instabilidade de dobra.

$$
\begin{aligned}
& B_{x e}>\frac{\mu_{0} I_{a} L}{\left(2 \pi r_{a}\right)^{2}} \\
& B_{x e}>\frac{2 H_{0} I_{a} L}{\left(2 \pi r_{c}\right)^{2}},
\end{aligned}
$$

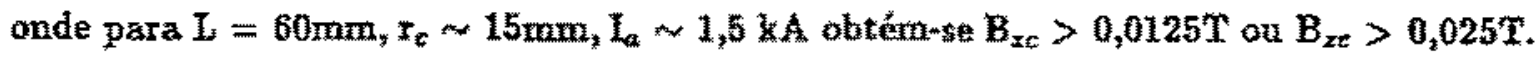

Na regiăo próxima ao catodo $(2<100 \mu m), n_{e}=n_{i} \sim 10^{23}-10^{25} \mathrm{~m}^{-3}, \mathrm{~T}_{i} \sim \mathrm{T}_{\mathrm{e}} \sim 1-5$ eV e para $B_{z} \simeq 0,05 \mathrm{~T}$ tem-se

$$
\beta=\frac{\operatorname{\Sigma n} k_{B} T}{\frac{B^{2}}{2 \mu_{g}}}>10
$$

e efeito do campo magnético axial é pequeno, região dominada por efeitos cinéticos.

Em praticamente todo o espaço entre o catodo e o anodo tem-se os parámetros $n_{e}=n_{i}=10^{20}$ $m^{-3}$ e $T_{0} \approx T_{i}<5$ eV o que dá $\beta<0,1$. Neste caso o campo magnético confina o plasma, diminuindo o rajo da coluna e corrente de particulas carregadas para a superñcie da cămara 


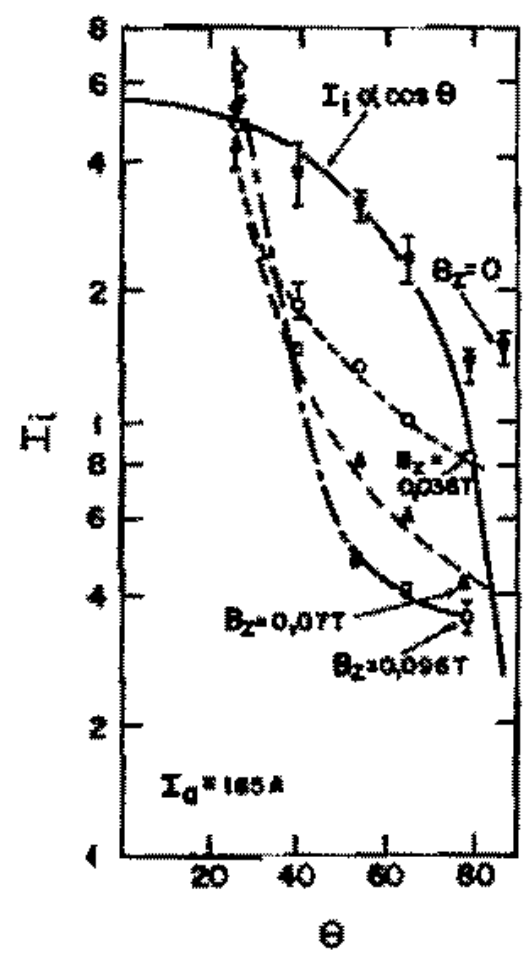

Figura 2.12. Distribuiģão angular da corrente de ions com o campo magnétítco axial aplicado, $I_{i}$ e a crrente de fons por unidade de ângulo sólido[59].

de vấcuo. Com isto, há uma concuntraçăo da corrente de áons na direçäo axial modificando a distribuiçäo dada pela eqquaçâa(2.4) e mostrada na Figura 2.5. A Figura 2,12 mostra os resultados experimentais obtidos na distribuiçāo angular da corrente de hons com o aumento do carnpo magnético axial [59].

Se um campo magnético é aplicado transversalmente $\left(B_{T}\right)$ à corrente do arco, isto é, paralelo a superficie do catodo há uma dístorçă na expansão do plasma corno indicado na Figura 2.13 [60]. Embora na PCEN o campo predominante seja axial, na posiçăo em quáe se encontra o catodo, pode existir uma pequena componente tangencial à superficie do catodo. $O$ resultado poderá ser um deslocamento do centro da coluna relativo ao centro da cämara de vacuo.

Um dos fenómenos mais intrigantes observados já em 1903 por Stark e que tem recebido durante todos estes anos uma quantidade enorme de tentativas de explicaçăo sem sucesso, é o movimento do ponto luminoso năo estacionárío na presença do campo tangencial B estacionário aparentemente o efeito ê pequeno). As obserraçöes experimentais referentes a esse 


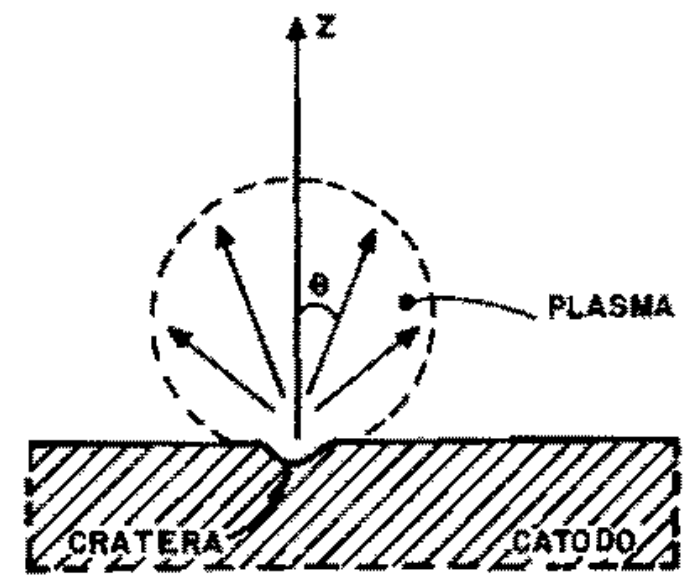

(a)

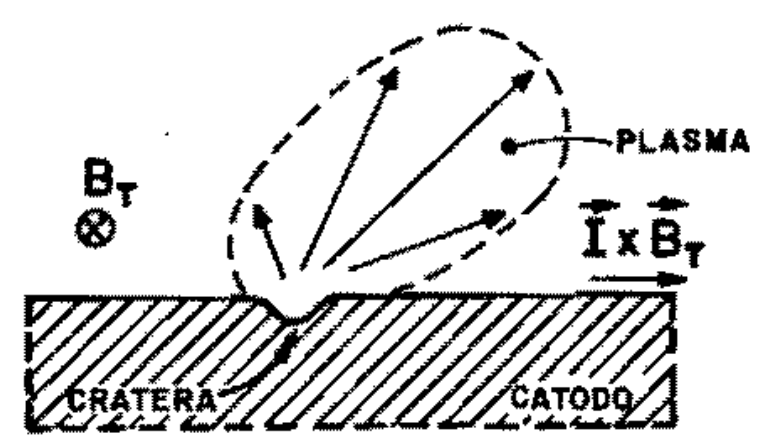

(b)

Figura 2.13. Expansä̀o do plasma a partir da cratera a) sem b) com campo magnético tangencial $\left(B_{T}\right)$ a superficie do catodo[60!. 
movimento sato:

- contrátio a expectativa, o ponto luminoso move-se na direçäo oposta a força $\vec{I} \times \overrightarrow{B_{T}}$ (movimento retrógrado).

- o plasma próximo ao catodo tem uma pressẫo p > 10 atm (ou muito maís) mas, basta uma pequena quantidade de gás ser introduzida $\left(\mathrm{p}_{\alpha}<0,1 \mathrm{~atm}\right)$ para diminuir o movimento retrógzado e, para urna pressão crítica $\mathrm{p}_{\sigma r}<0,5$ atm o movinento inverte, isto é, passa para a direçẩo da for $\vec{I} \ddot{I} \times \overrightarrow{B_{T}}$.

- para uma dada pressão do gás $\left(\mathrm{p}_{3}<\mathrm{p}_{\mathrm{cr}}\right)$ o movimento retrógrado aumenta com o campo mas para urn valor crítico $\left(B_{T}>1 T\right)$, a velocidade inverte aumenta na direçäo de $\vec{I} x$ $\overrightarrow{B_{T}}$ corn o sumento do campo.

- urn carnpo magrético axial ( normal s̀ superficie do catodo) diminnue o movimento retrógrado e também dá origern a um componente de velocidade paralelo a $\mathrm{B}_{T}$.

Desta exposiçāo resumida da descarga em arco no vắcưo pode-se notar ausêncla de um madelo que possa explicar todos os complexos fenomenos que ocorrem numa tal descarga. Dos conhecimentos obtidos até hoje, tanto teóricos como experimentais, os aeguintes parâmetros podern ser esperados.

- Densidade de partículas carregadas: $n_{i}=n_{e} \leq 10^{21} \mathrm{~m}^{-3}$.

- Temperatura de elétrons tons: $\mathrm{T}_{i} \leadsto \mathrm{T}_{\mathrm{i}} \leq 5 \mathrm{eV}$.

- Energia cinética dos fons: os tons tem uma energia cinética $\mathrm{E}_{i}>10$ eV o que significa uma velocidade axial $\mathrm{u}_{2} \times 10^{3}-10^{4} \mathrm{~m} / \mathrm{s}$.

- Estado de ionização dos íons: o plasma é composto de íons em vátrios estados de ionizaçăa. Para os catodos utilizados neste trabalho os seguintes valores médios para $\mathrm{z}$ sä̃ obtidos $[26] ; \mathrm{C}(\vec{Z}=1) ; \mathrm{Mg}_{\mathrm{B}}(\vec{z}=1,5) ; \mathrm{Al}(\vec{z}=1,7) ; \mathrm{Ni}(\vec{z}=1,8) ; \mathrm{Cu}(\vec{Z}=2,0) ; \mathrm{Zn}(\vec{Z}=1,2)$; $\mathrm{Cd}(\bar{Z}=1,3)$ e $\mathrm{Pb}(\bar{Z}=1,6)$.

- Grau de ionização do plasma: o plasma pode apresentar grau de ionazaçäo acima de $50 \%$ e atíngir até 80-100\% para o magnésio. Para catodos de ainco, cádinio e chumbo o grau de ionizzçäo diminui para $\sim 20 \%$. 


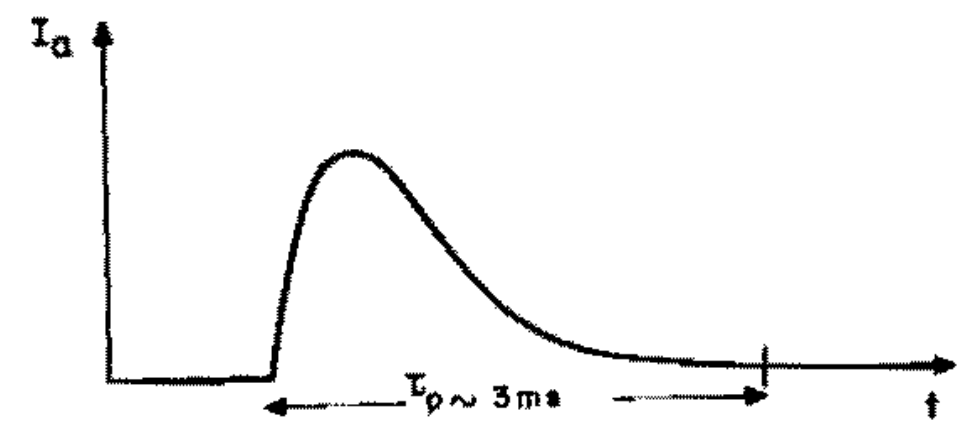

Figura 2.14. Pulso de corrente na PCEN antes de 1989.

Corn os valores de campo magnético, corrente de arco e tempo de duraçấo da descarga típicos na PCEN, tem-se um arco difuso, descrito pelo modelo de ponto lurninoso quase-estacionário (Tipo 2).

Seräo apresentados agora, os resultados das medidas efetuadas de vários parấmetros na centrífuga de plasma iniciada por arco no vácuo.

\subsection{Impedáncia do plasma e o circuito formador de pulso con- struido}

Até 1989 o circuito que polarizava o catodo ora un banco de capacitores de $50 \mathrm{mF} / 600 \mathrm{~V}$ e a Figura 2.14, mostra o pulso de corrente que era obtido com esta configuraçäo [61].

Este pulso, tinha a desvantagem de nầo ser possível atilização te circuito de varredura para a sonda de Langmuir, pois, näo é constante com o tempo. Isto obriga a obter a curva característica pela tếcnica de ponto a ponto, o que torna o diagnóstico do plasma demorado e cansativo. A obtençä́o de curvas características das sondas de Langmuir durante um único pulso de corrente de arco, facilita enormemente o diagnóstico do plasma.

Com a finalidade de agilizar a aquisiçă̌o de dados foi projetado e construido um circuito formador de pulso cujos detalhes serão dados a seguir. Este circuito possibilitou:

- abtençẵo de um pulso de corrente de arco corn duraçäo de $\sim 16 \mathrm{~ms}$ e praticamente 


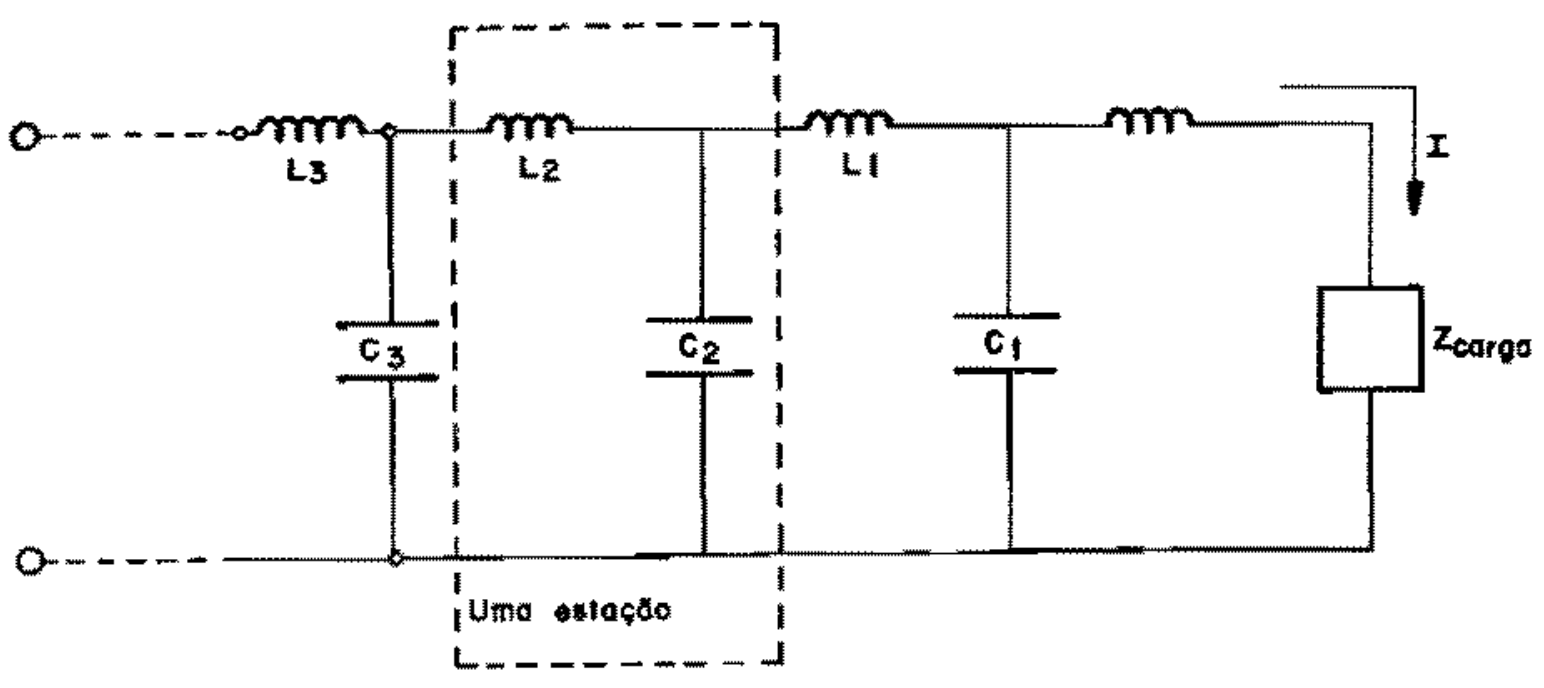

Figura 2.10. Esquema do circuito formador de pulso ou linha de transmissäo LC.

constante por $\sim 14 \mathrm{~ms}$ tornando possivel o uso de um circuito de varredura para a sonds de Langmuir;

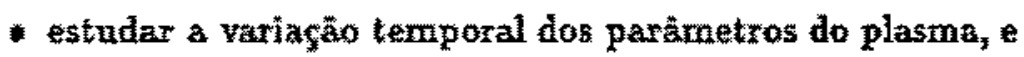

- o casamento de impedância entre o circuito e o plasma que melhora a transferéncia da energia armazenada no circuito para o plasma. Foi obserqado $[62,63]$ que con melhora do casamento da impedância, o fator de separaçāo aumentou numa centrífuga de plasma semelhante à $\mathrm{PCEN}$.

O esquema de uxn círcuito formador te pulso on linha de transmitusẫo LC está mostrado na Figura 2.15.

Se todas as indutâneias $\mathrm{L}_{i_{i}}$ e capacitâncias $\mathrm{C}_{4}$ forem iguạs, a impedăncia de surto do cìrcuito é

$$
z_{0}=\sqrt{\frac{L}{C}}
$$

A forma de onda da corrente na carga $\left(z_{q \times g}\right)$ pode ter a formas indicadas na Fugura 2.16 e 

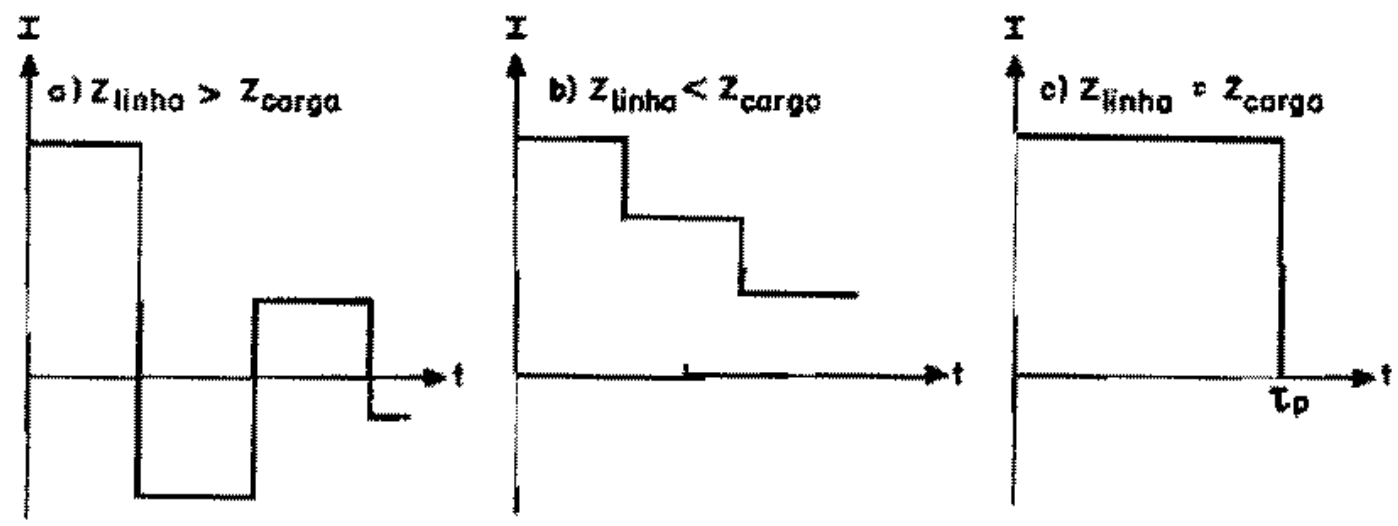

Figura 2.16. Formas de onda da corrente na carga conforme a relaçầo entre $Z_{0}$ \& $Z_{p} v$

no caso presente $\mathbf{Z}_{c \text { arz } \alpha}=\mathbf{Z}_{\text {pasma }}=\mathrm{Z}_{p}$.

Para se obter um pulso o mais uniforme possível deve-se ter $Z_{p} \simeq Z_{0}$. Se ha este casarnento de impedăncia a duraçăa do pulso é dada pos

$$
\tau_{p}=2 N \sqrt{L C}
$$

onde N ế o número de estaçŏes (células LC).

Os capacitores reais tern una resistência em sérìe e em paralelo os indutorez uma resistência em série e, circuito real tem a formo mostrada na Figura 2.17. Da Figura 2.18 tem-se as seguintes equaçôes de Kirchhoff para o circuito formador de priso:

$$
\begin{aligned}
& \frac{d Q_{i}}{d t}=I_{i+1}-T_{i}-\frac{Q_{i}}{R_{p i} C_{i}}(i \neq N) \\
& L_{i} \frac{d I_{i}}{d t}=V_{2}-V_{1} \\
& L_{i} \frac{d I_{i}}{d t}=R_{* i}\left(I_{i+1}-I_{i}\right)+\frac{Q_{i}}{C_{i}}-\left[R_{* j-1}\left(I_{i}-I_{i-1}\right)+\frac{Q_{i-1}}{C_{i-1}}\right]- \\
& -R_{l i} I_{i}(i \neq 1, \neq N) \\
& \left(L_{1}+I_{\text {cargo }}\right) \frac{d I_{1}}{d t}=-I_{1}\left(R_{m 1}+R_{\text {carga }}+R_{L 1}\right)+I_{2} R_{, 1}+\frac{Q_{1}}{C_{1}}
\end{aligned}
$$




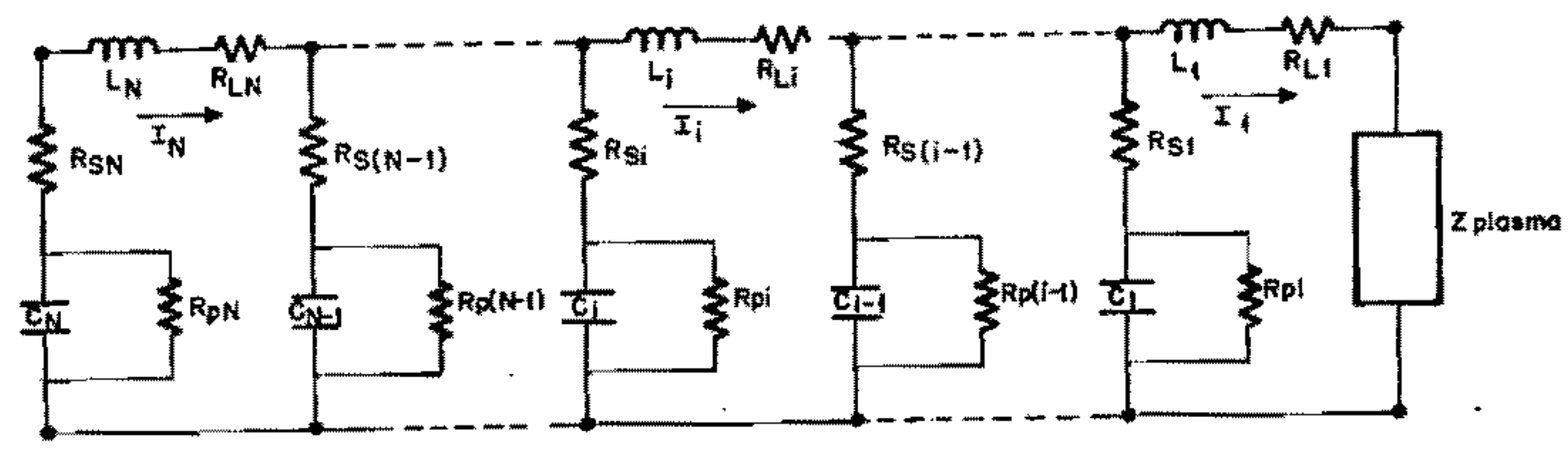

Figura 2.17. Esquema do circuito formador de pulso levando em conta a resistência zérie e paralelo do capacitor e a resistência série do indutor.

$$
\begin{aligned}
\frac{d Q_{N}}{d t} & =-I_{N}-\frac{Q_{N}}{R_{3 N} C_{N}} \\
L_{N} \frac{d I_{N}}{d t} & =V_{2}-V_{1} \\
L_{N} \frac{d I_{N}}{d t} & =-R_{N} I_{N}+\frac{Q_{N}}{C_{N}}-\left[R_{a(N-1)}\left(I_{N}-I_{N-1}\right)+\frac{Q_{N-1}}{C_{N-1}}\right]- \\
-R_{L N} I_{N} &
\end{aligned}
$$

Estas sä̀ $2 N$ equaçöes lineares em $2 N$ variáveis, foram resolvidas numericamente, Apêndice A. A corrente através da carga $\left(I_{1}\right)$ é a variável de interesse. Para resolver numericarnente estas equaçöes os dados de entrada säo: os valores da capacitância $\mathrm{C}_{N}$ e as respectivas resistências, indutor $L_{N}$ e respectiva resistencia, a impedancia do plasma $g_{p}$ composta da resistência $R_{p}$ e indutancita $\mathrm{L}_{p}$ e o número de estaçöes $\mathrm{N}$. As equaçöes $(2.23)$ e $(2,24)$ determinam $\mathrm{I}_{N}, \mathrm{C}_{N}$ e $\mathrm{N}$ visto que $\mathrm{Z}_{0} \approx \mathrm{Z}_{p}$ e $\tau_{p} \sim 15 \mathrm{~ms}$ é o ternpo pelo qual o carnpo magnético pode ser considerado praticamente constante em torno do seu valor máximo. As capacitāncias $C_{N}$ foram escollüass todas iguais a $7,5 \mathrm{mF}$, compostas de 3 capacitores eletrolíticos de $2500 \mu \mathrm{F} / 350 \mathrm{~V}$ em paralelo. Esta disposição de capacitores tem uma resistềncia em paralelo $R_{p} \sim 30 \mathrm{mn}$ e uma resistência em série $R_{s} \sim 100 \mathrm{k} \Omega_{z}$ dados estes obtidos dos valores individuais de cada capacitor fornecido pelo fabricante. A polarizaçäo máxima que pode ser aplicada ao circuito é $\sim 300 \mathrm{~V}$, visto que os capacitores suportam no máximo $350 \mathrm{~V}$.

A irmpedấncia do plasma $\left(q_{p}\right)$ foi obtida atrayếs do valor da tensäo aplìcada ao banco de ca* pscitores de $50 \mathrm{mF}$ dividida pelo pico da corsente de arco, isto é, $z_{p}=V_{c} / I_{p *}$ A Tabela 2.3 

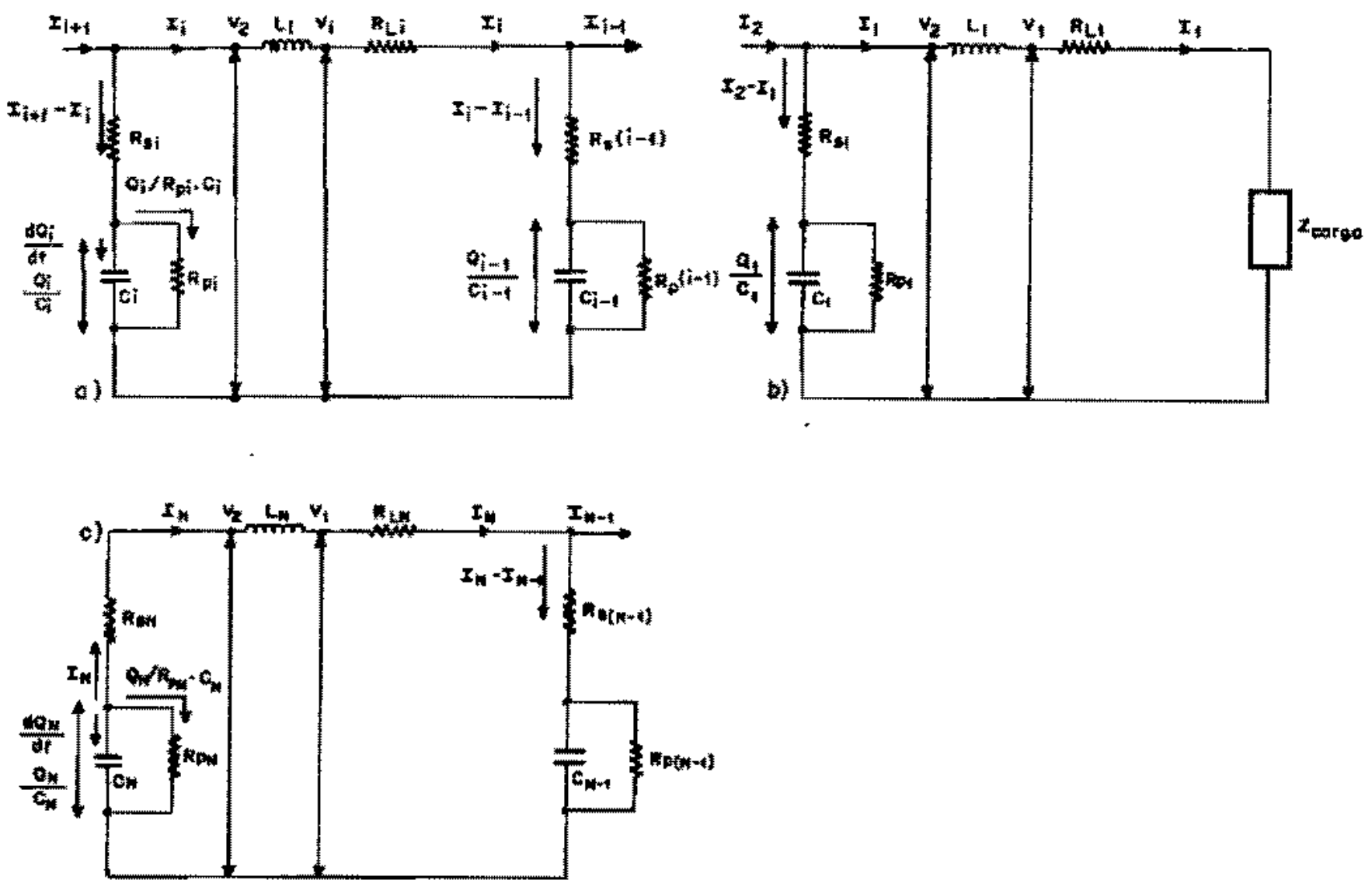

Figura 2.18. Diagrama para obtenção das equaģöes de Kirchhoff para o circuito tor* mador de pulso. 


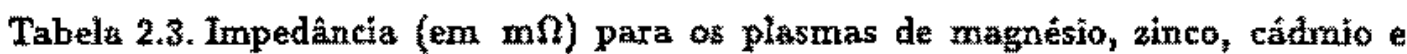
chumbo

\begin{tabular}{|c|c|c|c|c|c|}
\hline & \multicolumn{5}{|c|}{$B_{z}(\mathrm{~T})$} \\
\hline$U_{c}(\mathrm{~V})$ & 0 & 0,075 & 0,150 & 0,225 & 0,300 \\
\hline \multirow{3}{*}{40} & $30(\mathrm{Zn})$ & $41(\mathrm{Zn})$ & $55(\mathrm{Zn})$ & & \\
& $26(\mathrm{Cd})$ & $38(\mathrm{Cd})$ & $45(\mathrm{Cd})$ & & \\
& $30(\mathrm{~Pb})$ & $33(\mathrm{~Pb})$ & $41(\mathrm{~Pb})$ & & \\
\hline 50 & $34(\mathrm{Mg})$ & $39(\mathrm{Mg})$ & & & \\
& $25(\mathrm{zn})$ & $30(\mathrm{Zn})$ & $34(\mathrm{Zn})$ & $37(\mathrm{Zn})$ & $42(\mathrm{Zn})$ \\
\hline 60 & $23(\mathrm{Cd})$ & $28(\mathrm{Cd})$ & $32(\mathrm{Cd})$ & $35(\mathrm{Cd})$ & $40(\mathrm{Cd})$ \\
& $25(\mathrm{~Pb})$ & $26(\mathrm{~Pb})$ & $30(\mathrm{~Pb})$ & $35(\mathrm{~Pb})$ & $39(\mathrm{~Pb})$ \\
\hline 65 & $29(\mathrm{Mg})$ & $32(\mathrm{Mg})$ & $35(\mathrm{Mg})$ & $32(\mathrm{Mg})$ & $37(\mathrm{Mg})$ \\
\hline \multirow{3}{*}{80} & $23(2 \mathrm{n})$ & $26(\mathrm{Zn})$ & $29(\mathrm{Zn})$ & $31(\mathrm{Zn})$ & $35(\mathrm{Zn})$ \\
& & $25(\mathrm{Cd})$ & $28(\mathrm{Cd})$ & $31(\mathrm{Cd})$ & $33(\mathrm{Cd})$ \\
& $22(\mathrm{~Pb})$ & $23(\mathrm{~Pb})$ & $26(\mathrm{~Pb})$ & $29(\mathrm{~Pb})$ & $32(\mathrm{~Pb})$ \\
\hline
\end{tabular}

mostra or valores de $z_{\text {p }}$ obtidos para quatro catodos e com campo magnético axial variando de 0 a $0,3 \mathrm{~T}$. Observa-se desta tabela que $\mathrm{Z}_{p} \sim 30 * 40 \mathrm{~m} \cap$ para muitos dos valores de $\mathrm{B}_{x}$ e $\mathrm{U}_{c} . \mathrm{O}$ plasma foi considerado puramente resistivo, ou 5 eja, $\mathrm{I}_{p}=0$ e $\mathrm{R}_{p} \sim 30-40 \mathrm{~m}$. Assim deqe-se ter $z_{0}=30-40 \mathrm{mn}$ e com $\mathrm{C}=7,5 \mathrm{mF}, \mathrm{L}_{N}=10 \mu \mathrm{H}$ e $\mathrm{N}=22$ obtém-se das equaçöes (2.23) e (2.24), $z_{0}=36 \mathrm{~m} n$ e $\tau_{p}=12 \mathrm{~m}$. Durante simulaçäo numérica do pnlso fó observado que para se obter aro pulso com pouca qariaçäo temporal os indutores näo podiam ser todos iguais e, além do mais, a resistêncla dos mesmos tỉnha quue ser menor que $1 \mathrm{~m} \Omega[64,65]$. A forma final do circuito está mostrada na Figura 2.19 e o pulso de corrente obtido experimentalmente para o catodo de magnésio e carnpo magnético de 0,1T pode ser visto na Figura 2.1 .

A. Figura 2.20 mostra os pulsos de corrente de arco e o do campo magnético onde pode ser visto a pequena variação de $\mathbf{B}_{x}$ durante o pulso da corrente de arco.

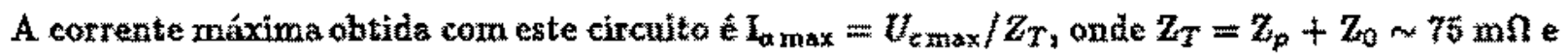
$\mathrm{U}_{\text {cranx }} \sim 300 \mathrm{~V}$, obtendo-se assim $\mathrm{I}_{\mathrm{amax}} \sim 4 \mathrm{kA}$. Foi observado que uma corrente alta, $\mathrm{I}_{\mathrm{a}}>2,5 \mathrm{kA}$, deteriorava rapidamente a grade te tungstënio que serve como anodo, para todos os catodos utilizados e, para o catodo de magnésio, ocorria a destruição da mesma em poucos pulsos para $I_{c}>2 \mathrm{kA}$. Por outro lado, para baixa tensăo de polarizaçăo do catodo, $\mathrm{U}_{c}<50 \mathrm{~V}$, (o que quer dizer baixa corrente $\mathrm{L}_{a}$ ) e tambẻrm para campo magnético alto $\mathrm{B}_{\mathrm{z}}>0,3 \mathrm{~T}$ a descarga ern arco nem sempre ocorre (dependendo do catodo). Experimentalmente foi observado que um pulso 


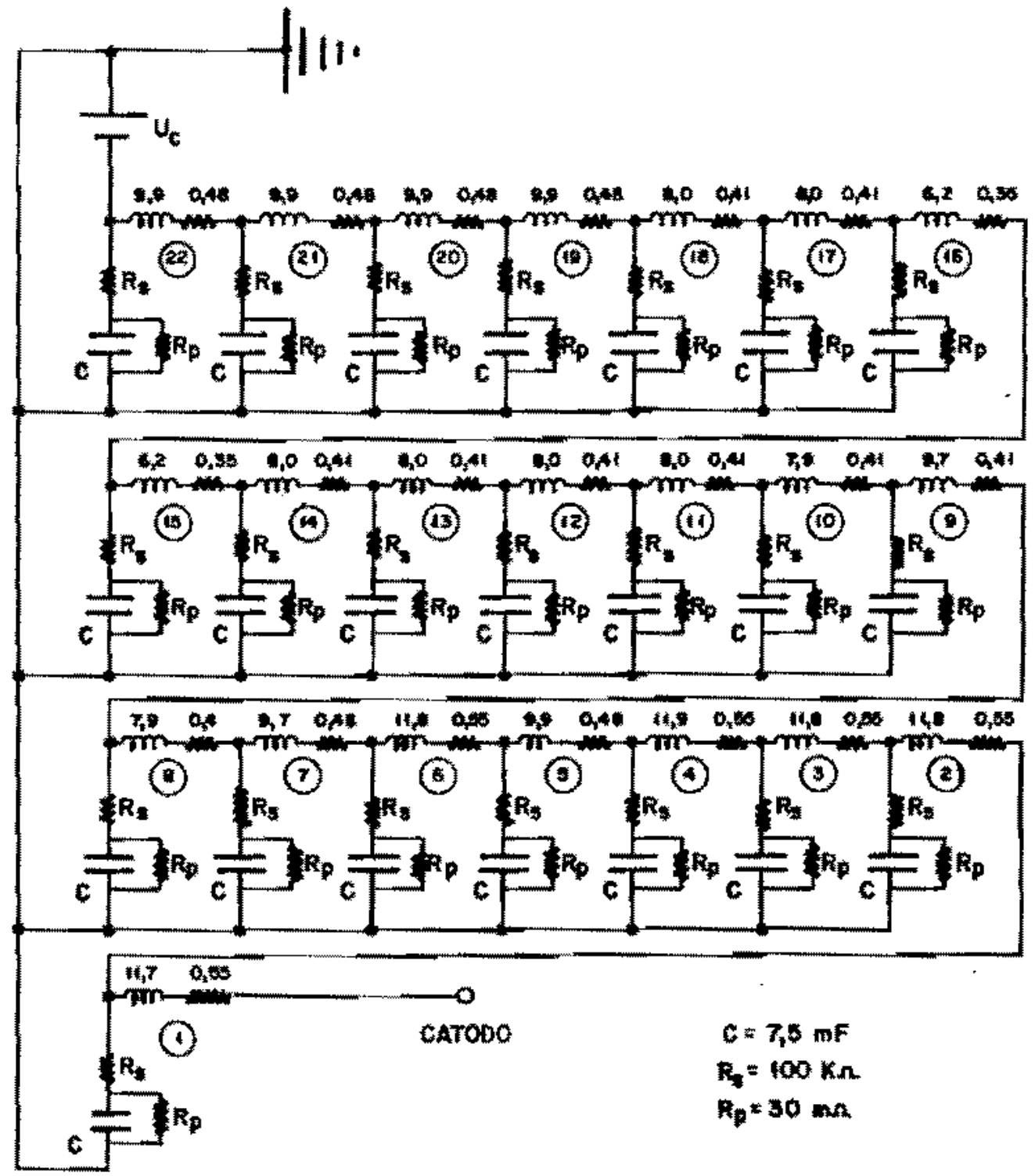

Figura 2.19. Forma final do circuito formador de pulso. 


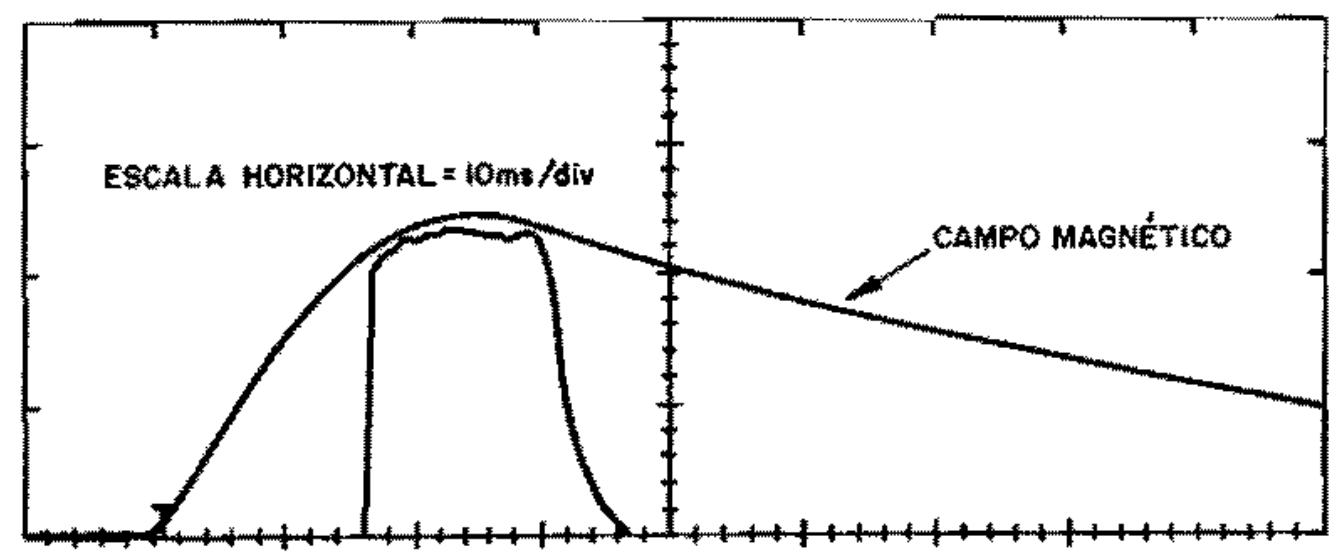

Figura 2.20. Pulsos da corrente de arco e do campo magnético axial.

de corrente de arco $\mathrm{I}_{a}$ sem Hutuaçöen e repetïtivo como o mostrado na Figurs 2.1 (considerado como o padrão para este trabalho) poderia ser obtido para $I_{a} \geq 1 \mathrm{kA} \quad B_{z} \geq 0,1 \mathrm{~T}$ e,desse modo, a maior parte das medidas efetuadas foram realizadas com $1 \mathrm{kA} \leq \mathrm{I}_{\alpha} \leq 3 \mathrm{kA}$ e $0,1 \mathrm{~T} \leq \mathrm{B}_{2} \leq 0,3 T$.

Os seguintes catodos sāo disponiveis com pureza maíor que $99,95 \%$ (a excessão do carbono que puro mas o gran de pureza é desconhecido): $\mathrm{C}, \mathrm{Mg}, \mathrm{Al}, \mathrm{T}, \mathrm{Ni}, \mathrm{Cu}, \mathrm{Zm}, \mathrm{Zr}, \mathrm{Mo}, \mathrm{Cd}, \mathrm{W}, \mathrm{Ta}$ e $\mathrm{Pb}$ no entanto nö̆o foi possivel fechar a descarga em arco no vácuo com todos eles. Materiais que apresentam baixa temperatura de fusäo/ebulị̧äo como $\mathrm{Mg}, \mathrm{Zn}, \mathrm{Cd}$ e $\mathrm{Pb}$ produzem facilmente a descarga no intervalo de $\mathrm{I}_{\mathrm{s}}$ e $\mathrm{B}_{\mathrm{z}}$ citado acima, e com o paìräo de pulso, ao passo que $\mathrm{Al}_{3}$ $\mathrm{Ti}, \mathrm{Ni}$ e Cu (temperatura de fusāo/ebuliç̧̧⿻ maior) produzem a forma de pulso desejada para $\mathrm{f}_{a} \geq 1,5 \mathrm{kA}$ e $\mathrm{B}_{x} \leq 0,1 \mathrm{~T}$; ou em outras palavras um intervalo mais restrito. Para materiais com temperatura de fusäo/ebuliçäo muito alta, como o $\mathrm{Zr}, \mathrm{Mo}_{4} \mathrm{~W}$ e Ta, näo foi possível obter a descarga ern arco. Estes materiaís tem uma tendência a apresentar pontos luminosos do tipo 1 - que requer maior temperatura $\mathrm{T}_{\varepsilon}$ e maior campo $\mathrm{E}_{\varepsilon}$ conforme mostrado na Figura 2.10 (modo 1). Provavelmente a descarga para estes catodos ocorreria para $\mathrm{J}_{e}>300 \mathrm{~V}$ obtendome assim $\mathrm{I}_{a}>4 \mathrm{kA}$. Algumas mudanças facilitariam a descarga tais como: diminuir a distância entre eletrodos $(L<60$ mm); fazer o catodo em forma de ponta; wtilizar urn laser mais potente (>30 MW) ou mudar o circuito para poder utilizar $\mathrm{U}_{c}>300 \mathrm{~V}$. Todas estas mudanças visam obter as condiçöes de campo elétrico e temperatura na superficie do catodo para a descarga ocorrer.

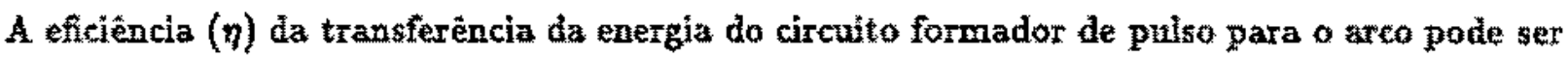


calculada corno a razāo entre a energia do arco $\Delta \mathrm{E}_{\mathrm{a}}$ (equaçăo 2,2) e a energia armazenada no circuito dado por

$$
\Delta E_{\mathrm{c}}=\frac{1}{2} C_{T} U_{c}^{2}
$$

ande $C_{T}=22 \times 7,5 \mathrm{mF}=165 \mathrm{mF}$. Para o magnésio obtém-se da Figara $2.1 \eta \sim 0,85$, ou seja, $\sim 85 \%$ da energia é transferida para o plasma e $\sim 15 \%$ é dissipad nos indutore capacitores. Da energia transferiou para o plasma $\approx 30 \%$ é dissipada ao catodo, $\sim 60-65 \%$ é convertida em energia cinética dos íons e $\sim 5-10 \%$ é transferida para a ionizaçäo.

\subsection{Tensão de arco, erosão e consumo de energia para a produção dos ions}

A tensâo de arco $U_{a}$ foi obtida utilizando-se uma ponta de prova entre o catodo e o anodo e, 0 sinal típico obtido esta mostrado na Figura 2.1. A teasāo de polarização do circuito formador de pulso $\left(U_{E}\right)$, a tensão de arco $\left(U_{c}\right)$, carga transferida para o plasma $\left(Q_{T}\right.$ obtida da curva

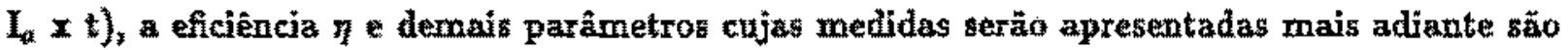
sumarizados na Tabela 2.4, no final deste capitulo. Esta tabela foi obtida para os catodos $C_{3}$ $\mathrm{Mg}, \mathrm{Al}_{\mathrm{\gamma}} \mathrm{Ni}_{2} \mathrm{Cu}, \mathrm{Zn}, \mathrm{Cd}$ e $\mathrm{Pb}$ nas condiçöes $\mathrm{Bz}=0,1 \mathrm{~T}$ e $\mathrm{I}_{a}=1,5 \mathrm{kA}$.

A erosüo do catodo foi medida pesando-se o catodo antes e depois de uma série de 50 pulsos do plasma [66]. A diferença de massa obtida dividida pelo número de puisos fornece a perda de massa era cada pulso. A taxa de erosāo $\rho$ é a razäo entre $\Delta \mathrm{m}$ e $Q_{T}$ e normalmente dada ema $\mu \mathrm{g} / \mathrm{C}$. A Tabela 2.4 mostra os resultados obtidos para p. Verifica-se que $\mathrm{Zn}_{\mathrm{q}} \mathrm{Cd}$ e $\mathrm{Pb}$ apresentam taxa de erosăo alta, especialmente o chumbo. Para o magnésio a erosä́n mostrou-se praticamente insensivel à variaçāo do campo magnético axial e corrente de arco $\mathrm{I}_{\alpha}$ como mostrado na Figura 2.21.

Nem todo material que evaporado do catodo é transmitido através da grade para a coluna de plasma Parte do vapor continua neutro (em maiot ou menor grau, dependendo do catodo) e pode ir para a parede da cärnara próximo ao catodo visto que o campo xagnético nào tem influência nestet caso. Pot outro lado, parte dos ions formadoz também pode ser carregada para 
a)

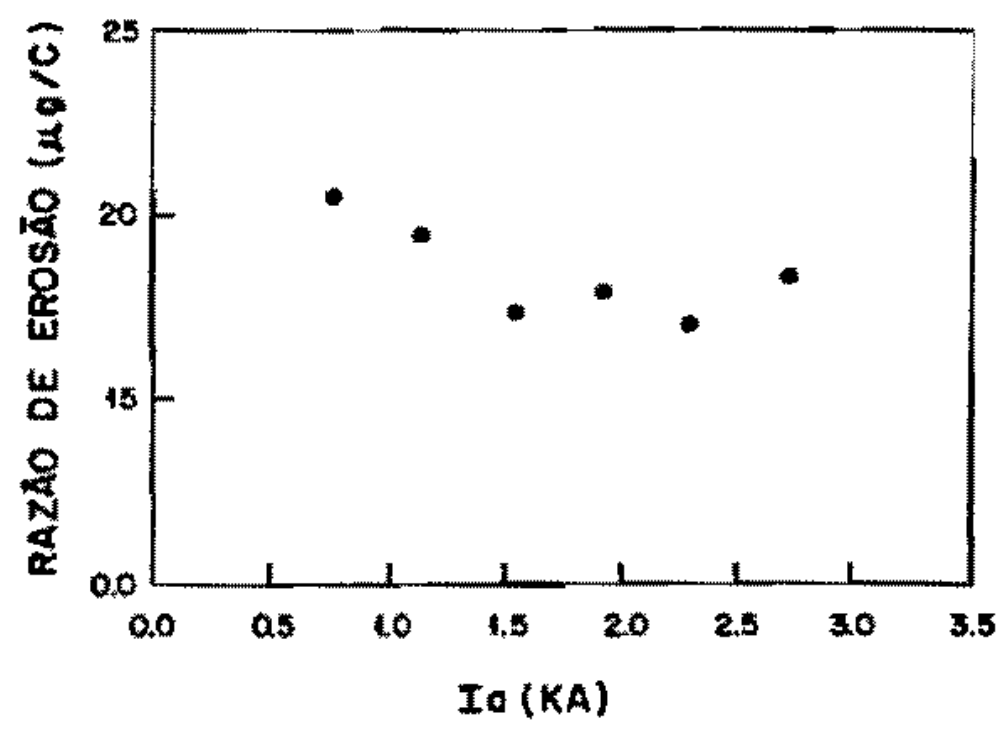

b)

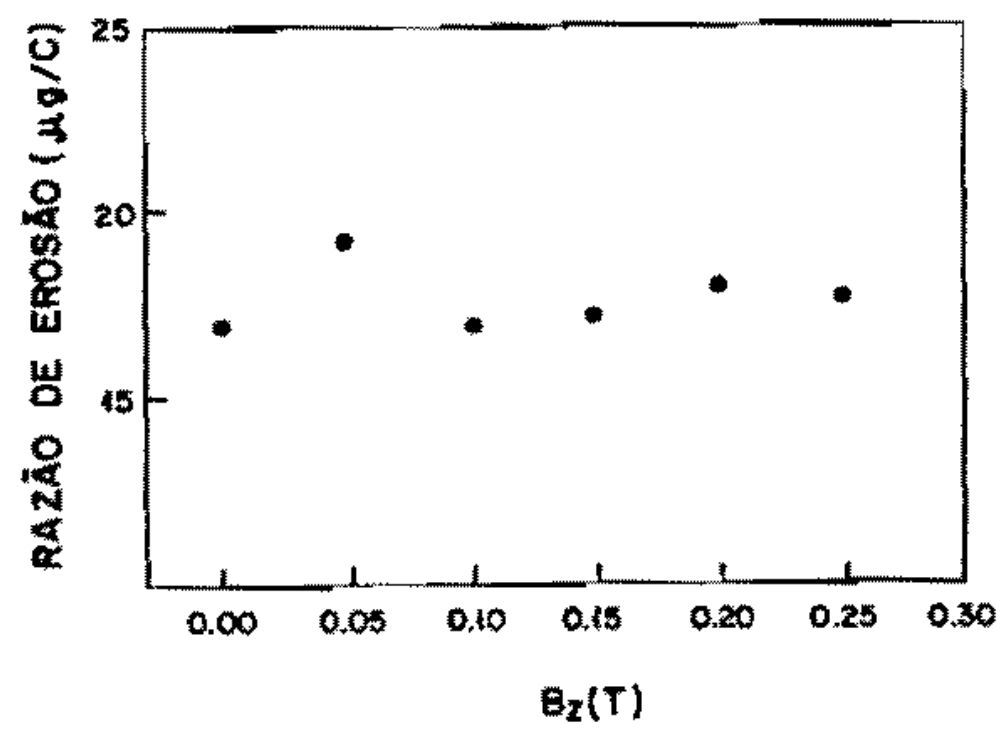

Figura 2.21. a) Taxa de erosäo como funçäo da corrente de arco $I_{a}\left(B_{z}=0,1 T\right)$ e b) como funçäo do campo magnético $B_{x}\left(I_{a}=1,5 k A\right)[66]$. 


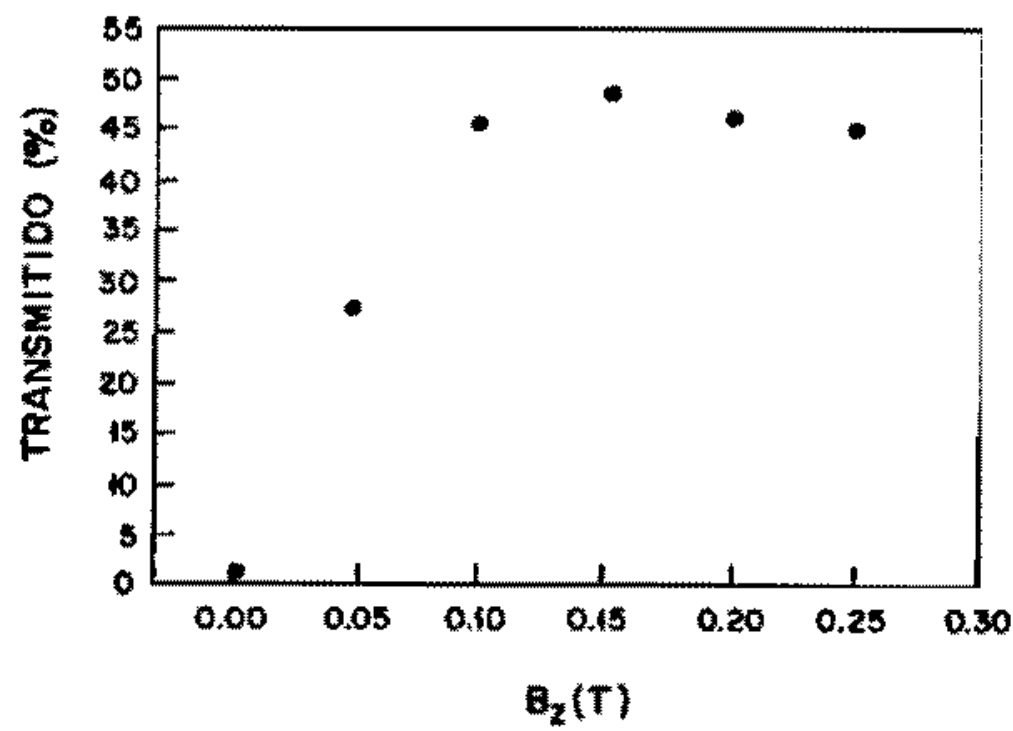

Figura 2,22. Porcentagem de fons de magnésto transmitidas através da grade como funçä̃o do campo magnético[66].

o flange atrús do catodo em vez de ir para o anodo, isto por causa da configuraçäo de campo magnético nesta regiăo. Foi observado que realmente ocorre uma deposiçăo de material no flange atrás do catoto e região próxima. Para determinar a porcentagem de lons que seguem para a coluaz de plasma, foi utilizado um coletor na forma de um disco colocado a $0,3 m$ do anodo. Do ganho de massa desse coletor depois de uma série de 50 pulses, juntamente com a taxa de exosäo medida, foi determinada a quantidade de fons transmitida. A Figura 2.22 mostra os resultados obtidos para o plasma de magnésio como funçüo do campo magnético para umz corrente de arco de 1,5kA. Como era esperado para campo bajxo $(<0,1 \mathrm{~T})$ a transmissä́ é pequeas (pouco confinamento pelo campo) e auments até saturar em $\approx 50 \%$ para $B_{x} \geq 0,1 T$ (a coluna é bern confinada). Uma melthor configuraçz̄o de campo deve ser determinada visando aumentar a transmissāo de ions para a coluna de plasma.

A energia consumida para produafr cada ion $\sum_{j}(\mathrm{eV} /$ íon) pode ser calculada conhecendo-se a taxa de erosão, a tensāo de arco e o grau de jonizaçāo atravếs da relaçăo

$$
\Sigma_{i}=\frac{A U_{a}}{e \rho \gamma N_{A}}
$$


onde $\mathrm{N}_{A}$ a o número de Avogadro, a a earga eletrônica e $\mathrm{A}$ o peso atómico do material do catodo. Of resultados destes cálculos estion na Tabela 2,4 .

\subsection{Velocidade axial de deriva, temperatura de elétrons, den- sidade de partículas carregadas e potencial de plasma}

Estes parâmetros foram medidos com a utilização de sondas de Langmuir e as medidas foram realizadas na coluna de plasma, isto é, no plasma transmitido através da grade de tunggtênio. Parte dos resultados serăo apresentados neste capitulo e o restante no próximo juntamente com 3 descriçāo tisica da coluna de plasma.

\subsubsection{Velocidade axïal de deriva}

A velocidade axial de dexiva foi medida utilizando-se duas sondas de Langmuir separadxs por uma distância $\mathrm{d}=0,51 \mathrm{~m}$ e polarizadas $-50 \mathrm{~V}$ para coletarem somente corrente de tons. Do atraso $\Delta t$ observado nos sinais das duas sondas a velocidade axial de deriva do plasma fot

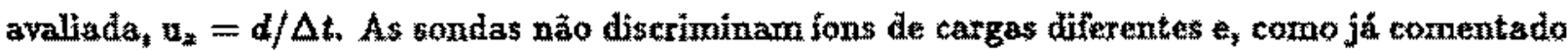
anteriormente, a energía cinética dos ions depende da carga dos mesmos conforme mostrado na Figura 2.6. Portanto as medidas da velocidade axial de deriva rezlizadas indicam a expansăo do plasma cono um todo.

Esta dificuldade removida para o plasma de carbono para o qual só o ín $\mathrm{C}^{+}$é encontrado. Neste caso, a velocidade de exparisẳo do plasma ta igual à do fon $\left(u_{i x}=u_{z}\right)$ e é possível estudar o efeito do campo magnétíco axial e da corrente do arco nesta velocidade. Para $I_{a}=1,5 \mathrm{kA}$ e com a variaģäo do campo $0,1 \mathrm{~T} \leq \mathbf{B}_{z} \leq 0,3 \mathrm{~T}_{\mathrm{z}}$ encontrou-se o valor $\mathrm{u}_{x}=3 \times 10^{4} \mathrm{~m} / \mathrm{s}$, independente do campo. Este resultado pode ser interpretado pelo fato de que na regiāo 2 (Figura 2.7), onde os Ions adquirem esta velocidade, os efeitos do campo magnético devern ser pequenos pois $\beta>10$,

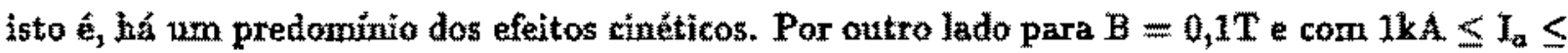
$3 \mathrm{kA}$, obteve- $3,6 \times 10^{4} \mathrm{~m} / \mathrm{s} \geq \mathrm{u}_{z} \geq 2,7 \times 10^{4} \mathrm{~m} / \mathrm{s}_{2}$ ou seja, un decréscimo da velocidade com - auraento da corrente de arco. Urn aumento da corrente significa tum aumento no potencial de arco e na densidade de partículas carregadas na regiăo 2 alterando-se, assirn, o campo elếtrico, o 
gradiente da pressāo e as colisótes entre elétrons e íns. Considerando estes trế elétos foi obtido [42] um decréscimo da energía dos íons com o aumento da corrente e este decréscimó é maior ou menor conforme o modelo adotado para o plasma; por exemplo, isotérmíco ou näo isotérmico, com condução ou nāo de calot etc. A energia cinética $\left(E_{K}\right)$ pars o íon $C^{\text {* }}$ a uma velocidade de $3 \times 10^{4} \mathrm{~m} / \mathrm{s}$ é $56 \mathrm{eV}$.

Os parämetros temperatura de elétrons, densidade de partículas carregadas e potencial de plasma foram obtidos através da curva característica de uma sonda de Langmuír cilíndrica com diấmetro de $0,5 \mathrm{~mm}$ e $4 \mathrm{~mm}$ de comprimento. As medidas foram realizades a uma distäncia $\mathrm{z}=0,6 \mathrm{~m}$ do anodo. A sonda foi polarizada por um circuito de varredura com forma de onda triangular [67,68], possibilitando desse modo a obtençāo de várias curvas características durante uma áníco pulso. Embora o circuito tenha um intervalo amplo de tensĩo de polarizaçäo e tempo de varredura, na obtenção das curvas características foi atilizado tipicamente o intervalo - 50 - oV e $\Delta \mathrm{t}_{*} \sim 3 \mathrm{~ms}$. Os sinais obtidos do pulso de plasma são armatenados exn osciloscópios digitais e imediatamente ap $6 s$ o pulso găo transferidos para um microcomputador através de ưn programa expecifico para tal operaçāo. Para a obtençä̃o dos parămetros fol desenvolvido um programa, Apèndice B, que permite divisāo andilise de cada uma das regiôes características do sinal da sonda, isto é, corrente de saturaçäo de fons (regíă A), da qual a deasidade de partículas carregadas pode ser obtida; crescimento exponencial da corrente coletada (região B), de onde a temperatura de

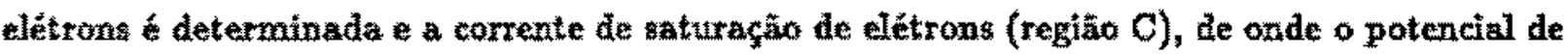
plasma teterminado. Uma distingäo dara entre estas regiües ś importante pois caso contrário erros apreciáveis, principalmente em $\mathfrak{T}_{\text {es }}$ podem ocorrer. A Figura 2.23 mostra o esquema utilizado para a obtençäo dos parämetros com a utilizaçăo de sondas de Langmuir.

As curvas caracteristicas obtidas säo livres de flutuaçöes fortes, isto porque, as futuaçöes no plasma tem un periodo de $* 10 \cdot 100$ us (como será visto no Capitulo 3), ao passo que o tempo de varredura da tensăo $\dot{e} \Delta t_{*} * 3 \mathrm{~ms}$. Por outro lado, há variação de pulso para pulso nos parämetros medidos o que obrigon a utilização de média de pelo menos cinco pulsos como salientado na introdugẵo. Quando por algum motivo (geralmente desconhecido) ocorria alguma distorçăo na curva característica esła era descartada e, desse modo uma pré-seleção dos sinaàs fol feita observandowos na tela do osciloscópio. 


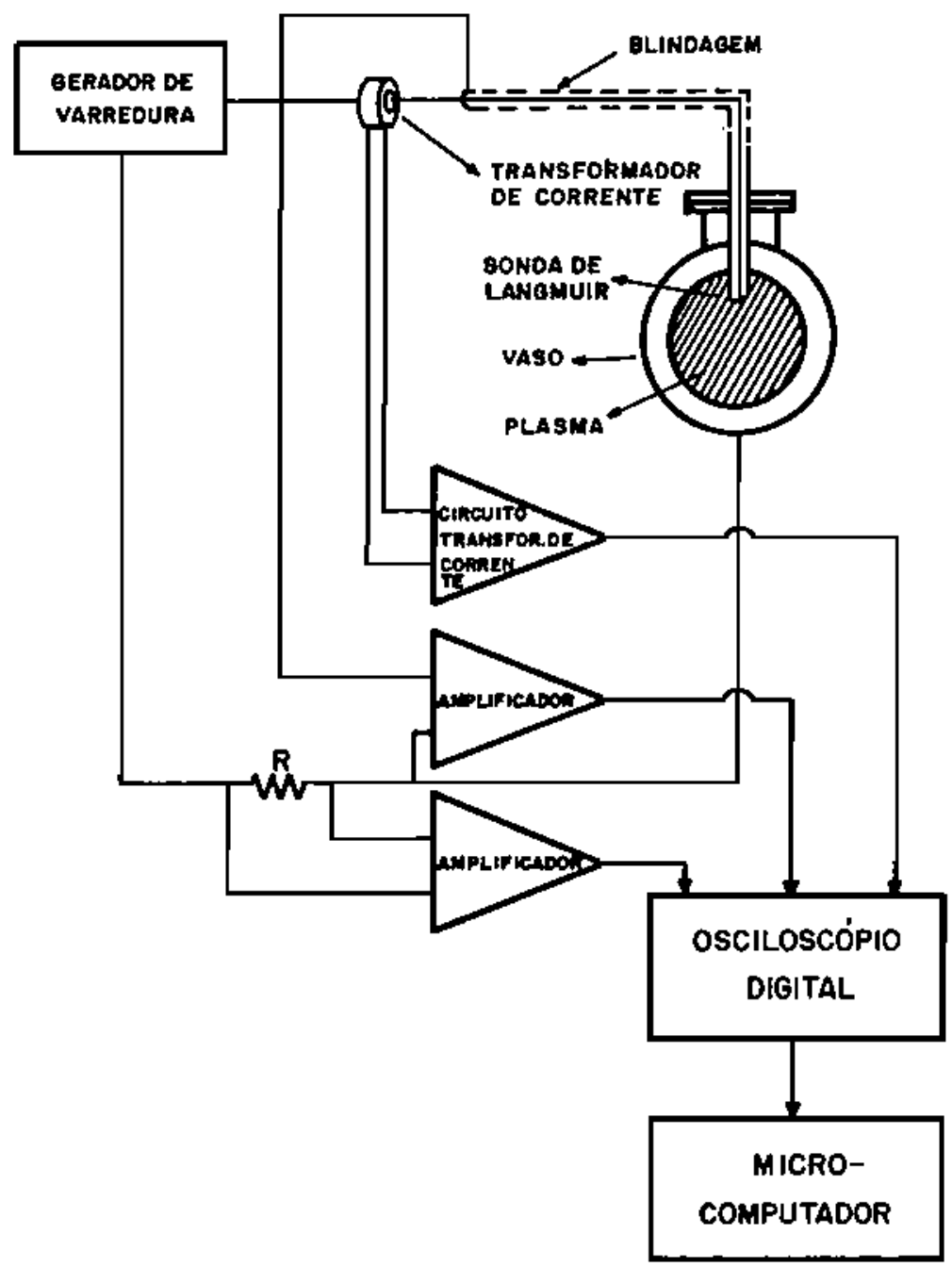

Figura 2.23. Esquema para aquisição e análise da curva característica da sonda de Langmuir. 


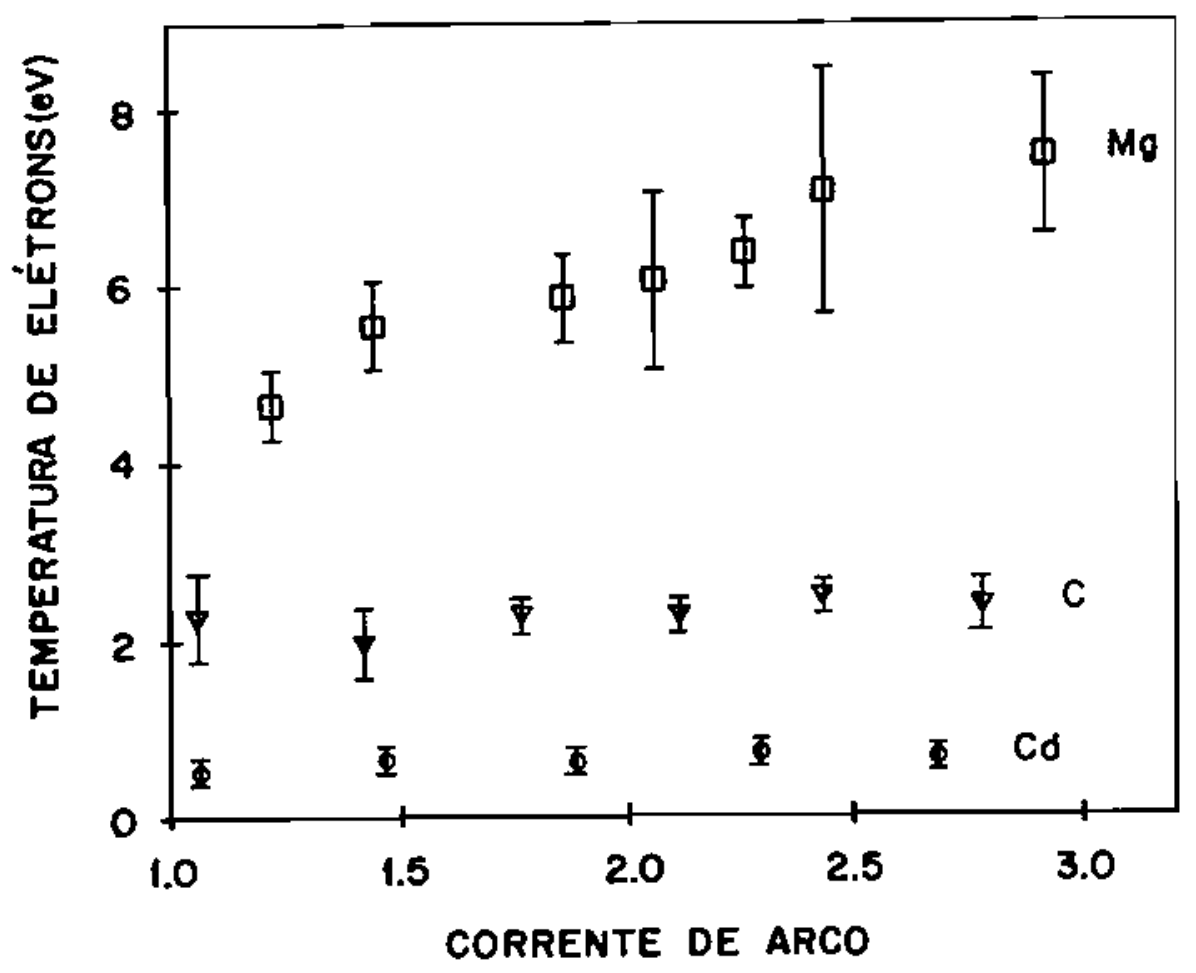

Figura 2.24. Temperatura de elétrons versus corrente de arco para os catođos de $C$, $\mathrm{Mg}$ e Cd.

\subsubsection{Temperatura de elétrons}

O fluxo de elétrons que atinge a sonda é de origem térmica visto que $u_{e} \uparrow \gg u_{e x}$ e,sendo a distribuiçāo Maxwelliana, a temperatura de elétrons é obtida de $\mathrm{T}_{\mathrm{e}}=(\operatorname{tg} \iota)^{-1}$ onde $\operatorname{tg\iota }=$ $\partial \ln \mathrm{I}_{e s} / \partial V_{s}, \mathrm{I}_{e s}$ é a corrente de elétrons coletada pela sonda na regiāo $\mathrm{B}$ da curva característica e, V, é a tensăo de polarizaçāo da sonda. A Figura 2.24 mostra os resultados obtidos para a temperatura de elétrons como funçāo da corrente de arco e campo magnético axial fixo em $0,1 \mathrm{~T}$ para os catodos de $\mathrm{C}, \mathrm{Mg}$ e $\mathrm{Cd}$.

No intervalo de corrente de arco 1-3kA a temperatura de elétrons para o plasma de magnésio apresenta um crescimento de $\sim 70 \%$ ao passo que para os plasmas de carbono e cádmio esta variação é menor, 20\% ( na Figura 2.24 esta variaçāo nāo é evidente por causa da diferença nos valores numéricos). Uma possível explicação para a dependència da temperatura eletrônica com o elemento do catodo pode ser dada em termos das diferenças no grau de ionização e taxa de erosão para os très catodos. O plasma de magnésio apresenta grau de ionização elevado ( $\gamma$ 


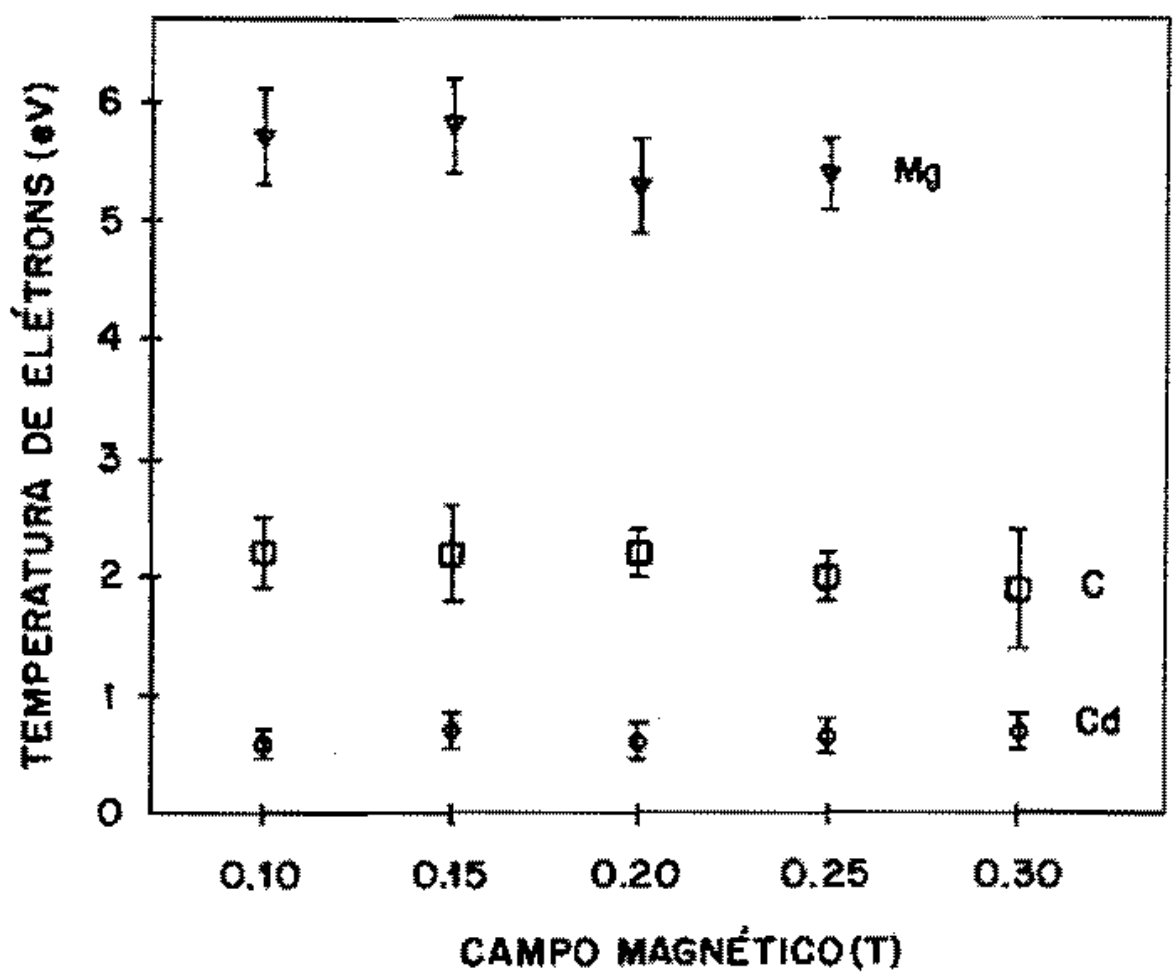

Figura 2.25. Temperatura de elétrons como funçăo do campo magnétíco axial com $I_{a}=1,5 k A$ para os catodos $\mathrm{C}_{3} \mathrm{Mg}$ e Cd.

$=0,8-1,0)$ e a razăo de erosão năo aumenta com a corrente de arco conforme mostrado na Figura 2.21, nä̋ havendo assim a produção de mais vapor $O$ acréscimo de energia depositada no plasma para correntes maiores deve ser distribuida entra aumentar o grau de ionizaçäo e a temperatura do plasma. No caso do plasma de magnésio o acréscimo de energia deverá resultar em um aumento acentuado da temperatura por causa da ionizaçầo quase completa ja existente neste plasma. Por outro lado, carbono e cádmio apresentam grau de ionização menores e, provavelmente, a energia depositada seja transferida preferencialmente para mais ionizaçö̌s do que para aumentar a temperatura.

Na Figura 2.25 pode ser vista a dependência da temperatura de elétrons com o campo magnético axial para uma corrente de arco de $1,5 k$.A.

Para os três catodos o valox do campo magnético temo pouca influência sobre a temperatura de elétrons. O processo de termalizaçä̌s dos elétrons ocorre na regiăo 2 (Fig. 2.7) onde os efeitos do campo magnético são pequenos, e isto, pode em princípio, ser a explicação para os resultados 
obtidos.

\subsubsection{Densidade de partículas carregadas}

Diferente do fluxo de elétrons, o fluxo de fons constitue um fluxo dirigido, isto porque $u_{k z} \gg u_{i T}$.

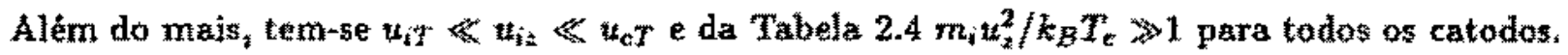
Nestas condiłçôes, urna expressäo muito usada para se determinar a densidade de carga a partir da corrente de saturaçän de ions $6[69]$

$$
I_{s a i}=\left(2 e r_{s} l u_{m}\right) n_{i}
$$

onde $\mathrm{r}_{\mathrm{s}}$ é o raio da sonda e $l$ o seu comprimento. Este expressäo ế válida, além das condiçóes acima, para plasmas de baixa densidade, isto $\hat{e}_{,} \xi_{p}=r_{s} / \lambda_{D}$ < 1 . Para os parámetros de arco no

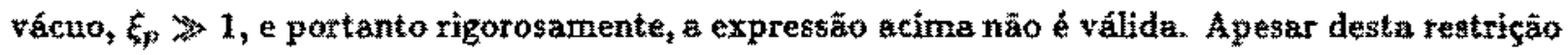
ela é utilizada pois năo hả nenhuma outra altemativa devido as dificuldades em se tratar o problema de uma sonda eletrostática num plasma de alta densidade com alta velocidade de deriva. Esta expressắ dá a densidade de cargas existentes no plasma, isto é, $\mathrm{en}_{6}=\mathrm{en}_{\mathbf{j}}=$ $e \sum_{z} \mathrm{Zn}_{z}$. Uma estimativa do número de particulas na forma de cons pasitivos no plasma é $\mathrm{n}_{p}$ $=n_{1} / 2$

A. Figura 2.26 mostra a corrente de saturaçato de ions para os plasmas de carbono, magnésio e cádmio como uma funçăo da corrente de arco pata um campo magnétíco de $0,1 \mathrm{~T}$. Um decréscimo na taxa de erosäo do catodo de carbono com o aumento da corrente de arco foi encontrado num experimento semelhante a PCEN [70]. Este fato, juntamente com os já mostrados neste trabalho, decréscimo da energia dos íons $\mathrm{C}^{+}$temperatura de elétrons praticanente constante com o aumento da corrente de arco, levam a supor que o acréscimo de energia depositads no plasma pelo aumento de correnta val para novas lonizaçōes justificando o aumento observados na densidade como visto na figura. Por outro lado, para o magnésto já existe uma lonìzaçäo quase completa, e assim, a densidade deve permancer praticamente constante com o aunento da corrente de arco, a energia extra depositada indo principalmente para o sumento da temperatura do plasma. 


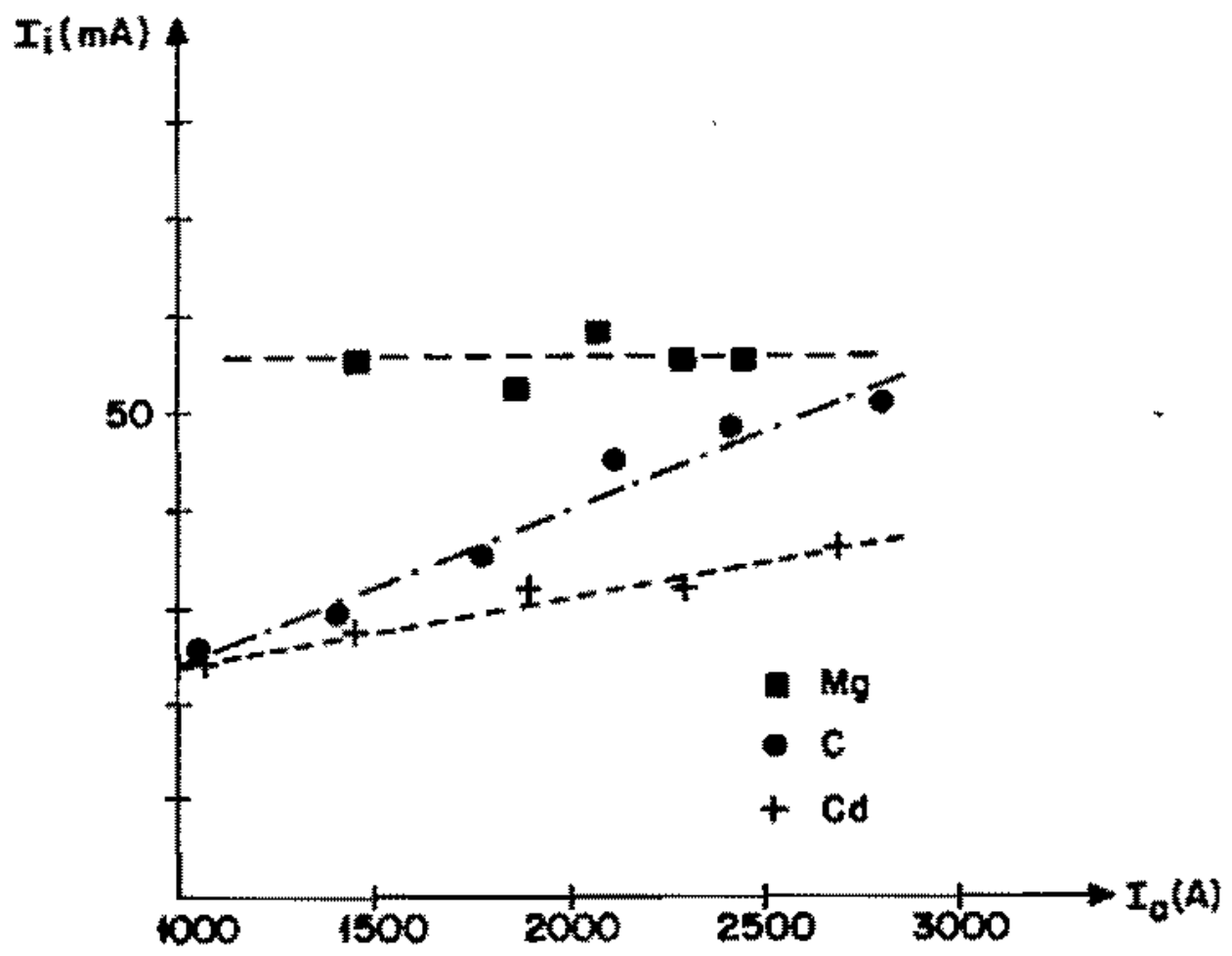

Figura 2.26. Corrente de saturaçäo de íns para os catodos $\mathrm{C}, \mathrm{Mg}$ e Cd como função da corrente de arco $\left(B_{z}=0,1 T\right.$ e $\left.r=0\right)$. 


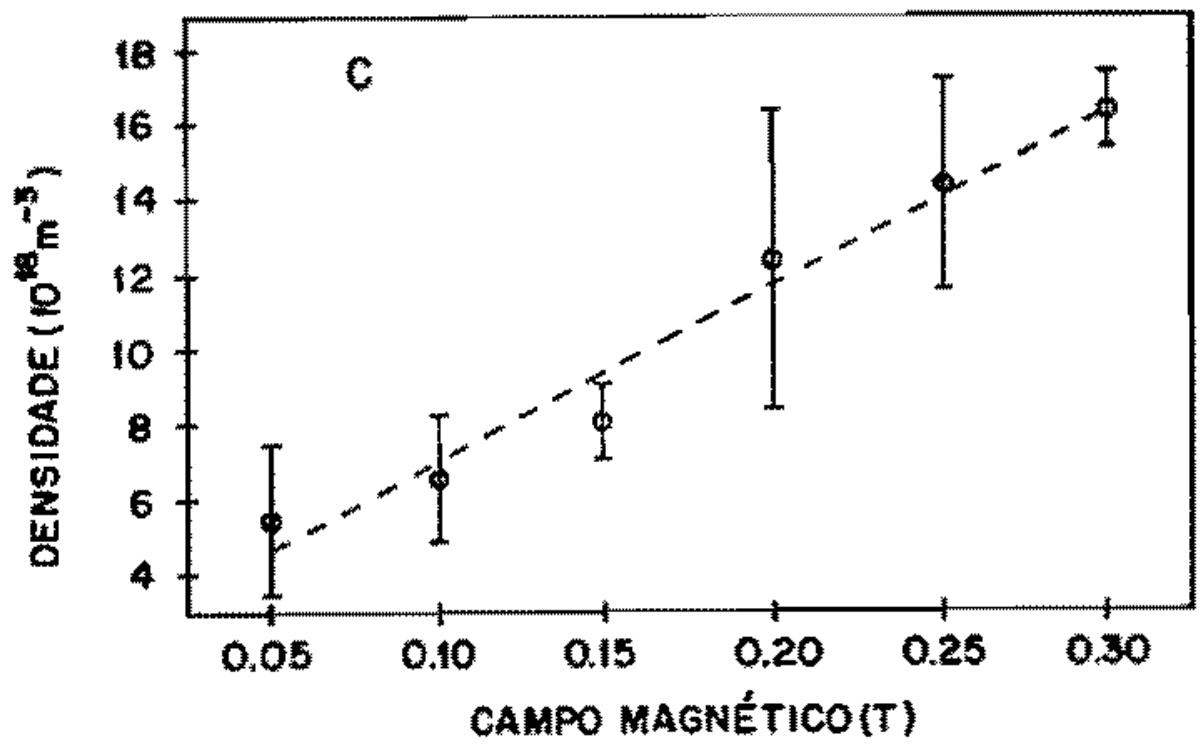

Figura 2.27. Densidude de iona $C^{+}$versus o campo magnético axial $\left(I_{a}=1,1 k A, r=\right.$ 0).

O comportamento da densidade de íons $\mathrm{C}^{+}$com o aumento do campo magnético está mostrado na Figura 2.27 para $I_{a}=1,1 k A$. Há um crescimento praticamente linear de $\mathbf{n}_{i}$ com $B_{*}$. Este aumento tem duas causas: a primeira devido a um aumento da razão de erosāo com o campo mangético observado para o catodo de carbono [70] e a segunda é devidó ao decrêscimo da difusäo de partículas através do campo magnético [71].

Uma avalizçẫo do grau de ionizaçäo do plasma pode ser obtids comparando-se o número de atomos emanados do catodo por unidade de volume $\left(n_{a}\right)$ com densidade de partículas carregadas na forma de lons medida $\left(n_{p}\right)$, isto é, $\gamma_{\operatorname{mp}}=n_{p} / n_{a}$. A densidade de átomos evaporados pode ser obtido da razâo entre o número de atomos evaporados por segundo e o volume varrido pelo plasma em expansäo

$$
\boldsymbol{n}_{\mathrm{a}}=\frac{P N_{A} Q_{T}}{A \tau_{p}\left(\pi r_{t}{ }^{2} t_{k}\right)}
$$

onde $\tau_{\mathrm{s}}$ e a ravo característico da coluna de plasma. Com os dados experimentais obtidos de $\rho_{\text {r }}$ $Q_{T}, T_{p}=16 \mathrm{~ms}, u_{x}$ levando-se em conta (e supondo que seja vallido para todos os catodos) que somente 50 tos fons väo para a coluna de plasma e utilizando os seguintes raios característicos: 


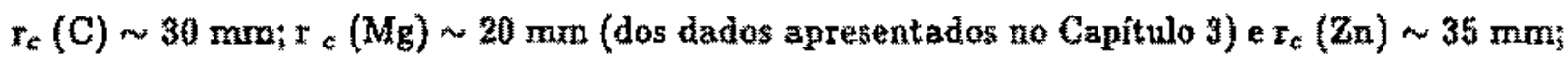

$I_{c}(\mathrm{Cd}) \sim 37 \mathrm{~mm} ; \mathrm{r}_{c}(\mathrm{~Pb}) \sim 40 \mathrm{~mm}$ (da referência [61]), obtém-se os wolos "yexp indicados na Tabela 2.4. Estes valores fornetem somente uma indicaçäo do grau de ionizaçẫo, visto que, na sua determinaçăo estäo enyolvidos mütos dados experimentais contendo erros näo quantificados.

\subsubsection{Potencial de plasma}

O potencial de plasma $\left(\phi_{x}\right)$ a princípio poderia ser obtido da curva característica, mas duas particularidades do plasma inviabilizaram este procedimento. A primeirs é por causa da alta densidade do plasma a corrente coletada pela nonda na regiäo de saturaçä́o de elétrons é $I_{\text {ate }}>$ $250 \mathrm{~mA}$, que é a corrente máxima suportada pelo circüto de varredura, ou em ontras palayras, a regiăo de satưação da corrente de elétrons năo foi obtida. A segunda é mesmo que se tenha

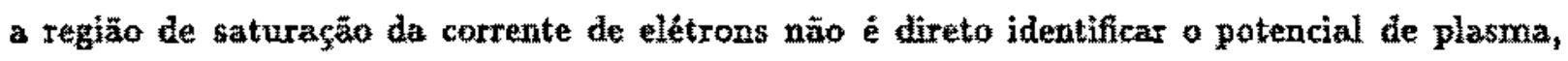
como no caso de plasma sem campo megnético e estacionário, visto que, o plasma da PCEN é magnetizado e tem alta yelocidade de deriva.

Neste caso, o potencial de plasma é obtido igualando-se a corrente de elitrons coletada com a de ions para o potencial de polarizaçäo da sonda igual ao potencial flutuante $\left(V_{*}=\phi_{f}\right)[72]$ *

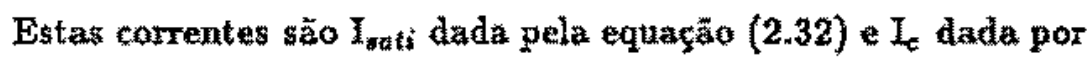

$$
I_{e}=r_{s} \ln _{\varepsilon} e \sqrt{\frac{2 k_{B} T_{e}}{\pi m_{z}}} \exp \left[\frac{e\left(\phi_{j}-\phi_{a}\right)}{k_{B} T_{e}}\right]
$$

onde $\phi_{\mathrm{a}}$ te potencial de plasma (ou espacia)). Da igualdade $\mathrm{I}_{\text {rali }}=\mathrm{I}_{c}$ obtém-se para o potential de plasma

$$
\phi_{s}=\phi_{f}-\left(\frac{k_{B} T_{c}}{\varepsilon}\right) \ln \left[u_{x} \sqrt{\frac{2 \pi m_{e}}{k_{B} T_{e}}}\right]
$$

Uma vez tendo sido determinada a velocidade axial de deriva e, da curva caracteristica, o potencial flutuante e a temperatura de elétrons, o potencisal de plasma pode ser inferido. 0 resultado raais importante para o potencial de plasma é o perfi radial do mesmo e será mostrado no próximo capítulo. 
Tabela 2,4. Parầmetros para descarga em arco no vácuo na PCEN para oito catom dos diferentes, com corrente de arco de $1,5 \mathrm{kA}$ e campo magnético axial de $0,1 \mathrm{~T}$.

\begin{tabular}{|c|c|c|c|c|c|c|c|c|}
\hline Material & C & $\mathrm{Mg}$ & $\mathrm{Al}$ & $\mathrm{Ni}$ & $\mathrm{Cu}$ & $\mathrm{Zn}$ & $\mathrm{Cd}$ & $\mathrm{Pb}$ \\
\hline$U_{c}(V)$ & 135 & 105 & 120 & 115 & 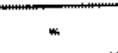 & 109 & 105 & 100 \\
\hline$U_{a}(V)$ & 60 & 35 & 44 & 42 & 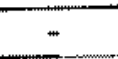 & 32 & 25 & 24 \\
\hline$Q T(C)$ & 23,7 & 23,1 & 23,8 & 23,5 & $=$ & 23,6 & 23 & 22,5 \\
\hline$\eta$ & 0,90 & 0,85 & 0,88 & 0,90 & 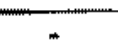 & 0,78 & 0,70 & 0,65 \\
\hline$\Sigma_{i}(\mathrm{eV} / \operatorname{ion})$ & 400 & $450 \times 550$ & $550-650$ & $480-580$ & - & 870 & 500 & $65-85$ \\
\hline$f\left(\mu_{b} / C\right)$ & 26 & 20 & 37 & 49 & - & 125 & 380 & 3474 \\
\hline$n_{*}\left(10^{1} \mathrm{~m} / \mathrm{s}\right)$ & 3,0 & 1,0 & 1,0 & 2,0 & 1,5 & 0,8 & 0,5 & 0,4 \\
\hline$E_{K}(e V)$ & 56 & 13 & 14 & 122 & 74 & 22 & 15 & 17 \\
\hline$T_{z}(\mathrm{eV})$ & 2,5 & 5,5 & 1,3 & 2,0 & 1,4 & 0,8 & 0,7 & 0,7 \\
\hline $\mathrm{Z}[26]$ & 1 & 1,5 & 1,7 & 1,8 & 2,0 & 1,2 & 1,3 & 1,5 \\
\hline$n_{0}\left(10^{19} m-3\right)$ & 0,8 & 5,0 & 3,2 & 1,3 & 1,8 & 28 & 4,3 & 4,6 \\
\hline$n_{p}\left(10^{16} m^{-3}\right)$ & 0,8 & 3,3 & 1,9 & 0,7 & 0,9 & 2,3 & 3,3 & 3,0 \\
\hline $7(\%)[27 * 30]$ & 70 & $80-100$ & 50.60 & 60.70 & $60-70$ & $15 \times 20$ & 15 & $18-25$ \\
\hline$\gamma_{\epsilon \in \mathrm{P}}(\%)$ & 60 & 100 & - & $=$ & - & 90 & 56 & 10 \\
\hline$\Sigma_{\text {iexp }}(\mathrm{eV} / \mathrm{ion})$ & 480 & 440 & - & - & $-\cdots$ & 190 & 140 & 160 \\
\hline$t_{t}(t s)$ & 27 & 80 & 80 & 40 & 54 & 100 & 160 & 200 \\
\hline
\end{tabular}

\subsection{Conclusäo}

Para efeito de comparaçăo da descarga em arco no vácuo gerado por catodos diferentes a Tabela 2.4 sumariza os resultados obtidos para oito catodos nas condiçöes $I_{\alpha}=1,5 \mathrm{kA}, B_{*}=0,1 \mathrm{~T}$. 0 s parârnetros obtidos com a sozuda de Langmuir $\left(n_{i}, T_{w}, u_{x}\right)$ foram medidos no centro da coluna $(x=0)$.

As seguintes conclusōes podem ser obtidas desta tabela:

- Densidade de íons: a densidade de partículas na forma de íons positivos é $\mathrm{n}_{p} \sim 10^{19} \mathrm{n}^{-3}$. É possivel aumentar $n_{p}$ de uma ordem de grandeza aumentando a corrente do arco $I_{a} e$ melhorando a transmissão de partículas através do anodo.

- Temperatura :supondo $T_{*} \sim T_{i}$ observa*se urna temperatura relativamente alta com 0,6 eV $\leq T_{e} \leq 6$ eV. Temperaturas de uma ordem de grandeza menor sería desejóvel para um melhor desempenho do separador isotópico baseado neste principio. A tempezatura elevada do magnésio pode ser explicada pelo fato de que os potenciais de ionizaçẩo săo: $\mathrm{Mg}^{+}(7,43 \mathrm{eV}) ; \mathrm{Mg}^{++}(15,03 \mathrm{eV})$ e $\mathrm{Mg}^{+++}(80,1 \mathrm{eV})$. Assim toda energia estará distribuida 
entre os fons $\mathrm{Mg}^{+}$e $\mathrm{Mg}^{++}$resultando numa temperatura major, visto que o fon $\mathrm{Mg}^{+4+}$ năo é criado devido ao alto potencial de ionizaçāo deste estado (muito maior que a tensắo do arco). Qualquer enexgia extra depositeda no plasma de magnésio vai para o aumento de temperatura como mostrado na Figura 2.24 .

- Velocidade axial de deriva e energía cinética : velocidade axial de deriva está no intervalo $\sim 10^{3}-10^{4} \mathrm{~m} / \mathrm{s}\left(13 \mathrm{eV} \leq \mathrm{E}_{K} \leq 122 \mathrm{eV}\right)$ onde geralmente os elementos de massa maior tem $u_{x}$ menor. $O$ tempo de tránsito dos íns numa coluna de comprimento $L_{q} \sim 1 \mathrm{~m}$ é 25 $\mu$ s $<t_{i}<250 \mu$ s com as velocidades dadas na tabela.

- Tensäo de arco, razão de erosäo, grau de ionizaçǟo e eficiência na transferência de energia do circuito para o plasma: estes parämetros devem estar correlacionados, isto porque, para $\mathrm{Zn}_{3} \mathrm{Cd}$ e $\mathrm{Pb}$ tem-se $\rho$ maior e $\left(\mathrm{U}_{\mathrm{a}}, \gamma, \eta\right)$ menores a passo que para $\mathrm{C}, \mathrm{Mg}, \mathrm{Al}, \mathrm{Ni}$ tem-se $\left(U_{a}, \gamma_{i} \eta\right)$ malores e $\rho$ menor. Como visto na seçăo 2.2 .1 os elétrons emitidos pelo catodo ganham exergia na bainha formada na regiäo $1 \operatorname{com} \Delta \mathrm{U}_{t} \sim \mathrm{U}_{a}$ e, desse znodo, $\mathrm{U}_{a}$ maior sìgnifica elétrons de major enexgìa na regiẫo 2 onde ocorre a ionização do vapor metálico. Isto cutäo poder resultar em temperatura de elếtrons mais elevada, grav de ionizaçāo maior e urn melhor acoplamento energético emtre circuito e plasma para $\mathrm{C}, \mathrm{Mg}, \mathrm{Al}, \mathrm{Ni}$ o mesmo nă ocorrendo para os catodos $\mathrm{Cd}, \mathrm{Zn}$ e $\mathrm{Pb}$ que spresentara $\mathrm{U}_{a}$ mais baixo como pode ser vinsto da tabela. Também, pode ser obserwado que embora a razāo de erosāo para $\mathrm{Zn}, \mathrm{Cd}$ e $\mathrm{Pb}$ seja muito mator que a do magnésio, a densidade de partículas carregadas nă sâo rauito diferentes, uma comprołaçä̊ indireta das diferenças no grau de ionizaçăo dos plasrnas. A alta taxa de exosäo do chumbo é devida ao fato de que $\sim 90 \%$ da emissäo acontece na forma de macropartículas [73].

- Consumo de energia para produğăo do íon: a energia consumida para produzir cala ion está no intervalo $\sim 100-500 \mathrm{eV}$, sendo que os materiais de ponto de fusäo/ebulição mais baixo $\left(\mathrm{Zn}_{,} \mathrm{Cd}_{3} \mathrm{~Pb}\right)$ apresentarn menor consumo energético.

Como já salientado anteriormente o ideal é ter jonizaçầo completa, mas os dados apontam que isto nen sempre ocorte na descarga em arco no vácuo. Apesar disto, a coluna de plasma, isto é, - plasma transmútido atrayés do anodo deve zer altamente ionizado. A raza para tal fato é que as particulas neutras são em sua maiorid macropartículas com concentraçāo maior em ângulos rasantes com relaçâo a superficie do catodo. O campo xangnético näo tem influëncia sobre estas 


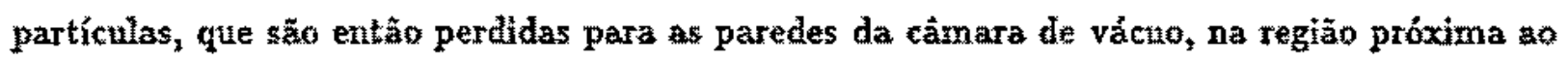
catodo. Somente uma pequena parte destas macropartículat pode se dirigir para a coluna de plasma. 


\section{CAPÍTULO 3}

\section{DESCRIÇÃO \\ MAGNETOHIDRODINÂMICA PARA A \\ COLUNA DE PLASMA E OS \\ RESULTADOS EXPERIMENTAIS}

\subsection{Introdução}

A coluna de plasma, isto é, o plasma que é transmitiơo através da grade de tungstểnio ê descríto pelo modelo de fluido. As simplificaçōes nas equações săo justificadas, sempre que possível, comn base nas medidas experimentaùs realizadas. Os principais rekultados que seguem da descriçăo da coluna de plasma com o modelo de fluido săo: os perfis radiais da densidade de partículas carregadas, do potencial de plasma e do fator de separaçä́ e a expressäo para a velocidade angular. Estes resultzdos teóricos sẵo confrontados corn os obtidos experimentalmente.

As seçöes 3.2 e 3.3 seguem de perto a análise contida nas referèncias $[74,75]$.

\subsection{Descriçăo física da coluna de plasma em rotaçăo}

Esta descriçầo estấ bastada na velocidade de deriva $\overrightarrow{E_{*}} \times \overrightarrow{B_{z}}$, onde $\overrightarrow{E_{r}}$ é o campo elétrico auto-consistente na direçăo radial existente na coluna de plasma, e no velocidade de deriva diamagnética devida a gradiente de pressâ.

Para ver como surge o campo elétrico radial aa coluna de plasma as seguintes frequèncias devem 
Ser calculadas: frequência ciclotrönica dos elétrons $\left(\Omega_{c c}\right)$; frequência cíclotrönics dos íon $\left(\Omega_{c i}\right)$;

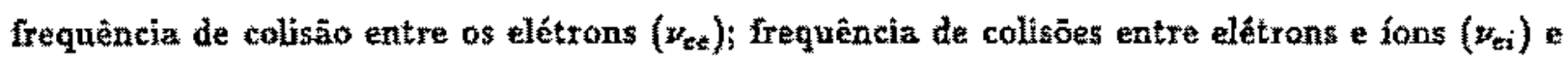
frequểncia de colisäo entre os íons $\left(\nu_{i i}\right)$.

As expressōes para estas frequências são:

$$
\begin{aligned}
& \Omega_{c \varepsilon}=\frac{e B_{z}}{m_{e}} \\
& \mathrm{n}_{a}=\frac{Z e B_{z}}{m_{i}} \\
& \nu_{e s}=5 \times 10^{-1 n} \frac{n_{e \sigma} \ln A}{T_{e}^{\frac{3}{2}}} \\
& \nu_{\mathrm{ei}}=2 \times 10^{-12} \frac{2 n_{\mathrm{e} 0} \ln A}{T_{e^{\frac{3}{2}}}^{\frac{3}{2}}} \\
& z_{i i}=Z^{4}\left(\frac{m_{k}}{m_{i}}\right)^{\frac{1}{2}}\left(\frac{T_{e}}{T_{i}}\right)^{\frac{3}{2}} z_{e e}
\end{aligned}
$$

$\operatorname{comn} \mathbf{n}_{m 0} e m m^{-3}$ e com $T_{e}$ e $T_{i} e m e V$

Fixando-se no plasma de magnésío tem-se corn os dados da Tabela $2.4\left(\mathrm{~T}_{\mathrm{e}} \sim \mathrm{T}_{\mathrm{i}}=5,5 \mathrm{eV}, \overline{\mathrm{Z}}\right.$ $=1,5, \mathrm{n}_{\mathrm{x}}=5 \times 10^{15} \mathrm{~m}^{-3}$, In $A \sim 10$ e $\left.\mathrm{B}_{x}=0,1 \mathrm{~T}\right)$, os seguintes valores: $\Omega_{\infty}=1,8 \times 10^{10} \mathrm{rad} / \mathrm{s}$

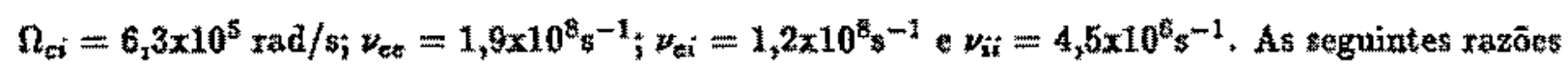
entre as diversas frequências săo obtidas: $2 \pi \nu_{s e} / \Omega_{c o} \sim 0,07$ e $2 \pi \nu_{i} / \Omega_{t i} \sim 48.0$ significado físico destes valores é que os ínz sofrem muito mais colisões do que os elétrons durante o giro ciclotrónica, e, consequentemente, os elétrons tāo mais presos do que os fons às linhas de campo magnético. $O$ resultado é que inicialmente, ocorre uma maior difusão dos íons através das linhas de campo, eztabelecendo-se posteriormente uma difusăo ambipolar. 0 resultado final é o estabelecinento de umo campo elétrico radial interno auto-consistente, direcionado para o centro dá coluna. A interaçăo deste campo elétrico radial com o campa magnético axial dá origem à velocidade de deriva na direçăo azimutal

$$
\overrightarrow{u_{E}}=\frac{\overrightarrow{E_{r}} \times \vec{B}}{B^{2}}
$$

que coloca a coluna de plasma em rotaçắo ao redor do eixo z.

Será visto mais adiante que a dersidade de partítulas carregadas tern un perfl radial Gaussiano 
a)

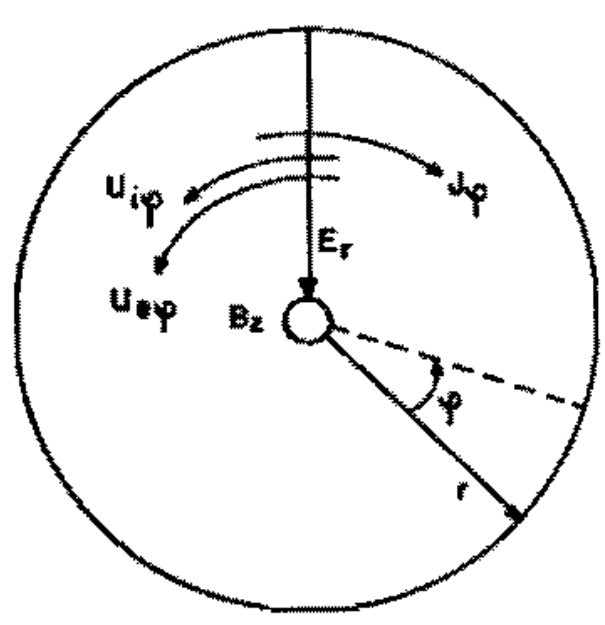

b)

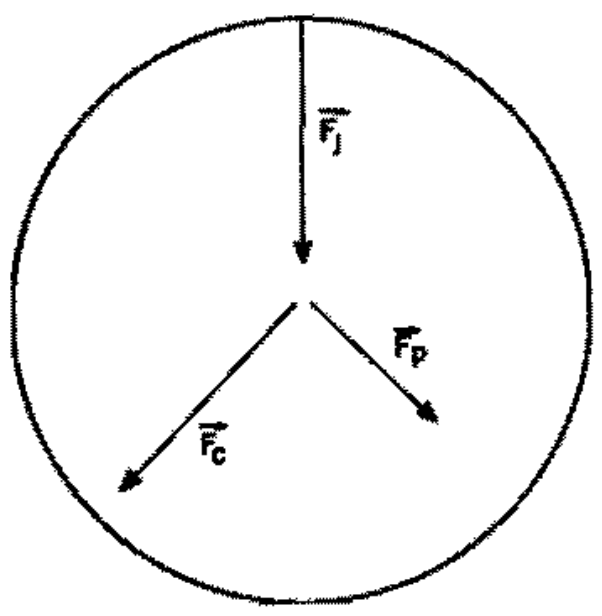

Figura 3.1. a) Velocidades de deriva resultantes na direçāo azimutal para os elétrons $\left(u_{e \varphi}\right)$ e jons $\left(u_{i \varphi}\right)$ e a densidade de corrente $J \varphi_{.}$b) Diagrara esquemático das forģas atuando na coluna de plasma $\left(F_{C}=\right.$ força centrifuga, $\overrightarrow{F_{I}}=\overrightarrow{I_{\varphi}} \times \vec{Q}$ e $\overrightarrow{F_{p}}=-\nabla p$ ).

com pico em $\mathrm{r}=0$. Desse modo, há um gradiente de prestäo na direçăo radial resultando na velocidade de deriva diamagnética na direçǟo azimutal dada pox

$$
\overrightarrow{u b}=-\frac{\nabla_{p} \times \vec{B}}{n_{\alpha} Q_{\alpha} B^{2}}
$$

onde $\alpha=$ e para elátrons e $\alpha=1$ para fons.

As duas velocidades de deriva estäo no mesmo sentido para os elétroñ e em sentidos opostos para os íons. A resultante ế que, embora tanto as ions quanto os elétrons girem no mesmo sentỉdo, os elêtrons giram com una velocidade maior. Isto dá origem a uma densidade de corrente azimutal, cujo sentido é oposto ao movimento das partículas, como está mostrado na Figura 3.1a. Anteraçăo dessa corrente azimutal com a campo magnético dá origem à torça $\overrightarrow{J_{p}} \times \vec{B}$ dirigida para o centro, equilibrando desse modo a força centrif́uga devido a rotaçäo do planma e força dewido a gradiente de pressän, ambas dirigidas para fork. Na Figura a.lb estä mostrado esquematicamente o diagrama das forgas atuando na coluna de plasma.

A força centrifuga causa a separaçăo radial entre partículas de razäo massa/carga diferentes. Os 
perfis radiais da densidade das vărias espécies de fons (embora Gaussianos) näo são iguais e um enriquecimento radial 6 atingido em que os tons de mass maior säo mais abundantes para raios malores.

\subsection{Modelo de fluído para a coluna de plasma em rotação}

Embora, no modelo de partfeulas seja possivel obter uma boa descrição fisica da coluna de plasma era rotaçä́, esta năo fornece maiores informaçöes sobre os perfis radiais da densidade, velocidade de rotação, campo elétrico e fator de separaçăo. Estas informaçöes são obtidas com a utilizaçäo das equaçôes magnetohidrodinămicas para descrever a coluna de plasma em rotaçăto. As equaçóes usadas na descriçäo deste plasma são equaçäo da continuidade, a equação do monento a equaçäo da energia aplitadas a cada espécie de partícula que compōenn a columa de plasma. Por exemplo, para um plasma de carbono existem trés expecies de partículas: os ions ${ }^{12} C^{\frac{1}{6}}{ }^{13} C^{+}$e os elétrons.

A equação da continuidade aplicada a cada espécie, levando-se em conta a produçă e perda de partículas é

$$
\frac{\partial n_{\alpha}}{\partial t}+\vec{\nabla} \cdot\left(n_{\alpha} \overrightarrow{u_{\alpha}}\right)=P_{\alpha}-L_{\alpha}
$$

onde $\alpha$ denota a espétie de partícula, $n_{\alpha}(\vec{F}, t)$ sua densidade, $\overrightarrow{u_{\alpha}}(\vec{F}, t)$ a velocidade $\vec{P}_{\alpha}(\vec{T}$, t) * $I_{c k}(\vec{r}, t)$ sāo os termos de produçâa e perda de partículas, respectivamente, A produçăo de partículas ocorre na regiäo prórima ao catodo, e, assim, na coluna de plasma (isto é, longe do catodo) tern-se $P_{a}(\vec{F}, t)=0$. $O$ termo de perả $L_{a}$ e devido ao processo de recombinação. Em um plasma corapletamente ionizado e com $T_{e} \geq 1$ eV a razāo de retombinaçāo é pequena podendo ser desprezada; entäo $\mathrm{L}_{\alpha}=0$.

A equaçẵo da conservaçăo de momento incluindo efeitos da rotaçăo, força eletromagnática, gradiente de pressäo colisöes entre as partículas é

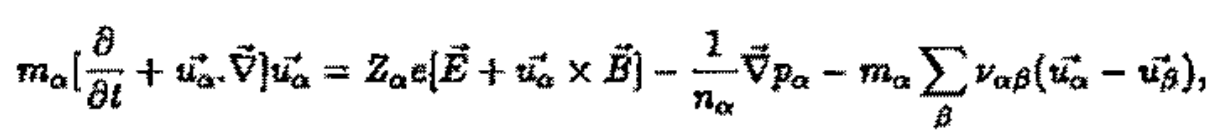


onde $\mathrm{m}_{\alpha}$ é a massa da partícula, $\mathrm{z}_{\alpha} e$ a carga, $\vec{E}$ o campo elétrico auto consistente, $\vec{B}$ o campo magnético, $p_{\alpha}$ a pressä̀ cinética escalar e isotrópica e $\nu_{\alpha \beta}$ a frequência de colisöes para transferéncia de momento entre as espécís $\alpha$ e $\theta_{\text {: }}$ feita a hipótese de que o campo magnético produzido por cortentes internas a coluna de plasma e pela tariaçăo temporal do campo elétrico interno seja pequeno. Portanto, o campo magnético que aparece na equaçẵo (3.5) é o campo magnético axial aplicado externamente, $\vec{B}=\mathbf{B}_{x} \overrightarrow{e_{x}}$. Os elementos do tersor pressāo fora da diagonal podem ser desprezados se forem pequenos em relação aos da diagonal principal, isto é, $p_{j k} / \mathrm{p}<1$ (j $\mathrm{k}$ ). Os elementos fora da diagonal são proporcionais a viscosidade e ao gradiente da velocidade, $\mathrm{p}_{j k} \propto \mu \vee \vec{z}$, que em uma primeira aproximaţăo pode ser escrito como $\mathrm{p}_{j k} \sim \mu \mathrm{w} / \mathrm{t}$ $=f \omega_{i}$ onde $\omega_{i}$ é a velocidade angular dos ions. Pars os elementos na diagonal $\mathrm{p}=\mathrm{nkT}$. Como $\Omega_{a \mathfrak{a}} / 2 \pi \nu_{i \mathrm{i}} 1$, a expressäo para a viscosidade

$$
\mu_{i} \sim \frac{n_{a 0} k_{g} T_{i}}{n_{i i}}
$$

A viscosidade dos íns é muito maior que a dos elétrons, por esta razăo, s viscosidade do plasma é determinada essencialmente pelos ions [76]. A velocidade angular para os ions no plasma de magnésio é $\omega_{i} \sim 2,5 \times 10^{5} \mathrm{rad} / \mathrm{s}$ obtendo-se entăo

$$
\frac{p_{i j}}{p} \approx \frac{\omega_{i}}{2 \pi \nu_{i i}}<1
$$

Se a temperatura dos ions anisotrópica e tem os valores $\mathrm{T}_{i \mid}$ e $\mathrm{T}_{\mathrm{i} i}$, paralela e perpendicular ao campo respectivamente, (e consequentemente, $p \rightarrow p_{\|}, p_{1}$ ) as tolisōes ion-fon tendem a igualar $T_{i \perp}$ e $T_{i||} \cdot O$ grau de anisotropia é $\left(T_{i 1}-T_{i \|}\right) /\left(T_{i \perp}+T_{i \mid}\right) \sim(1 / 10)\left(\omega_{i} / R_{c i}\right)^{2}<1$, com os dados obtidos para o plasma de magnésio. Tambếm, para os elétrons tem-se que as colisōes elétron-elétron e elétron-ín tendern a igualar $T_{t \mid l}$ e $T_{t 1}[5]$. Desta analise conclù-se que a hüpótese de uma pressä́o escalar e isotrópica é válida para a coluna de plasma de alta densidade, completamente ionizada e em rotaçăo.

As equaçöes (3.4) e (3.5) devem ser complementadas pela equação de conservaçāo de exerğă, relacionando $p_{\alpha}(\vec{r}, t)$ com $n_{\alpha}(\vec{F}, t)$ e $\overrightarrow{u_{\alpha}}(\vec{r}, t)$. No entanto, com uma temperatura constarite 
e uniforme $\mathbf{T}_{\alpha}$ através do plasma (isotérmico) è suficiente usar a equagăa de estado de urn gás ideal para fechar o sistema de equaçóes,

$$
p_{\alpha}=n_{\alpha} k_{B} T_{\alpha}^{*}
$$

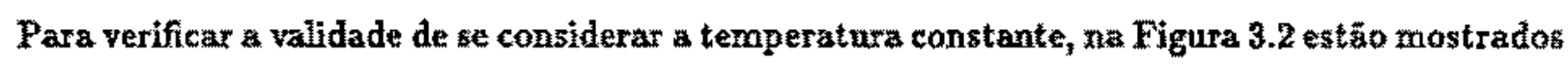
os perñs radiajs de $T_{t}$ obtidos para os plasmas de magnésio e carbono. A temperatura pode ser considerada constante para $x<20$ mm no plastna de magnétio e $r<30$ mm no de carbono.

O campo elétrico auto consistente $\vec{E}(\vec{r}, t)$ pode bet expresso em termos do potencial elétrico $\phi(\vec{r}, t)$

$$
\vec{E}=-\nabla \phi
$$

onde $(\vec{r}, t)$ satisfaz a equaçäo de Pósson dentro do plasma

$$
\nabla^{2} \phi=-\frac{p}{\epsilon_{0}}
$$

com a densidade de carga dada por

$$
p=e \sum_{\alpha} z_{\alpha} n_{a}
$$

Como já salientado no Capitulo 2, plasma originado na descarga em arco no vácuo tem tama neutralizaçāo quase que total de cargas $\mathrm{e}_{2}$ assim, em yez de se resolver numexicamente a equaçäo de Poisson, a condiçăo de quase-neutralidade é usada $\rho \simeq 0$. A neutralizaçẵo de cargas näo deve ser perfeita pois há ura campo elétrico auto-consistente na coluna de plasma.

As equaçôes a serem resolvidas em coordenadas cilíndricas $(r, \varphi, z) \operatorname{com} \vec{B}=B_{z} \overrightarrow{e_{z}}$ com condiçōes de contorno apropriadas sä̌:

$$
\begin{aligned}
& \frac{\partial n_{\alpha \alpha}}{\partial t}+\vec{\nabla} \cdot\left[n_{\alpha \alpha} u_{\alpha+}\right]=0
\end{aligned}
$$

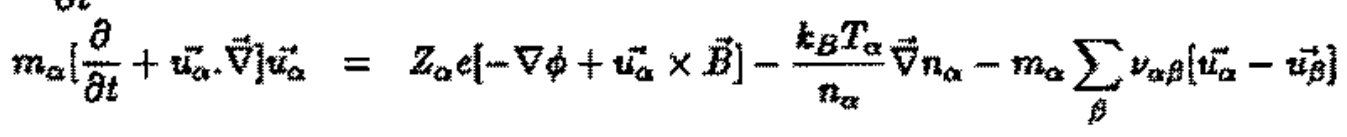

$$
\begin{aligned}
& \sum_{\alpha} z_{\alpha} n_{\alpha}=0
\end{aligned}
$$



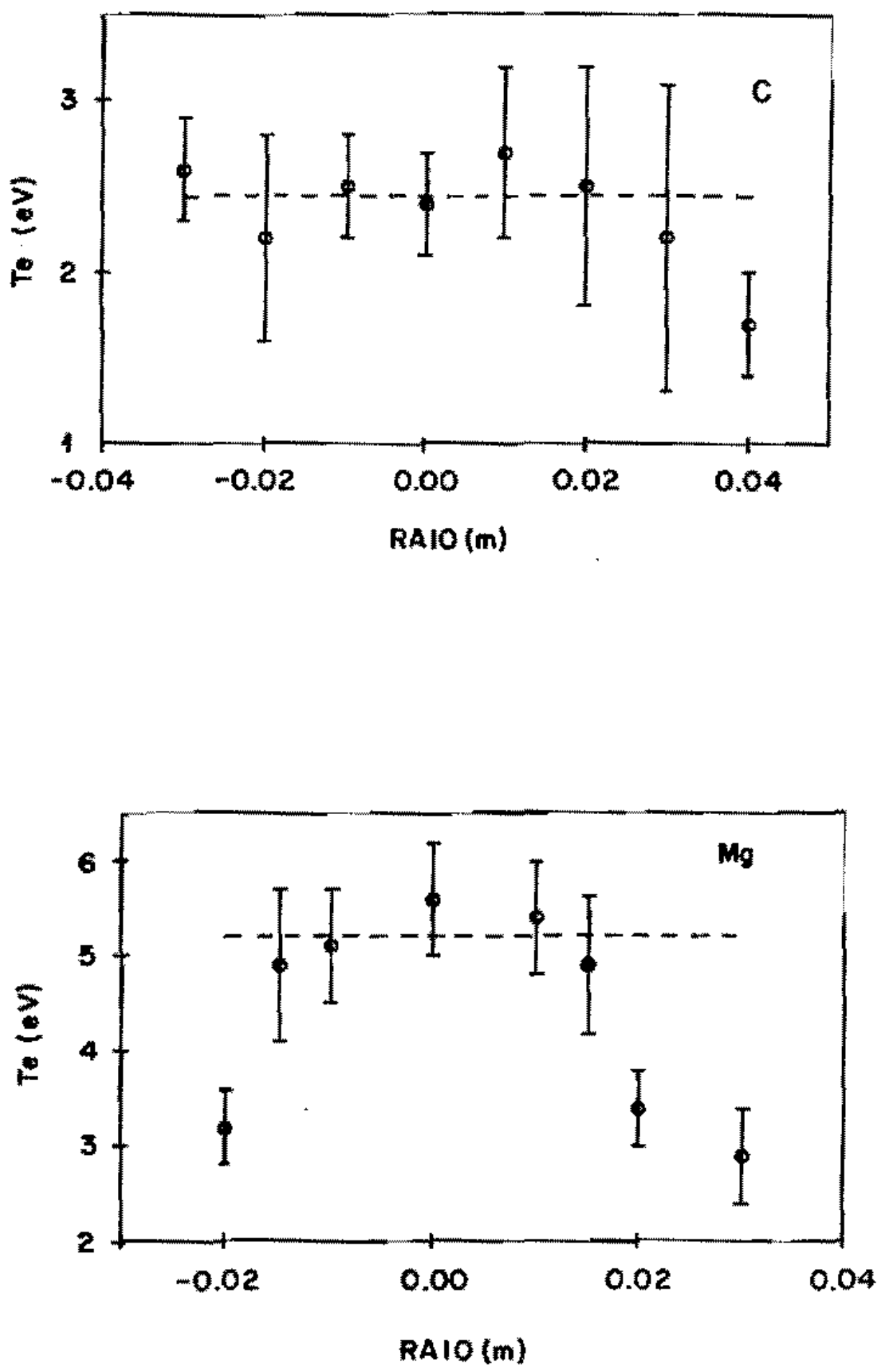

Figura 3,2. Perfil radial du temperatura de elétrons para os plasmas de carbono e magnésio com $I_{a}=1,5 k, B_{x}=0,1 T=8 \mathrm{~m}$ * 
Em coordenadas cilíndrìcas, a equação da continuidade e os trës componentes da equaçâo da conservăăo do momento sāo expressư por

$$
\begin{aligned}
& \frac{\partial n_{\alpha}}{\partial t}+\frac{1}{r} \frac{\partial\left(r n_{\alpha} t_{\alpha r}\right)}{\partial r}+\frac{1}{r} \frac{\partial\left(n_{\alpha} t_{\alpha \phi}\right)}{\partial \varphi}+\frac{\partial\left(n_{\alpha} t_{\alpha z}\right)}{\partial z}=0 \\
& m_{\alpha}\left[\frac{D z_{\alpha \tau}}{D t}-\frac{u_{\alpha \psi}^{z}}{r}\right]=z_{\alpha} e\left[E_{\psi}+w_{\alpha \psi \phi} B_{z}\right]-k_{B} T_{\alpha} \frac{\partial \ln \left(n_{\alpha}\right)}{\partial r}- \\
& -m_{\alpha x} \sum_{\beta} \nu_{\alpha \beta}\left[u_{\alpha r}-u_{\beta r}\right] \\
& m_{\alpha}\left[\frac{D u_{\alpha \psi}}{D t}+\frac{u_{\alpha \varphi} u_{\alpha r}}{\tau}\right]=z_{\alpha} e\left[E_{\varphi}-t_{\alpha r} B_{*}\right]-k_{B} T_{\alpha} \frac{1}{\frac{\partial \ln \left(n_{\alpha}\right)}{\partial \varphi}} \\
& -m_{\alpha} \sum_{\beta} y_{\Delta x \beta}\left[u_{\alpha \varphi}-t_{\beta \varphi}\right] \\
& m_{\alpha} \frac{D u_{\alpha z}}{D t}=z_{\alpha} e E_{z}-k_{\beta} T_{\alpha} \frac{\partial \ln \left(n_{\alpha}\right)}{\partial z}- \\
& -m_{\alpha \alpha} \sum_{\beta} v_{\alpha \beta}\left[t_{i z z}-u_{\beta x}\right] \\
& \frac{D}{D t}=\frac{\partial}{\partial t}+u_{\alpha r r} \frac{\partial}{\partial t}+t_{\alpha<\%} \frac{1}{\partial} \frac{\partial}{\partial \varphi}+t_{\alpha z} \frac{\partial}{\partial z}
\end{aligned}
$$

Algưnas simplificaçōes nestas equaçöes são:

- Simetria azimutal - todas as variaveis säo independentes de $\varphi$, neste caso $\mathrm{E}_{\varphi}=0$, como requerido da equação $\nabla \times \vec{E}=0$, consitulerando $\vec{B}$ constante.

- Veloxidade axial constante $\left(\mathrm{u}_{\alpha x}\right)$ - isto è verdadeiro, pois, como ja fổ visto no Capítulo 2, esta velocidade é adquirìna na regiāo prốxima so catodo. Esta velocidade poderia ser alterada se o componente axial do campo elétrico $\left(\mathrm{E}_{2}\right)$ fosse grande na caluna de plasma, o que nāo ocorre como setá visto mais adiante.

- Condiçẵo de estado estacionário $0 / \partial t=0$. A Figura 3.3 a mostra o perfil temporal da densidade de particulas para os plasmas de carbono e magnésio e na Figura $3.3 \mathrm{~b}$ o da temperatura de elétrons. Também os perfis termporais da velocidade angular e do fator de separaçăo mostram uma invariança (mostrados maís adiante neste capitulo) com o tempo e, assimn, a condiçăo de estado estacionário é satísfeita.

- Invariança com a coordenada $z_{2} \partial / \partial z=0$ - Esta condiçäo pode näo ser satisfeita na PCEN por duas razōes: a primeira devido ao gradiente do campo magnético ao longo do eixo z e a segunda devido a pequeno extensão axial da coluna de plasma / $\sim 0,8 \mathrm{~m}$. 


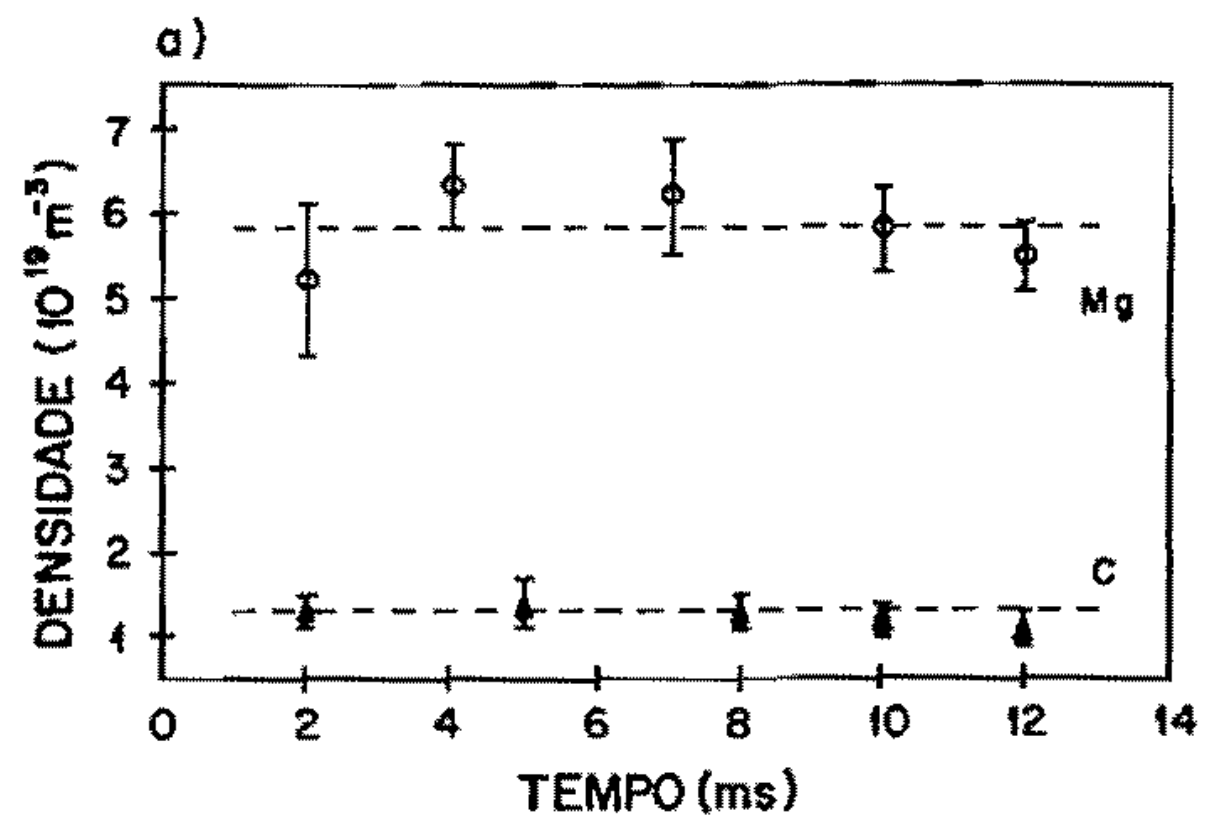

b)

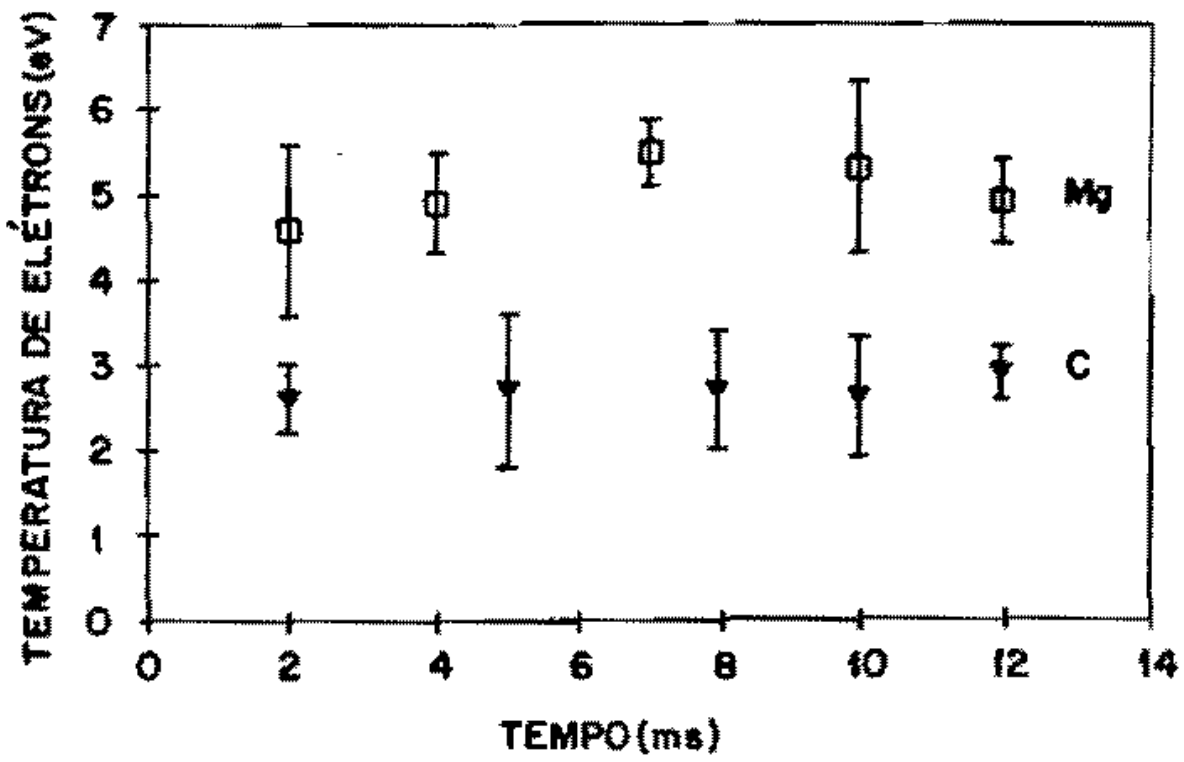

Figura 3.3. a) Perfil temporal da densidade de partículas carregadas. b) Perfil temporal da temperatura de elétrons, para carbono e magnésio com $I_{a}=1,5 k A, B_{*}=0,1 T$ e $r=0$. 
- Rotaçắo da coluna como corpo rígido - Neste caso tem-se

$$
u_{\alpha x p}=\omega_{\alpha} r_{p}
$$

onde to é a velocidade angular da espécie $\alpha$. As collsōes entre fons devem levar a uma equalizaçầ da velocidade angular das diferentes espécies de ions abob condịọos de estado estacionation $O$ tempo entre colisōes para os ions de magnésio é $1 / y_{i j} \sim 0,2 \mu s$ e o tempo de trãnsito destes fons na coluna de plasma e $\sim 80 \mu s$ (da Tabela 2.4), ocorrendo então $\sim$ 400 colisōes entre os mesmos. Os elétrons por sua vez devem ter uma velocidade angular major que a dos fons de modo a dar origem a força radial $\overrightarrow{J_{j}} \times \vec{B}$ que confina o plasma.

Em resumo, o plasma pode ser considerado como wma coluna cilindrica isotérmica girando como um corpo rigito sob condiçōes de estado estacionário, com nenhuma dependência azimutal e axial (coluna inininitamente longa) e nenhuma condiçầo de contorno envolvida. Deste modo, o plasma $a$ desacoplado do catodo, do anodo e das paredes.

Os perfis radiais para o campo elétrico, para a densidade, para o fator de separaçäo e a expressăo pars a velocidade angular, obtidos a partir deste modelo simplificado, serão apresentados a segrairr[74,75]. Também serão apresentados os resultados experimentais obtidos na PCEN para estę parầnetros.

\subsubsection{Campo elétrico radial e potencial de plasma ou espacial}

O carnpo elétrico radial varĭa linearmente com $\mathrm{r}, \mathrm{e}$, consequentemente, o potencial elêtrico tem um perfil radial parabólico, ou zeja

$$
\begin{aligned}
\vec{E}_{r}(r) & =-a r \overrightarrow{e_{r}} \\
\phi(r)-\phi(0) & =\frac{a}{2} r^{2}
\end{aligned}
$$

onde a é uma constante positiva, pois o campo elétrico radial deve estar direcionado para o centro da coluna de plasma.

As Figuras 3.4 e 3.5 mostram os resultados obtidos para os perfis radiais do potencial flutuante $\left(\phi_{1}\right)$ e de plasma $\left(\phi_{s}\right)$ nas condíçoes $I_{a}=1,5 \mathrm{kA}, B_{z}=0,1 \mathrm{~T}$ e ro tempo $\mathrm{t}=8 \mathrm{~ms}$ da descarga $\mathrm{o}$ 
raelhor ajuste de uma parábola aos pontos experimentais. No cálculo do potencial de plasma foi utilizada a expressäo (2.35), onde foram utilizados os valores medidos de $u_{z}$ e $T_{e}$. No argumento da funçäo logarítraica toi utilizado um valo: constante para $T_{t} T_{t}=2,5 e V$ para carbono e $T_{e}$

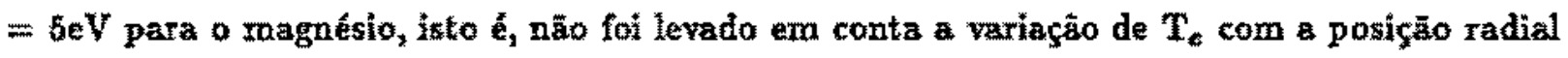

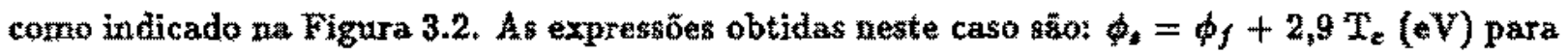
o plasma de carbono e $\phi_{t}=\phi_{f}+4,3 \mathrm{~T}_{\mathrm{e}}$ (eV) para o de magnésío.

Destes dados experimentais, obserwase que para o plasma de carbono é possível um ajuste ao perfil parabólico para $\mathrm{E} \leq 30 \mathrm{~mm}$, já para o plasma de magnésio o ajuste é posažvel somente para $x<20 \mathrm{~mm}$.

Do ajuste parabólico para o potencial de plasma de magnésio obtểnmse $\mathrm{E}_{\mathrm{r}}=-\left(\mathrm{d} \phi_{\mathrm{s}} / \mathrm{dr}\right)=-6,774$ $\times 10^{4} \mathrm{r}$ e para $\mathrm{s}=20 \mathrm{~mm}, \mathrm{E}_{\mathrm{r}}=* 1,35 \times 10^{3} \mathrm{~V} / \mathrm{m} . \mathrm{O}$ componerte $\mathrm{E}_{x}$ do campo elétrico pode ser avaliado da relaçāo $\mathrm{E}_{z}=\eta_{\mid \mathrm{I}} \mathrm{J}_{z}$, Supondo corno indica a Fig 2.22, que $50 \%$ das cargas sejam transferidas para a coluna de plasma tem.se $\mathrm{J}_{2} \sim Q_{2} / 2 \tau_{\mathrm{p}} A$ onde com $\mathrm{Q}_{\mathrm{q}} \sim 23 \mathrm{C}$ (Tabela 2.4 ), $\tau_{p} \sim 16 \mathrm{~ms}$ A $\approx 1,3 \times 10^{-3} \mathrm{~m}^{2}(\mathrm{r}=20 \mathrm{~mm})$ resultando em $\mathrm{J}_{*} \sim 5,5 \times 10^{5} \mathrm{~A} / \mathrm{m}^{*}$. A resistividade é dada pela expressẫo

$$
\eta=6,2 \times 10^{-5} \frac{Z \ln A}{T^{\frac{3}{2}}(\mathrm{eV})}(\Omega . m)
$$

Com os valores para o plasma de magnésio, $\mathrm{Z}=1,5, \ln A=10$ e $\mathrm{T}_{\varepsilon}=5,5 \mathrm{eV}$, tem-te $\eta_{\|}=6 \times$ $10^{-5} \Omega . m$, resultando em $\mathrm{E}_{x} \sim 30 \mathrm{~V} / \mathrm{m}$. Desse modo, na coluna de plasma $\mathrm{E}_{\mathrm{r}} \gg \mathrm{E}_{x} \mathrm{E}_{\psi}=0$.

\subsubsection{Densidade de partículas carregadas}

A densidade de partículas tanto de elĕtrons como a de íons seguem um perfil Gaussiano. Os perfis radiaśs sāo

$$
\begin{aligned}
& n_{e}(r)=n_{e}(0) \exp \left(-\beta_{c} r^{2}\right) \\
& n_{i}(r)=n_{i}(0) \exp \left(-\beta_{i} r^{2}\right)
\end{aligned}
$$

onde

$$
\begin{aligned}
& \theta_{e}=\frac{e}{2 k_{B} T_{i}}\left(w_{c} B_{x}-a\right) \\
& \beta_{i}=\frac{z_{i}}{2 k_{B} T_{i}}\left[a-\omega_{i} B_{A}\left(1+\frac{\omega_{i}}{\Omega_{c i}}\right)\right]_{x}
\end{aligned}
$$




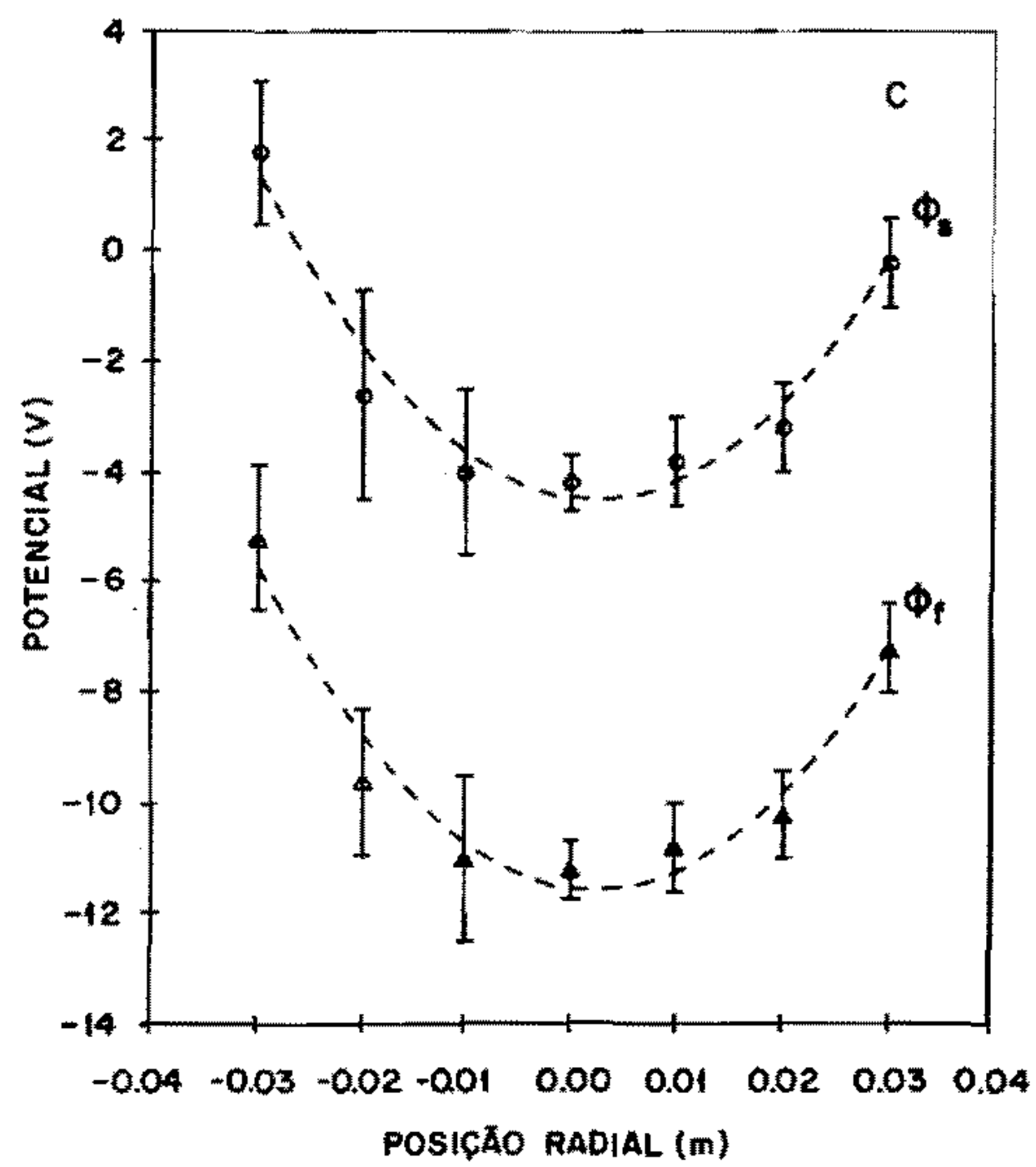

Figura 3.4. Perfil radial do potencial flutuante e de plasma para plasma de carbono $\left(I_{a}=1,5 k A_{z} B_{z}=0,1 T\right.$ e $\left.t=8 \mathrm{~ms}\right)$. 


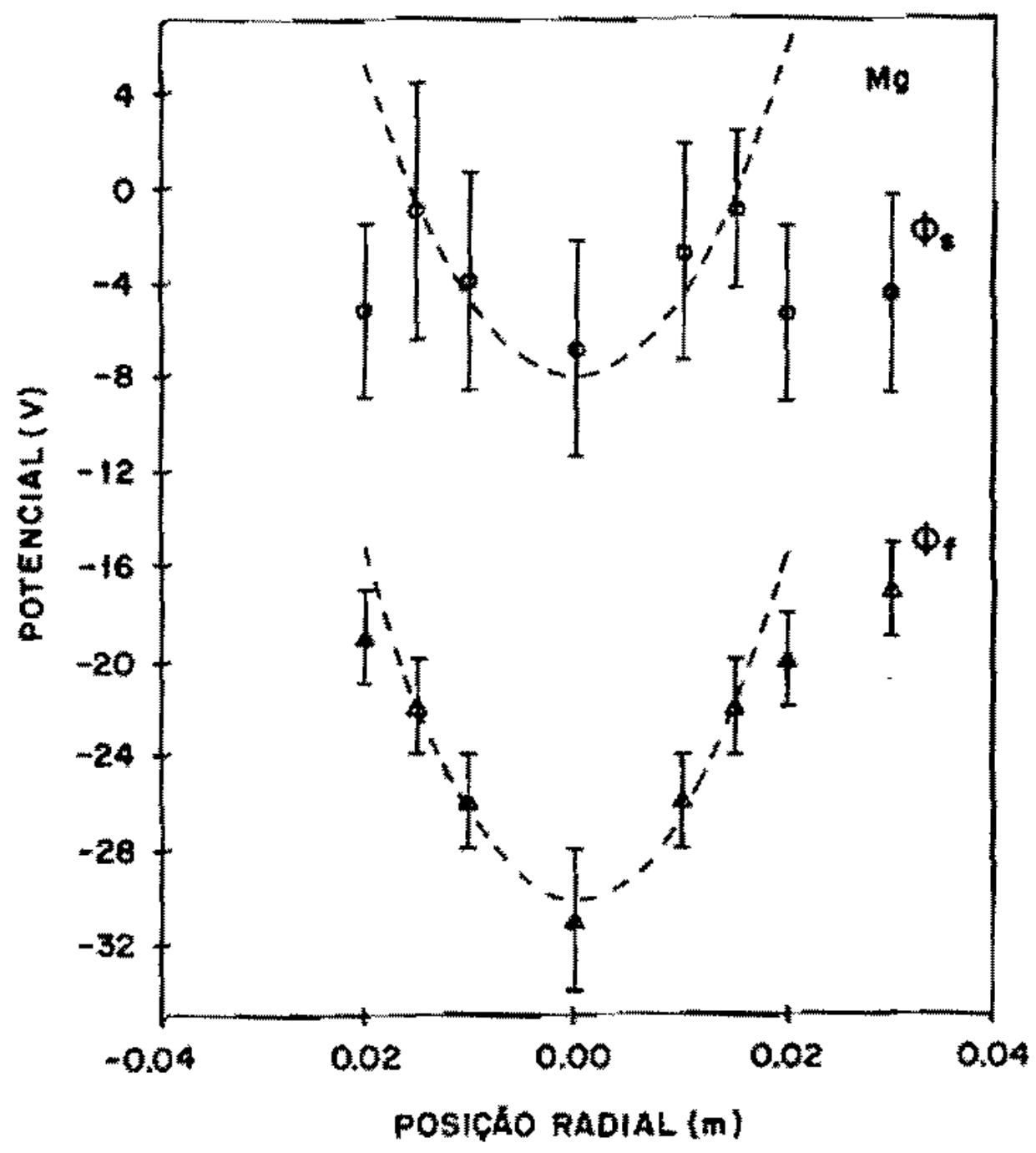

Figura 3.5. Perfil radial do potencial flutuante de plasma para plasma de magnésio $\left(I_{a}=1,5 k A_{1} B_{z}=0,1 T\right.$ e $\left.t=8 m s\right)$. 


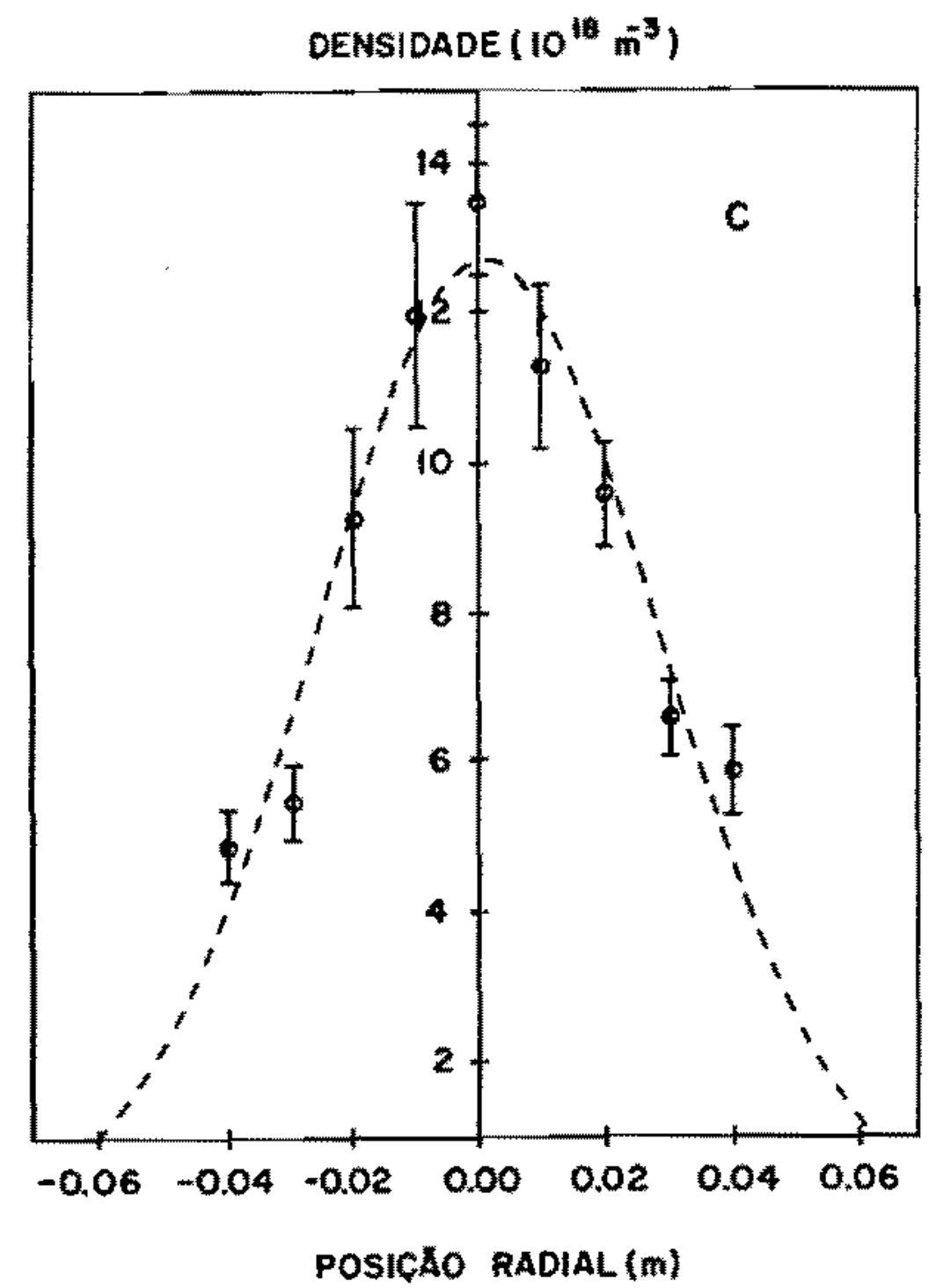

Figura 3.6. Perfil radíal da densidade de fons para o plasma de carbono.

$\operatorname{com} \beta_{k}, \beta_{i}>0$ para confinamento, $\partial \hat{n}_{\alpha \alpha} / \partial r<0$

As Figuras 3.6 e 3.7 mostram os perfis radiais obtidos com o melhor ajuste de urna Gaussiana part os plasmas de carbono e magnésio nas condiçöes $I_{a}=1,5 \mathrm{kA}, B_{z}=0,1 \mathrm{~T}$ e $t=8 \mathrm{~ms}$.

\subsubsection{Velocidade angular}

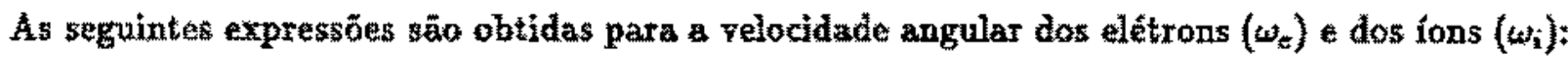




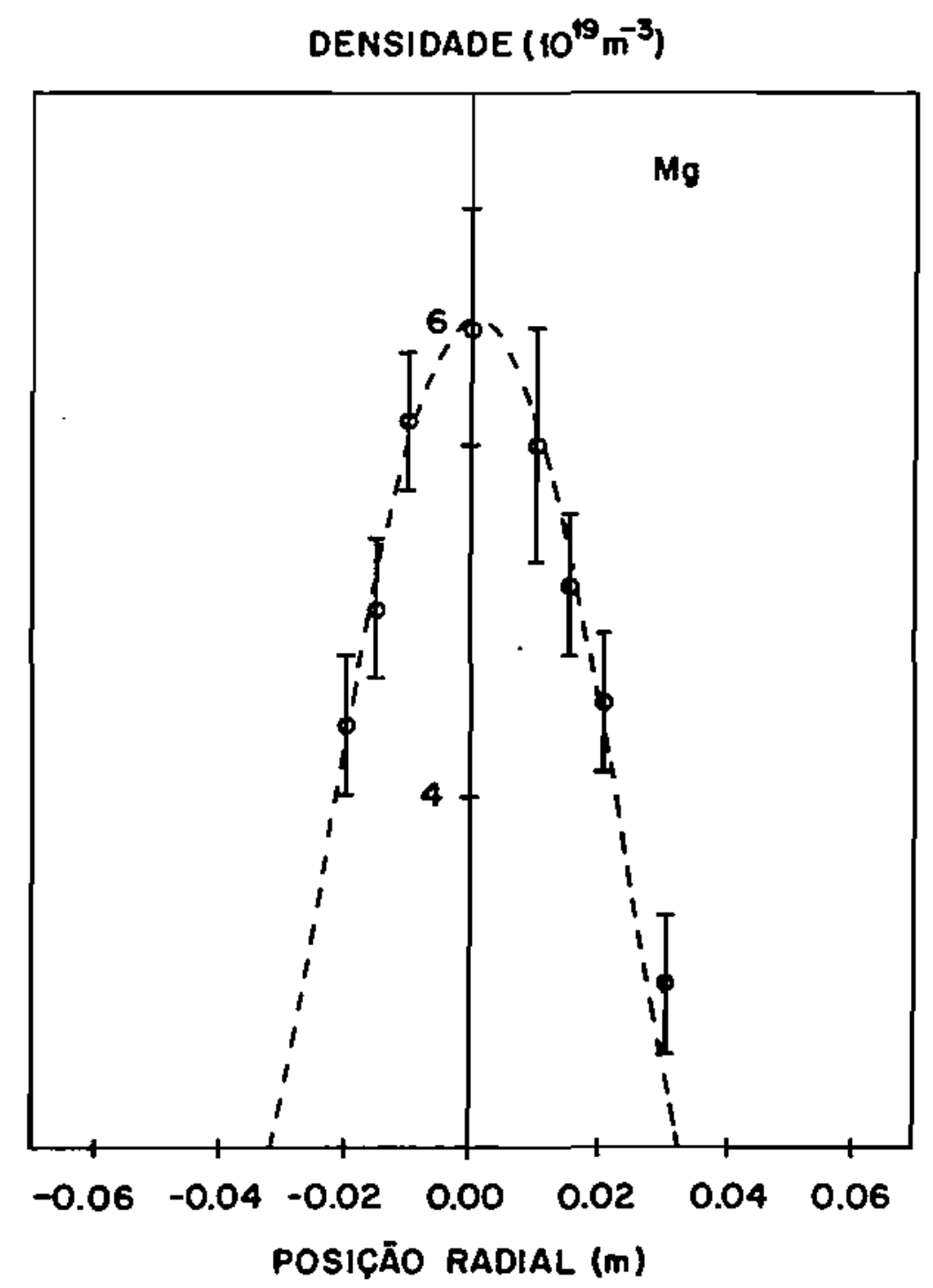

Figura 3.7. Perfil radial da densidade de íons para o plasma de magnésio. 


$$
\begin{aligned}
& \omega_{c}=-\frac{1}{F}\left[\frac{E_{r}}{B_{x}}+\frac{k_{B} T_{x}}{B_{B_{x}}} \frac{\partial \ln \left(n_{e}\right)}{\partial r}\right]
\end{aligned}
$$

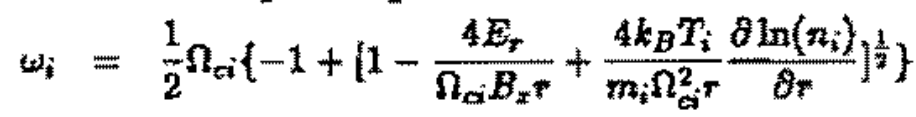

Destas expressổes podem ser obțđăas as segruintes conclusöes:

- a velocidade de rotaçāo dos elétrons é maior que a velocidade de dexiva uE, isto é:

$$
u_{z q}=\omega_{e} r>-\frac{E_{r}}{B_{z}}
$$

- da expressaxio (3.18), sendo $p_{3}>0$ tem-se a condição:

$$
a>\omega_{i} B_{x}\left(1+\frac{\omega_{i}}{\Omega_{c i}}\right)
$$

onde da expressāo $(3.15) \alpha=-E_{y} / r$, tendo-se entäo

$$
u_{i \varphi}=w_{i r}<-\frac{\frac{E_{E_{x}}}{1+\frac{w_{i}}{\hat{a}_{z i}}}}{2}
$$

e os ions giram com uma velocidade menor que $\cdot E_{y} / B_{z}$.

Uma vez medidas $T_{i}, T_{e}$ e obtidos os perfis $\phi_{d}(r)\left(E_{r}=-d \phi_{s} / d r\right)$ e $n_{i}(r)=n_{e}(r)$ os valores de $\omega_{c}^{*}$ e $\omega_{i}$ podem ser obtidos da expressão (3.19). Os seguintes resultadow sāo obtidos com os perfis mostzados nas Figuras 3.4 - 3.7. Para o plasma de carbono: $\omega_{E}=E_{Y} /+B_{z}=1 \times 10^{5}$ $\mathrm{rad} / \mathrm{s}, \omega_{\varepsilon}=1,3 \times 10^{5} \mathrm{rad} / \mathrm{s}, \omega_{i}=7 \times 10^{4} \mathrm{rad} / \mathrm{s} e_{3}$ de acordo com teoria $\omega_{e}>\omega_{\varepsilon}>\omega_{i}$. Para o plasma de xaagnésio: $\omega_{E}=6,8 \times 10^{5} \mathrm{rad} / \mathrm{s}, \omega_{e}=7,7 \times 10^{5} \mathrm{rad} / \mathrm{s}$ e $\omega_{i}=4 \times 10^{5} \mathrm{rad} / \mathrm{s}$.

A medida direta da velocidade angular foi realizada utilizando-se duas sondas eletrostátícas colocadas na mesma posif̧ão radial mas, separadas por $90^{\circ}$ na direçăo azimoutal. 0 esquerna utilizado para esta medida está mostrado na Figura 3.8 .

A esseñntia do método consiste em observar a defasagem $\left(\Delta t_{f}\right)$ entre as oscilą̧öes nos sinais apresentados pelas sondas quando estão no potencial futuante. A defasagern surge por causa 


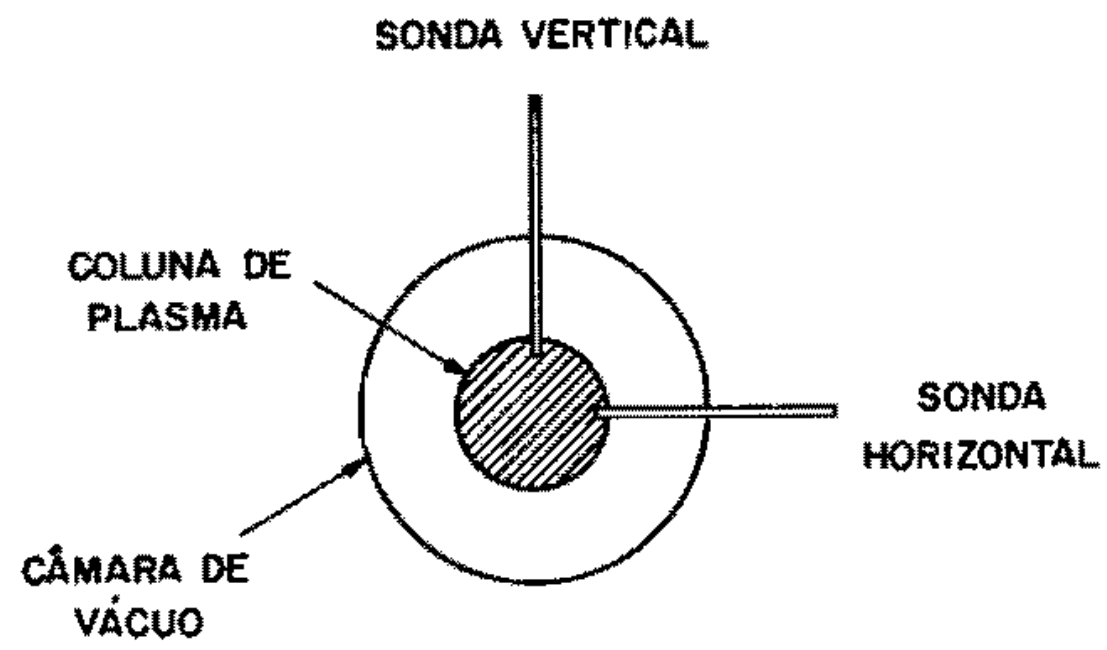

Figura 3.8. Esquema para medix a yelocidade angular utilizando-se duas sondas.

da rotaçāo da coluna de plasma, isto é, um determinado volume da coluna de plasma primeiro atinge urna das sondas e depois de um tempo $\Delta t_{z}$ atinge a outra sonda. O periodo (T) é igual a $4 \Delta t_{f}$, obtendo-se, entäo, para a velocidade angular, $\omega_{i}=\pi / 2 \Delta t_{i}$. As oscilaçōes também aparecem na corrente de saturaçäo de ions (por isso a associaçäo corn a velocidade angular dos

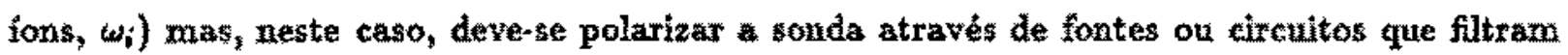
os sinais, o que aäo ocorre se as sondas estiverem futuando. A Figura $\$ .9$ mostra os sinais apresentados para o potencial flutuante durante todo o pulso da corrente a Figura 3.10 o sinal expandido em torno do tempo $t=12,5 \mathrm{~ms}$ da descarga, mostrando a detasagem $\Delta t_{f} \sim 7,5 \mu s$ entre os sinais. Os sinais mostrados sǟ para un plasma de magnésio $\operatorname{com} \mathrm{I}_{a}=1,5 \mathrm{kA}, \mathrm{B}_{z}=$ $0,1 \mathrm{~T}$ ena posiçẵo radial $\mathrm{r}=15 \mathrm{~mm}$.

Neste trabalho näo é feito nenhum estudo sobre a origem dessas flutuaçốes mas̆, pelo padrão apresentado, devem estar relacionadas a alguma oscilaţäo ben estabelecida. Algumas possíveis causas podem ser:

- alguma ostilaçäo relacionada com a descarga em arco que não a instabilidade de dobra, que deve estar estabilizada poís $\mathrm{B}_{z}>\mathrm{B}_{z \varepsilon}$;

- ondas de deriva; 


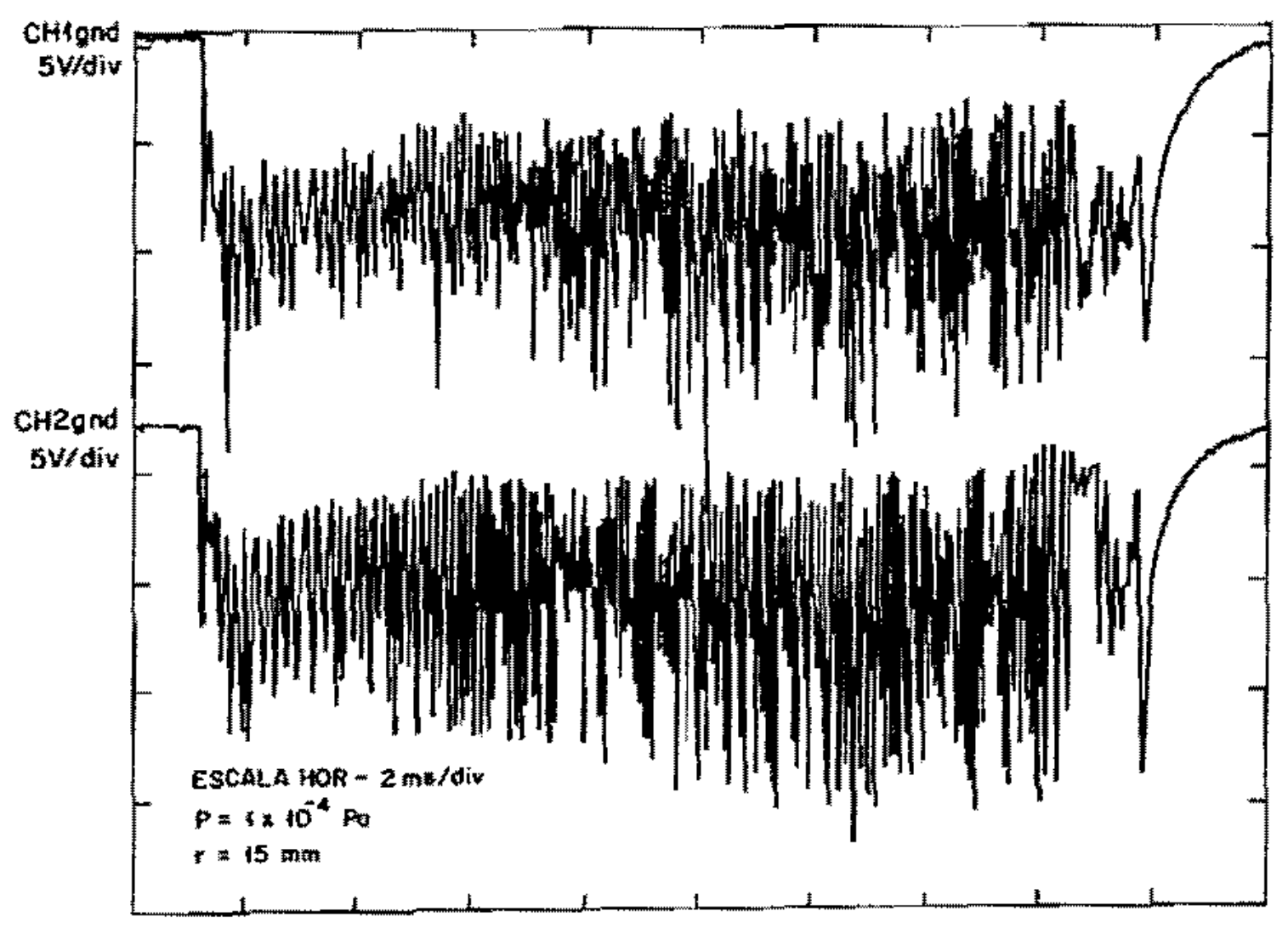

Figura 3.9. Sinais do potencial flutuanie apresentados pelas sondas durante o pulso de plasma. 


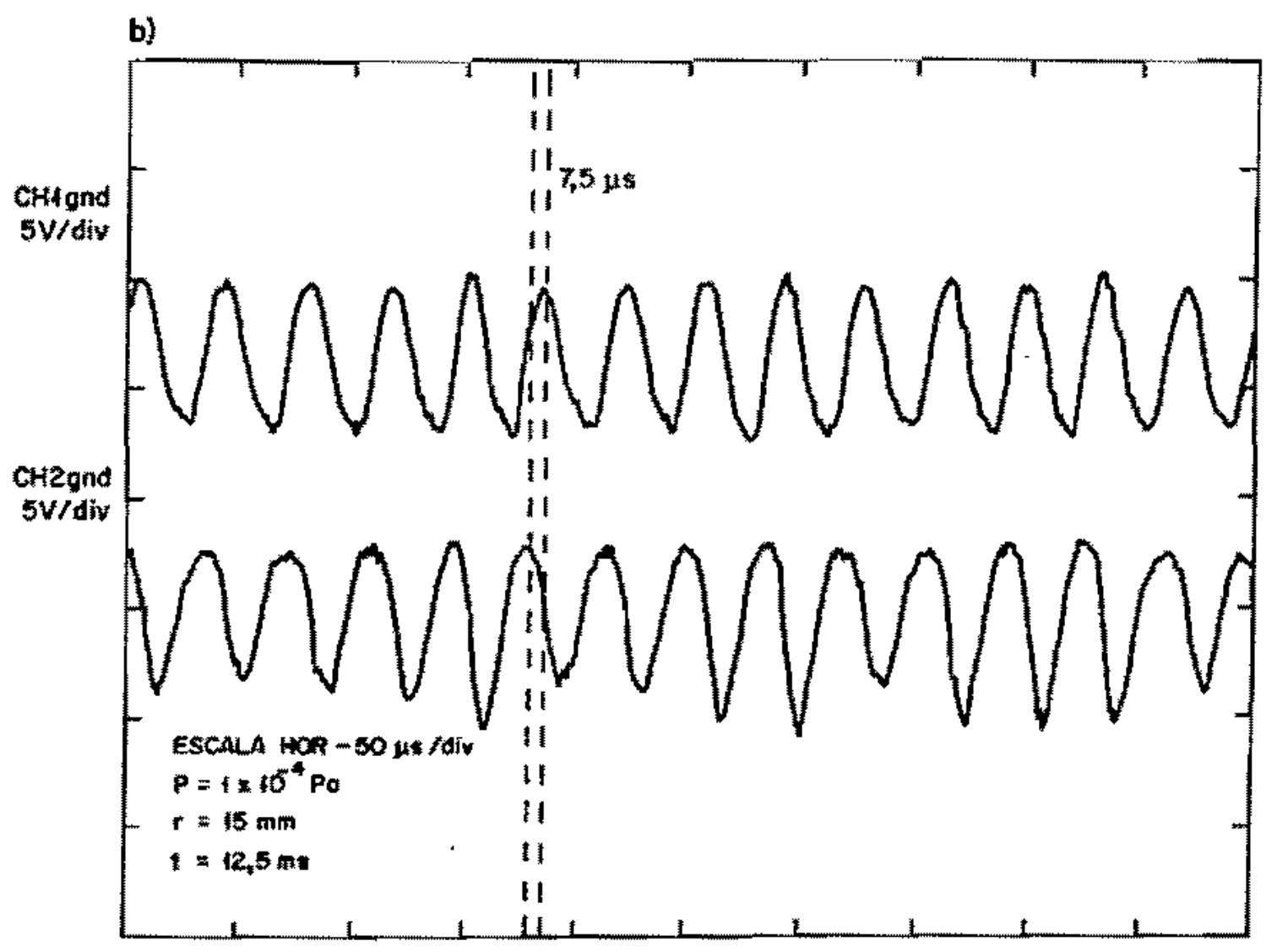

Figura 3.10. Sinaís da Fig. 3.9 expandidos em torno do tempo da descarga $t=$ $12,5 \mathrm{mus}$. 
- instabilidade que ocarre quando um fujdo de maior densidade está sobre um de menor densidade (instabilidade gravítacional ou Raylégh. Taylor). Este modo também ocorre quando wrn fivido condutor é suportado por un campo magnético contrs a gravidade, uma força centrifuga ou pressão térmica. No plasma em rotaçăo existe o campo de força centrifuga $\overrightarrow{g_{c}}=w^{2} r \overrightarrow{e_{r}}$ que faz o papel do campo gravitacional;

- instabilidade devido ressonăncia ciclotrönica que ocorre quando frequêrcia ín clclotrônica é um mültíplo de $\omega_{i}$, e

- Instabilidade de Buneman.

A determinaçäo da velocidade angular foi feita de tois modos diferentes a partir dos sinais das duas sondas. O primeiro modo consistiu em determinar a defasagem diretamente da tela do osciloscópio, como mostrado na Figura 3.10. No segundo, os sinais sä́n transferidos do osciloscópio para un microcomputador onde através de um programa, Apêndice $\mathrm{C}_{\text {, é feita a }}$ correlação entre os sinais e obtida a defasagern entre os mesmos. Este mátoto tem a vantagern da anמ̆lise de um maior número de períodos, e, portanto, de fonnecer resultados mais confizveis. No entanto, como os sinais possuem um padräo bem definido de oscllaçăo, a diferença entre os dois métodos nầ foi maior que $10 \%$. Os dados apresentados neste trabalho sta os obtidos atravế da correlaçäo dos sinats.

A Figura 3.11 mostra a evoluçăo temporal da velocidade angular para o plasma de magnésio $\operatorname{com} \mathrm{Y}_{z}=1,5 \mathrm{kA}, \mathrm{B}_{z}=0,1 \mathrm{~T}$ e $=15 \mathrm{~mm}$. Este resultado demonstra, mats uma vez, alidade da condỉ̧zăo de estado estacionário, $\partial / \partial t=0$.

Para comprovar que a coluna de plasma gira como um corpo rígido, foi medido o perfil radial da velocidade angular. A. Figura 3.12 mostra o resultado obtido para o plasma de magnếsio, com $\mathrm{I}_{a}=1,5 \mathrm{kA}, \mathrm{B}_{2}=0,1 \mathrm{~T}$ e $t=8 \mathrm{~ms}$. Tem-se $w_{i} \sim 2,5 \times 10^{5} \mathrm{rad} / \mathrm{s}$ para $\mathrm{r} \leq 25 \mathrm{~mm}, \mathrm{justificando}$ a coluna de plasma como umn corpo rígido em rotaçäo.

Os resultados das medidas direta de $\omega_{i}$ mostrados nas Fig 3.11 e 3.12 fornecem $\omega_{i} \sim 2,5 \times 10^{5}$ $\mathrm{rad} / \mathrm{s}$ ao passo que o resultado obtido com a expressä̌ $(3.19)$ e $\omega_{i} \sim 4 \times 10^{5} \mathrm{rad} / \mathrm{s}, \mathrm{mos}$ trando urna boa concordancia entre os resultados. 


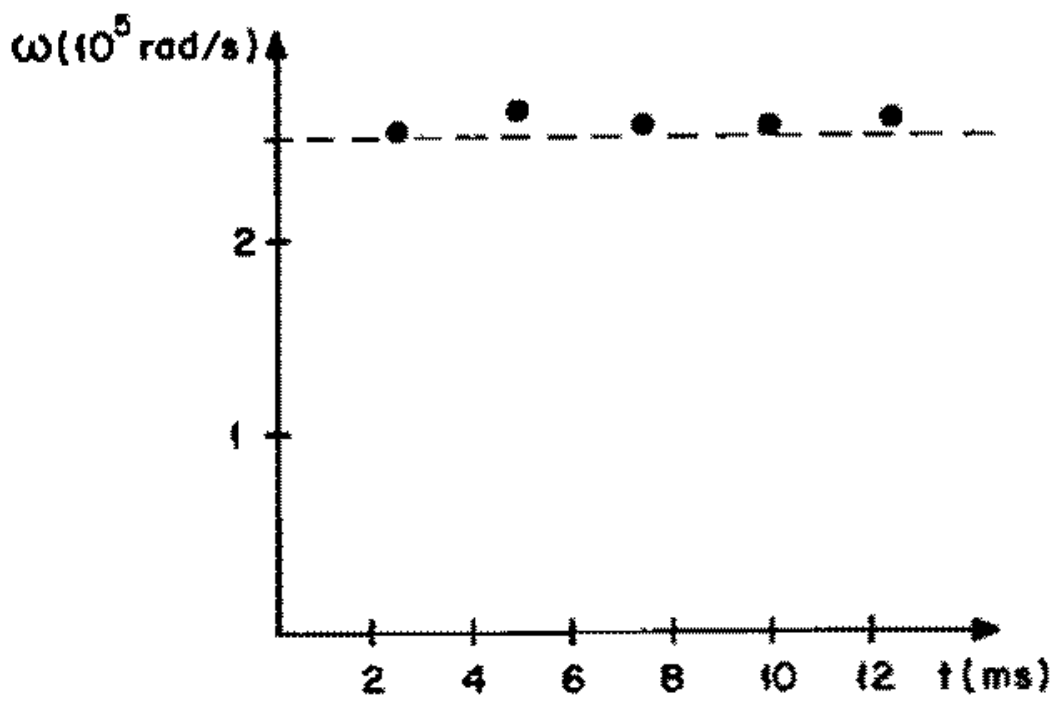

Figura 3.11. Perfil temporal da velocidade angulat no plasma de magnetsio com $I_{a}=$ $1,5 k A, B_{z}=0,1 T$ er $=15 \mathrm{~mm}$.

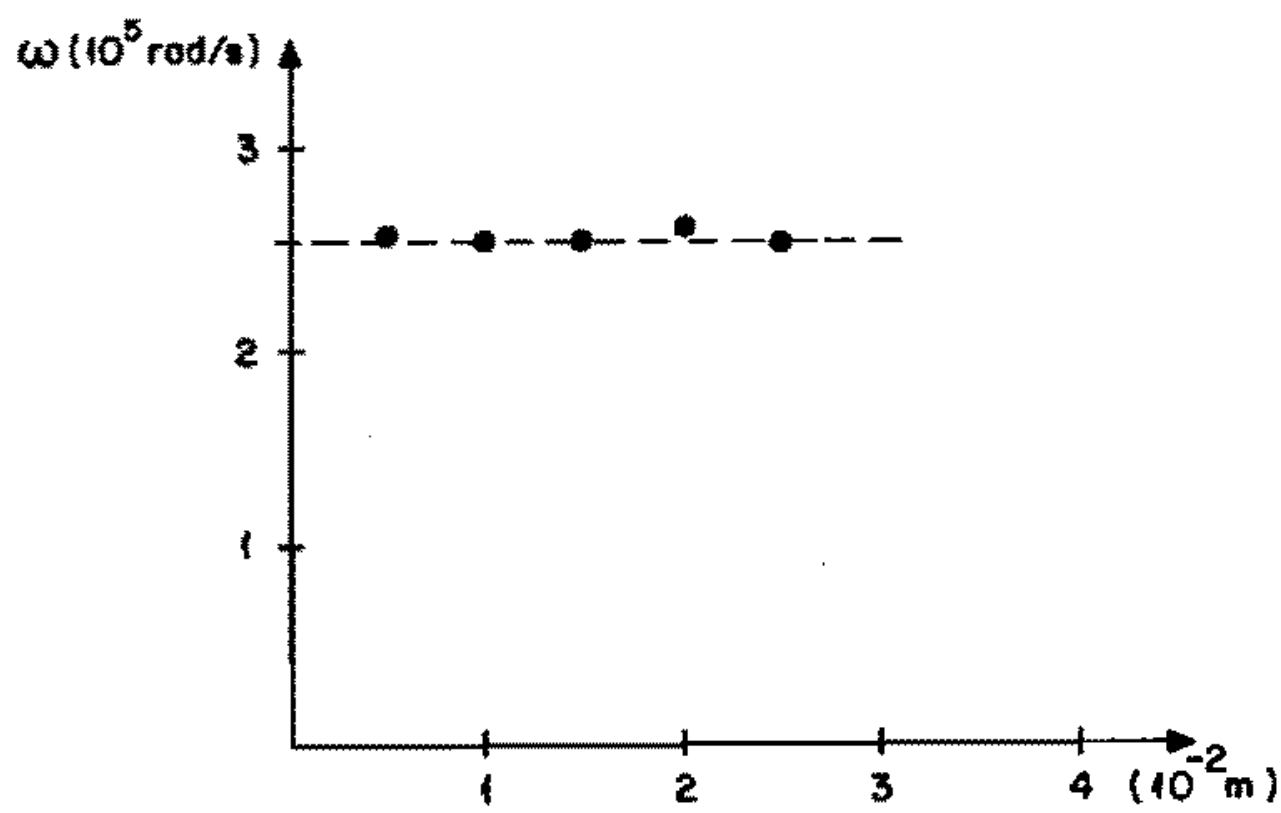

Figura 3.12. Perfil radial da velocidade angular para una coluna de plasma de magnésio. 


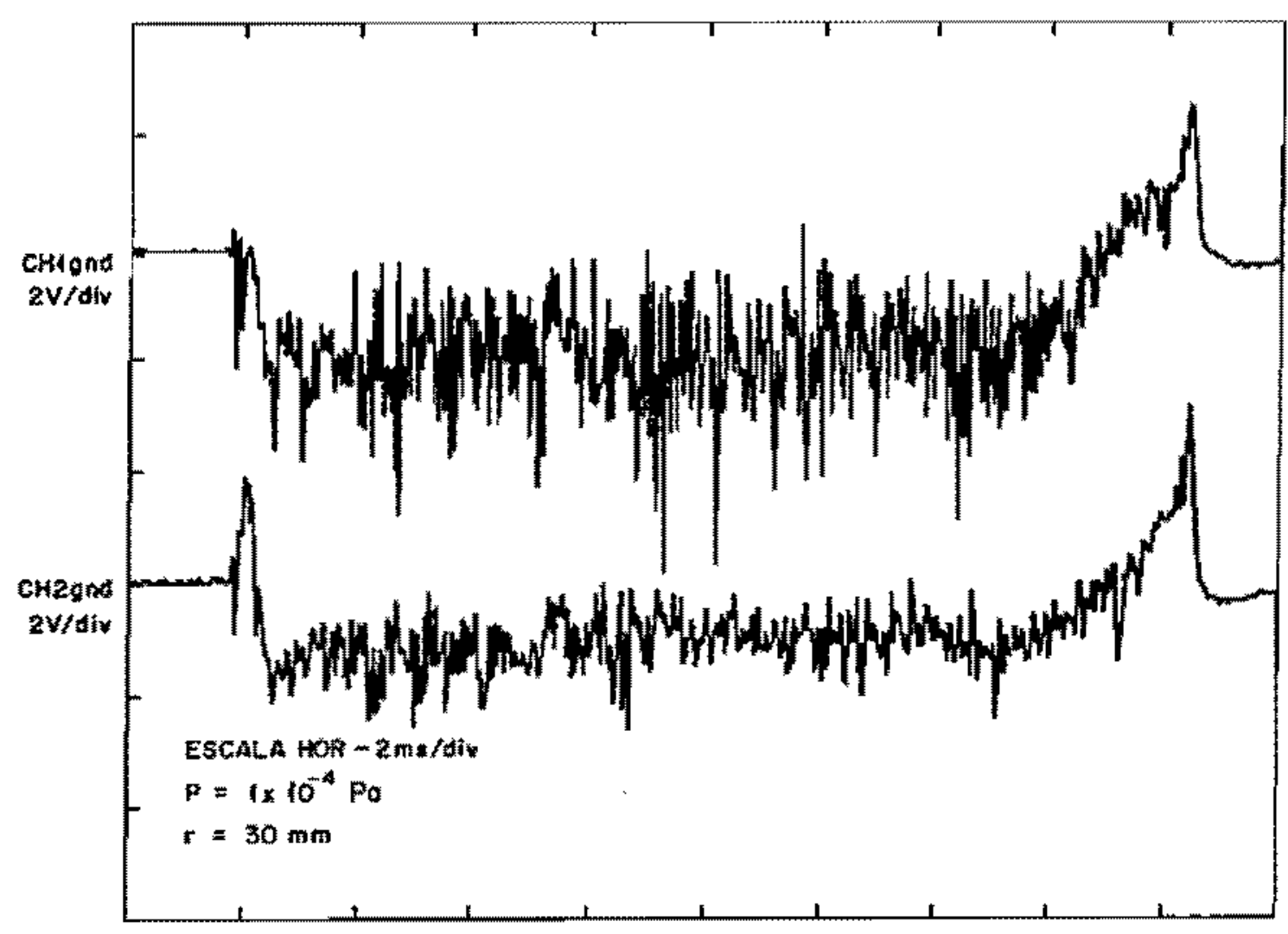

Figura 3.13. Plutuaçöes apresentadas pelas sondas para o raio $x=30 \mathrm{~mm}$.

Os dados indicam uma rotação de corpo rígido para $x \leq 25 \mathrm{~mm}$. Para $\mathrm{z}>25 \mathrm{~mm}$ os sinais das sondas näo apresentam mais as oscilaçöes regulares como as da Figura 3.10. As Figuraz 3.13 e 3.14 apresentam os sinais das sondas para $z=30 \mathrm{~mm}$ e $x=40 \mathrm{~mm}$ respectivamente para 0 plasraa de magnésio $\operatorname{com} \mathrm{L}_{\alpha}=1,5 \mathrm{kA}$ e $\mathrm{B}_{z}=0,1 \mathrm{~T}$ e na Figura 3.15 os sinais para $*=30 \mathrm{~mm}$ estăo expandilos em torno de $=12,5 \mathrm{~ms}$, onde pode-se observar (comparar com a Figura 3.10) uma difitil correlação entre os sinais. Neste taso, o método baseado nos sinais das sondas para determinar wiă ne aplica.

$O$ potencial futuante é $\phi_{f} \leq 0 \mathrm{~V}$ para $\mathrm{r}=30 \mathrm{~mm}$ como pode ser visto na Figura 3.13 . O potencial de plasma é $\phi_{t}=\phi_{t}+4,3 \mathrm{~T}_{t}(\mathrm{eV})$, o que quet dizer que para $\mathrm{r}>25 \mathrm{~mm}$ o potencial de plasma é positivo indicando um possível excesso de cargas positivas pars raios maiores, formando-se á uma bainha de fons. Os dados apresentados para o perfil radial da temperatura (Fig, 3.2), do potencial de plasma (Fig 3.5), da densidade de íns (Fig. 3.7), da velocidade angular (Fig. 3.12) 


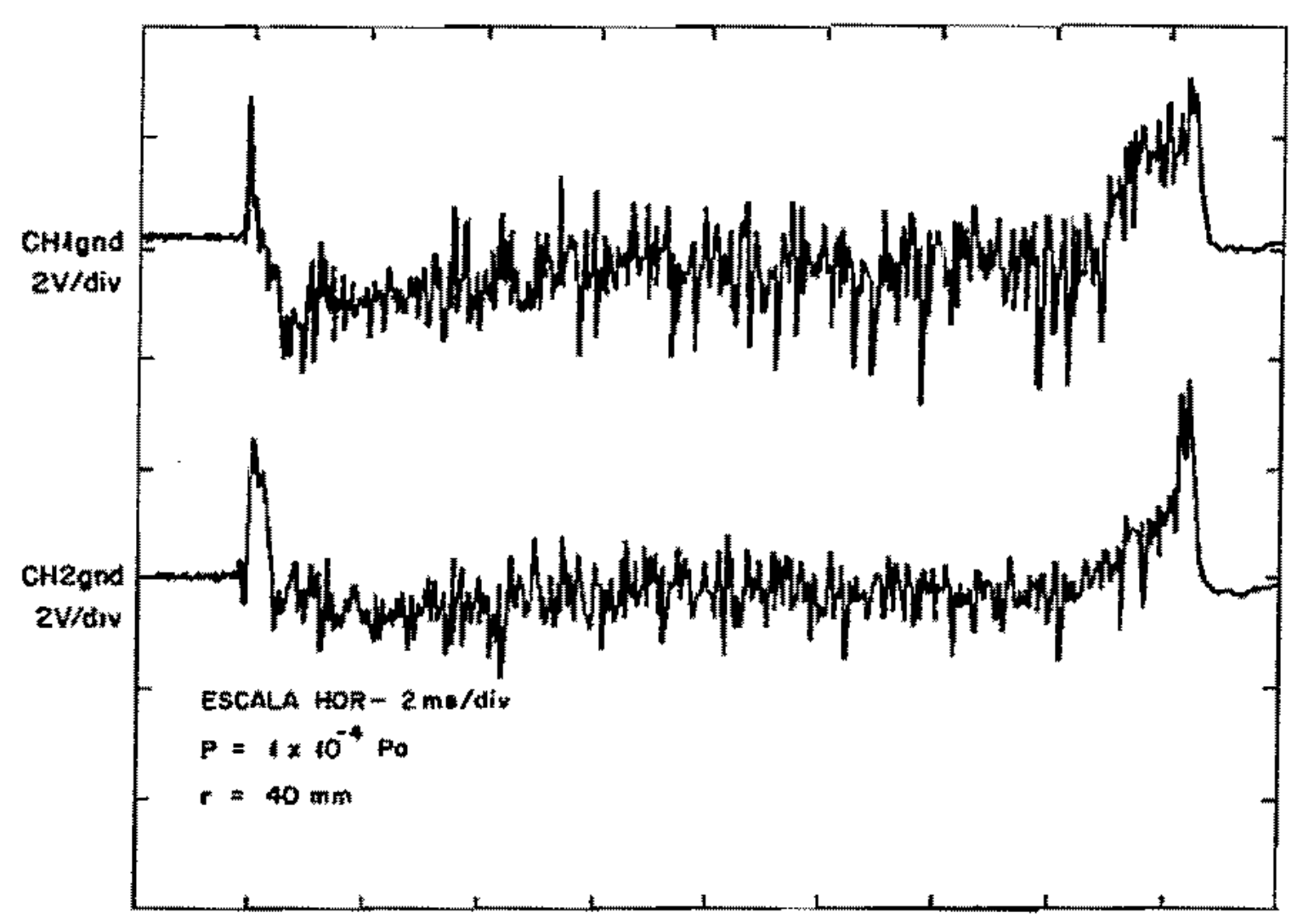

Figura 3.14, Flutuaçöes apresentadas pelas sondas para o raio $\mathrm{x}=40 \mathrm{~mm}$. 


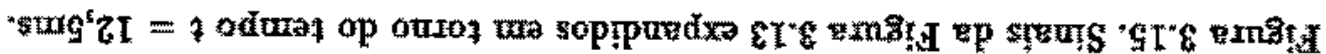

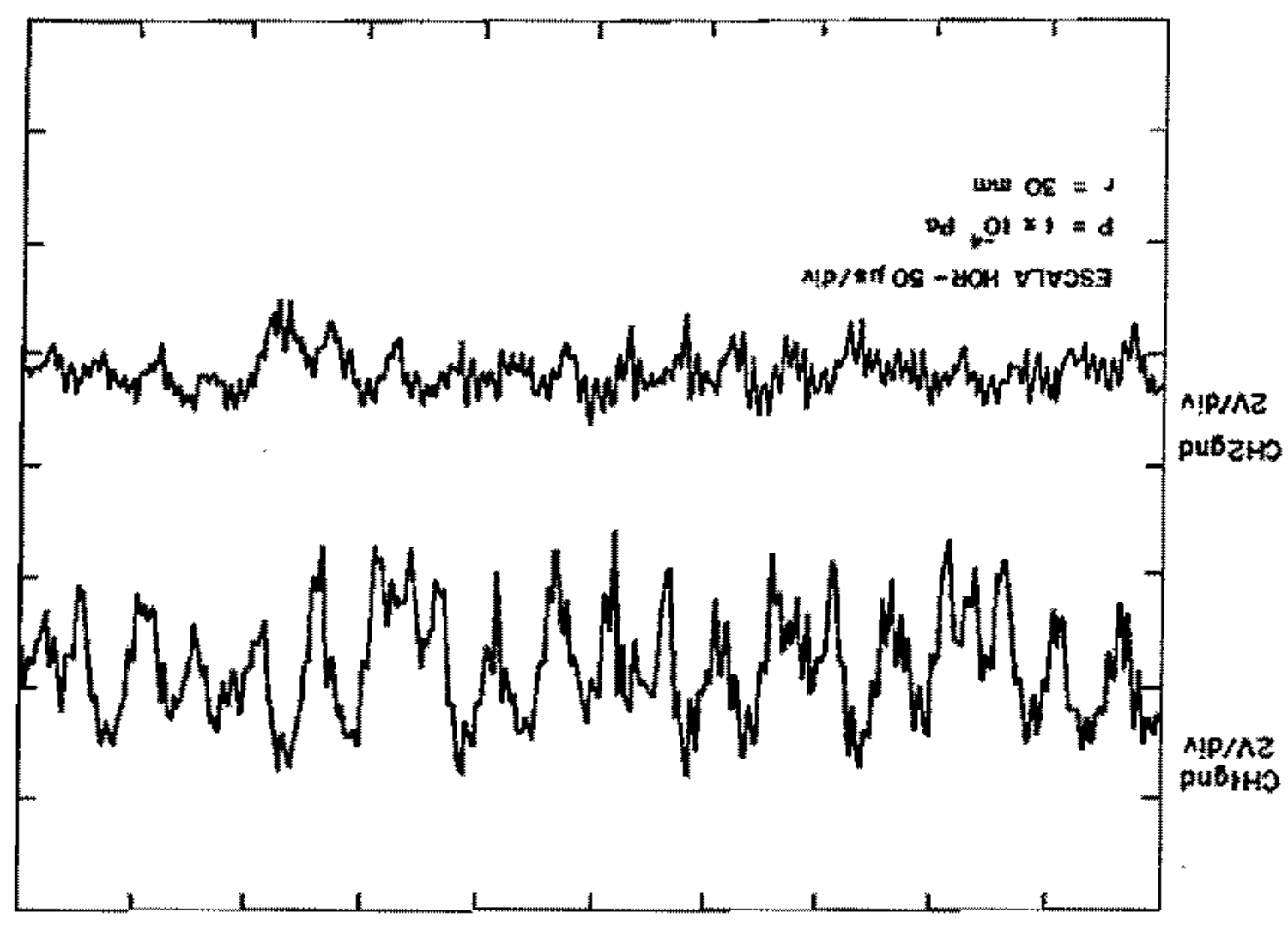


e das flutuaçöes para $x=30 \mathrm{~mm}$ (Fig 3.15 ), indicam que a hipótese de rotaçăo da coluna como um corpo rígído é vatida em um plasma de magnésio con $\mathrm{L}_{c}=1,5 \mathrm{kA}$ e $\mathrm{B}_{z}=0,1 \mathrm{~T}$, somente para I $\leq 25 \mathrm{~mm}$. É importante ressaltar que o perfl parabólico para o potencial e perfil Gaussiano para a densidade seguem da hipótese da coluna de plasma estar girando como um corpo rigído. Para $r>25 m n_{z}$ tem-se um plasma de baixa densidade e temperatura, provavelmente girando com uma yelocidade menor que a coluna central.

Anterlormente a este trabalho, quando o pulso de corrente na PCEN tinha forma mostrada na Figura 2.14, foi realizado o estudo da variaçä́o da velocidade angular com o campo magnético para vários plasmas [77]. $O$ resultado destas medidas sāo mostrados na Figura 3.16. Observa-se que a velocidade angular aumenta com o aumento do campo magnático e para um dado campo, decresce com a aumento da massa atômica do catodo utilizado. 0 comportamento observado da velocidade angular para campos acima de 0,2T pode ser explicado como segue. $O$ aumento do campo magnético confina cada vez mais a coluna de plasma diminuindo-se, assim, o raio da coluna. Com isto, para campos acima de $0,2 \mathrm{~T}$, as sondas jả estāo fora da coluna central, isto é, na borda do plasran (apresentando um padrẵo de flutuaçāo como mostrado ra Figura 3.15), e consequentemente uma velocidade angular menor.

Para o plasma de magnétio com $I_{w}=1,5 \mathrm{kA}, B_{x}=0,1 \mathrm{~T}$ os componentes das velocidades dos ions apresentam os seguintes valores: $u_{i z}=1 \times 10^{4} \mathrm{~m} / \mathrm{s}$ e $u_{i \varphi}=\omega_{i} \mathrm{r}=5 \times 10^{3} \mathrm{~m} / \mathrm{s} .0$ componente $u_{i p}$ pode ser avaliada utilizando-ze a lei de Ohm generalizada

$$
\begin{array}{r}
\frac{1}{\epsilon_{0}\left(\omega_{p e}^{2}+\omega_{p i}^{2}\right)} \frac{\partial \vec{J}}{\partial t}=\vec{E}+\vec{a} \times \vec{B}-\eta \vec{J}+ \\
+\frac{1}{e p_{0}}\left[m_{i} \nabla p_{e}-m_{e} \nabla p_{i}-\left(m_{i}-m_{e}\right)(\vec{J} \times \vec{B})\right]
\end{array}
$$

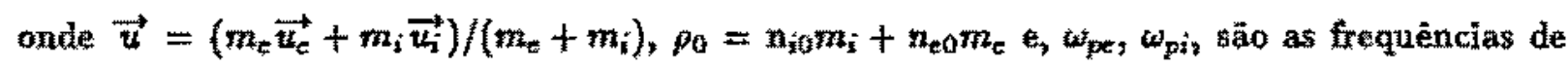
plasma dos elétrons e ions, respectivamente. Com as simplificaçōes, $\partial / \partial t=0, m_{c} / m_{i} \ll 1$, supondo que $J_{x}=0$ e lembrando que $E_{\varphi}=0, \nabla_{p_{e x}} \nabla_{p_{i}}$ só tem cornponente radial, a componente $\varphi$ da lei de Ohm generalizada fornece

$$
u_{i r}=\frac{\eta_{\varphi}}{B_{z}}
$$

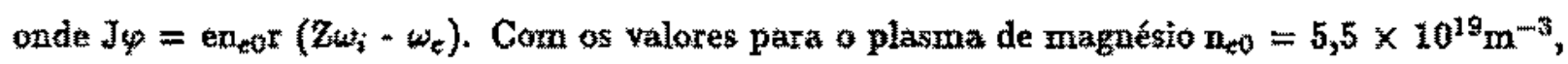
$\omega_{i}=4 \times 10^{5} \mathrm{rad} / \mathrm{s}_{2} \omega_{\mathrm{e}}=7,7 \times 10^{5} \mathrm{rad} / \mathrm{s}, B_{x}=0,1 T, \eta=6 \times 10^{-5} \mathrm{\Omega} . \mathrm{ma}, \mathrm{Z}=1,5 \mathrm{e}=20 \mathrm{~mm}_{3}$ 


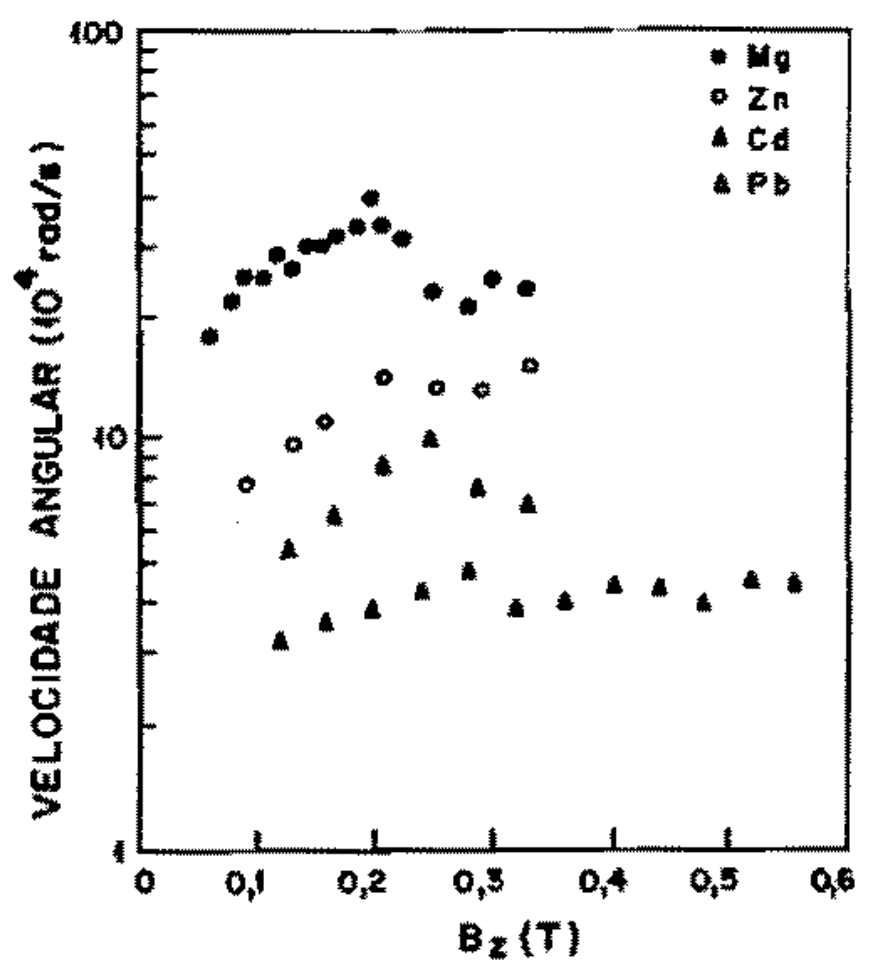

Figura 3.16. Velocidăe angular ern funçäo do campo magnético axial para os plasmas de magnésio, zinco, cảmio e chumbo para $\mathrm{x}=20 \mathrm{~mm}$ com $I_{a}=0,9 \mathrm{kA}$ (ralor de pico)[?7]. 


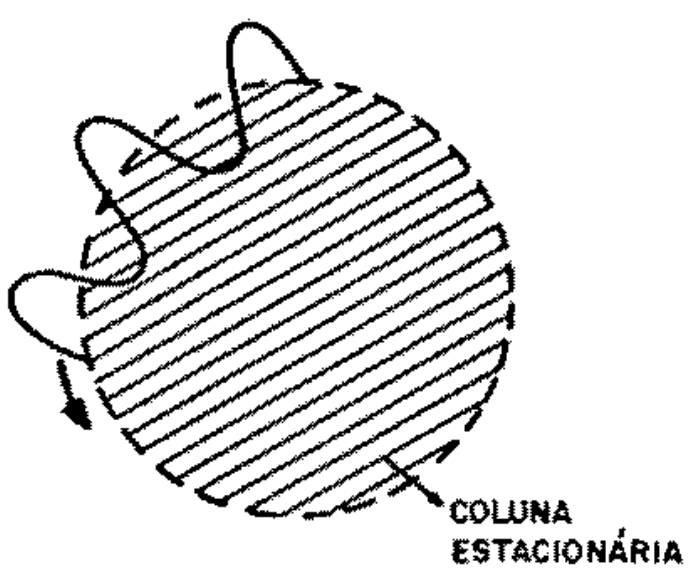

(a)

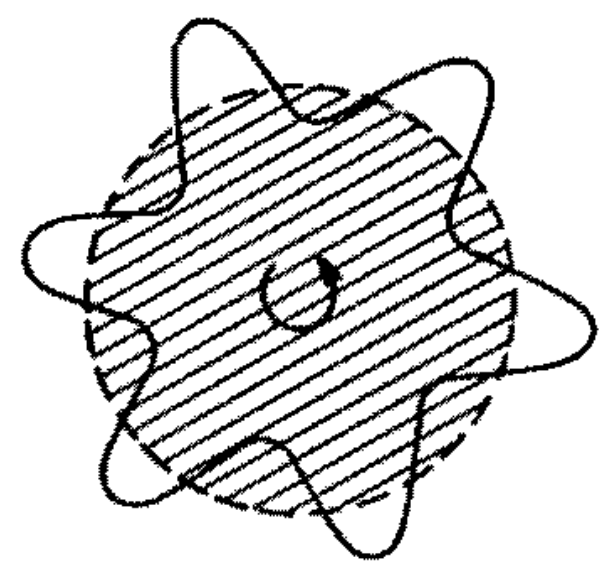

(b)

Figura 3.1\%. Duas possibilidades para as oscilaçöes apresentadas pelas sondas a) coluna estacionária e a onda visjando ao redor da coluna e b) a coluna girando e onda "travada" solbe a coluna.

obtem-se $u_{i r}=20 \mathrm{~m} / \mathrm{s}$. Desse moda, os componentes de velacidades obedecen a desigualdade $\mathbf{u}_{i z}>\mathbf{u}_{i q} \gg \mathbf{u}_{i \mathrm{r}}$

O método de medida da velocidade angular baseada na defasagem dos sinais das sondas pode gerar algumz dúvida. As oscilaçöes podem estar se propagando nurn plasma estacionário Fig. $3.17(a)$ on serem mados "travados" ns coluna de plasma que gira Fig.3.17(b).

Como os modos que se propagam num plasma estacionário o fazem com a velocidade de deriwa que depende de $\nabla p$, e cono o campo radial que pöe a coluna em movimento (caso b) também é proporcional a $\nabla p$, näo hâ como distinguir com sondas qual te mecanismo que realmente está ocorrendo. Uma determinaçäo inequívoca da velocidade de rotaçäo da coluna teria que ser feíta por por exemplo, métodos óticos ( deslocamento de Doppler em linhas de $\mathrm{Mg}$ ). Os resultados obtidos a partir dos perîs radiais da densidade, temperatura, campo elétrico da expressão teórica praticamente confirmam o mesmo valor daquele obtido da defasagern dos simats. Por outro, lado a medida da velocidade angular utilizando-se interferometria Fabry-Perot apresenta boa concordancia com a obtida a partir da defasagem entre os sinais das sondas [78]. Ema resumo, as medidats diretas com a ntilizaçâo de sondas é confiảvel, embora, esteja limitađa a existêneia de um padräo de oscilaçäo bem definido. 


\subsubsection{Fator de separaç̄o}

O fator de separaçäo ( $\alpha)$ entre duas espécies de fots ( $\mathbf{j}$ e $\mathrm{k}$ ) é definido como:

$$
\alpha(r)=\frac{n_{j}(r) / n_{k}(r)}{n_{j}(0) / n_{k}(0)}
$$

Tendo as fons a mesma pelocidade angular e a mesma temperatura $e$, ainda, se estiverem no

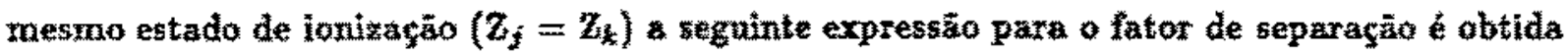

$$
\alpha(r)=\exp \left[\frac{\left(m_{j}-m_{k}\right) \omega_{i}^{2} r^{2}}{2 k_{B} T_{i}}\right]
$$

Se os estados de ionizaçāo sāo diferentes $\left(\mathbf{z}_{i} \neq \mathbf{z}_{k}\right)$ tem-se:

$$
\left.a(r)=\exp \left(\frac{m_{j}}{z_{j}}-\frac{m_{k}}{Z_{k}}\right) \frac{w_{i}^{2} r^{2}}{2 k_{B} T_{i}}\right)
$$

A expressăo (3.26) é a mesma que a da centrífuga mecânica, mas tanto $\omega_{i}$ como $\mathfrak{T}_{i}$ sắ muito maiores na centrifuga de plasma iniciada por arco no vácuo. Muitas vezes fala-se em termos do enriquecimento obtido dado em porcentagem, a inqé̉s do fator de separaçāo. $O$ enriquecimento em porentagem pode see obtido am termos do fator de separaçio como (o-1) $\times 100 \%$.

Para a medida do fator de separaçäo foi utilizado um espectrồmetro de massa do tipo quadrupolo elétrico. As medidas foram realizadas utilizando-se o magnésio como catodo, tuja composiç̧̌so natural e. ${ }^{24} \mathrm{Mg}(78,8 \%) ;{ }^{25} \mathrm{Mg}(10,1 \%)$ e ${ }^{26} \mathrm{Mg}(11,1 \%)$. O fator de separaçäo foi medido em relaçâo ao isốtopo ${ }^{24} \mathrm{Mg} \mathrm{e}_{3}$ no que segue $\alpha_{25}$ é o fator de sepatação do isototopo ${ }^{25} \mathrm{Mg}$ com relaçăo ao ${ }^{24} \mathrm{Mg} \mathrm{e}_{2} \alpha_{26}$ é o do isótopo ${ }^{25} \mathrm{Mg}$ relativo ao ${ }^{34} \mathrm{Mg}$. $\mathrm{O}$ magnésio foi escolhido por apresentar maior velocidade angular, o que em principio deve resultar en un fator de enriquecimento mais elevado, facilitando as medidàs. Por outro lado, corno são trēs isótopos, isto representa ums dificuldade maior para a obtençăo do espectro de massa. 
Durante as medidas do fator de separaçăo com o espectrômetro de massa várias dificuldades surgiram, salver:

- $O$ instrumento utilizado tem varredura temporal do espectro ta baixa quanto I u,m.a./ms (u.m.a = unidade de massa atômiea) e uma varredura em massa de $\Delta m=4$ u.m.a., serìa suficiente para se obter o espectro do magnésio. A princípjo em $\Delta t=4 \mathrm{~ms}$ seria obtido o espectro, ou seja, em um tempo menor que o tempo da descarga $(\Delta t \sim 16 \mathrm{~ms})$. A fentatiza de se obter o espectro dessa maneira foi frustada pois, $o$ instrumento não conseguia resolver as picos de massa do magnésio com a varredura rápida do espectro. Isto obrigon a fazer as medidas ponto a ponto, isto é, o instrumento era ajustado a uma determinada massa para cada pulso de plasma, o processo sendo continuado até a complementação do espectro, $O$ sinal do espectrômetro para cada massa selecionada era armazenado no mierocornputador. A Figura 3.18 mostra um sinal típico da corrente de plasma e do espectrômetro para uma massa fixa.

- Foi observado que o ganho da multiplicadora de elétrons do instrumento apresentava uma variaçăo muito grande de pulso para pulso de plasma no ínicio da operação. Esta variaçäo dỉninuia (embora sempre o ganho decrescia) com o número de pulsos de plasma. Para minimizar este efeito, antes da tomada de dados uma série de $\sim 50$ pulsos era realizada para se obter uma certa estabilização do sinal. Esta variaçāo cstá associada, em boa parte, aos gases absorvidos nas pazedes da multiplicadora de elétrons.

- Descobriu-se que o centro da coluna de plasma estava deslocada do centro geométrico da câmara. Isto impossibilitou de se posicionar o espectrômetro exn $x=0$ (da coluna), no qual da expressāo teórica (3.26) abtem-șe $\alpha=1$. A medida experimental em $\mathrm{r}=0$ (da coluna) deveria dar un valor muito próximo de $\alpha=1 \mathrm{e}$, isto, de certa maneira, é uma comprovaçä́o de que esta tudo correto com o processo de medida. A posiçắo da colnna de plasma fó medida através da deposị̂äo de magnésio deixada no flange depois de uma sếrie de no 25 pulsos. $O$ centro da coluna foi determinado estando na posiçäo radial coma coordenadas ( $x_{0}$ Yo) $=(-15 \mathrm{~mm}, 10 \mathrm{~mm})$, na posiçăo axial em que se encontra o espectrônetro. As posiçōes radiais em que foram feitas as medidas com o espectrometro foram corrigidas relativo a este centro. A determinaçäo do centro da coluna năo é mưto precisa pois, os contomos

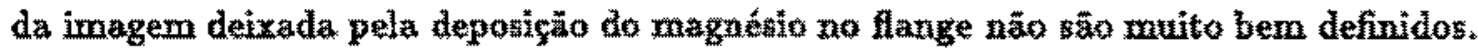




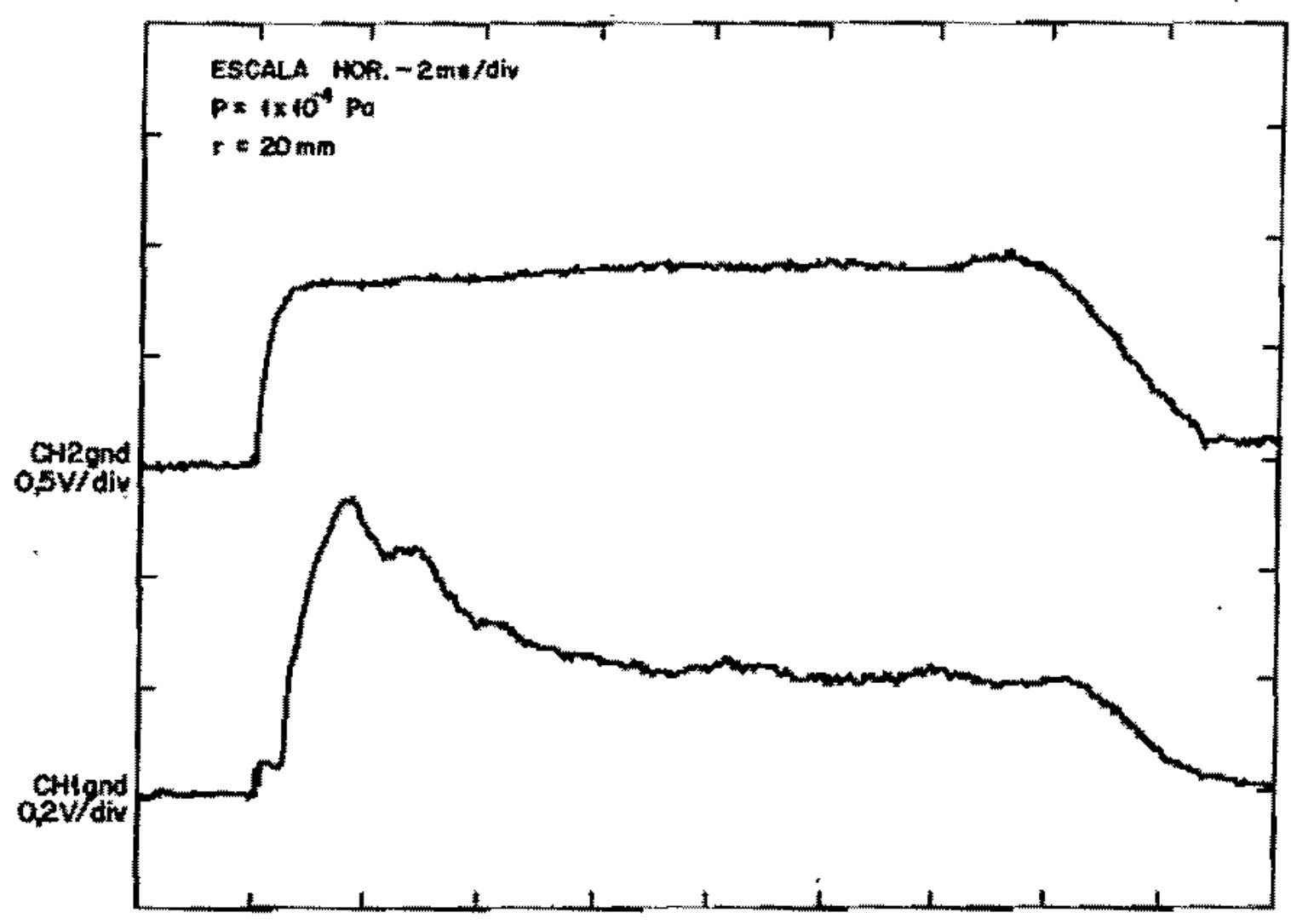

Figura 3.18. Sinal do pulso de corrente e do espectrômetro de massa para urma massa fixa. 
- Como as medidas da temperatura, potencial de plasma, densidade e velocidada angular jấ indicaram, a coluna de plasma de magnésio é fina, isto $\varepsilon, r \leq 30 \mathrm{~mm}$. Para uma variaçäo na posiçắo radial do espectrómetro de $\sim 10 \mathrm{~mm}$, poucos pontos podem ser obtidos para o perfil radial do fator dé separação.

O processo fe medida nestas circunstäncias consistiu em:

- observar o intervalo no qual o espectrômetro apresentava o sinal devido ao magneésio, isto $\dot{e}_{\text {, de }} \sim 23$ u.m.a. a $\sim 27$ u.m.a.

- dividir este intervalo em 40 massas diferentes, concentrando um maior númato de pontos em torno dos pícos e, para cada massa, um total de 5 pulsos de plasma foi dado nas mesmas condiçổes para thus de média.

- identificax onde ocorriam os picos ${ }^{24} \mathrm{Mg},{ }^{25} \mathrm{Mg} \mathrm{e}^{25} \mathrm{Mg}$.

- para dìminuir os efeitos da yariação do ainal de pulso para pulso, os sinaís das massas em torno dos picos eram obtidos primeiro, numa sequência de ida e volta, até seremn completados os cinco pulsos para cada massa. Por exemplo, fixando-se inicialmente a massa em 23,9 u.m.a., dava-se o pulso de plasma e o sinal do espectrömetro era transferido para o mierocomputador. Fin seguida, a massa era fixada em 24,9 e depois em 25,9 , inciando-se entāo a volta $(25,9 ; 24,9 ; 23,9)$. A sequência de ida e volta era continuada até se completar os cinco pulsos para estas massas, passsando-se entäo para outras massas por exemplo $(24,1,25,1$ e 26,1$)$.

Para abtençăo de urn espectro foram necessários 200 pulsos de plasma para cada posiçào radial (e struando-se $\sim 50$ pulsos para conditcionamento, o total é $\sim 250$ pulsos). Todos os pulsos foram armazenados no microcomputador, onde, com a ajula de um prograrna, Apếndice $D$, foi feito um ajuste de tal maneira a retratar o mais fielmente possivel o espectro de massa do maznésio a

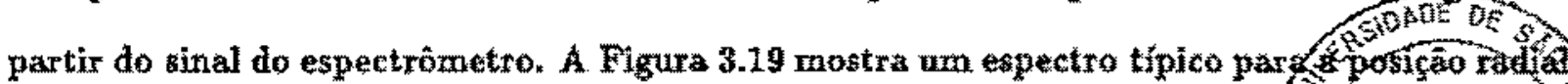
$t=10 \mathrm{~mm}$ e no tempo $\mathrm{t}=8 \mathrm{~ms}$.

O fator de separaçäo é obtido a partir dos valores dos pícos da curva ajust

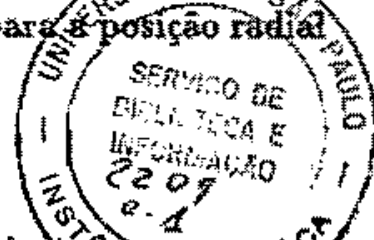
experimentais, conforme a definiçä́o dada pela expressão (3.25). Para a obtençấo do perfi 


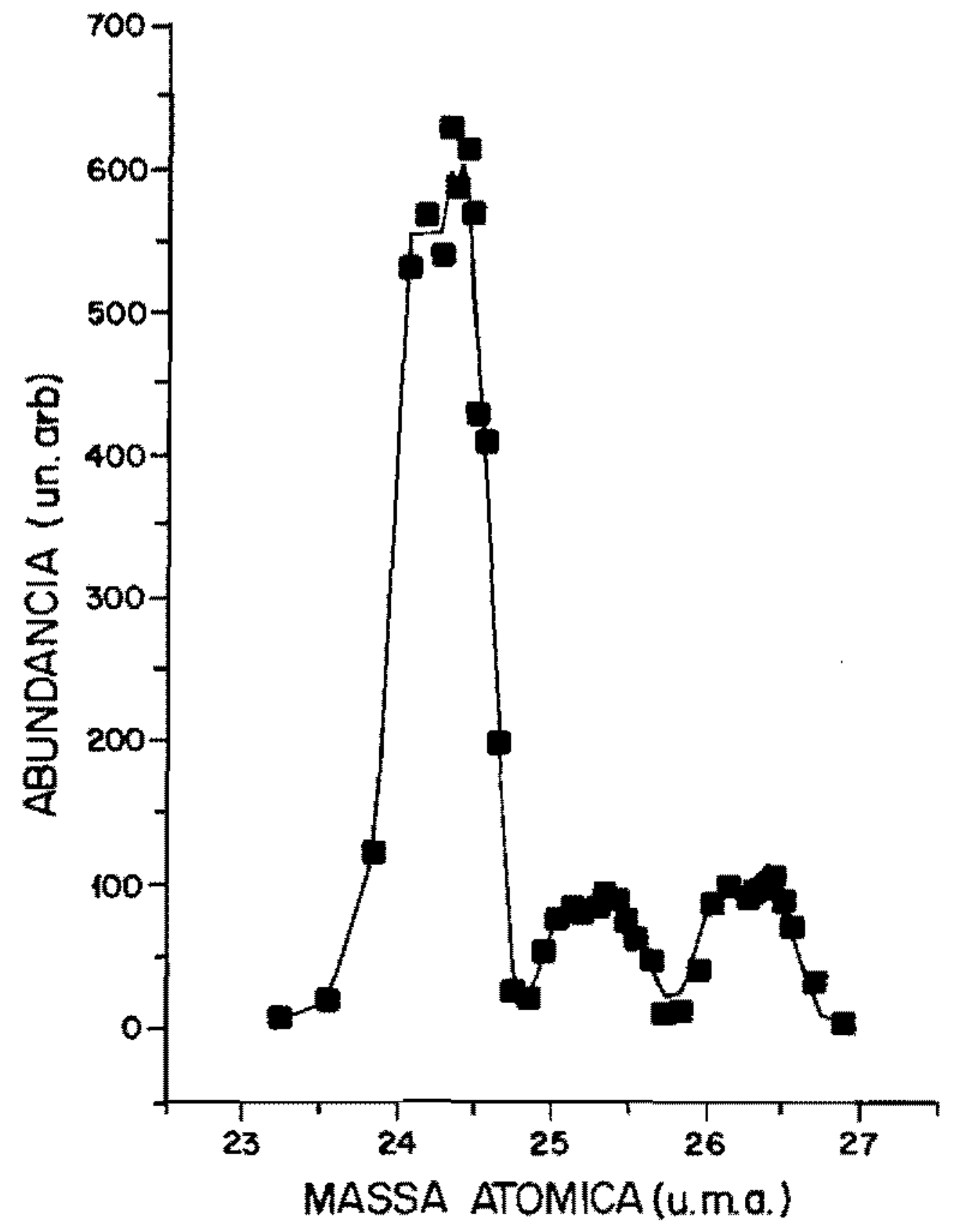

Figura 3.19, Espectro de massa obtido e o melhor ajuste aos pontos experimentais, $r=10$ mon et $=8 \mathrm{~ms}$. 
temporal do fator de separaçāo, fol feito o espectro de massa entre os teropos $t=2 m s$ e $t=$ $14 \mathrm{~ms}$ da descarga em inter valos $\mathrm{At}=1$ ros. Com a finalidade de minimizkr o efeito das flutuaçôes que porventura ocorram no sinal do espectronetro de massa durante o pulso de plasma, foi feíta uma média do sinal em torno dos tempos escolhidos para o perfil temporal. A Figura 3.20 mostra o perfil temporal do fator de separaçāo onde $\mathrm{l}_{a}=1,5 \mathrm{kA}, \mathrm{B}_{x}=0,1 \mathrm{~T}$ e $\mathrm{r}=10 \mathrm{~mm}$. $\mathrm{Da}$ expressão 3.26 pode ser mostrado que $\alpha_{26}-1 * 2\left(\alpha_{25}-1\right)$, o que é verificado como pode ser visto na figura. Observs"se, tambêm, que o fator de separação näo varia muito durante a descarga.

As Figuras 3.21 e 3.22 mostram o perfil radjal para o valor médio do fator de separaçäo tomado entre os instantes $t=4 \mathrm{~ms} t=14 \mathrm{~ms}$ do pulso de plasma. Juntamente com os dados experimen* tais duas tentativas de ajuste säo mostradas utilizando-se os valores medidos da temperatura (supondo $T_{i}(r) \sim T_{e}(r)$ ), da velocidade angular $w_{i}=2,5 \times 10^{5} \mathrm{rad} / \mathrm{s}$ (obtida da defasagem dos sinais da sonda), $\omega_{i}=4 \times 10^{3} \mathrm{rad} / \mathrm{s}$ (obtida da expressü̃o 3.19) e a expreștōo teórica 3.26. Para a temperatura foi considerado o perfil mostrado na Figura 3.2 , onde $T_{i} \sim T_{e} \simeq 3$ eV para $x$ $>15 \mathrm{~mm}$. Um melhor ajuste ocorre quando se supốe $\omega_{i}=4 \times 10^{5} \mathrm{rad} / \mathrm{s}$. A falta de am bom ajuste pode näo ser só devido às dificuldadea em se obter o fator de separaçăo. Na posiçẫo en que o espectrômetro está instalado (na extremidade da cẳmara) o campo magnético é muito baixo cono pode ser visto na Figura 1.8. A contequência disto deve ser uma abertura grande da coluna de plasma, provavelmente destruindo o perfil exponencial como previsto pela expressão 3.26, que foi deduzida considerando $B_{z}=$ constante. Ao supor $\omega_{i}=\times 10^{5} \mathrm{rad} / \mathrm{s}$, o fator da separaçäo mediuto para $r=36 \mathrm{~mm}$ fica murto abaixo da curva. Isto pode ser explicado das conclusöes anteriores onde para as pesiçōes tadiais $\mathrm{r}>25 \mathrm{~mm}$, o espectrômetro deve estar $\mathrm{da}$ coluna central do plasma.

Como no caso da velocidade angular, o efeito do campo magnético no fator de separaçāo foì estudado anteriormente a este trabalho [79] e o resultado está mostrado na Figura 3.23 . O fator de separação cresce com o aumento do campo magnético no intervalo $0,1 \cdot 0,2 \mathrm{~T}$ como era de se esperar da expressän 3.26, pois, como mostrado nus Figuras 2.25 e 3.16 , o aumento do campo magnético nāo influencia a temperatura mas, aumenta a velocidade angular. $O$ decréscimo do fator de separaça para $B_{z}>0,2 T$ tem uma explicą̧äo similar a dada para o decréscimo da velocidade angular com o anmento do carnpo. Com o aumento do campo há um maior confinamento da coluna de plasma e, como consequếncia, o espectrômetro de masssa fica fora da 


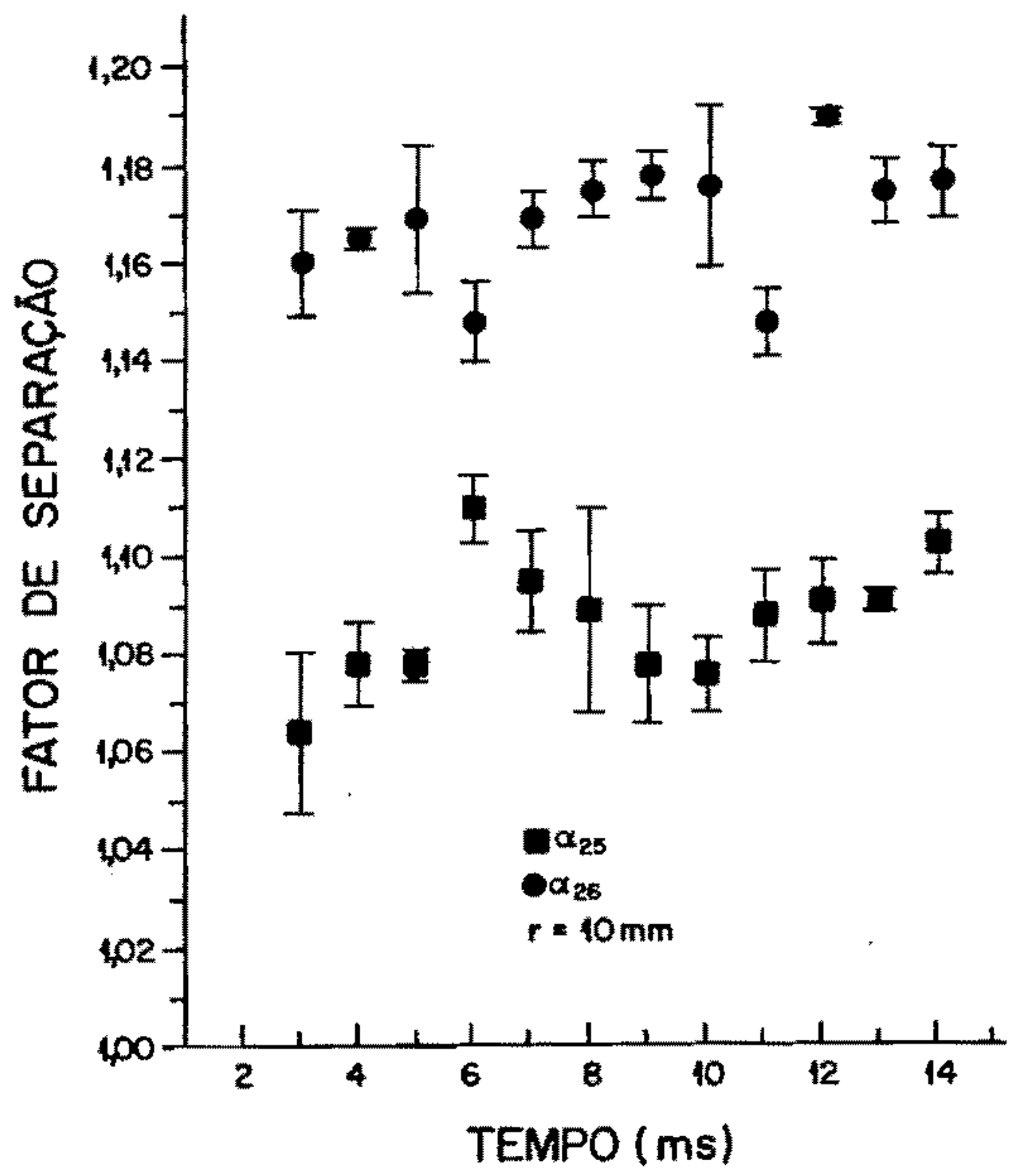

Figura 3.20. Fator de separação como função do tempo, $t=10 \mathrm{~mm}$. 


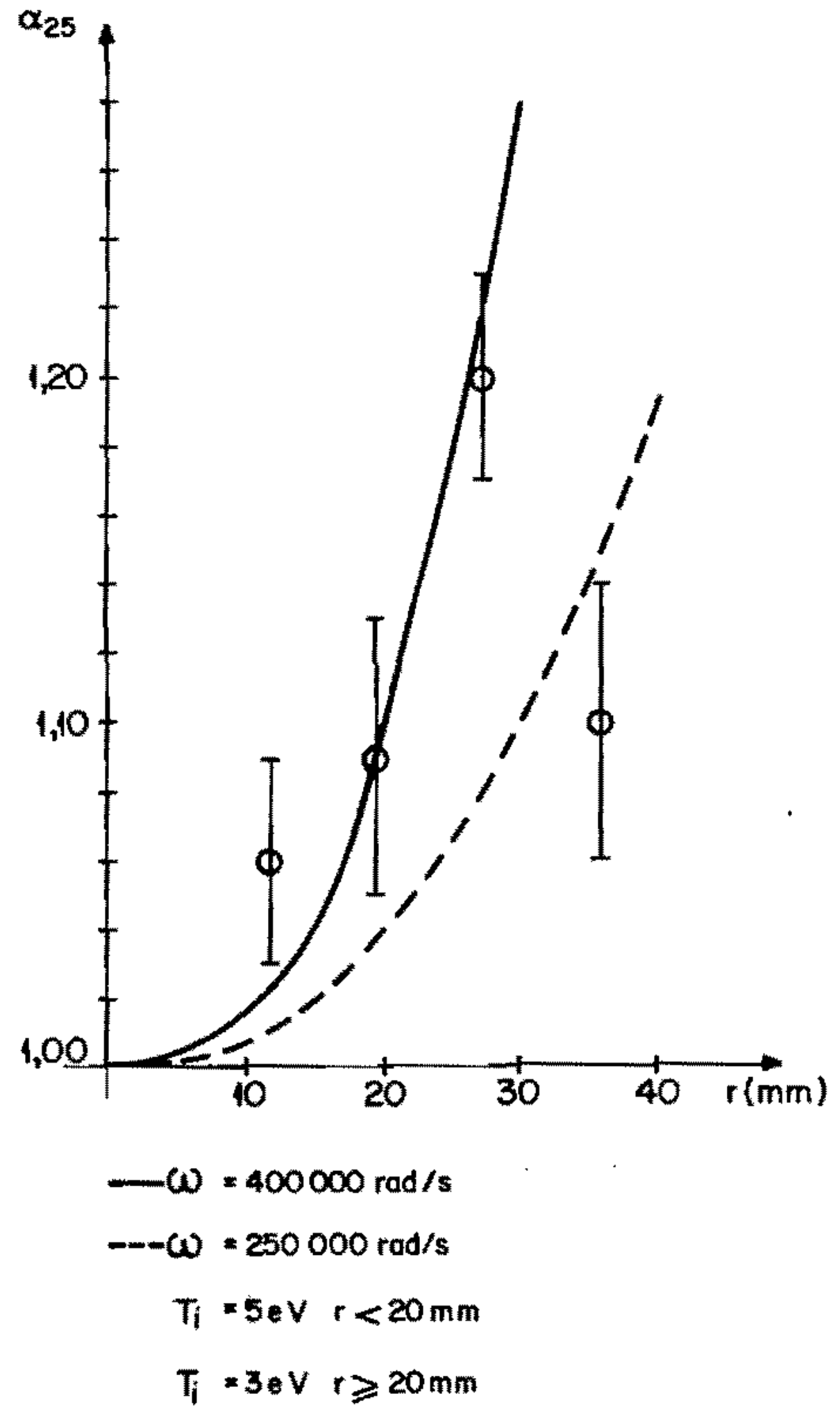

Figura 3.21. Perfil radial para o valor médio do fator de zeparaçà̃o tomado entre os instantes $t=4 \mathrm{~ms}$ e $t=14 \mathrm{~ms}$ da descarga para o isótopo $\mathrm{Mg}-25, \mathrm{O}$. dados experimentais. 


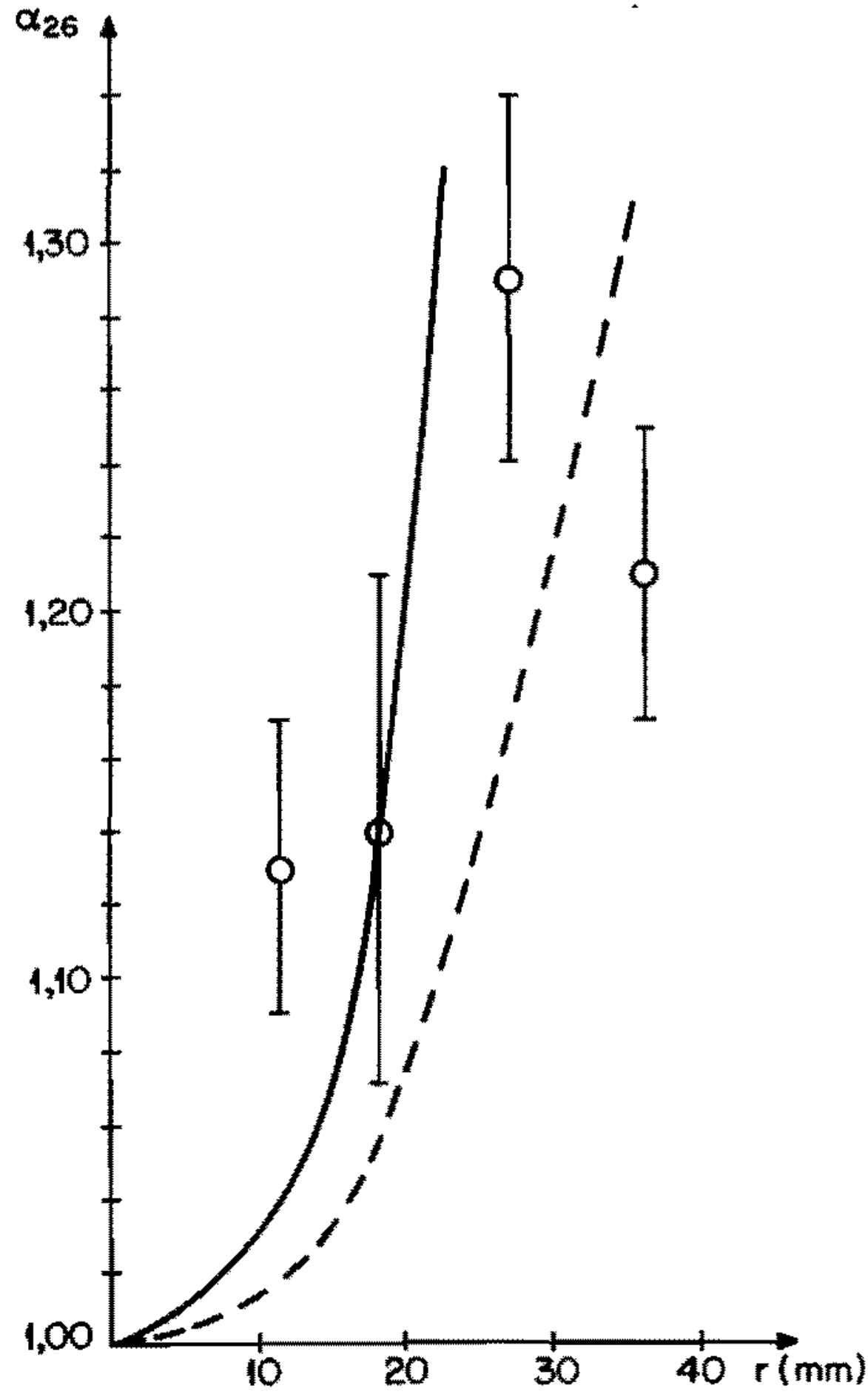

$$
\begin{aligned}
-\omega & =400000 \mathrm{rad} / \mathrm{s} \\
-\omega & =250000 \mathrm{rad} / \mathrm{s} \\
T_{i} & =5 \mathrm{eV} r<20 \mathrm{~mm} \\
T_{i} & =3 e V \mathrm{r} \geqslant 20 \mathrm{~mm}
\end{aligned}
$$

Figura 3.22. Perfl radial para o valor médio do fator de separaçäo tomado entre os instantes $=4 \mathrm{~ms}$ e $t=14 \mathrm{~ms}$ para o isótopo $\mathrm{Mg}-26, \mathrm{O} \cdot \mathrm{dados}$ expeximentasts. 


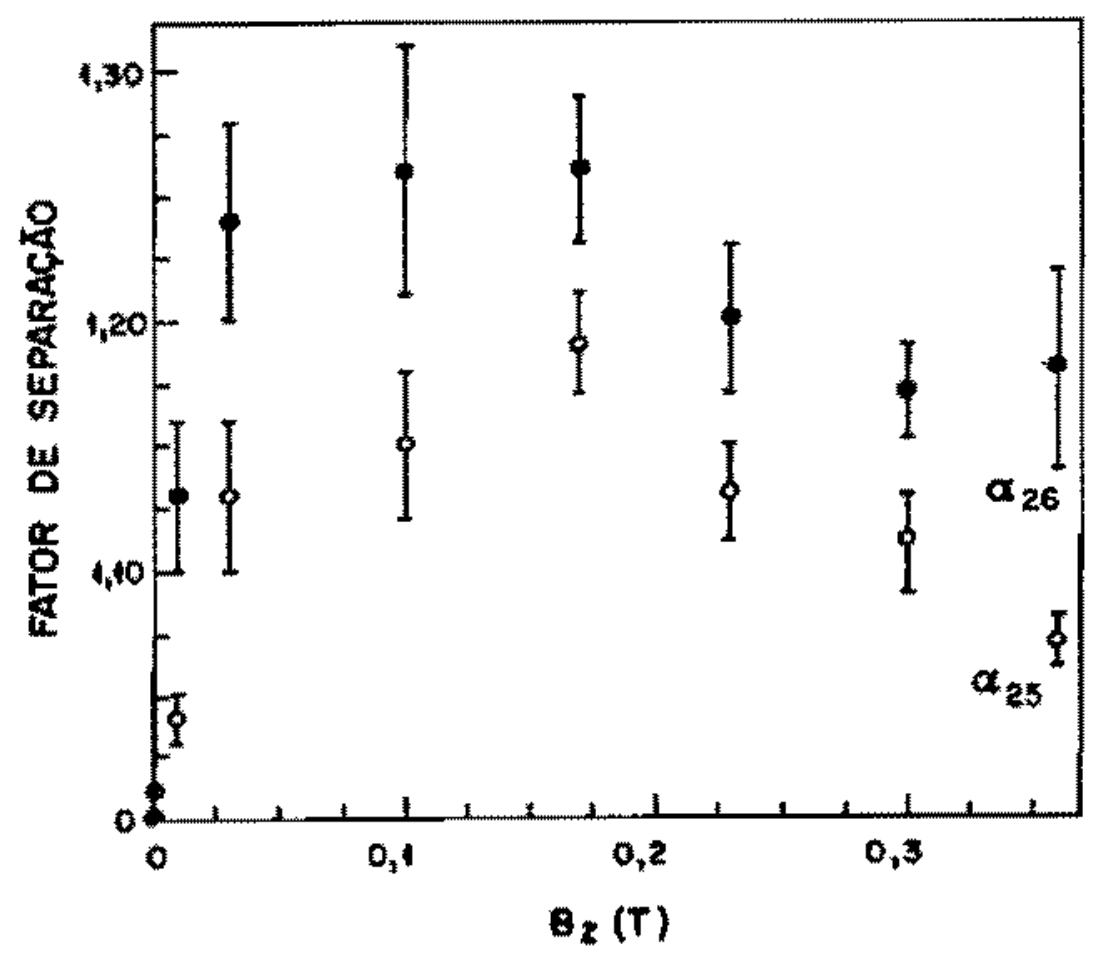

Figura 3.23. Fator de separał̧ão corno funçäo do campo magnético, para plasma de magnêsio com $I_{s}=1,7 k \mathrm{~A}$ (ralor de pico) e $r=40 \mathrm{~mm}[7 \mathrm{~g}$ ).

coluna central, coletando plasma onde a velocidade angular é menor, resultando em um fator de separaçẫo mais baixo.

\subsection{Conclusão}

Os resultados experimentais obtidos na PCEN confirnam as previsōes teóricas a partĩ de urn modelo de flưdo simplificado para a coluna de plasma em rotaçāo, apesar do gradiente na dîreção axial existente no campo magnético. Um exriquecimento de $\sim 20 \%$ foi obtido para o isótopo ${ }^{25} \mathrm{Mg}$ e $\sim 29 \%$ para o ${ }^{26} \mathrm{Mg}$ para $\mathrm{x}=27 \mathrm{~mm}$. Para o xaio $\mathrm{r}=36 \mathrm{~mm}$ o enxiquecimento cain para $10 \%$ e $21 \%$ respectivamente. Esta queda para raios maiores é explicada em termos das dimensões radiais da coluna de plasma.

Uma outra deficièncja da PCEN é a pequena dimensä̌ axial da coluna de plasma, $1 \sim 0,8 \mathrm{~m}$. Isto pode ser visto comparando-se o tempo de trânsito (Tabela 2.4) ao período de rotação da 
coluna de plasma $\left(T=2 \pi / \omega_{i}\right)$. Com os dados mostrados na Figura 3.16 e da Tabela 2.4 tem-se para $B_{*}=0,1 \mathrm{~T}$ que um elemento de plasma de magnassio executa $\sim 3$ giros, de zinco $\sim 2$ giros, de câdmio e churnbo $\sim 1$ giro, até atingir a extremüdade do dispositivo, Isto aignifica que para os plasmas de massa atômica elevada nâo deve ter sido atingido um equilibrio na díreçäo axial. Neste caso, ofator de separação depende da posiçăa axial. Para que a coluna de plasma execute um maior número de giros o comprimento axial da mesma deve ser aumentado.

Tanto os resultados teóricos como os experimentais permitem tirar algumas conclusöes com respeito a separaça isotópica em uma centrifuga de plasma iniciada por atco no vácuo, tais corno:

- Dos perfis radiais a densidade é baixa onde o fator de separzęüo é alto (e vice-versa) e, isto năo é o desejável na maioria das vezes, onde se deseja tanto alta densidade conno alto enriquecimento (como no caso da centrifuga mecänica (ver Figura 1.2). Uma caso onde esta deficiência nâo ocorre é quando se deseja obter um enriquecinento para a massa menor. Por exemplo, o chumbo tem a seguinte composiçāo natural: ${ }^{204} \mathrm{~Pb}(1,4 \%) ;{ }^{206} \mathrm{~Pb}(24,1 \%)$ ${ }^{207} \mathrm{~Pb}(22,1 \%)$ e ${ }^{208} \mathrm{~Pb}(52,4 \%)$. Neste caso o isótopo ${ }^{204} \mathrm{~Pb}$ terá uma abundância maior que a natural, isto é, serä enriquecido em tomo do centro da coluna onde a densidade é măxxì̛n\&.

- A velocidade angular decreste com o aumento da massa atömica e consequentemente o fator de separaçäo. Para se obter alto enriquecimento para massas maiores que 100 u.m.a. é necessário uma coluna de raio maior, de modo a se ter uma velocidade periférica $u_{\varphi}=$ (wr alta. Mesmo no caso de massas atônicas altas pode haver enriquecimento moderado se a diferença de massa entre os isótopos $(\Delta m)$ for grande e a temperatura for baixa, o que entäa pode compensar em alguma extensāo a velocidade angular menor. Para os elementos de massa atömica $<100 \%, m . a .$, quando $\Delta m$ for grande o enriquecimento poderá ser elevado, por exemplo ${ }^{40} \mathrm{Ca} ;{ }^{43} \mathrm{Ca}$.

- A variação do campo magnétíco pode controlar o enriquecimento, podendo ser ajustado para ram enriquecimento desejado, embora os dados mostrem que näo é muito ampla a variação. $O$ aumento do campo tem o efeito adverso de comprimir a coluna, o que resulta pasa urn determinado raio em um enriquecimento maior mas, com ums densidade menor. 


\section{CAPítulo 4}

\section{EFEITOS DE GASES RESIDUAIS NOS PARÂMETROS DA CENTRÍFUGA DE PLASMA INICIADA POR ARCO NO VÁCUOO}

\subsection{Introdução}

Os dados obtidos para a temperatura revelaram valores excessivamente altos. Da expressão para o fator de separaçäo, vè-se que ưna diminuiçẫo da temperatura levará a urn fator de separaçâo maior. Na tentativa de se obter uma temperatura menor para o plasma foi feito o estudo da influência dos gases hidrogênio, hélio e argônio neste pazầmetro. Durante este estudo observou* se que qárias mudanças ocorriam nà descarga obrigando, também, a se estudar a influência dos gases nos demais parâmetros, a saber: densidade de partículas carregadas, velocidade angular e no fator de separaçäo.

\subsection{Influência de gases residuais nos parâmetros: temperatura de elétrons, densidade de partículas carregadas, velocidade angular e no fator de separação.}

O estudo foi realizado no intervalo de pressäo $1 \times 10^{-4} \mathrm{~Pa}$ (vácuo) com os gases sendo intro

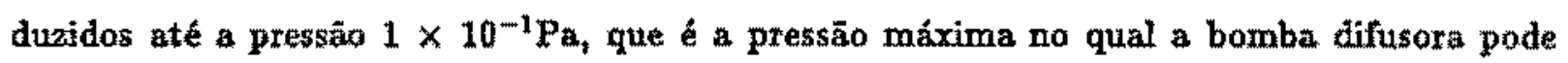
ser mantida emoraçäo. Os métodos de medida dos paràmetros são iguais aos utilizados nos Capítulos 2 e $\$$, isto $\hat{e}_{1}$ utilizando se sondas de Langmuir e espectrômetro de massa. Os maiores 
valores experimentais obtidos para $T_{e}, n_{\infty}$ e $\omega_{f}$ foram para o plasma de magnésio e, espera-se assim, uma maior infuência dos gases residuais para este plasma. Desse modo, todas as medidas realizadas neste capitulo foram para o plasma de magnésio com $I_{a}=1,5 \mathrm{kA}$ e $B_{z}=0,1 \mathrm{~T}$. A seguir é detalhado os estudos realizados na PCEN sob estas novas condiçöes.

\subsubsection{Efeitos de gases residuais na temperatura de elétrons}

A Figura 4.1 mostra o perfil temporal da temperatura de elétrons com a introduçăo dos trës gases até uma pressäo de $1 \times 10^{-1} \mathrm{~Pa}$. As seguintes mudanças podem ser observadas qute săo comuns aos três gases utilizados:

- temperatura nä̃o contante durznte a durą̧ão da descarga, como no caso do vácuo mostrado em tracejado, isto é, nāo há mais a condição de estado estacionário;

- a maior variação da temperatura ocorre no início da descarga e tende an valor do vácto no fim do pulso de plasma;

- O decréscimo na temperatura aumenta com o sumento de pressäo do gás;

- com o aumento da pressäo do gás a influència zobre a temperatura se prolonga mais durante o pulsa,

A Figura 4.2 mostra a vatiaçäo da temperatura como funçäo da pressäo para três instantes da descarga (princípio, melo e fim) onde pode sex visto a maior influência do gás no início da descarga e para pressóes altas $\left(>10^{-2} \mathrm{~Pa}\right)$. A interpretaçăo dos resultados com a introdução de gases é muito complexo devido a novos processos que ocorrem, que estavam ausentes quando da condiçäo de vácuo, tais como ionizaçäo e recombinaçäo [80]. Uma possível explicaçāo para a diminuiȳöo da temperatura dos elêtrons com o aumento da pressäo é devido a supressāo da instabilidade de Buneman, que é wan mecanismo efetivo para o aquecimento dos elétrons no campo elëtrico que existe na descarga em arco no vácuso $[81,82]$. 

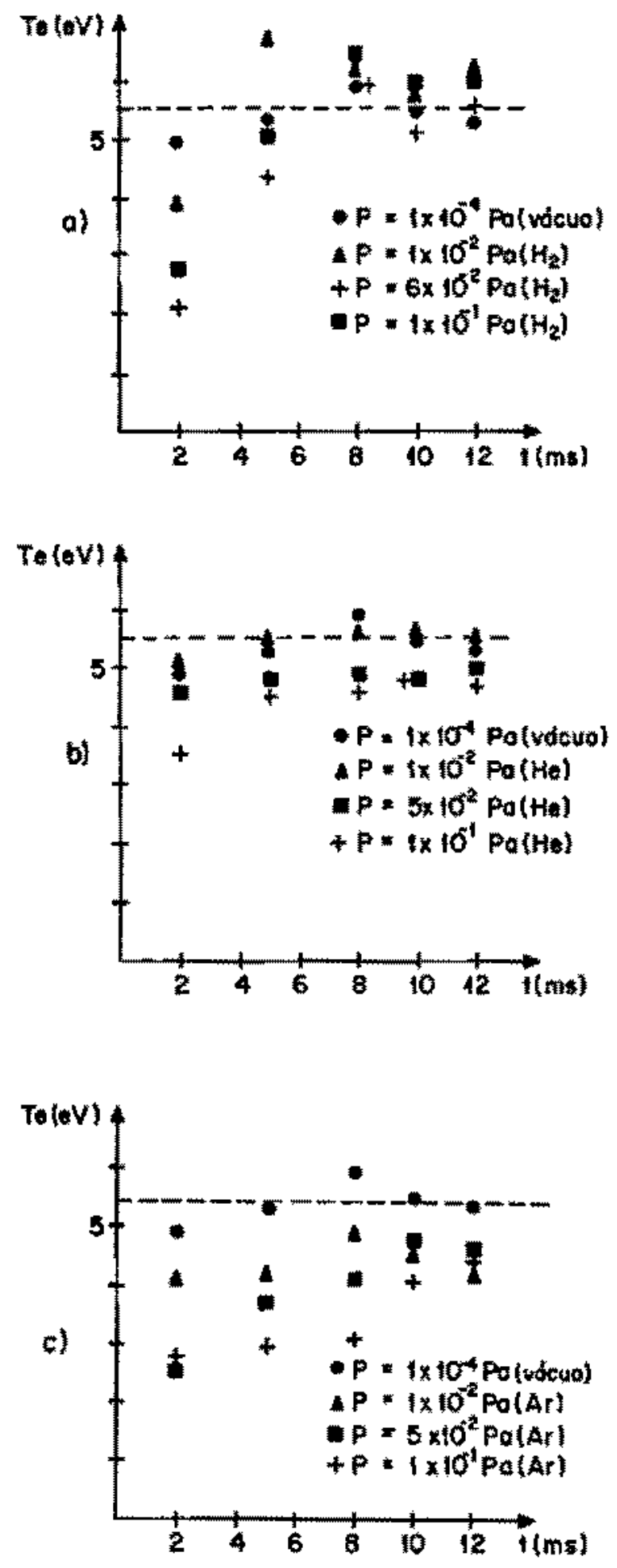

Figur 4.1. Evoluçāo temporal da temperatura de elétrons quando säo introduzidos separadamente os gases hüdrogenio, hélio e argônio na destarga $(r=0)$. A. linha tracejada é o valor médio dos pontos experimentais na condiçäo de vácuo $p=1 \times 10^{-4} \mathrm{~Pa}$. 


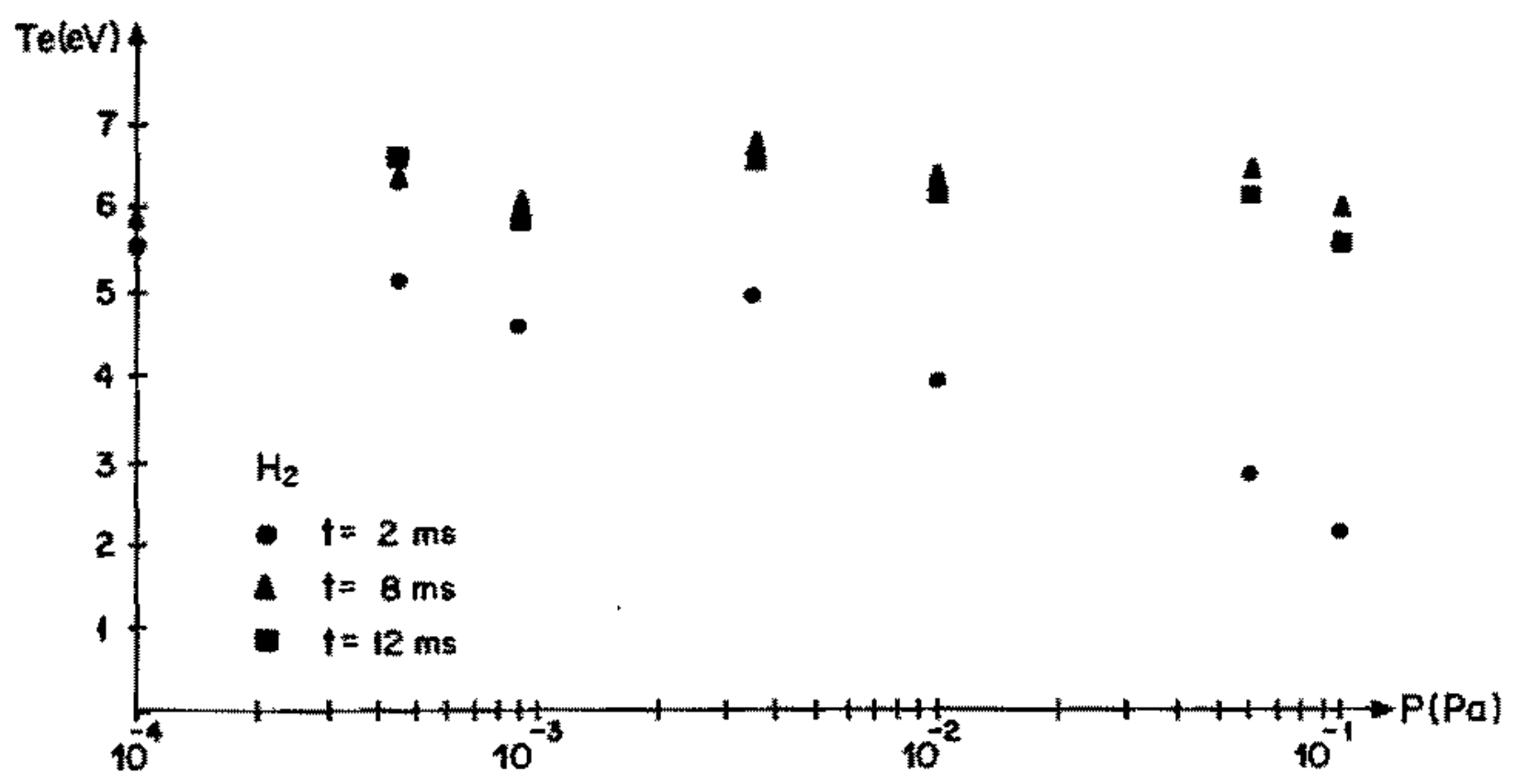

Figura 4.2. Temperatura de elétrons como funçāo da pressäo do hưdrogênio como gás residual nos instantes $t=2,8$ e $12 \mathrm{~ms}$ da descarga $(\mathrm{r}=0)$.

\subsubsection{Efeitos de gases residuais na densidade de partículas carregadas}

A Figura 4.3 mostra a evoluçăo temporal da corrente de saturaçäo de ions da sonda de Langmuir com $a$ introd̆uçẵo de gases na descarga.

Pode ser observado um aumento na corrente de saturaçāo de ions e, portanto, da dexisidade com a presença de um gás na destarga. Este aumento atinge um valor máximo em torno de t $5 \mathrm{~ms}$ da descarga, decaindo a partir deste instante, para valores próximos ao de vácuo (linha tracejada) nos instantes finais. Como jo salientato snteriormente, a descarga em arco no vảcuo para o magnésio, apresenta urn grau de lonizaçäo de $\sim 100 \%$ (Capítulo 2) e, o aumento verificado na densidade é provápel ser devido a ionizaçäo do gás introduzido na descarga. No entanto, o intervalo de tempo para ocorrer a ionizaçầ do gás é muito pequeno comparado a $t \sim 5 \mathrm{~ms}$ onde ocorre o aumento da densidade. A frequência de colisão elétrons-neutro ( $\left.v_{\text {en }}\right)$ é dada por $\nu_{\mathrm{c}}=2,8 \times 10^{6} \sigma^{2} \mathrm{n}_{m} \mathrm{~T}_{e}^{\frac{1}{2}}, \operatorname{com} \mathrm{T}_{\mathrm{e}}$ em $\mathrm{eV}_{3} \mathrm{n}_{\mathrm{m}}$ as densidade de moléculas neutras e $\sigma$ é essencialurente o raio clássico das mesmas $\left(\sigma \sim 10^{-10}\right.$ m). Para uma pressão de $1 \times 10^{-1} \mathrm{~Pa}_{\text {, }}$ $n_{m} \sim 10^{19} \mathrm{mn}^{-3}$ e com $T_{e} \sim 5,5 \mathrm{eV}$ resulta em $\nu_{e n} \sim 6 \times 10^{5} \mathrm{~s}^{-1}$, o tempo para ionizaçäo 
sendo então de microsegundos. Uma outra possibilidade é a instabilidade de áonizagāo que surge num plasma de duas temperaturas (possivelmente o plasme formado a partir do gás tenha uma temperatura diferente do plasma metálico) sujeito a campos elétrico e magnético truzados [88]. Quando esta instabilidade desenvolve, o grau de ionizaçăa cresce exponencialmente. Esta instabilidade ocorre quando um anmento local na razāo de aquecimento Joule dos elétrons excede a razāo pelo qual o calor gerado pode ser transferido por colisōes, radiação e condução. A razăo de crescimento para esta instabilidade com os parâmetros da PCEN é $\sim 1 \mu s_{\text {q }}$ o que, evidentemente, nẫo condiz com a apresentado na Figura 4.3. Porlanto, outro mecanismo deve estar envolvido, que possa explicar este fato experimental.

A Figura 4.4 moostra a corrente de saturação de fons como função da pressão de hidrogênio para dois tempos diferentes, podendo ser visto a major variaçăa em relaçă ao valor do vảeuo $(1 \times$ $10^{-4} \mathrm{~Pa}$ ) no instante inicial da descarga para $\mathrm{p} \geq 1 \times 10^{-2} \mathrm{~Pa}$

\subsubsection{Efeitos dos gases residuax́s na velocỉdade angular}

A ủntroduçầo de gases na descarga revelarara duas mudanças no padrāo de oscilaçāo apresentada pelas sondas quando no potencial futuante. A primeira delas esta mostrada na Figura 4.5 com argônio como gás residual, onde diferente do caso do vácuo, as fluturçôes sāo suprimidas no inicio da descarga (comparar com a Figura 3.9). Esta supressäo avança lo longo do pulso com - aumento da pressāo. $O$ sinal expandido da Figura 4.5 em torno de tempo da descarga $t=$ $12,5 \mathrm{~ms}$ está mostrado na Figura 4.6.

Neste caso, o método de medir a pelocidade angular baseado nas defasagens dos sinais apresen tados pelas sondas näo se aplica no intervalo de tempo em que as atutuaçōes foram suprimidas.

A segunda mudança ocorze na extensīo radial das flutuzçōes. Como ja fol observado para o caso da ausência de gases residuais $\left(\mathrm{p}=1 \times 10^{-4} \mathrm{~Pa}\right)$ as flutuaţổes deixavam de ter um padräo definido para $F>25 \mathrm{~mm}$ o que impossibilita medida da velocidade angular para raios maiores. No entanto, quando da presénça de gás residual as futuaçŏes ainda apresentavam padrǟo bem defuidos para raios até 40mm. A explicação paxa isto somente será possivel quando se obtiver uma melhor compreensăo das oscilaçöes apresentadas pela coluna de plasma em rotaçāo. A 
a)

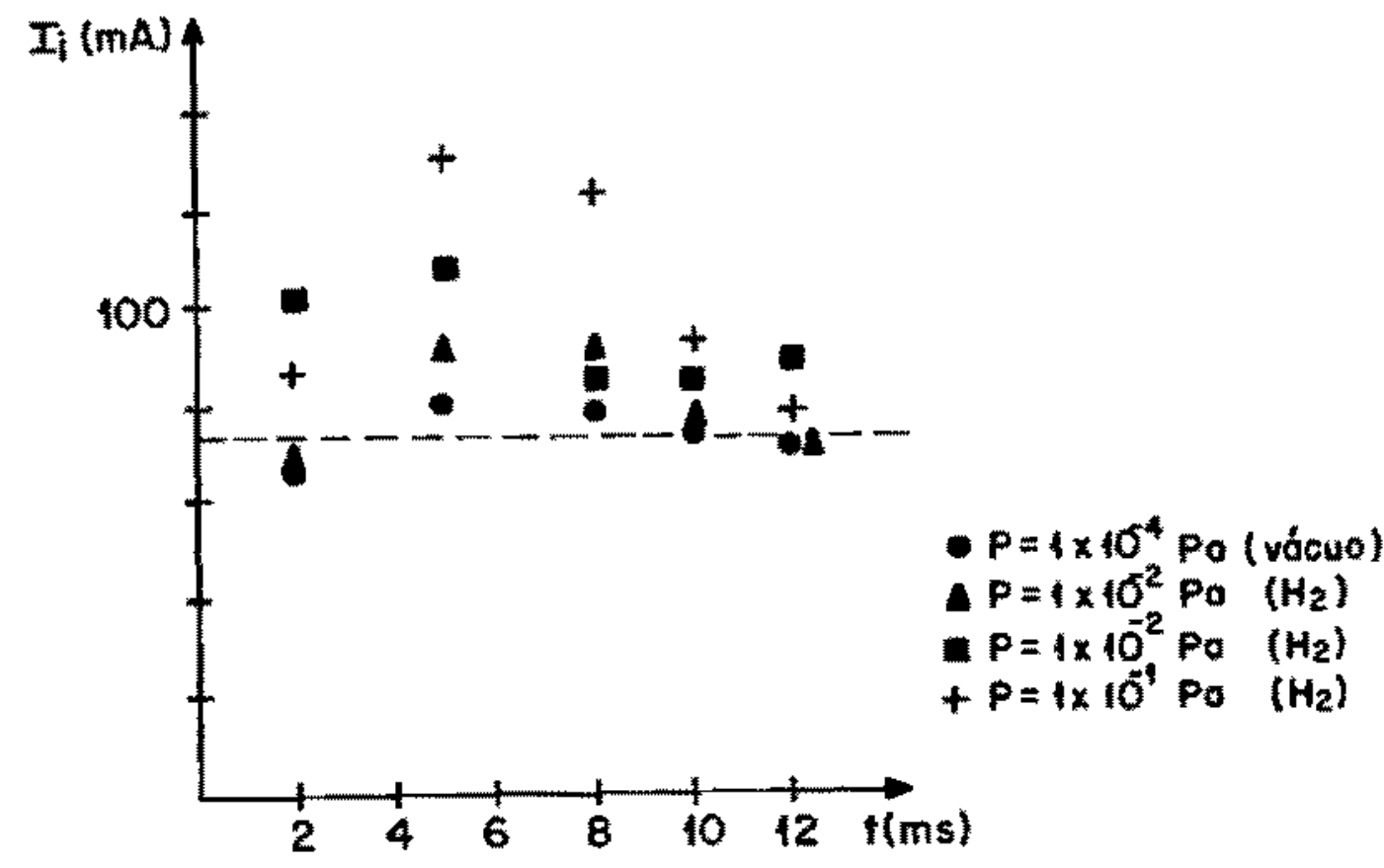

b)

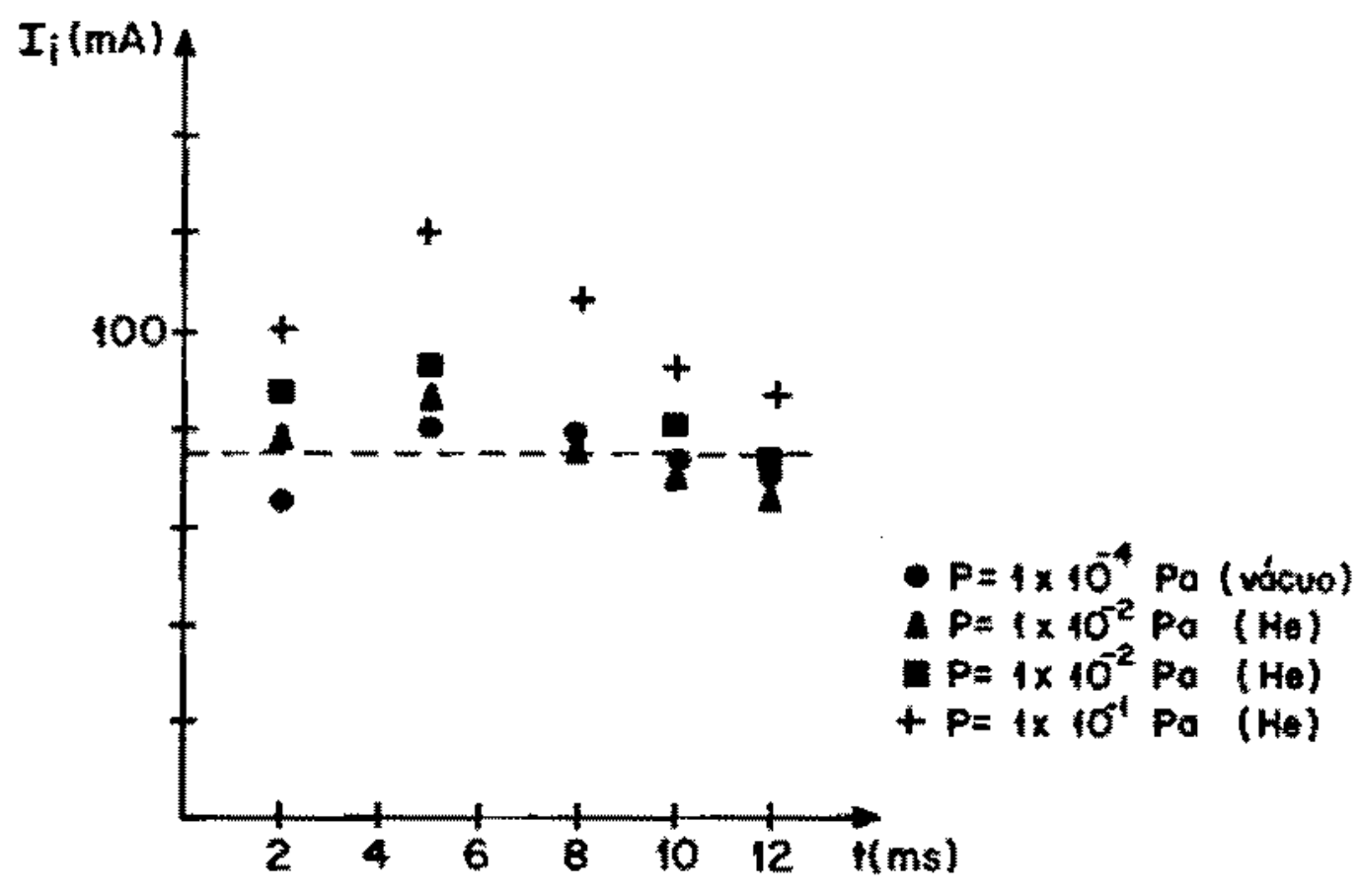

Figura 4.3. Corrente de saturaçẵo de ions como função do tempo da descarga a) com gás hưdrogênio na cârnara; b) com gás hélio. A linha tracejada é o valor métio dos pontos experimentais na condị̧̧äo de vácuo $p=1 \times 10^{-4} \mathrm{~Pa}$. 


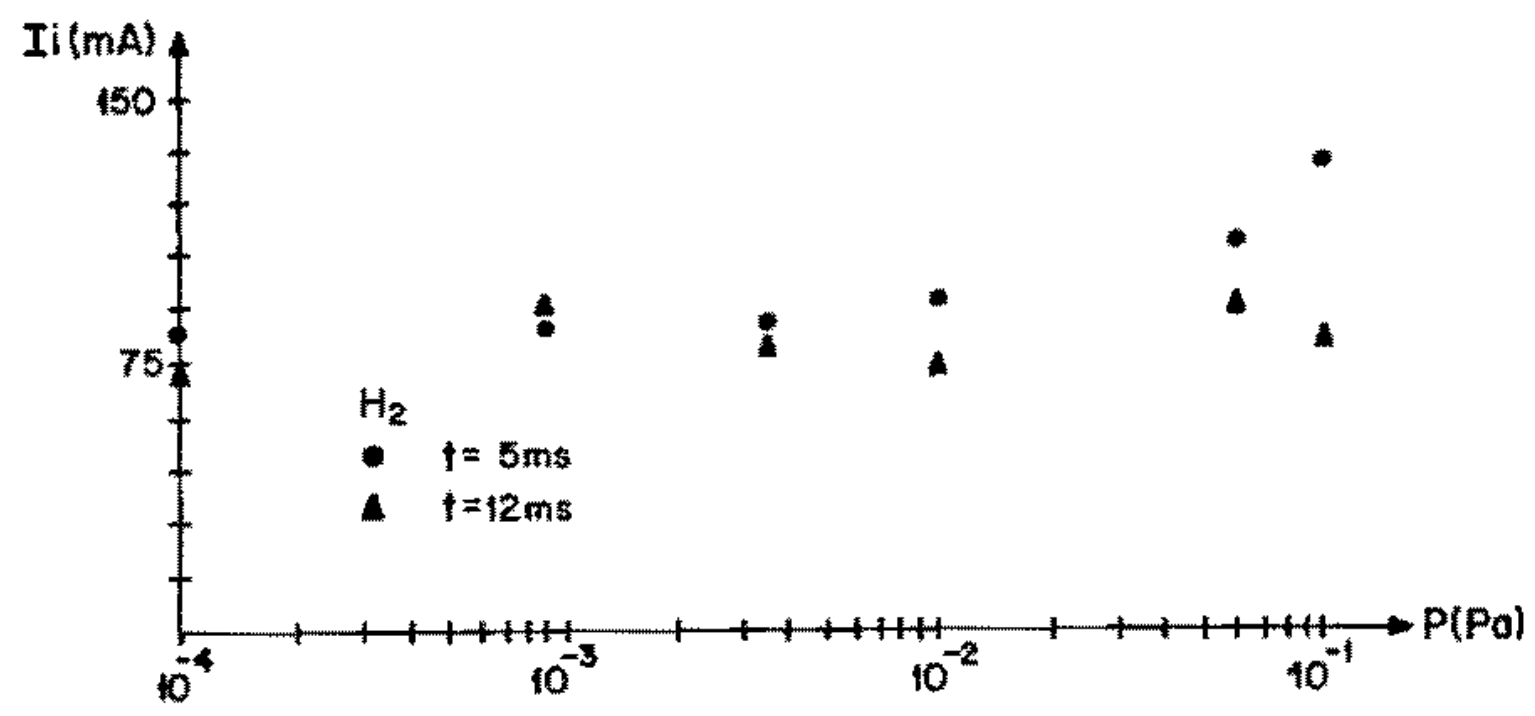

Figura 4.4. Corrente de saturaçăo de fons versus pressão do gắn hidrogênio para dois inatantes da descarga.

Figura 4.7 apresenta o sinal expandido em torno de $t=12,5 \mathrm{~ms}$ pars a posiçâo $\mathrm{x}=40 \mathrm{x}$ ma quando da ausêncià de gás residual e na Figura 4.8 quando da presença de argônio a pressä́ $p_{A r}=5 \times 10^{-2} \mathrm{~Pa}$.

A Figura 4.9 mostra a evoluçäo temporal da velocidade angular medida pelo uso de duas sondas,

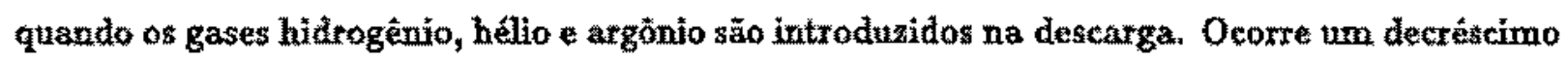
mais acentuado da velocidade angular no inicio do pulso de plasma com a introdinçāo dos gases. Para pressōes acima de $10^{-2} \mathrm{~Pa}$ a influência ocorre sobre todo o tempo da descarga, as medidas estando restritus aos instantes em que as fintuaçöies se façam presentes.

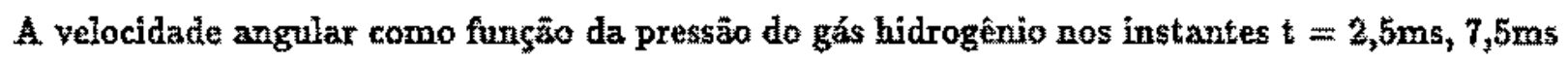
e 12,ơns estấ mostrado na Figura 4*10. Para $\mathrm{p}<10^{-7} \mathrm{P}$ a a influência na velocidade angular sỏ ocorre nos instantes iniciais mas, quando $\mathrm{p}>10^{-3} \mathrm{~Pa}$, há wm decréscino na yelocidade angular durante toda a descargar.

Una outra verificaçäo da influência de gás residual no plasma é sobre a rotaçăo da coluna como corpo rígido. Para isto, foi medido o perfil radial da velocidade angular e o resultado obtido está mostrado na Figura 4.11 para os gases hidrogênio $\left(\mathrm{p}=1 \times 10^{-1} \mathrm{~Pa}\right)$ e argönio $(\mathrm{p}=5$ 


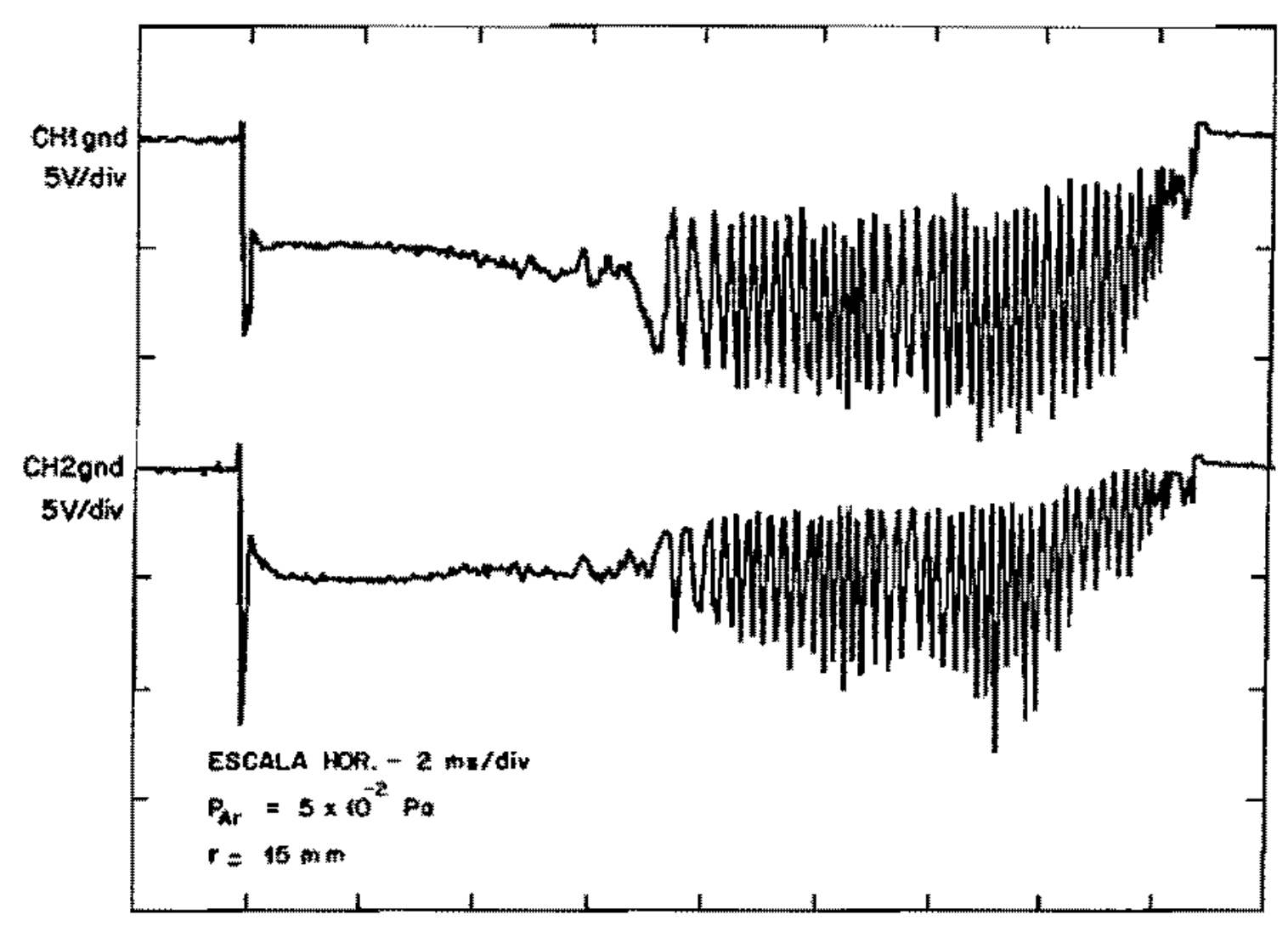

Figura 4.5. Padrāo de oscilação do potencial flutuante apresentado pelas sondas com argônio a pressä̌ $p_{A r}=5 \times 10^{-2} P a, r=15$ mm. 


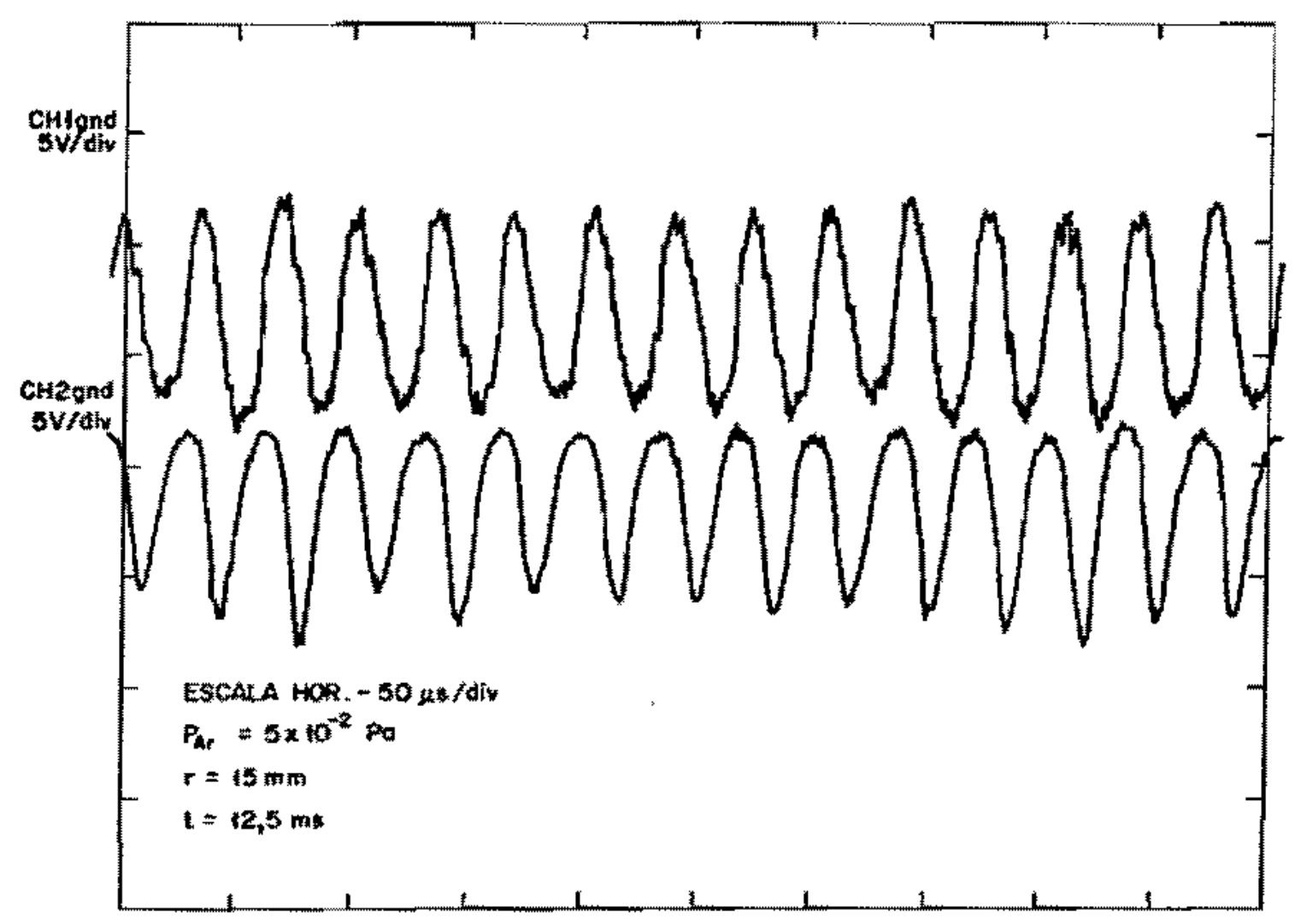

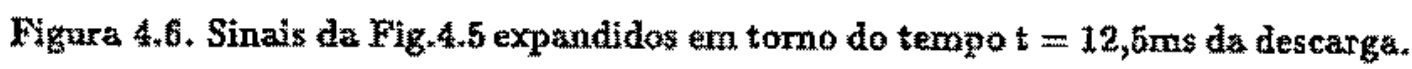




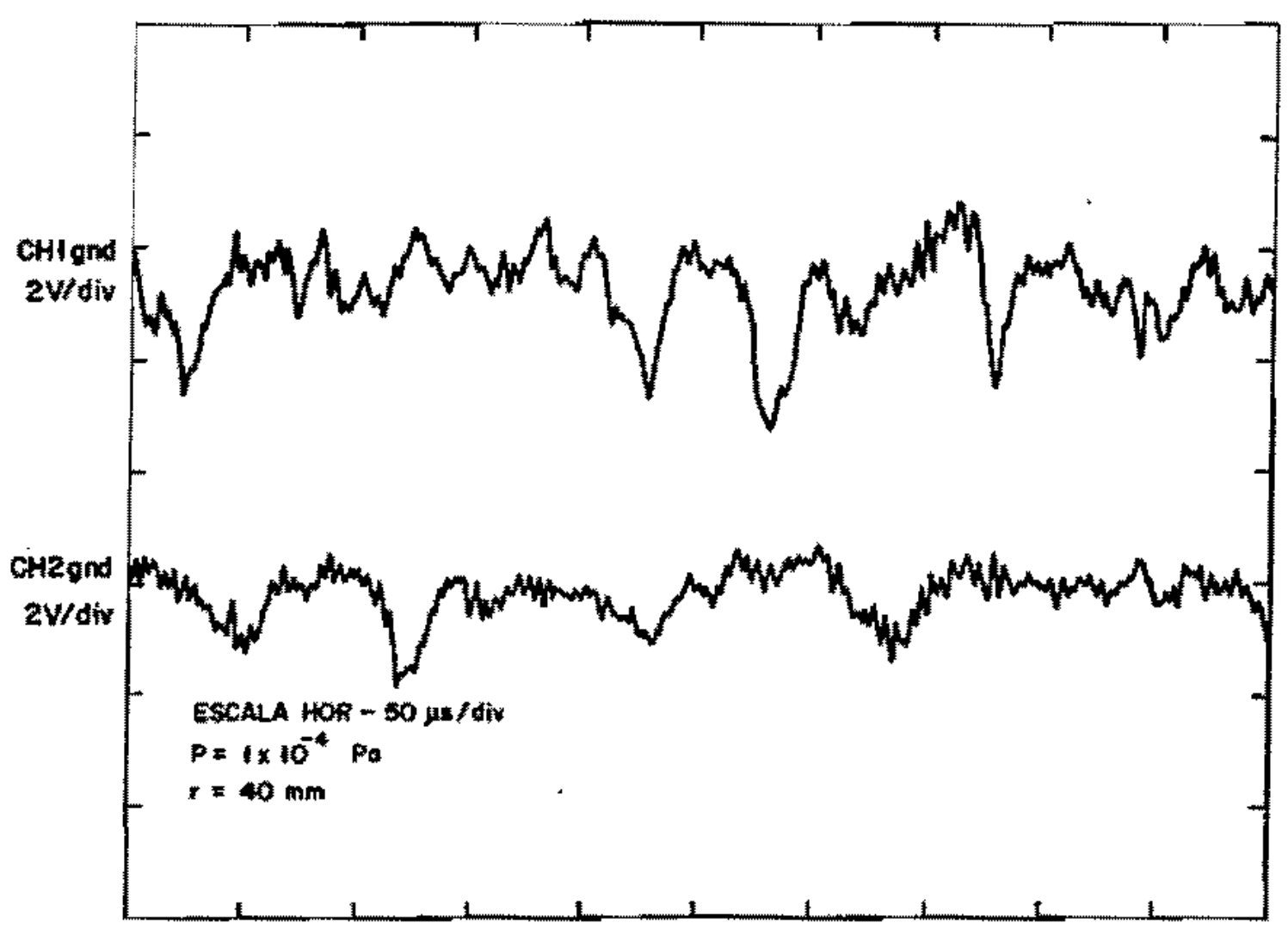

Figura 4.7. Sinaís apresentados pelas sondas para $t=40 \mathrm{~mm}$ e $p=1 \times 10^{-4} \mathrm{~Pa}$, expandidos em torno de $t=12,5 \mathrm{~ms}$. 


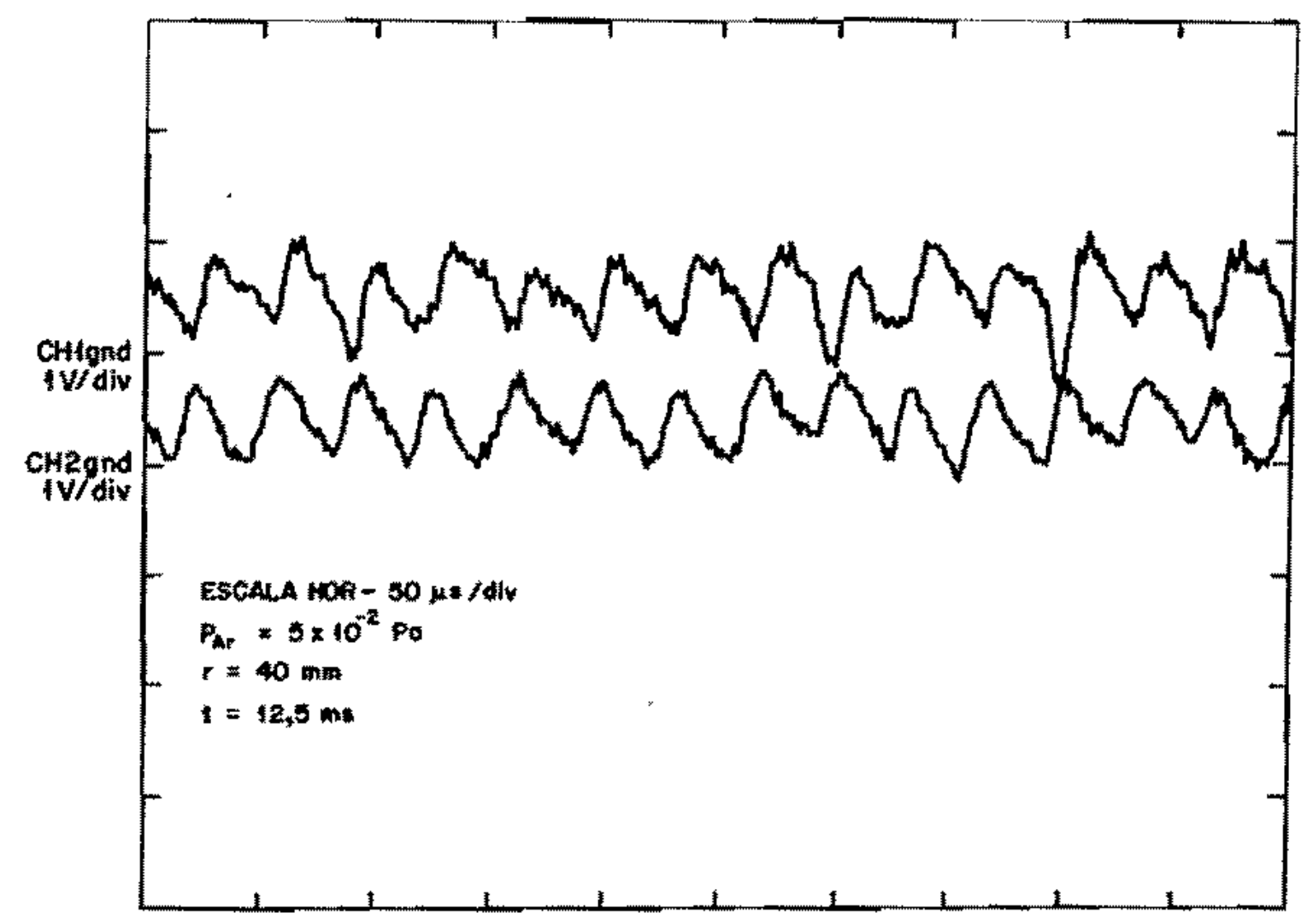

Figura 4.8. Sinais apresentados pelas sondas para $x=40 \mathrm{~mm}$ e $p=5 \times 10^{-2} \mathrm{~Pa}$, expandidos em torno de $t=12,5$ ms. 

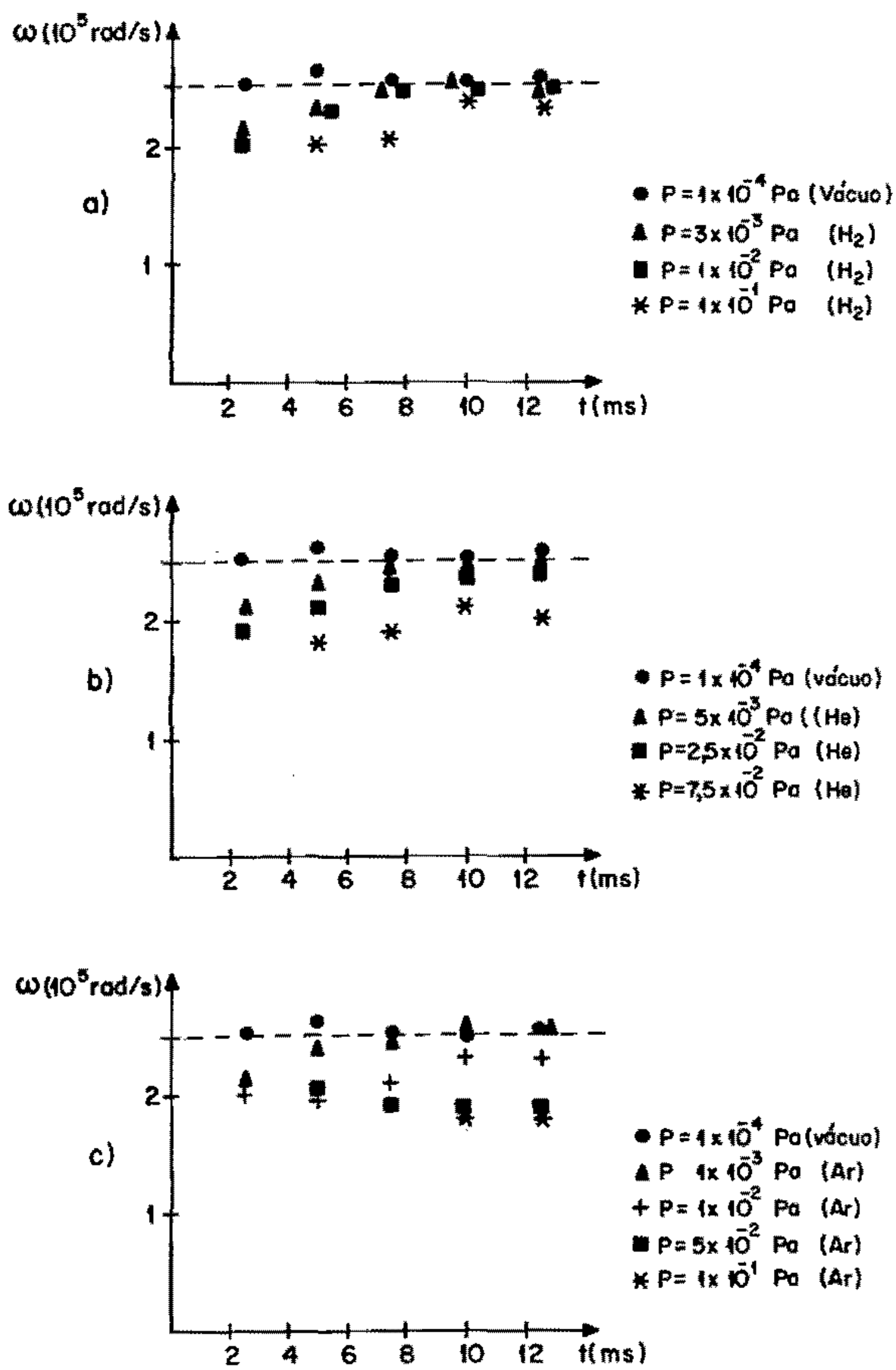

Figura 4.9. Evoluçāo temporal da velocidade angular com a introduçầo dos gases: a) hudrogènio b) hélio e c) argônio. A linha tracejada é o valot médio dos pontos experimentais na condîção de vácuo $p=1 \times 10^{-4} \mathrm{~Pa}$. 

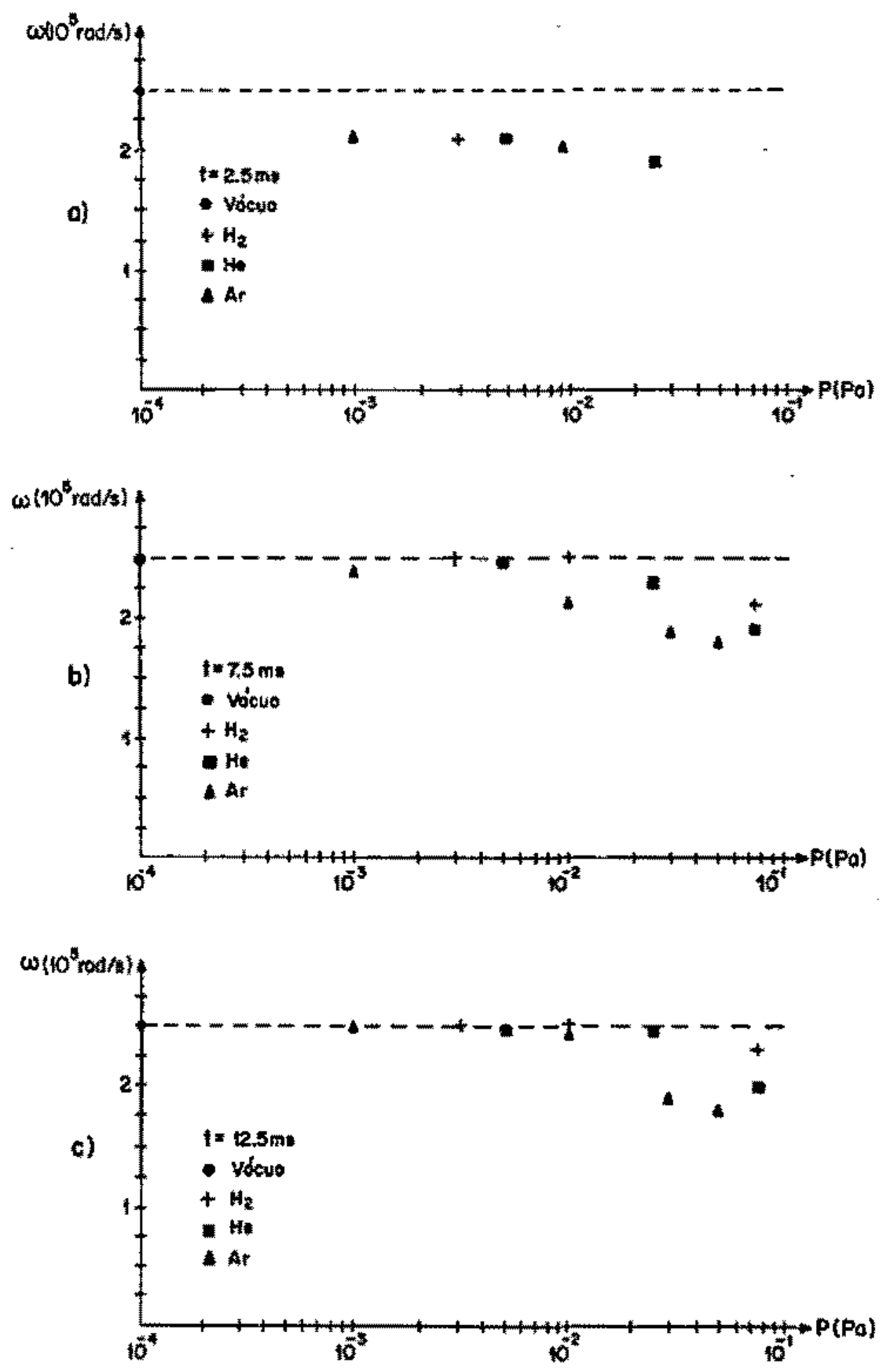

Figura 4.10. Velocidade angular como função da pressä́ para trës instantes da descarga: a) $t=2,5 \mathrm{~ms}$; b) $t=7,5 \mathrm{~ms}$ e c) $t=12,5 \mathrm{~ms}$. A linha tracejada é o valor obtido para a velocidade angular na condição de vảcuo $p=1 \times 10-4 \mathrm{~Pa}$. 


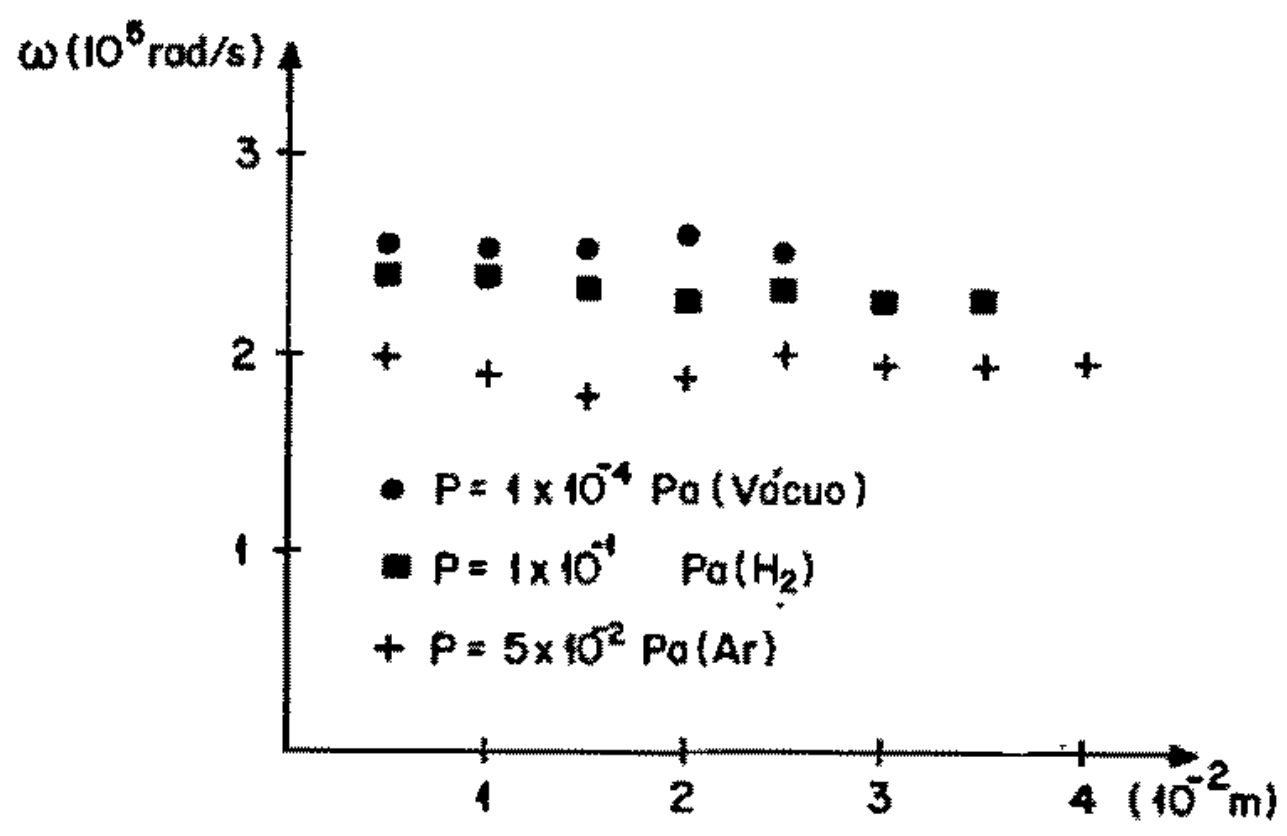

Figura 4.11. Perfil radial da velocidade angular carn a presença de gás residual, $1 \times 10^{-4} \mathrm{~Pa}$ (vácuo), $p=1 \times 10^{-1} \mathrm{~Pa}\left(H_{2}\right)=5 \times 10^{-2} \mathrm{~Pa}(\mathrm{Ar}) \mathrm{no}$ instante $\mathrm{t}=12,5 \mathrm{mns}$.

$\times 10^{-2} \mathrm{~Pa}_{\mathrm{a}}$ ). O argônio tem uma influencia maior sobre a velocidade angular, como já foi salientado, as medidas foram possiveis para $\mathrm{s}>25 \mathrm{~mm}$, quando da presença de gases residuais. A coluna de plasma comporta-se como um corpo rígido nestas condiçöes mas girando com uma velocidade angular menor.

\subsubsection{Efeitos de gases residuais no fator de separação}

Dos resultados mostrados observa-se que a presença de um gás residual causa alteraçẫo em todos os parametros do plasma. $O$ efeito resultante sobre o fator de separaçäo pode ser avaliado somente com a medida direta do mesmo.

O fator de separaşāo foi medido utilizando se o hidrogênnio como gás residưal a uma pressǟo de $1 \times 10^{-1} \mathrm{~Pa}$. Como nos demais parămetros, o fator de separaçăo tem uma evoluçăo temporal, mostrando-ge pequeno nos instantes iniciais e crescendo com o decorrer do tempo. A Figura 4.12 mostrs a evolução temporal para ofator de separaçăo para $\mathrm{x}=10 \mathrm{~mm}, \mathrm{I}_{a}=1,5 \mathrm{kA}$ e $B_{z}=$ 
$0,1 T$.

O resultado mats importante da investigaçäo do efeito de gás residual a comparaçäo entre os resultados do fator de separaçào obtidos na pressăo $\mathrm{p}=1 \times 10^{-4} \mathrm{~Pa}$ (vácuo) es obtidos com $\mathrm{p}$ $=1 \times 10^{-1} \mathrm{~Pa}\left(\mathrm{H}_{2}\right) .0$ resultado desta comparaçăo está mostrado nas Figuras 4.13 e 4.14, onde foi tomado o valor médio do fator de separaçä̀o entre os instantes $t=4 m s$ e $t=14 \mathrm{~ms}$ da descarga para várias posiçôes radiajs com e sem gás residual. O resultado mostra o efeito negativo, isto é, o decréscimo do fator de separaçāo quando da presença de gás residua na coluna de plasma. 


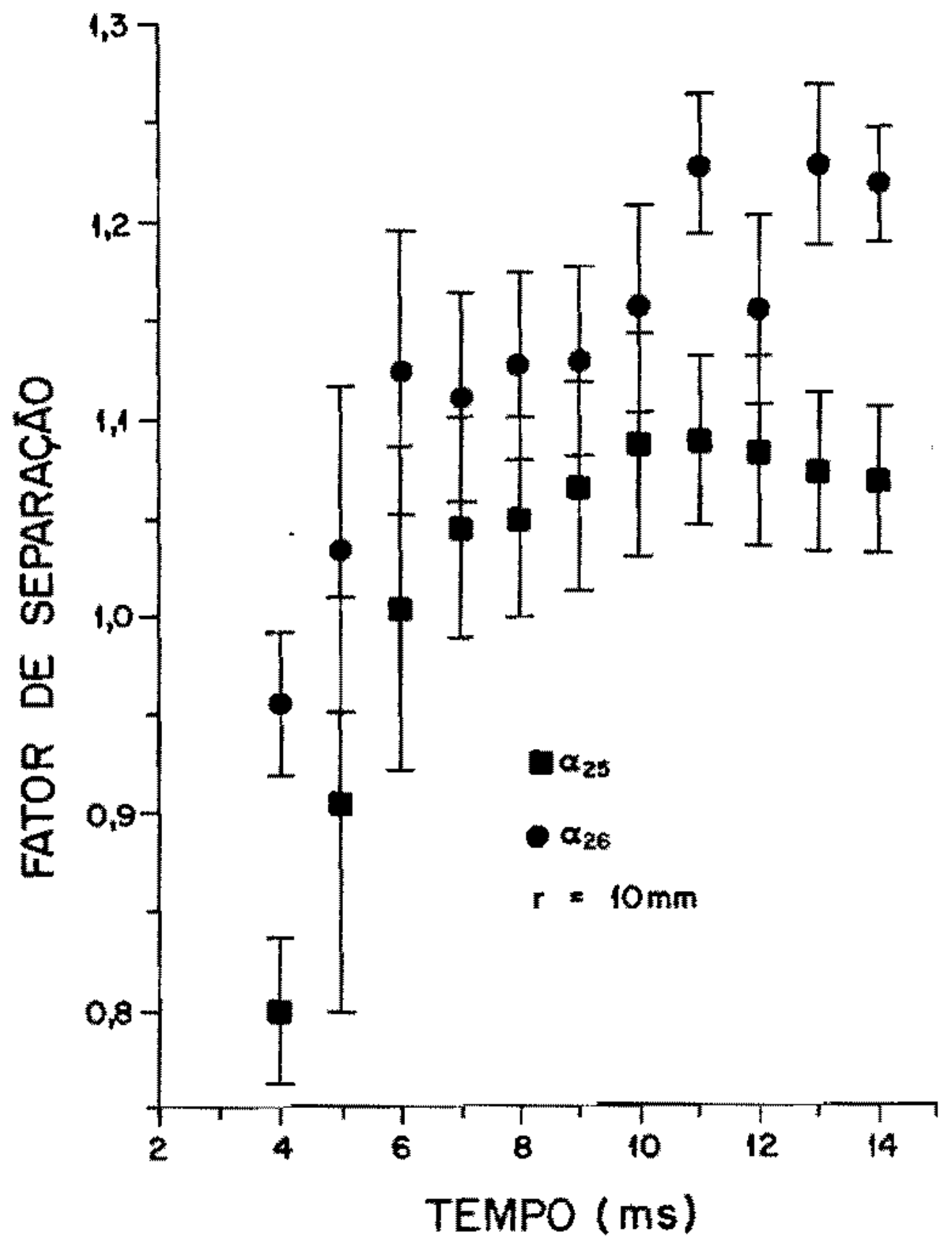

Figura 4.12. Evoluçăo semporal do fator de separaçäo com hidrogento na pressäo $p=1 \times 10^{-1} P_{a, r}=10 \mathrm{~mm}$. 


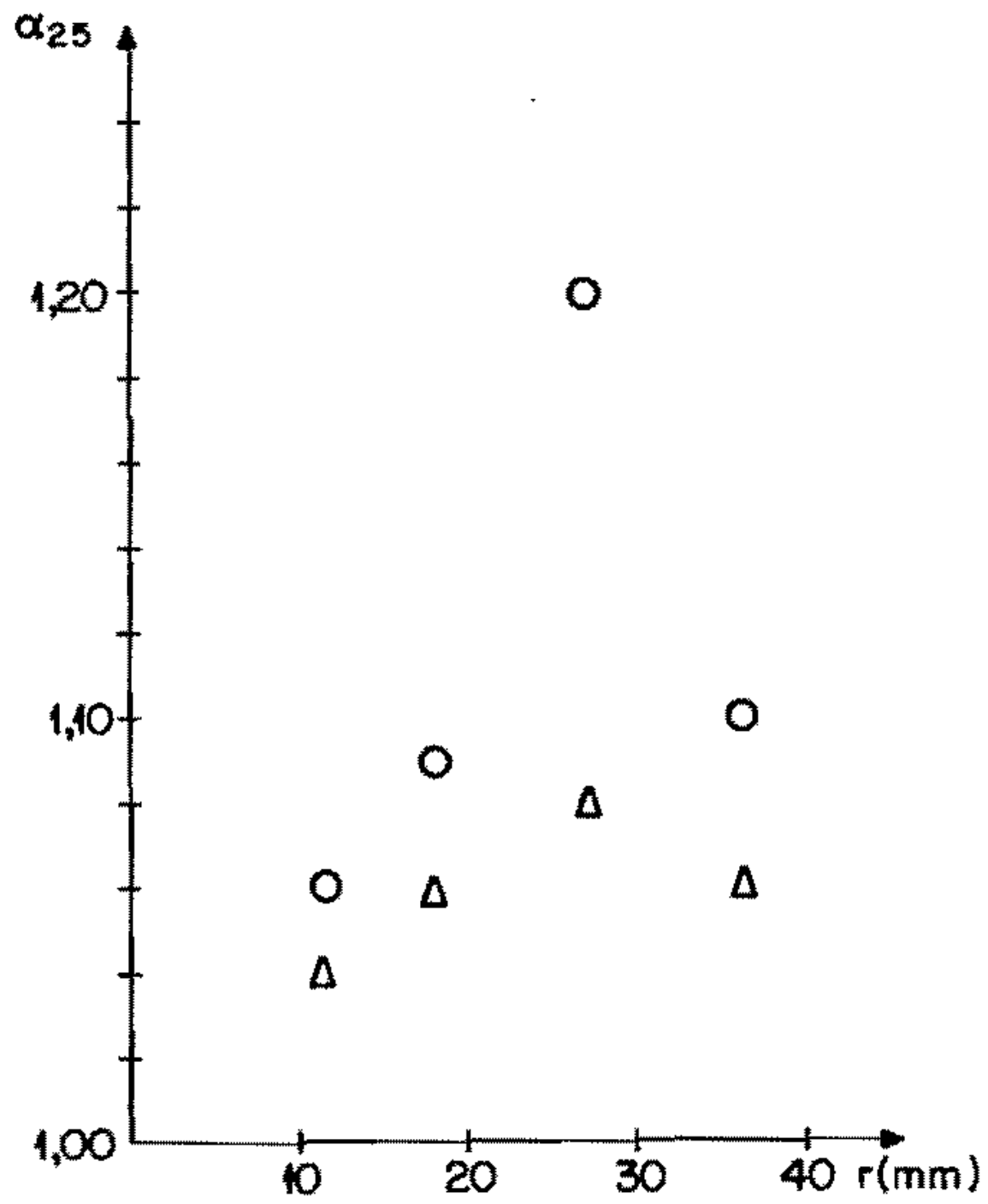

O VÁCUO

$\triangle$ HIDROGÊNIO $\left(P=\left\{\times 10^{-1} \mathrm{~Pa}\right)\right.$

Figurz 4.13. Fator de separaçăo para o isótopo ${ }^{25} \mathrm{Mg}$ tomado entre os instartes $\mathrm{t}=$ $4 \mathrm{~ms}$ e $t=14 \mathrm{~ms}$ da descarga para várias posiçōes radiais aas pressōes: $O p=1 \times 10^{-4} \mathrm{~Pa}$ ( rácuo) e $\Delta p=1 \times 10^{-1} \mathrm{~Pa}\left(H_{2}\right)$, 


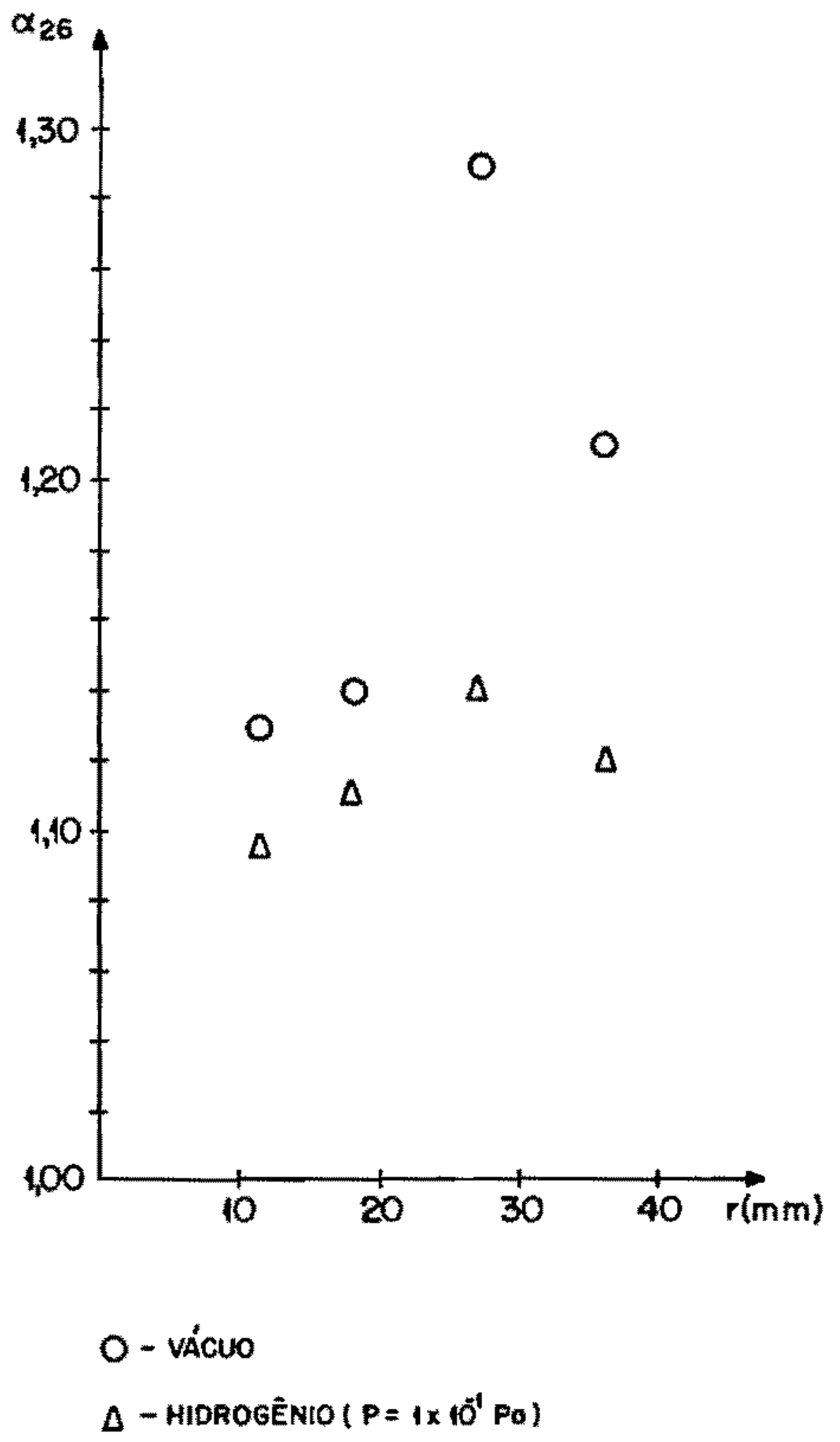

Figura 4.14. Fator de separaçāo para o isčtopo ${ }^{26} M g$ tomado entre os instantes $t=$ ims e $\mathrm{t}=14 \mathrm{~ms}$ da descarga para várias posiçŏes radjais nas pressóes: $O p=1 \times 10^{-4} P$ (váeuo) e $\triangle p=1 \times 10^{-1} P a\left(H_{z}\right)$. 


\subsection{Conclusão}

Embora a introduçäo de gases residuais tenha resultado no efeito desejado, isto $\hat{e}_{1}$ abaixou a temperatura do plasma, o balanço final foi negativo na medida em que o fator de separaşäo dimixuiu.

A presença de gases na coluna de plasma revelou uma complexidade maior nos fenōnemot; ocorrendo uma evoluçāo temporal nos parámetros, destruindo-se assim, condị̂ăto de estado estacionário. Os termos de produçăo e perda de partículas devern ser diferentes de zero nestas condiçōes. Por outro lado, a supressão das oscillaçōes em grande parte do pulso de plastra e sua maior extensão radial, podem ser investigadas do ponto de vista acadêmico, embora, deva ter pouca utilidade para fins de इeparaçäo isotópica. 


\section{CAPÍTULO 5}

\section{ESTUDO COMPARATIVO ENTRE OS DIVERSOS MÉTODOS DE SEPARAC̆̈O ISOTÓPICA APRESENTADOS}

\subsection{Introdução}

Será feito neste capítulo um estudo comparativo, baseando-se nos resultados experimentais obtidos, eatre a centrifuga de plasma iniciada por arco no vắcuo e os outros métodos de separaçäo isotópica apresentados no Capítulo 1 .

\subsection{Enriquecimento do Vanádio-50}

A primeira comparaçäo será com relą̧āo a energis consumida para enriquecer vanádio-bo (Tabela 1.4), pelos separadores isotópicos: calutron, laser, centrifuga mecânica, ressonâneja fon cì clotrônica e a centrifuga de plasma iniciada por arco no văcuo.

Os seguintes valores podem ser esperados para o plasma de vanălio: da Tabela $2.4, \sum_{i} \sim 500$ eV/ion e $T_{i} \sim 1 \mathrm{eV}$, vissto que as propriedades termo-físicas do vanádilo săo próximas as do níquel, e da referencia [77], $\omega_{i} \sim 1,5 \times 10^{5} \mathrm{rad} / \mathrm{s}$ e raio característico da coluna $r_{c} \sim 35 \mathrm{~mm}$. A composiçāo natural do vanádio é ${ }^{5 i} V(99,75 \%),{ }^{50} V(0,25 \%)$ e, o isótopo ${ }^{50} V$ será enriquecido para os raios mais internos da coluna. Dos dados apresentados, um fator de separaçằo de $a=1,10$ ocorre para $\tau_{0} \sim 30 \mathrm{~mm}_{1}$ ou seja, o isótopo ${ }^{50} \mathrm{~V}$ será enriquecido a $10 \%$ para $r<30 \mathrm{~mm}$. 
A densidade segue um perfil Gaussiano da forma $\left.n=n_{0} e^{-(r / r}\right)^{2}$ tesultando em

$$
n_{r}(r) \simeq n_{51}(r)=n_{0} \exp \left[-816 r^{2}\right]
$$

Da definiça do fator de separaçäo, expressăo 3.26 , resulta para o perifl radial da densidade do tatstopo ${ }^{* 0} \mathrm{~V}$

$$
n_{50}(r)=\left[\frac{n_{50}(0)}{n_{51}(0)}\right] n_{51}(r) \exp \left[-\frac{\Delta m \omega_{i}^{2} r^{2}}{2 k_{z} T_{i}}\right]
$$

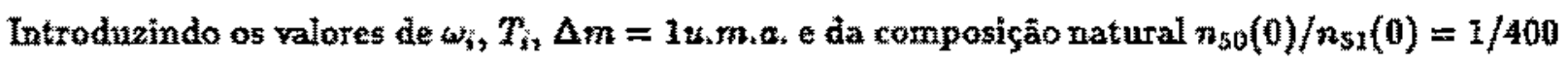
obstern-ge

$$
n_{30}(r)=\frac{1}{400} n_{0} \exp \left[-933 r^{2}\right]
$$

A fraç̄̄o de ions ${ }^{50} \mathrm{~V}$ coletados com enriquecimento de $10 \%$ é dada pela razão $R=N_{50} / N_{T}$ onde

$$
\begin{aligned}
N_{r} & =\int_{0}^{r 0} 2 \pi \operatorname{rn} r(r) d r \\
N_{t 0} & =\int_{0}^{r_{0}} 2 \pi \sin (r) d t
\end{aligned}
$$

Com os perfis de densidade $(5.1),(5.3)$ e $r_{0}=30 \mathrm{~mm}$ obtëm-se $R=0,0024$. Somente $50 \%$ dos íons säo transmitidos para coluna, o que resulta no custo enargético efetivo de $\sim 1000$ eV/fon transmitido. 0 custo energético araliado para separar o fon ${ }^{50} \mathrm{~V}$, com eariquecimento de $10 \%$, na centrifuga de plasma injuiada por arco no vácuo é entäo $1000 \mathrm{eV} / 0,0024$, $420 \mathrm{keV} / \mathrm{ion}$ separado. Esta avaliaçāo também pode ser feita a partir dos resultados obtidos para o magnésio. O magnésio ten a seguinte composiçăo natural: ${ }^{24} \mathrm{Mg}(78,8 \%) ;{ }^{25} \mathrm{Mg}(10,1 \%)$ e ${ }^{26} \mathrm{Mg}(11,1 \%)$. 0 perfil radial è da Figura 3.7, $n_{T}(r)=6 \times 10^{19} e^{-662,5 r^{2}}$ onde $n_{r}(r)=n_{24}(r)+n_{35}(r)+n_{26}(r)$

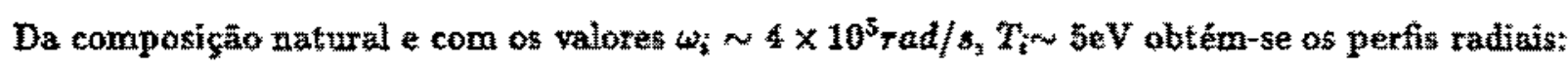

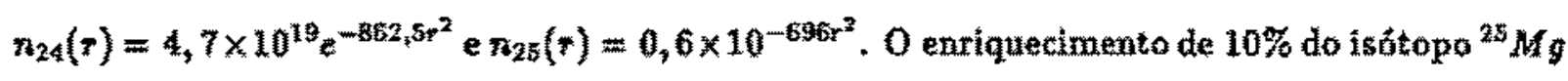


relativo eo isótopo ${ }^{24} \mathrm{Mg}$ ocorre, da Figura 3.21, entre 8 s pasiçōes radiais $r_{1} \sim 17,5 \mathrm{~mm}$ e $r_{2} \sim$

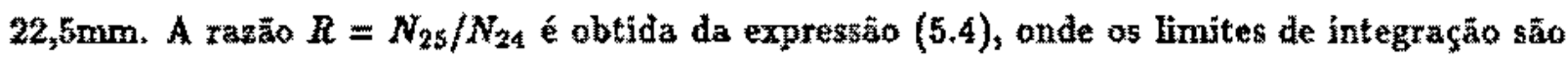
entre as posiçōes radiais $n_{1}=17,5 \mathrm{~mm}$ e $\tau_{2}=22,5 \mathrm{~mm}$. Com os perfis radiais de $n_{24}(r)$ e $n_{25}(r)$ resulta em $\mathrm{A}=0,14.0$ consumo energético efetío para cada ion é $\cdots 1000 \mathrm{eV} /$ ion $\mathrm{e}_{2}$ assim, para exriquecer cada ion ${ }^{25} \mathrm{Mg}$ com enriquecimento de $10 \%$ na centrifuga de plasma inieiada por arco no vácuo será consumido $\sim 1000 \mathrm{eV} / 0,14$ ou $\sim 7 \mathrm{keV} /$ ín separado. $O$ consumo energétíco para separar o lon ${ }^{50} V$ com enriquecimento de $10 \%$ será mator na razāo $(99,75 / 0,25) \times(10,1 / 78,8)=$ 51 , ou seja, $\sim 350 \mathrm{keV} /$ ion separado. Os valores dados na Tabela 1.4 para enriquecer o vanadio

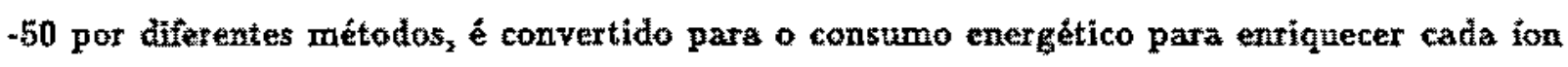
${ }^{50} \mathrm{~V}$ com exriquecimento de $10 \%$ obtendo-se: calutron $\left(6 \times 10^{6} \mathrm{keV} / \mathrm{ion}\right) ;$ laser $(500 \mathrm{keV} / \mathrm{ion})$; centrifuga mecänica (130 keV/ Ion); e ressonäncia fon ciclotronica (1900 keV/ion),

As seguintes comparaçöes podem sez feitas:

- Centrifuga de plasma iniciada por arco no yâcuo versus Calutron: Devido a enorme diferença no custo energético este tipo de centrifuga de plasma pode substituĩ vantajosar mente o Galutron. Alétn do mais, outra zantagem e capital que deve ser investido para

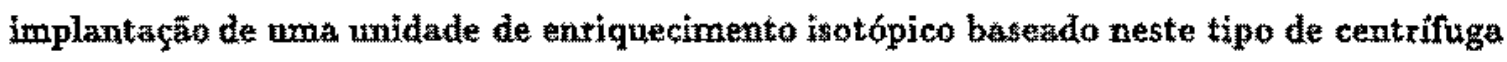
de plasma, que muto menor que a do Calutron.

- Centrífuga de plasma iniciada por arco no văcuo versus Laser: Neste caso, os dois métodos apresentam praticamente o mermo custo enetgético. A centrifuga de plasma teria a van" tagem sobre o Laser poís este só poderia star bintonizado na separaçẳo do ${ }^{50} \mathrm{~V}$ ao passo que, a centrifuga de plasma estaria apta a fazer separação isotópica sobre todos os ele-

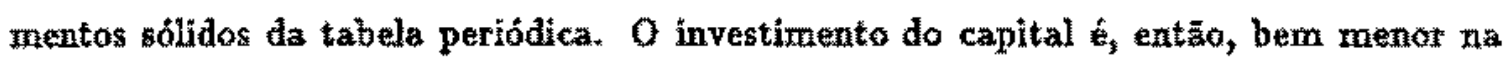
centrifuga de plasma o que a torna atrativa neste caso.

- Centrifuga de plasma iniciada por arco no vácuo versus centrífuga mecânica: $A$ centrifuga mecâtica apresenta urna certa vantagem sobre a centrifuga de plasma. No entanto no computo geral a centrifuga de plasma deve ser mais recomendada isto porque:

- para a obtençäo de urn entiquecimento de $10 \%$ viã centrifugaçäo mecânica será rê. querido um número muito grande de separadores em série/paralelo, o que quer dizer um investimento muito alto. Por outro lado, s centrifuga de plasma obterá um en- 
riquecimento de $10 \%$ num únito estágì, requerendo um investimento pequeno. Como 8 utilizaçäo de isótopos estáveis é para pequenas quantidades, a amortizaçāo do capital investido é lenta, o que entäo torna maís atrativo a ceritrifuga de plasma;

- para a separaçồ do vanádio na centrifuga mecânics deve ser procurado um composto do vanádio na forma gasosa que tenha uma pressāo de vapor elevada e este é o VF Este composto é muito corrosivo sendo isto urn ponto a favor para centrifuga de plasma que utìliza o ranádio na forma sólida.

- Centrífuga de plasma iniciada por arco no vắcuo versuś ressonância fon-ciclotrônica: a vantagem é para centrífuga de plasma que além do mais apresenta um investimento de capital menor para a implantaçŭ̌ de uma usina de separaçäo isotópica.

Em xesurno, para a separaçäo de isótopos estáveis em que o enriquecimento isotópico desejado näo seja muito elevado, a centrffuga de plasma iniciada por arco no vácuo apresenta boas perspectivas quando comparada com outros métodos.

\subsection{Enriquecimento do Urânio-235}

A outra categoria de isótopos que deve ser analissda é para fins energéticos, ísto é, o enriquecím xnento do uranio-235 a 2-3\% Primeiramente serố calculada a razäo $P / V_{\text {max }}$, onde $\mathrm{P}$ é a potencia consumida (kW) e $V_{\text {max }}$ é a funçäo valor (kgWU/s). A potência constumida pode set obtida da Figura 2.1 onde para $I_{\alpha} \sim 1,5 k A$ $U_{\mathrm{a}} \sim 35 V$ resultando em $P \sim 50 k W . O$ valor de $U_{\max }$ para a centrifuga de plasma pode ser obtido utilizando-se a mesma expressäo da centrifuga mecânica [84] ou sejs,

$$
U_{\max }=\frac{x}{2} D p_{0}(\alpha-1)^{2} l
$$

onde $\mathrm{D}$ é o coeficiente de difusão, $\rho_{0}=\mathrm{nM}$ a densidade e lo comprimento do separzador isotópico. O coeficiente de difusäo é obtido a partir da equaçäo da continuidade 


$$
\frac{\partial n}{\partial t}+\vec{\nabla} \cdot \vec{\Gamma}=0
$$

onde $\vec{\Gamma}=-D \vee n$

Como $\partial n / \partial t=0$, a seguñte equaça é obtida para $\mathrm{D}$ em coordenadas cilindricas

$$
\frac{D}{r} \frac{d}{d r}\left(r \frac{d n}{d r}\right)+\frac{d n}{d r} \frac{d D}{d r}=0
$$

Com o perfil da forma $n=n_{0} e^{-\left(r / r_{0}\right)^{2}}$ tem-se a soluçắo $D=\left(1 / r^{2}\right) e^{\left(r / r_{0}\right)^{2}}$, o coeficiente de difusäo dependendo só da forma do perfil da densidade. Para o plasma de urântó sấo esperados os seguintes valores: $n \sim 1 \times 10^{19} \mathrm{~m}^{-3}, T_{i} \sim 0,5 \mathrm{eV}, r_{t} \sim 50 \mathrm{~mm}$ e $\omega_{i} \sim 3 \times 10^{4} \mathrm{rad} / \mathrm{s}$, resultando en $D=1000 m^{2} s^{-1}$, para $r=r_{t}$. A funçăo valor $\operatorname{com} l=1 m_{3}, M=238$ u.m.a., $\alpha=1,03$ é $U_{\text {max }} \sim 2 \times 10^{-2} \mathrm{~kg} S W U / h$ levando a $P / U_{\text {max }} \sim 2500 \mathrm{kWh} / \mathrm{kg} S W U$. Para a centrifuga mecantca $P / U_{\max } \sim 100-250 \mathrm{kWh} / \mathrm{kg} S W U$ na separaçāo do orānio.

A razăo $\mathrm{kWh} / \mathrm{kgSWU}$ para o uränio pode também ser avaljada da seguinte forma. A energia para produzir cada ín é $\sum_{\text {i }} \sim 500 \mathrm{eV}$, e como $\sim 50 \%$ sä० transmitidos para coluna de plasma o consumo efetivo é então $\sum_{i e f} \nsim 1000 \mathrm{eV} /$ fon. 0 número de íons na coluna com $1 \sim 1 \mathrm{~m}$, $\mathrm{n} \sim 1 \times 10^{19} \mathrm{~m}^{-3} * \mathrm{r}_{\mathrm{e}} \sim 50 \mathrm{~mm}$ é $\mathrm{N}_{i}=\pi r_{0}^{2} \ln \sim 7,8 \times 10^{26}$ ions. A energia total depositada nos fons é $\mathrm{N}_{i} \sum_{\mathrm{inf}}=12,5 \mathrm{~J}$ e com $\tau \simeq 1$ ims resulta na potencia $P \sim 0,83 \mathrm{~kW}$. $O$ fluxo de massa que cruxa uma seçăo transversal $A=\pi r_{k}^{2}$ e $F=n m_{i} t_{z} A\left(k_{g} / s\right)$, onde, para o urânío, $m_{i}=2384 . m a$. e $u_{z}+0,4 \times 10^{4} \mathrm{~m} / \mathrm{s}$ (supondo que a velocidade de deriva axial para o urânio seja próxima à do clumbo, Tabela 2,4). A funçäo valor e $U_{m a x}=F(\alpha-1)^{2}(\mathrm{~kg} S W U / \mathrm{s})$. onde, para enriquecer o uränio $\operatorname{com} a=1,03$ tem-se $U_{\text {max }} \sim 1,1 \times 10^{-7}(\mathrm{~kg} S W V / \mathrm{s})$ e a razäo $P / U_{\max } \approx 2000(\mathrm{kWh} / \mathrm{kg} S W U)$.

A centrífuga mecänica é o método mais vantajoso neste caso, isto porque, embora o custo para a implantaçă̌o de uma usina sejo muito malor a grande quantidade de material que é consumida 
amortiza rapidamente o investimento realizado. Para zentrifuga de plasma iniciada por arto no vácuo tornar-se competitiva, $U_{\text {max }}$ deveria ser pelo menos uma ordem de grandeza maior (para a 1 fxo). A única maneira de se fazer isto, é aumentar densidade, como pode ser visto da equaçäo (5.5), mas isto implica em sumentar a corrente de arco $\mathrm{I}_{a}$. Embora, possa ser esperado un aumento da densidade com a corrente de arco (ver Figura 2.26), a potêneia consumida aumentará também, visto que $P=I_{a} V_{a}$, onde tanto $\mathrm{I}_{a}$ como $\mathrm{U}_{a}$ serăo maiores para densidades matores. Em resumo, a centrífuga de plasma íniciada por arco no vácuo é inviável para separar urãnio quando comparada com centrî́fuga mecảnica.

\subsection{Conclusão}

Dos resultados experimentais obtidos e da comparaçāo entre os vários métodos de separaçăo isotópica seguintes vantagens e desvantagens podern ser resumidas para a centrifuga de plasma inicisda por arco no vácuo:

- Vantagens

- versatilidade na separaçăo isotópica de isótopos estáveis de metais ou mistura de metais. Qualquer elemento sólido ou composto nấo condutor pode também ser feita a separaçäso isotópica impregnando-os numa matriz condutora.

- o segarador isotópico baseado neste princípio sexia compacto e apresentando uma necessidade de inqestimento mezor que os outros métodos analisados para a implantaçăo de uma unidade de separaçāo isotópicica.

- Desvantagens

- a densidade é baixa onde o fator de separaçấo é alto (e vice-versa), sendo o ideal ter alta densidade juntamente com alto enriquecimento.

- a obtençẵo de enriquecimento alto (> 50\%) ê muito dificil, esta dificuldade aumenta para massas atzmicas maiores ( $>100 \mathrm{u}, \mathrm{m} . \mathrm{a}$.) . Pode ser esperado enriquecimento alto quando a diferença de massa entre os isótopas é grande (exemplos ${ }^{40} \mathrm{Ca}-{ }^{48} \mathrm{Ca}{ }^{90} \mathrm{Zr}$

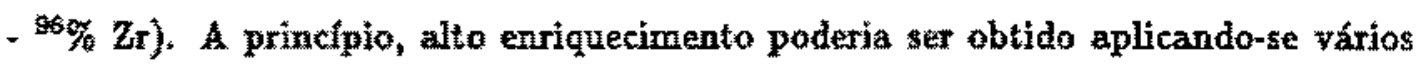


estágios de enriquecimento, isto é, o material enriquecido coletado para certo raio seria novamente compactado e utilizado como catodo para um novo estágío de enriqueci mento. Depois de um terto número de estágios seria obtido o enriquecimento desejado. A andise deste processo revelou dois comportamentos distintos [85]. Quando o isótopo mais pesado era o de interesse (o que significa rajos mais externos da coluna), s utilização de yắrios estágios de enriquecimento nāo representou nenhuma vantagem. A utillizaçẵo de estágios de enriquecimento só se revelou atraente quando o isótopo mais leve é o de interesse (localizado para taios mais internos da coluna).

Como já foi dito na introduçăo, os işótopas estáveis utilizados atualmente são da ordem de 200, com diferente graus de enxiquecimento. lsto implica que dificilmente haverá um separador isotópico nniversal, ou seja, aplicável para todos os isótopos estáveis e com grau variado de enriquecimento isotópico. Provavelmentte sera necessário a ntilizą̧ăo de doís ou mais métodos diferentes para realizar esta tarefa Do exposto, s centrifuga de plasma iniciada por arco no yácuo poderá sér útil na tarefa de enriquecimento de iśtotopos estányeis naqueles casos onde o enriquecimento desejado nāo seja muito alto. O enriquecimento alto só seris possivel nos casos onde a diferença de massa entre os iśótopos for grande. 


\section{CAPÍtULOO 6}

\section{CONCLUSÃO}

Neste trabalho foram apresentados os resultados experimentais obtidos no experimento centrfuga de plasma iniciada por arco no vácuo, PCEN, desenvolvida no Laboratónio Associado de Plasma do Instìtuto Nacional de Pesquisas Espaciais (LAP/INPE).

Inicialmente foi feito um relato das necessidades de isótopos, especjalmente o de isótopos estaveis, e apresentados alguns métodos para a separaçăo isotópica. Dentre estes métodos foi apresentado o príncipio de funcionamento do dispasitivo PCEN.

O plasma na PCEN é gerado por uma descarga em arco no vácuo. Foram apresentadas di. versas características desta descarga, os modelos existentes para descreve-la. Da medida da impedância deste plasma, foi possível projetar construír un circuito formador de pulso, com impedância casada corn a do plasma. Dm pulso de corrente de arco, praticamente constante por cerca de 14ms foi obtido. Este pulso, possibilltou que város parämetros do plasma e da coluna de plasma em rotação, fossem obtidos como funçâo do tempo. Foram reaijzadas medidas de di* versos parämetros para oito diferentes plasmas metảlicos. Estas medidas permitiran determinar certos paràmetros relełantes para a separaçüo isotópica tais como: a densidade, a temperatura, a velocidade axial da coluna de plasma o consumo de energia para a produçào de cada íon.

O plasma transmitido através da grade de tungstënio, constituindo-se assim na coluna de plasma em rotą̧äo, foi descrita utilizando-se um modelo de fluído já disponível. Todăas as aproximaçöes feitas neste modelo, foran sempre que possivel, justificadas com as medidas experimentais realjzadas. Foram obtidos experimentalmente os perfis radiaís do potencial de plasma, da densidade, 
da velocidade angular e do fator de separaçẫo. Os tesultados experimentait mostraram aer possível ume descrição teórica da coluna de plasma em rotação através de um modelo de fúdo simplificado.

As medidas realizadas da temperatura. revelaram um valor relatimamente alto para fins de separaçāo isotópica. Com a finalidade de dimintur a temperatufa, assim aumentar of for de separaçăo, os gases hidrogênio, hello argỏnio fortam introduzldos separađärnente na cămara de vácuo. A presenf̧a de um gás provocau mudanças profundas no plasma metálico. Foram estudados os efeitos do gás nos parámetros: temperatura de elétrons, densidade, velocidade angular no fator de separação, 0 efeito de todas estas mudanças ocorridas no plasma metálico, fol um decréscimo no fator de separaçato, quando comparado com o velor obtido na ausência de gás na càmara de vácuo. Disto concluin-se que, o melhor desempenho deste tipo de separador isotópico, ocorre na condição de melhor vácuo possível.

Um estudo comparativo entre os diversos métodos de separaçāo isotópica $e_{\text {; }}$ a centrífuga de plasma iniciada por arco no vắcuo foi realizado. Neste estudo comparativo, foram utilizados os resultados esperados para a separação do isótopo do vanádio e do turânio, pelos metódos de separaçăa apresentados. Este estudo possibilitou delimitar a possivel utilização da centrffuga de plasma inùciada por arco no vácuo, como um separador isotópico para isótopos estáveis. Dos resultados experimentais obtidos, foi possível apontar as vantagens e desvantagens deste dispositivo como urn separador isotópico.

A continuaçấo do trabalho junto ao projeto PCEN (aproveitando a capacidade instalada) envolverá tanto fenömenos de física básica quanto aplicada. Os fenömenos básicos a serem estudados sẫo relativos à descarga em arco no vácuo e as oscilaçôes da coluna de plasma em rotaçāo. Na parte aplicada, será dada continuidade a construção de um espectrômetro de massa tipo setor magnético com varredura temporal do espectro de massa, possibilitando a obtençāo to fator de separaçä̀ durante urn único pulso. As características da descarga em arco no văcuo tais como a alta densidade, o alto grau de ionizaçäo, fons de cargas multiplas e com energia

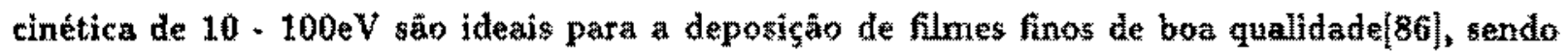
esta também uma das possíveis aplicaçổ a serem desenvolvidas.

Pars fins de separaçăo isotópica, algumas modificaçöes deveräo ser feitas tás como: aumentar \& 
dimensăo axial; tornar o campo axial mais unitorne; melhorar a qualidade do vácuó substituir o laser por outro sistema de gatillho; melhorar a transmissão de lons para a coluna de plasma; modificar o anodo ou até mesmo estutlar outras fontes de fons de alta densidade e temperatura mais baixa. 


\section{Referências Bibliográficas}

[1] E.Engels and F.Verheest, "Wave propagation in rotating plasmas and influence of the Coriolis force", Astrophysics and Space Science, vol. 37, pp,427-440, 1975.

[2] W.Horton and J.Liu, "Drift waves in rotating plasmas", Phys, of Fluids, vol.27, no.8, pp.2067-2075, 1984 .

[3] W.Horton, J.Liu, J.D.Meiss and J.E.Sedlak, "Soltary vortices in a rotating plasma", Fhys. of Fludds, vol. 29, no. 4 , pp.1004-1010, 1986 .

[4] S.N.Paw, P,K.Kashyapi and B.Chakraborty, "Nonlinear effects on the propagation of waves in magnetiqed rotating plasma", IEEE Trans. on Plasma Sci., vol.20, no.5, pp. 481-486, 1992.

[5] B.Lehnert, "Rotating plasmas", Nuclear Fusion, vol.11, pp.485-533, 1971.

[6] G.Friendlander and H.N.Wagner Jr.(Eds.), "Separated isotopes: Vital tools for science and medicine", Nat.Acad,Press; Washington DC, 1982.

[7] S.Villani (Ed.), "Uranium Entichment", Springer-Yerlag: New York, 1979, d.1.

[8] P.Louret, "Review of isotopic plasma separation processes", Prockedings of the Second Workshop on Separation Phenomena in Liquids and Gases, Versailles, July 10-12, Vol.1, pp. 5-104, 1989 .

[9] L.Danielson, "Review of the critical velocity of gas-plasma interaction I: Experimental Observations", Astrophysics and Space Science, vol. 24, pp.459.485, 1973.

[10] J.C.Sherman, "Review of the critical velocity of gas-plasrna interaction II: Theory", Astrophysics and Space Science, vol. 24, pp.487-510, 1973.

[11] B.W.James and S.W.Simpson, "Isotope separation in the plasma centrifuge" , Plasma Phys., vol.18, pp.289-300, 1976. 
[12] M.Krishnan, M.Geva and J.L.Hirshfield, "Plasma centrifuge" , Physical Rev. Letters, val, 46, no.1, pp.36-38, 1981 .

[13] $\mathrm{C} . \mathrm{W}$.Kimblin, $\mathrm{A}$ review of arcing phenomena in Facuum and in the transition to atmospheric pressure arcs", IEEE Trans, on Plasma Sci., vol. PS-10, no, 4, pp.322-330, 1982.

[14] H.C.Miller, "A review of anode phenomena in vacuum arcs", IEEE Trans. on Plasma Sci., vol. PS-13, no. 5, pp.242-252, 1985.

[15] H.Schellekens, "The diffuse vacuum-arcs; A definition", TEEE Trans; on Plasma Sci, vol. PS-13, no, 5, pp.291-295, 1985.

[16] J.Watanuki, R.S.Dallaqua E.Del Bosco, "Manual de Operaçäo de um laser de $\mathrm{CO}_{2}$ pulsado de $40 M W^{\prime}$, INPE-4365 - NTI/282.

[17] T.P.Hughes, "Plasmas and Laser Light ", Adam Hilger Itd.: London, 1975, ch.8.

[18] J.E.Daalder, "Energy dissipation in the cathode of a vacuurn are", J.Phys. D. Appl.Phys., vol. 10, pp,2225-2234, 1977 .

[19] G.A.Farral, in "Vaccurn Arcs - Theory and Application (J.M.Lafferty, Ed.), Wiley: New York, 1980, ch.2.

[20] T.Kaneda, E.Kaneko, S.Yanabu and H.Ikeda, "The characteristits of vacuum arcs with magnetic fields parallel to its columns", Physica, 104C, pp.124-129, 1981.

[21] B.E.Djakov and R.Holmes, "Cathode spot division in vacuum arcs with solid metal cathodes", J.Phys. D: Appl. Phys, vol. 4, pp.504-509, 1971.

[22] V.I.Rakhowsky, "State of the art of physical models of vacuum arc cathode spots", IEEE Trans. on Plasma Science, vol. PS-15, no. 5, 481-487, 1987.

[23] A.Z.Nemirovskii and V.F.Puchkarev, "Arc voltage as a function of cathode thermophysical properties", J.Phys. D* Appl. Phys., vol. 25, pp.798.802, 1992.

[24] M.S.Agarwal and L. Holmes, "Arcing voltage of the metal vapour vacuura arcs", J.Phyt. D: Appl. Phys, vol. 17, pp.757.767, 1984.

[25] C.W.Kimblin, "Cathode spot erosion and ionization phenomena in the transition from vacuum to atmospheric pressure arcs", J.Appl. Phys., vol. 45, no. 12, pp.5235-5244, 1974. 
[26] I.G.Brown and X.Godechot, "Vacuum are ion charge state distributions", IEEE Thans, on Plasma Sel, vol. 19, no.5, pp.743-717, 1991.

[27] A.A.Plyutto, V.N.Ryzkov and A.T.Kapin, "High speed plasma streams in vacuum arcs", Sov.Phys. JETP, vol. 20, no.2, pp.328-337, 1965.

[28] W.D.Davis and H.C.Muller, "Analysis of the electrode products emitted by de arcs in a vacuur ambient" J.Appl. Plys, yol.40, no.5, pp.2212-2221, 1969.

[29] J.Kutwner and H.C.Miller, "Integrated ion flux emitted from the cathade spot region of diffurive vecuum arc", J.Rhys. D: Appl. Phys, vol. 25, pp.686-693, 1992.

[30] C.W.Kimblin, "Erosion and ionization in the cathode spot regions of vacuum arcs", J.Appl. Phys., vol. 44, no.7, pp.3074-3081, 1973.

[31] G.A.Lyzbinov and V.I.Rakhovsky, "The cathode spot of a vacuum are", Sov.Phys. Usp.: vol. 21, no.8, pp.693-718, 197\%

[32] E.Hantzche, "Theory of cathode spot phenomena", Physica, vol. 104C, pp.3-16, 1981.

[33] E.I.Murphy and R.Y.Cood $J_{r}$, "Thermoionic emission feld emission, and the transition region", Physical Review, vol. 102, no.4, pp.1464*1473, 1956.

[34] Y.A.Ivanov, B.Jütituer and H.Pursch, "Time resolyed measurements of the parameters of arc cathode plasmas in yacuum", IEEE Trans. on Plasma Science, vol. PS-13, no.5, pp.334336,1985 .

[35] S.M.Shkol'nik, "The plasma parameters in the interelectrode gap of the vacuum arc", IEEE Trans. on Plasma Science, vol. PS-13, No.5, pp.336-338, 1985.

[36] J.Kutzner and M.Glinkowski, "Electron temperature and probe floating potentials in a plasma of the low current vacuum arc", IEEE Trans. on Plasma Sci., vol. PS*11, no.3, pp.233-238, 1283

[37] J.Kutzmer and H.C.Miller, "Ion flux from the cathode region of a vacuum are", IEEE Trans, on Plasma Scï, vol.17, no.5, pp.683-694, 1989.

[38] G.A.Lyubimov, "Mechanism of acceleration of cathodic vapor jets", Sov.Phys. Dokl, vol. 20, no.12, pp.830-832, 1976 . 
[39] G.A.Lububimov, "Dynamics of cathode vapor jets", Sov.Phys. Tech.Phys., vol.22, no.2, pp.173-177, 1977.

[40] M.P.Zektzer and G.A.Lyubimov, "Fast plasma jets from the cathode spot in a vacuurn arc", Sov.Phys. Tech.Phys, vol. 24, no.1, pp.1.5, 1979.

[41] B.Ya Moizhes and V.A.Nemchinskii, "Erosion and cathode jets in a vacuum are", Sov.Phys* Tech.Phy.;., wol. 25, no.1, pp43-48, 1980.

[42] E.Hantasche, "Theory of the expanding plasma of vacurm arcs", J.Phys. D: Appl.Physu, vol. 24, Pp.1339.1353, 1991.

[43] V.L.Sizonenko, P.I.Markov, L.I.Kiselevskii and G.G.Shergin, "Buneman instability in an arc cathode spot", Sov.Phys. Tech,Phys., vol.29, no.11, pp.1259-1263, 1984.

[44] N.Graneau, "An electrodynamic vacuum arc ion acceleration mechanism based on Amperets force law", IEEE Trans. on Plasma Science, vol.21, no.6, pp.701-713, 1993.

[45] J.E.Daalder, "Random walk of cathode arc spots in vacuum", J.Phys. D: Appl. Phys., vol. 16, pp.17\%27, 1983.

[46] E.A.Jitvinov, G.A.Mesyats and D.I.Proskuroyskii, "Field emission and explosive electron emistion processes in vacuum dìcharge", Sov.Phys. Usp., vol.26, no.2, pp.138-159, 1983.

[47] G.N.Fursey, "Field emission and vacuum breakdown", IEEE Trans, on Electrical Insulation, vol.EI-20, no.4, pp.659-670, 1985.

[48] G.A.Mesyats, "Explosive processes on the cathode in a vacunm discharge", IEEE Trans. on Electrical Insulation, vol.EI-18, no.3, pp.218*225, 1983.

[49] E.A.Litvinov, "Theory of explosive electron emission ${ }_{3}^{3}$ TEEE Trans. on Electrical Insulation, vol.EI-20, no.4,pp.683-689, 1985 .

[50] G.A.Mesyats, "A cyclical explosive model of the cathode spot", IEEE Trans. on Electrical Insulation, vol. EI-20, no.4, pp.729-734, 1985.

[51] E.A.Litvinov, G.A.Mesyats, A.G.Parfyonov and N.B.Volkov, "An explosive emission model of the vacuum cathode spot", XIII ISDIEV, Paris, pp.158-160, 1988.

[52] A.C.Parfyonov "Concerning the type of cathodes spots", IEEE Trans. on Plasma Sci., vol.PS-13, no.5, pp.27\% $280,1985$. 
[53) V.I.Rakhorsky, "Critical parameters of the cathode region of a vacuum arc", IEEE Trans. on Plasma Sti. vol.18, no.3, pp.677-681, 1990.

[54] B.Jüttner, "Characterization of the cathode spot", IEEE Thans, on Plasma Sci, vol,PS-15, no.5, pp.474-480, 1987.

[55] V.F.Puchkarev and A.M.Murzakayev, "Current density and the cathode spot lifetime in a vacuum are at threshold currents", J.Phys.D: Appl. Phys, vol.23, pp.26-35, 1990.

[56] G.Ecker, in "Vacuum Arcs-Theory and Application", (J.M.Lafferty, Ed.), Wiley: New York, 1980, ch.7.

[57] G.Ecker, "Review of present understanding of electrode phenomena" ${ }_{1}$ IEE E Trans. on Glec. trical Insulation, vol. EI-16, no.3, pp.243-252, 1983.

[58] O.Morimiya, S.Sohuna, T.Sugawara and H.Mizutani, "High current vacuum ares stabilized by axial magnetic fields", IEEE Trans ${ }_{*}$ on Power Apparatus and Systems, vol.PAS- $92_{\text {z }}$ no.5, pp.1723-1732, 1973.

[59] J.Y.R.Herberlein and D.R.Forto, "The interaction of veuum are ion currents with axial magnetic fields", IEEE Träns. on Plasma Sci., wol.PS-11, no.3, pp.152-159, 1983.

[60] M.G.Drouet, "The physics of tite retrograde motion of the electric arc", IEEE Trans. on Plasma Sci., vol.PS-13, no.5, pp.235-241, 1985.

[61] E.Del Bosco, "Centrífuga de plasma com descarga em arco no vácuo aplicada a teparaçäo de isótopos estáneis", Tese de Doutorado, INPE, 1989.

[62] P.J.Evans, F.J.Paoloni, J.T.Noorman and J.V.Whichello, "Measurements of mass separam tion in a vacum are centrifuge", J.Appl.Phys., vol.66, no.1, pp.115-118, 1 July 1989.

[63] J.V.Whichello, P.J.Evans and F.J.Paoloni, "Measurenents of isotope separation in a vacuum arc centrifuge", Proccedings of the Second Workshop on Separation Phenomena in Líquids and Gases, Verssilles, Jnly 10-12, 1989, vol.1, pp.119.137.

[64] R.S.Dallaqua, E.Del Bosco, G.O.Ludwig e A.Montes, "Projeto e construçäo de um circuito formador de pulso para a centrifuga de plasma", INPE - 5161 RPE/639, Outubro, 1990. 
[65] R.S.Dallaqua, E.Del Bosco, A.Montes and G.O.Ludwig, "Plasma impedance and matched impedance $\mathrm{LC}$ network in a plasma centrifuga", Rev. de Física Aplicada e Instrumentação, vol. $v_{3}$, no.4, pp.508-517,1990.

[66] H.S.Neqưv, E.Del Bosco and R.S.Dallaquta "Preliminary results of cathode erosion in a vacuum arc discharge ${ }^{n}$, 20. Encontro Brasileiro de Física dos Plasmas, 27-29 Outubro, Serra Negra, pp.34-37, 1993.

[67] R.P.da Siva, "Transporte de partículas e energia no plasma do Tokamak TBR-1: Di* agnóstico e estudo experimental", Tese de Doutorado, IFUSP, 1989.

[68] R.P.da Silva, R.S.Dallaqua and L.C.Nascimento, "Langmuir probe measurements in TBR-1 Tokamak", Rev de Física Aplicsda e Instrumentaçāo, vol.s. no 2, pp.175-193, 1990.

[69] P.M.Chung, L.Talbot and K.J.Touryan, "Electric Probe in Stationary and Flowìng Plasmas - Theory and Application, Springer-Verlag: New York, 1975, pp.35.

[70] R.R.Prasu, R.Consiglio and M.Krishnan, "Power flow and cathode erosion in a vacuum-arc centrifuge", IEEE Trans. on Plasma Sci., vol.PS-14, no.4, pp.498-502, 1986.

[71] F.F.Chen, "Lntroduction to Plasma Physics and Controlled Fusion, vol.1, Plenum Press: New York, 1984, pp.190.

[72] F,F,Chen, in "Plasma Diagnostic Techniques "(R.H.Hudlestone and S.L.Leonard, Eds.), Academic Press: New York, 1965, pp.178.

[73] S.Anders, A.Anders, K.M.Yu, Y.Yao and L.G.Brown, "On the macroparticle flux from vacumm arc cathode spots", IEEE Trans on Plasraa Sci-, yol.21, no.5, pp.441-446, 1993.

[74] J.A.Bittencourt, "Theoretical behayiour of fully lonized multiple species magnetized plas" mas under rotation", INPE-3915-RPE/510, Jun, 1986.

[75] J.A.Bittencourt and G.O.Ludwig, "Steady state belaviour rotating plasmas in a vacuum arc centrifuge", Plasma Phys, and Controlled Fusion, vol.29, no.5, pp.601-620, 1987.

[76] S.I.Eraginskii, "Transport processes in a plasma", in Reviews of Plasma Physics (M.A.Leontovich, Ed.), Consultants Bureau: New York, 1965, p,205.

[77] E.Del Bosco, S.W.Simpson, R.S.Dallaqua and A.Montes, "Speed of rotation in a vacuum are centrifuge", J.Phys. D: Appl. Phys., vol.24, pp.2008-2013, 1991. 
[78] R.R.Prasad and M.Krishnan, "Theoretical and experimental study of rotation in a yacuum are centrifuge", J.Appl.Phys vq $_{\text {q }}$ vol.61, no.1, pp.113-119, 1 Jan.1987.

[79] E.Del Bosco, R.S.Dalaqua, J.A.Bittencourt and G.0.Ludwig, "Vacutum-arc plasma centrifuge experiment", IEEE Trans. on Plasma Scï, vol.17, no.5, pp.701-704, 1989.

[80] L.M.Biberman, V.S.Vorob "ev and I.T.Yakubov, "Kinetics of Nonequilibrium Low" Temperature Plasmas", Consultants Bureau: New York, 1987.

[81] I.I.Aksenov, L.L.Konovalov, V.G.Padalka, V.L.Sizonenko and V.M.Kharoshikh, "Instabill* ties in the plasma of a vacuum are with gas in the discharge gap: 1", Sov.J.Plasma Phys., vol.11, no.11, pp.787-791, 1985.

[82] I.I.Aksenov, I.I.Konovalov, V.G.Padalka, V.L.Sizonenko and V.M.Kharoshikh, "Instabili" ties in the plasma of a vacuum are with gas in the discharge gap: II" Sov.J.Plasma Phys.; vol.11, no.11, pp.791-794, 1985 .

[83] M.Mitchner and C.H.Kruger Jr, "Partially Ionized Gases", John Wiley \& Sons: New York, 1973, pp. 230.

[84] F.Boeschoten and N.Nathrath, in Uranium Enrichment (S.Villani Ed.), Springer-Verlag; New York, 1979, pp.297.

[85] M.Krishnan and R.R.Prasad, "Parametric analysis of isotope enrictunent in a vacuum-arc centrifuge", J.Appl.Phys., vol.57, no.11, pp.4973-4980, 1 Jume 1985.

[86] P.C.Johnson, in Plysics of Thin Films, vol.14 (M.H.Francombe and J.L. Vosien Eds.), Academic Press; Sann Diego, 1989, pp.129. 
APÊNDICES 
REALA Y (60), YP (60), T, TOUT, RELERR, ABSERE, NORK (303)

DIMENSION XT(300), YC (300)

COH 10 N N, RLOAD, XELOAD

COMON RP $(30), R C(30), R L(30), C(30), R=(30)$

INTEGER WEON, IFEAG, IWORK (IS)

EXTERNAL $\mathbf{F}$

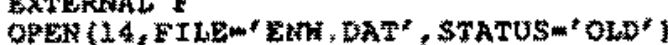

c

OPEN (2t

s: -22

DO $300 \mathrm{~T}=1, \mathrm{~N}$

RP $(I)=0.03$

$R G(x)=2, E+5$

Fa, $(x)=.52+3$

C(I) $-7.55-3$

READ $(24,0)$ ate $1 x$

$x(\boldsymbol{z})=0$.

160 contrivus

RLOAD $=40,8-3$

ALYOAD-O

vomit.

DO $2 B 0$ O $X=1$, NA

IIm

$\boldsymbol{I}+\boldsymbol{I} I+\mathrm{N}$

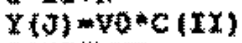

200 CONTrNUE

io

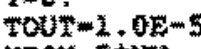

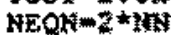

EELERR -1 整-8

ABSERR $=1$. $E-8$

If $L=R O=1$

$00500 \mathrm{r}=\mathrm{m}, 300$

$X x^{2}(I)=0.0$

$500 \mathrm{Yc}(\mathrm{x})=0.0$

Do $300 \quad K=1,300$

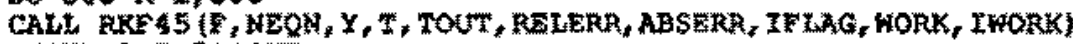

A TOt

c TIF 302, ATOUT, Y (1), TELAG

WRT TE $\{15,301)$ ATOUT, $\$(1)$, IFIAG, $K$

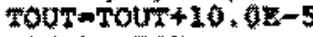

X

$x C(R)=\times(1)$

300 CONTTEVE

WhTt $(15,303)$

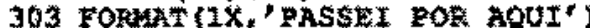

CALL GRAE (XW, YC)

301 EOAMAT $\left(2 E_{2} 2.4,5 x, 12,5 X, 13\right)$

302 mowat (2F12,4,12)

axt)

c.

SUBROUTWE F $(T, X, Y Z)$

FGAL* $Y(60), Y P(60)$

COAON NN, RLOAD, ALIOAD

Con

WNW $m$ 2* WN

WII $=\mathrm{kN}+1$

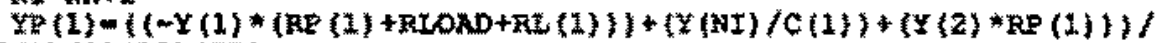

S(A2) (1) +BLIDAD)

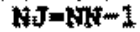

HKK $=$ WIN -1

DO 500 int 2 , NJ

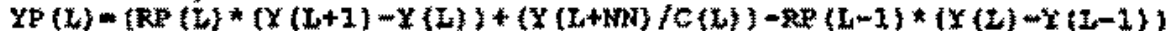

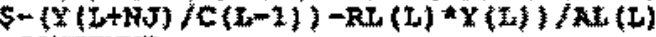

500 CONTINUE

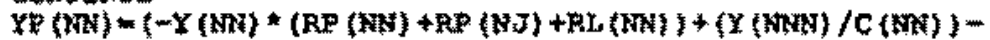




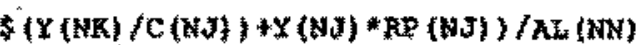

DO $600 \mathrm{MWN}, \mathrm{NK}$

$X P(M)-Y(K-N J)-Y(M-N N)-Y(M) /(C(N-K N) * R C(M-N N))$

600 iCONTINUE

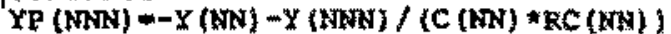

RETURN

$\mathbf{c}$

ZND

c

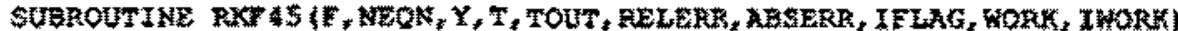

IHTEEER NEON, IFLAC, THORK (5)

DOUBLE PRECISTON X [NEON], T, TOUT, RCLERE, ABSERR, WORK (

SXTERHAL $\bar{E}$

c

INTEGER $\mathrm{Ki}, \mathrm{K} 2, \mathrm{~K} 3, \mathrm{KA}, \mathrm{K5}, \mathrm{K} 6, \mathrm{~K} 1 \mathrm{M}$

- $X I Y M \mathrm{NEON+1}$

$K 1-K I M+1$

K2 $m \mathrm{MI}+\mathrm{NBON}$

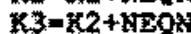

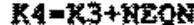

KS-MCHEON

6

$\mathrm{K} G=\mathrm{K} S+\mathrm{KEQ} \mathrm{QN}$

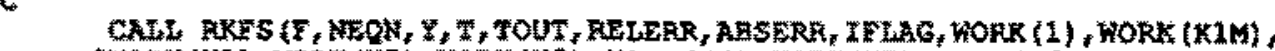
\$WORE $\{\mathrm{K} 1\}$, WORK (K2), WORR (K3), HORR \{R4), WORK (K5), WORK (K6)

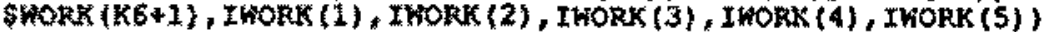
RETUR

$\stackrel{\mathrm{c}}{\mathrm{c}}$ ENDD

6

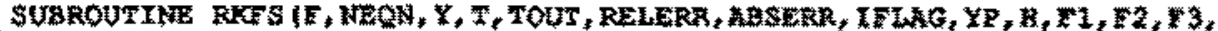

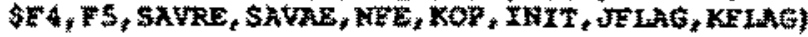

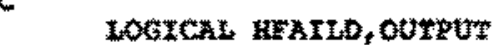

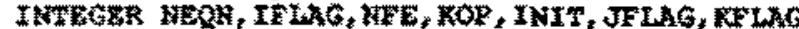

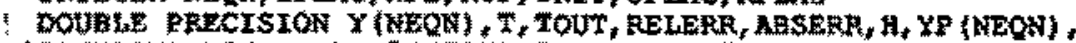

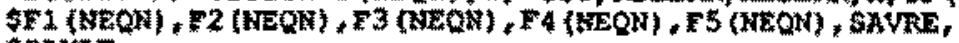
SSAVAE

EXTERAN $E$

DOUSt,E PRECISION $A, A E$, DT, EE, EEOET, ESTTOL, ET, HTH, REMUN, RER,

\$SCALE, TOL, TOLN, TWOERS, U2, 6, XPR

IWTEGER $\mathrm{R}$, MAXNTE, METAG

$c$

DOUBLE DRECISION DABS, DWAX, BWEWI, DSTGH

c

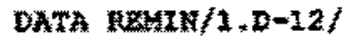

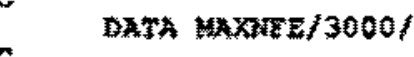

$c$

6

DATA wOFP, U26/4,4D-16,5.72D-157

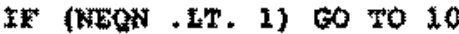

IF (1RELERR LTT O.ODO) OOR. (ABSERR .LT. 0.ODO) CO TO 10 MFIAGMIABS (IFLAG)

IF (MELAC ,GE. 1) .AND, (MFLAE .LE. B) GO TO 20

10 IFLACm

RETURA

c

20 If (1)

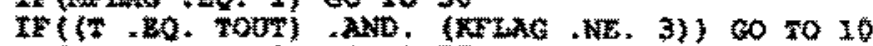

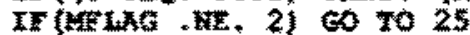

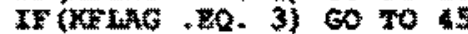

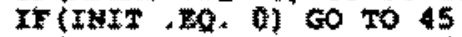

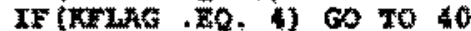

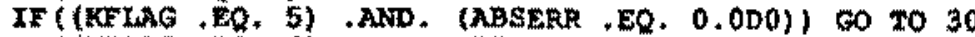

IF ( (KFLAG, EO, 6) .AND. (RELLERR, ISE SAVRE) .AND.

S(ABSERR , LE. SAVAE)) GO TO 30 
$c$

25 TF IIFLAG , 20. 3) 60 to 45

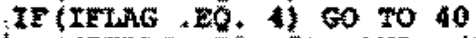

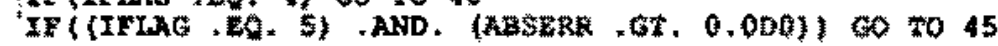

6

c

30 \$TOR

10 NFrm

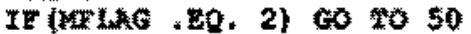

15 IELACDTHA

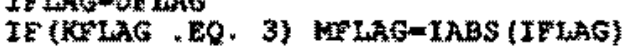

50 IFISG =IRTAG

XTLAG $=0$

SAVTREMELEERR

MAVAEMAESERR

c

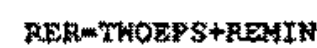

IF (NELERR , TE. REE) 607055

RELLER:

Ir: 2 G

XFLAG-3

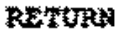

55 DT-

IT) (MAG . Be, 1) to To 60

$\therefore 00$ 50 80

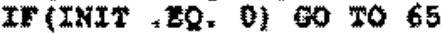

$\mathrm{c}$

60 INIT $=0$

$\mathrm{KOZ}=\mathrm{O}$

A-T

CALS: $(A, Y, X P)$

सT: 1

IF r $^{2}, \mathrm{NE}$. TOUn

If

BETURN

65 INITH'

FMDAES (DW)

TOLNEO.

DO $70^{\circ} \mathrm{x}=\mathrm{T}$, NEON

TOL=PEY SRR DAES $(Y(K))+$ ASSEH

IFE (TOE .LE, 0.$)$ SO TO 70

Trot: $*$ Tot

YPR-DASS (YP (K)

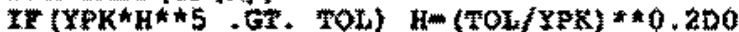

70 contrinut

IF (TOL),

B-DMAX1 (A, V26*DAAX1 (DABS (

s JFLAG-YSIGW $(2$, IFLAG)

C

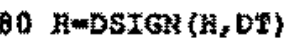

IF (DABS (A) .GE. 2, ODOADABS (DT) XOP-XOR+1

IF (KOP .NE . 100) to 3085

Kop $=0$

IFLAG'm?

RETURN

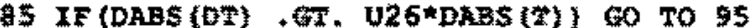

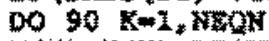

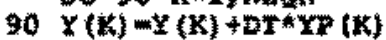

$x=T$ Tht

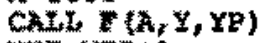

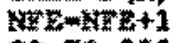

60 整 300

c

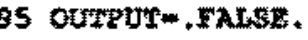

SCALE-2, ODO /RELERR

AE-SCALE*ADSER 


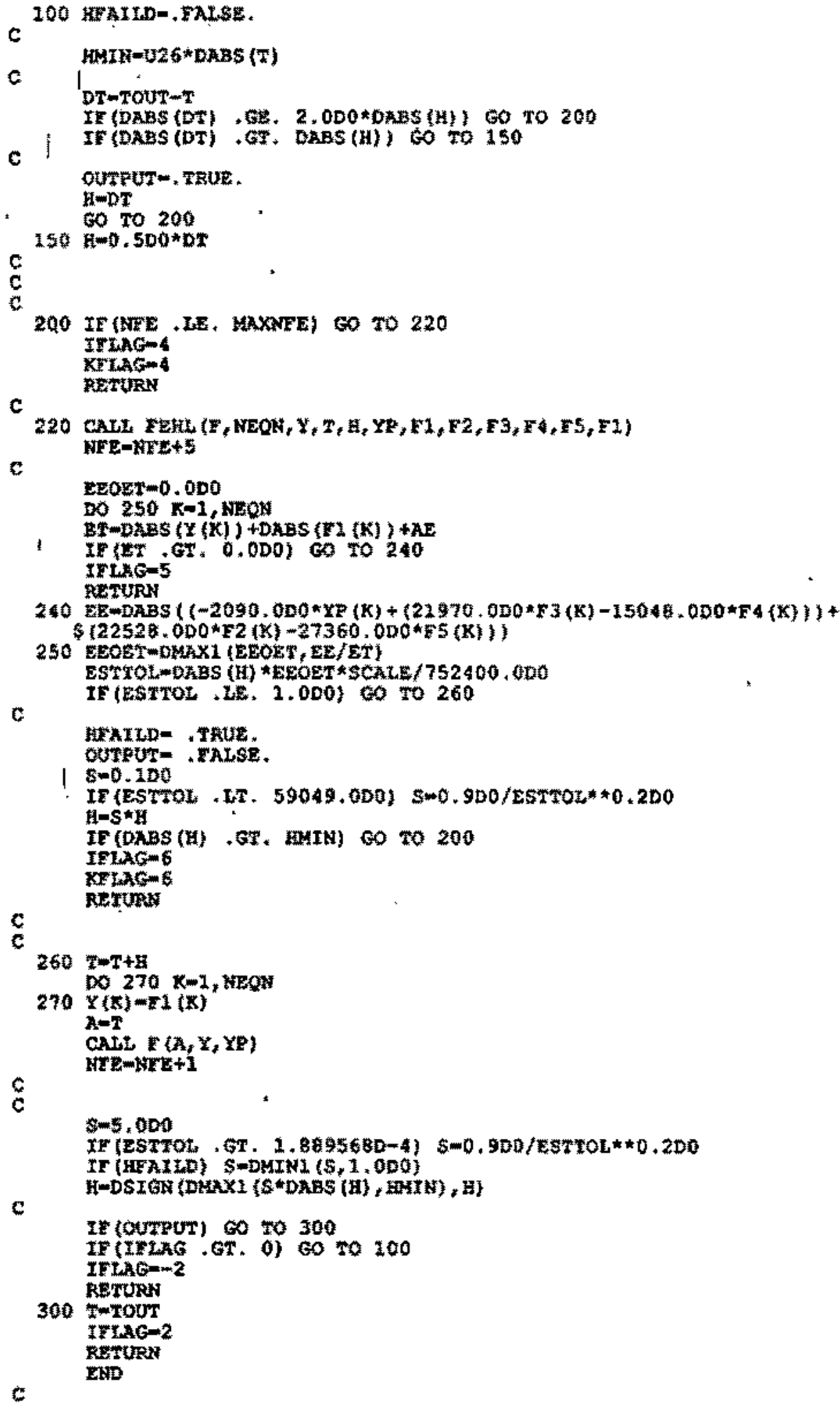




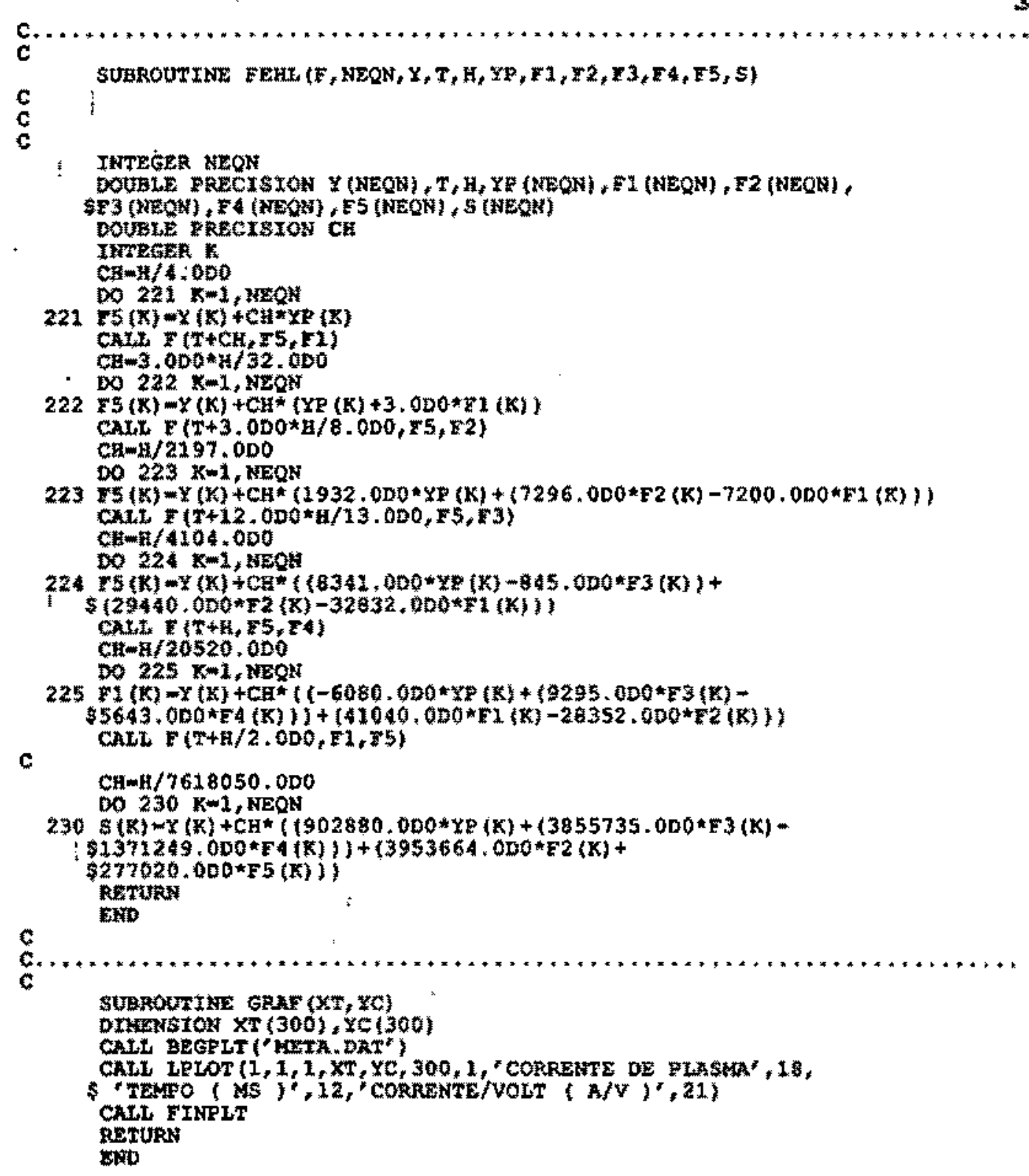




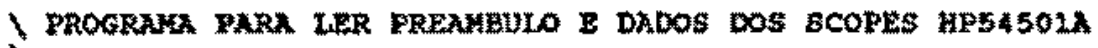

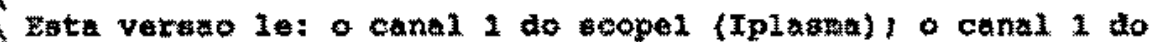

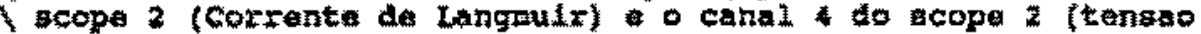
(de vartodura)

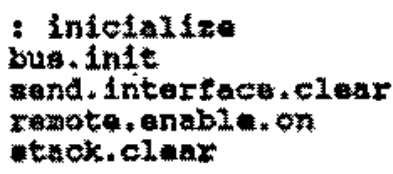


* :waveform: source channel 1* talk

- :waveform:xref?" talk

me listener scopel talker

"xrer 11 sten

untalk unlisten

nxref 32 number xres :=

me talker scopel listener

" :waveform: source channelin talk

" :waveform:yinc?" talk

me listener scopel talker

"yinc 1 isten

untalk unlisten

nyinc 32 "number yinc :

\#e talker scopel listener

" :waveform: source channel1" talk

n :waveform:yor?n talk

me listener scopel, talker

"yor listen

untalk unlisten

"yor 32 "number yor :=

me talker scopel listener

" :waveform: source channel1" talk

n :waveform:yrei?n talk

me listener scopel talker

"yres $118 t e n$

untalk unlisten

r

"yree 32 "number yret :0

\.... word para ler os pontos do canal 1 scope $1 . .$.

- read.datacisi

stack.clear

me listener scopel talker scopel w.data [jgpib.buefer

we talker scopel listener

" : waveform: source channelin talk

n :waveform: format compressed" talk

" : waveform:data?" talk

me listener acopel talker bufter.11sten

w.data unpack sub[11,500] w.data :=

polnts $1+1$ do $100 \mathrm{p}$$$
\text { w.data [ } 1 \text { ] yref - yinc } \text { yor + voltclsl [ } 1 \text { ]:= }
$$

voltclsi y.auto.plot bell

points $1+1$ do

1 xref - xinc xor + a.time[1]:=

$100 p$

a.time voltclsi xy.auto.plot bell

1.... word para ler preambulo do canal 1 do scope 2....

- read.preclez

stack.clear

me talker scope2 listener

* : waveform: source channel1" talk

- :waveform: points?n talk

me listener scope2 talker

"points listen

untalk unlisten 


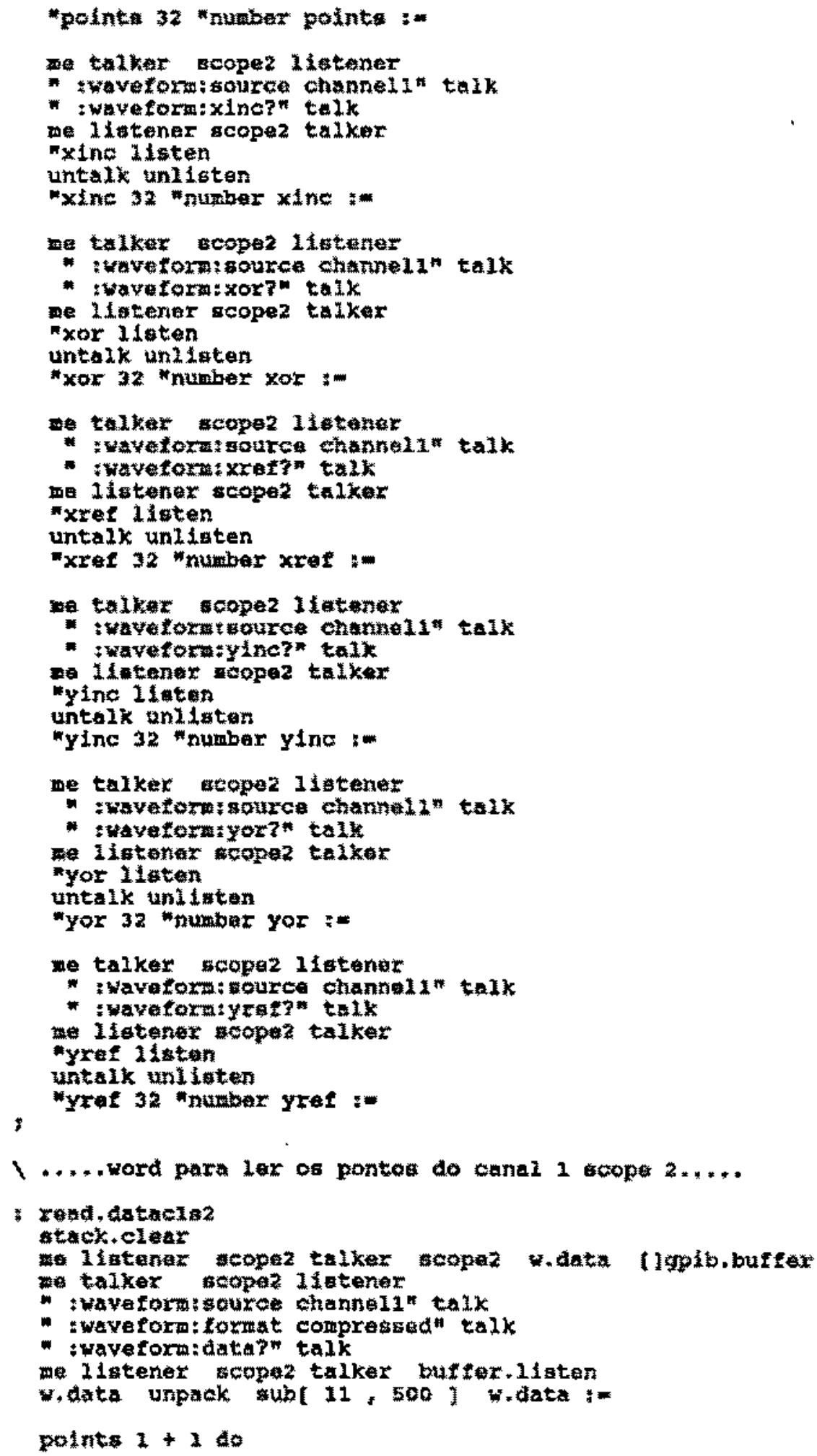




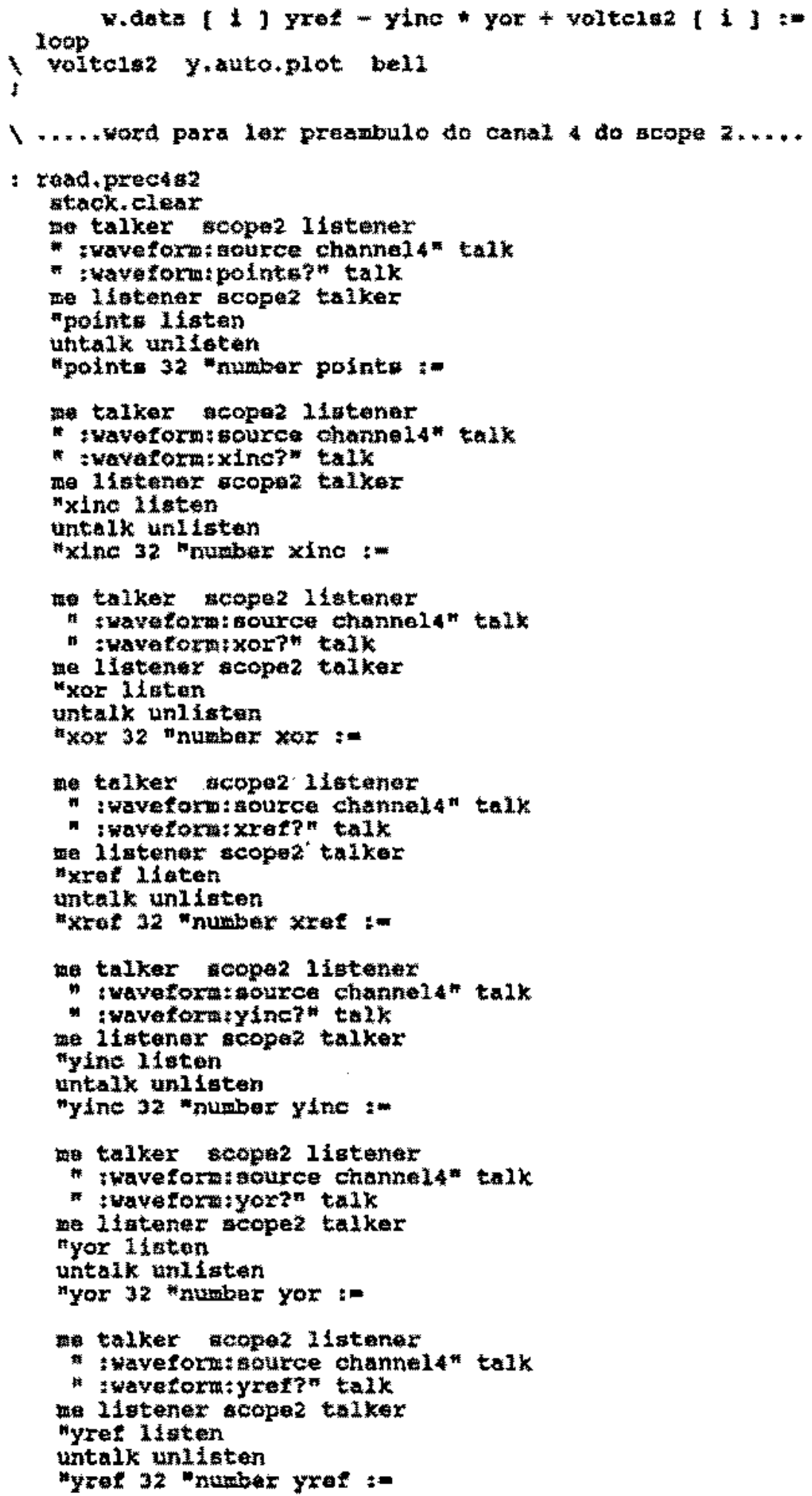


| .....tord para ler ow pontos do canal 4 stope $2 \ldots .$.

- raad. datroctar

ttack. eloer

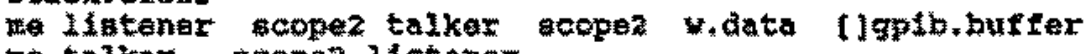

wh taker seoper 31etener

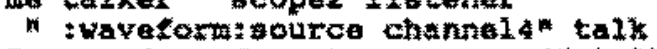

* Fwaverorm: forpat compressed" talk

" : wavoform : data?" talk

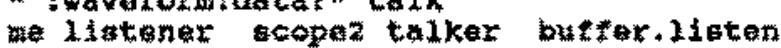

w. date unpack subl 11,500 \% wat :"

polntas +1 to

loop

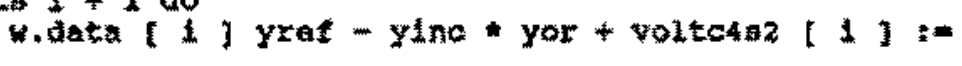

:

voltc4e2 y.tuto.plot bell

1 ..... wara de exacucato....

10

inictalize

reat.

read. dm taclal

read precter

readidataclet

read.prectis

rad datacte?

n

$\Delta$. voltcas voltelaz voltelal

setup

ball 1

,

ESTE FROGRAMA PXz $x$ ANALISE DE DADOS PARX DETERMINAR $\lambda$

TERPERATURA DE FIETTRONICA DA FCEN.

Y

Estz vergao 1 e o arqulvo previambnte guardado com tord

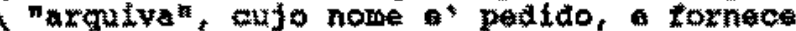

(1- corrente de plespa (t).

2- The

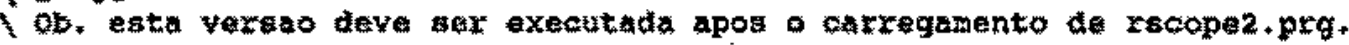

token $y *$ toxan

token $x$,token

real netar ct 20.0 ot :- \ constante multiplicatica da tensao varratura real salar eo 0.02 cc :

15 turing flinenato

3 atring dataname

60 string parameters

: yesno?

mingut 1 ieft "olup

$m y^{\prime \prime}{ }^{n}=$ moskl

;

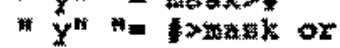

$\checkmark$ constinte mult. da corterte di conda

2012379 Halow (text.down)

$\checkmark$ define area inferlor para texto

grap.diap

?graphics a aplay

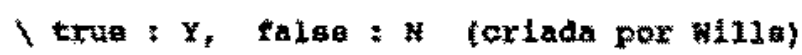

1 19a moxo gratico 


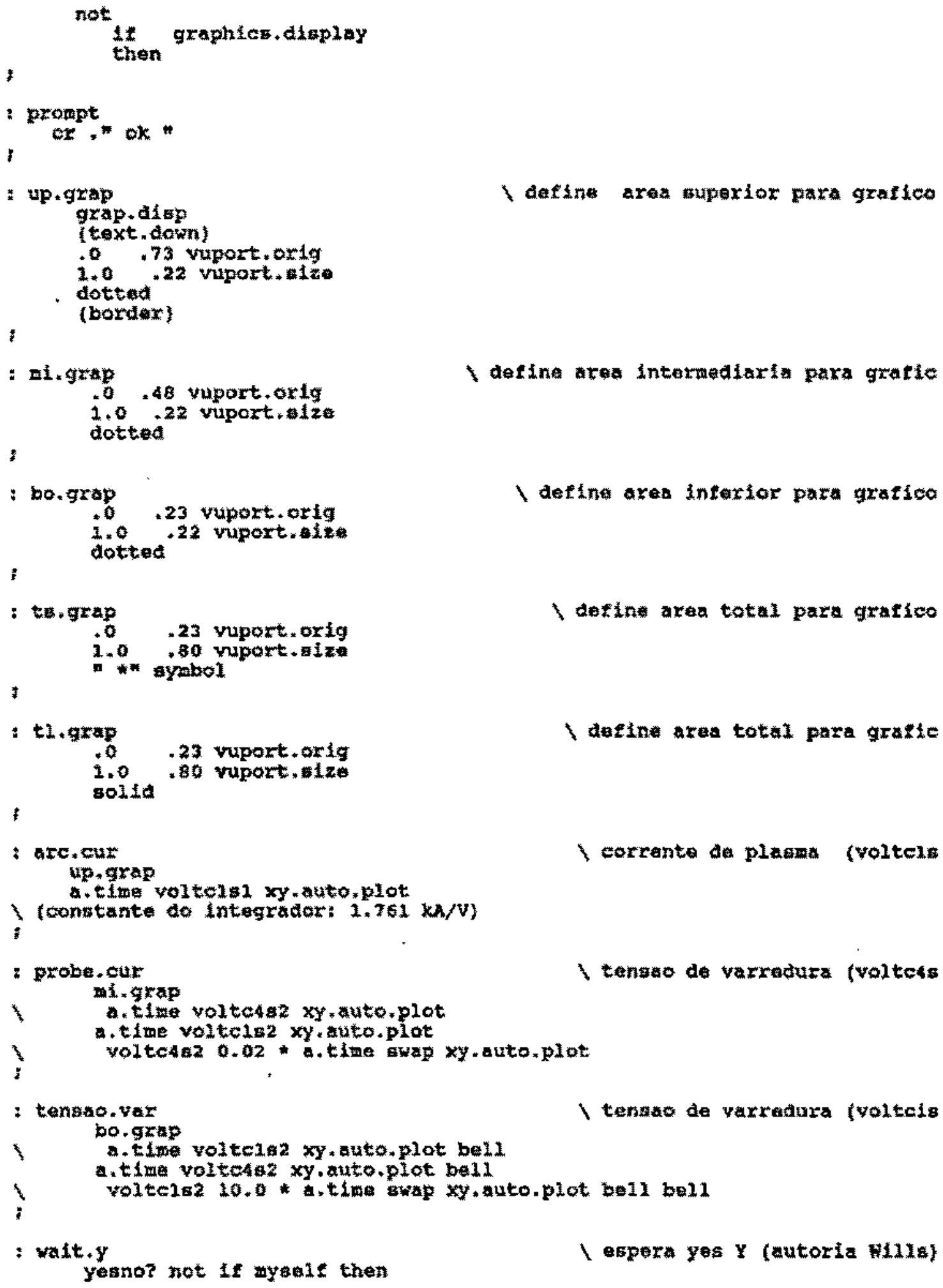


;

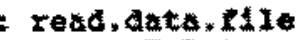

cr." Dntre com a nowa do arequivo:

160 expivo

tmul 1 lienana w:

*input 13ienama ${ }^{*}:$ :

tilenume datary ille.open

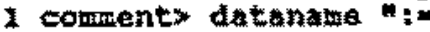

2 comanty parataterg $n$

1 gubftie voltcisi filetarway

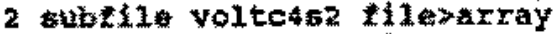

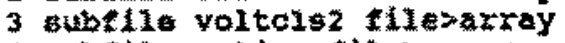

4 atollie a.time tilasarray

1.1. . Eloga

2 detele

stack, claw

read. at thotie

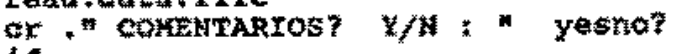

11

cr dutamane ntype or

cx paranetara istype cr

then

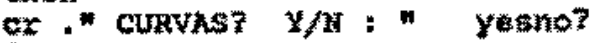

31

arc, cult

proba - cux

terise

thett

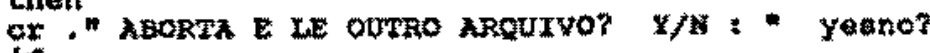

和

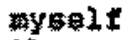

tren

dimt 4 rala array curatax

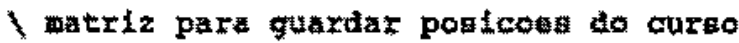

* 1nterrato

matray, rextodut

norma 1 cootat

, 4.5 rextoutpoostion

vor $1 \mathrm{a}$, coowda

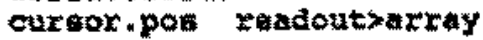

cx

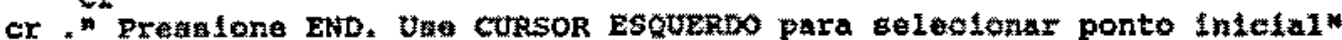

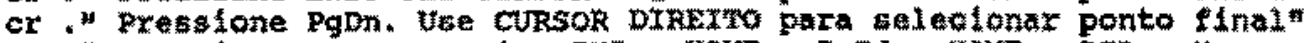

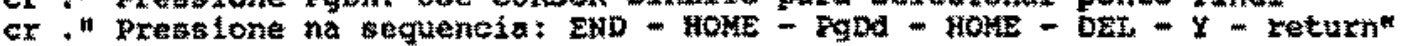

tis

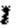
walt.y

real Eealax minp

real sealdx wexp

real selax nump

zeal onstax

* survasa,polntw

I Ita cumis volts $x$ ponto

up.grap

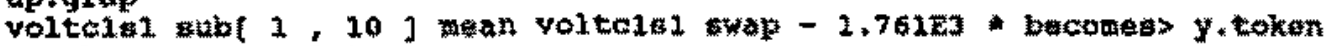
Y. taken y.auto.plot

norma 1 , coords

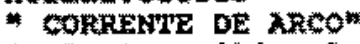

6.17 .9 posdtion inbel 


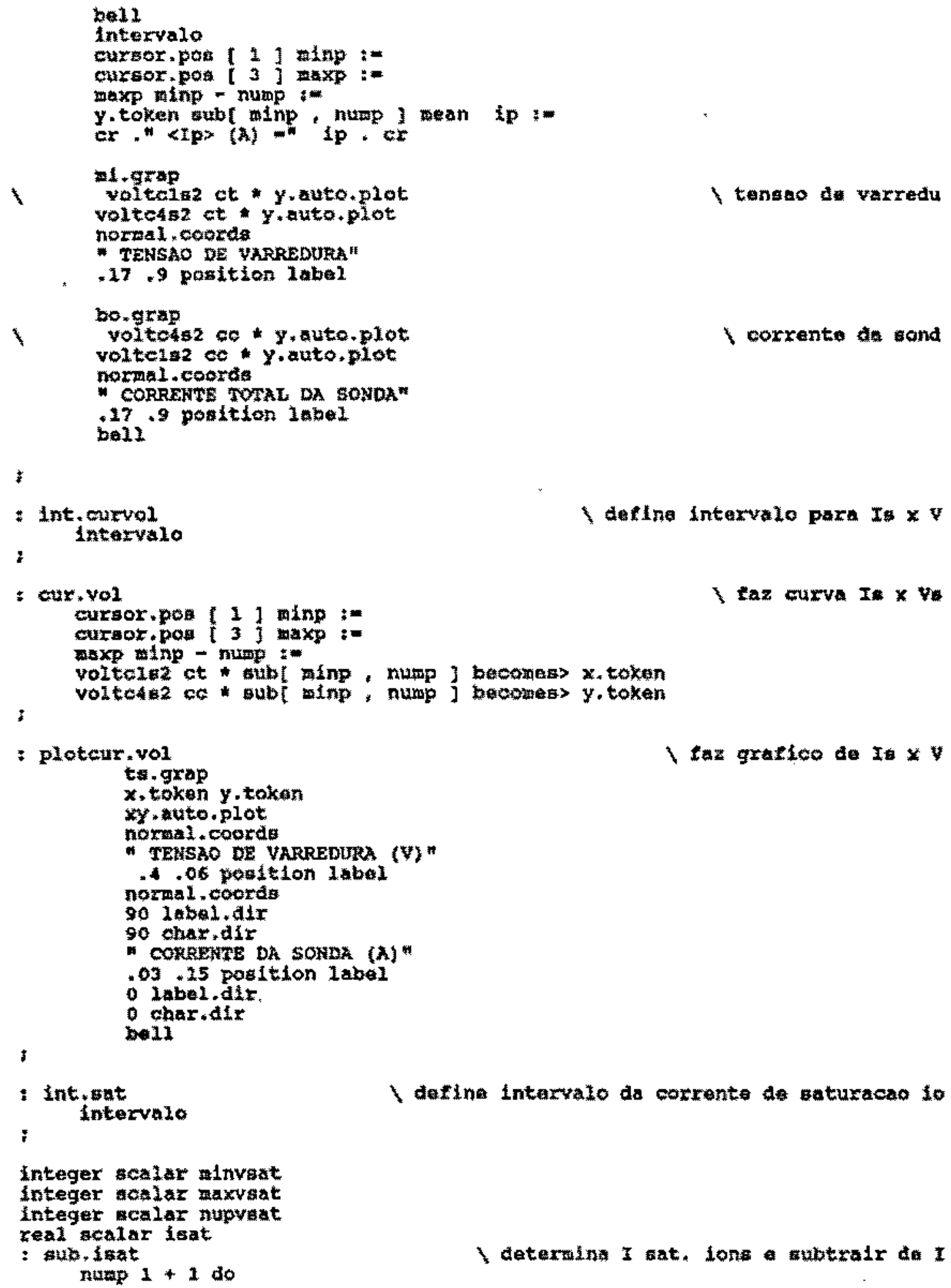

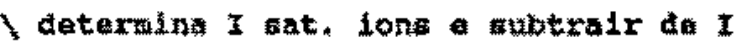




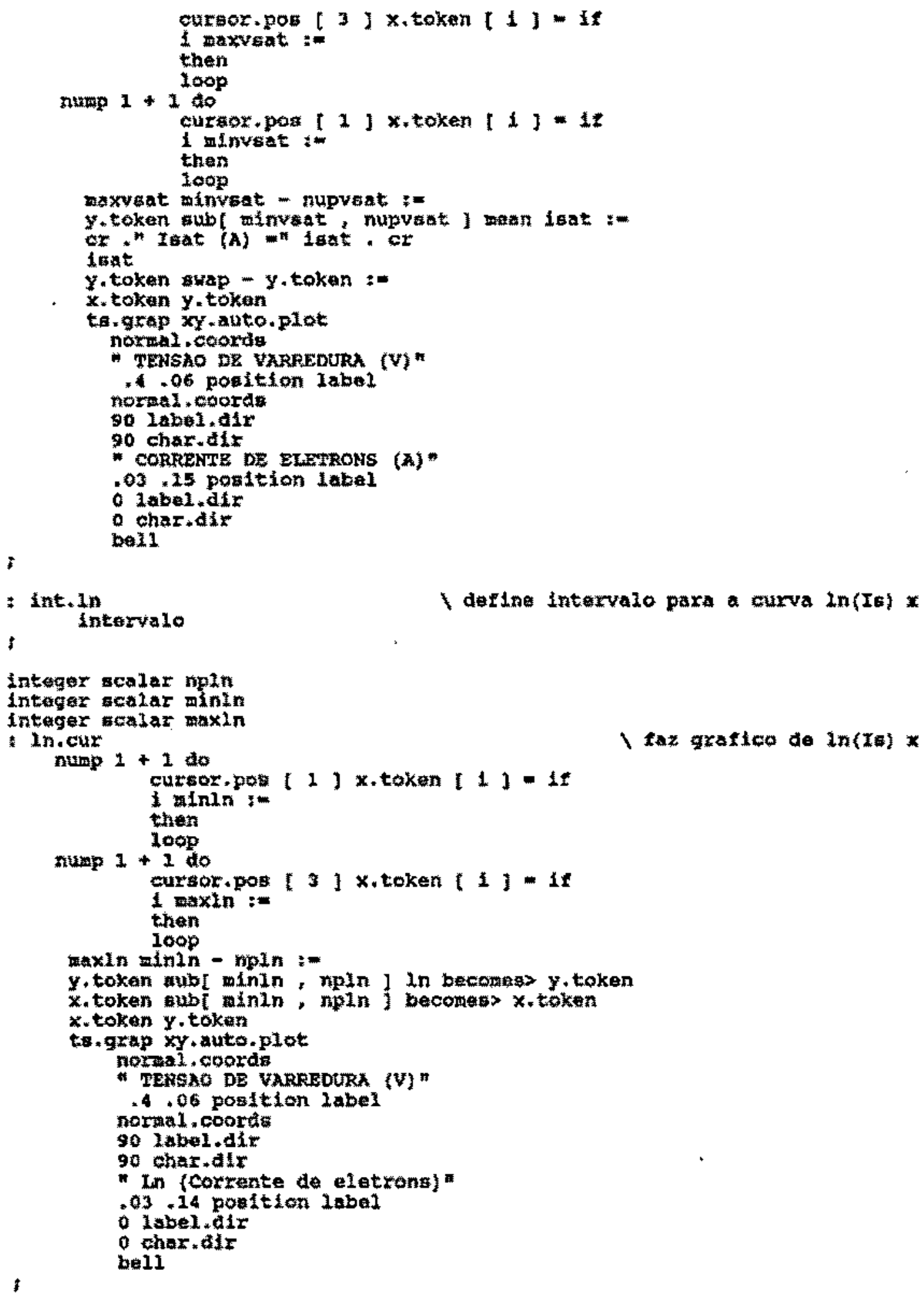


$$
\text { * int reta }
$$$$
\text { Interyalo }
$$

1 aefine intervalo waxa ajugtor ret

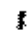

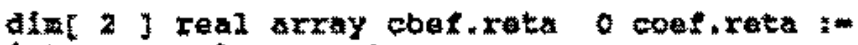

intage sealar noxata

interar sos lax" wareta

Integer sealaz minrota

did[ 2 i real array pontoy 0 pontoy :-

1. 2 I real arxay pontox 0 pontox :

* ajuste.trets npin $1+1$ do

f ajusta rata ax+buy nos pts solutelonad

cuxacx.pos [ i j x.token $(1\}=3 x$

1 minxata :m

then

loop

npln $2+1$ do

cursor,pos $[3] x$.token $[1]=12$

1 saxratio i

then

loop

mexreta minrata - nprets :-

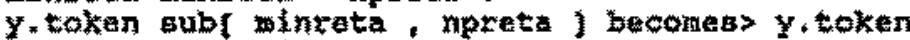

$x$. token subl minreta, nprota 1 becmes> $X$, waken

$x_{*}$ token $y$ thoken

th.grap xy.auto.plot

$x \cdot \operatorname{toxan} y \cdot \operatorname{token} 1$

leatig-poly +it

coat rata :-

ecal, zata

.

\section{cursox, tate}

coet "rata ( 1 ) xutoken ( 1 ) cost.retin ( 2 )

pantoy $(1):=$

x. toxan $[1]$ pontox [ 1$]$;

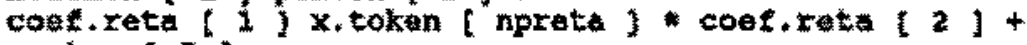
pontoy $[2]:=$

$x$. token [ npreta ] pontox [ 2 ]:

pontox pontoy

soldd $x y$, datektot

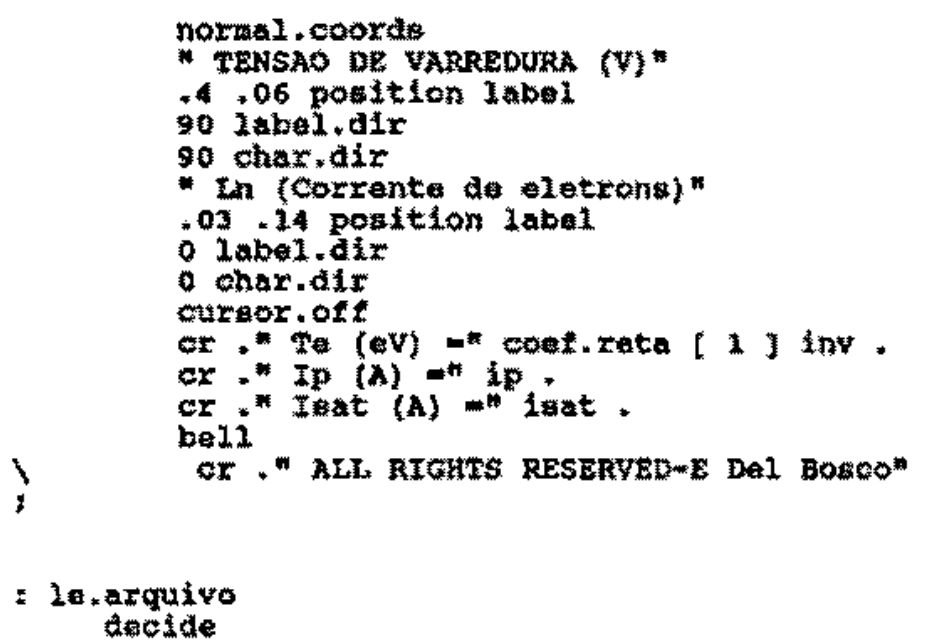



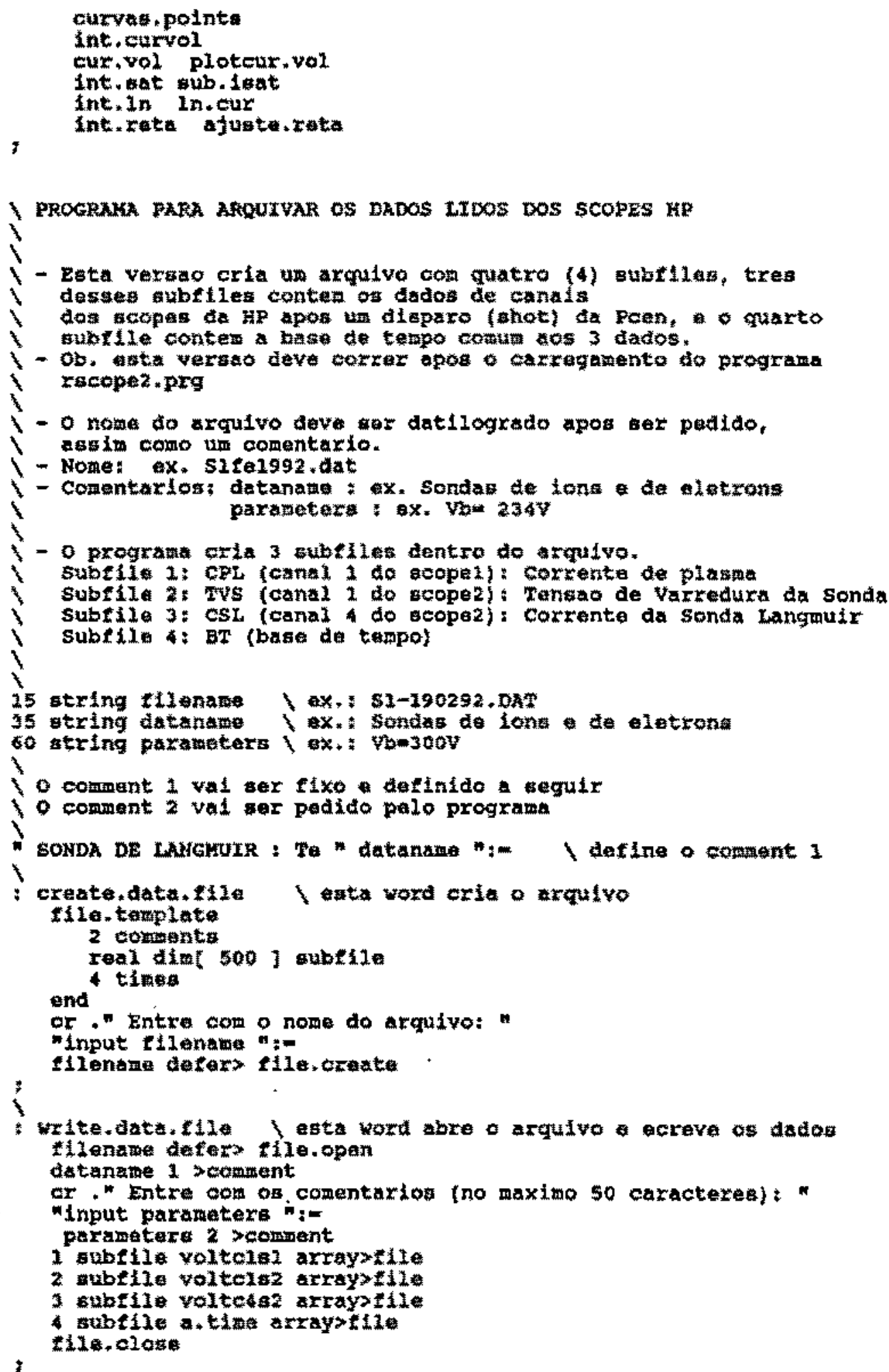


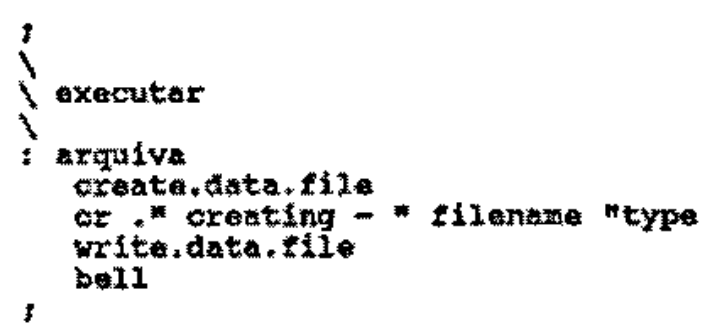

B-12 
1 ESTE PROGRAMA CALEULA A CORREZACAO CRUZADA DAS TORAS DE ONDA

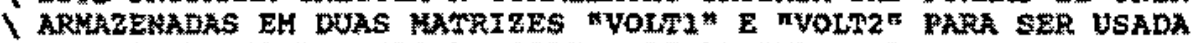
F NO CALCULO DA ROTACXO DA COLUNA DE PLASKA DA PCEK.

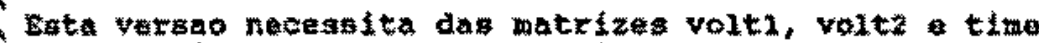

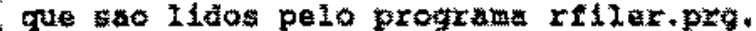

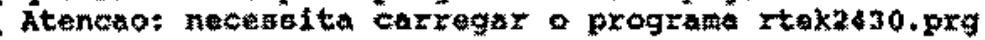

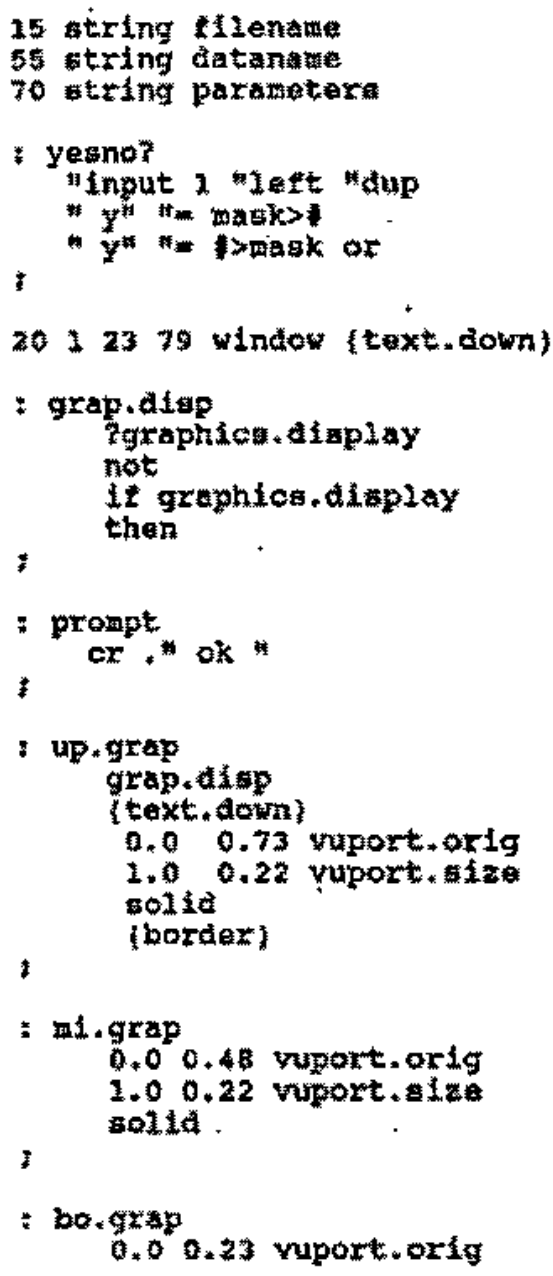




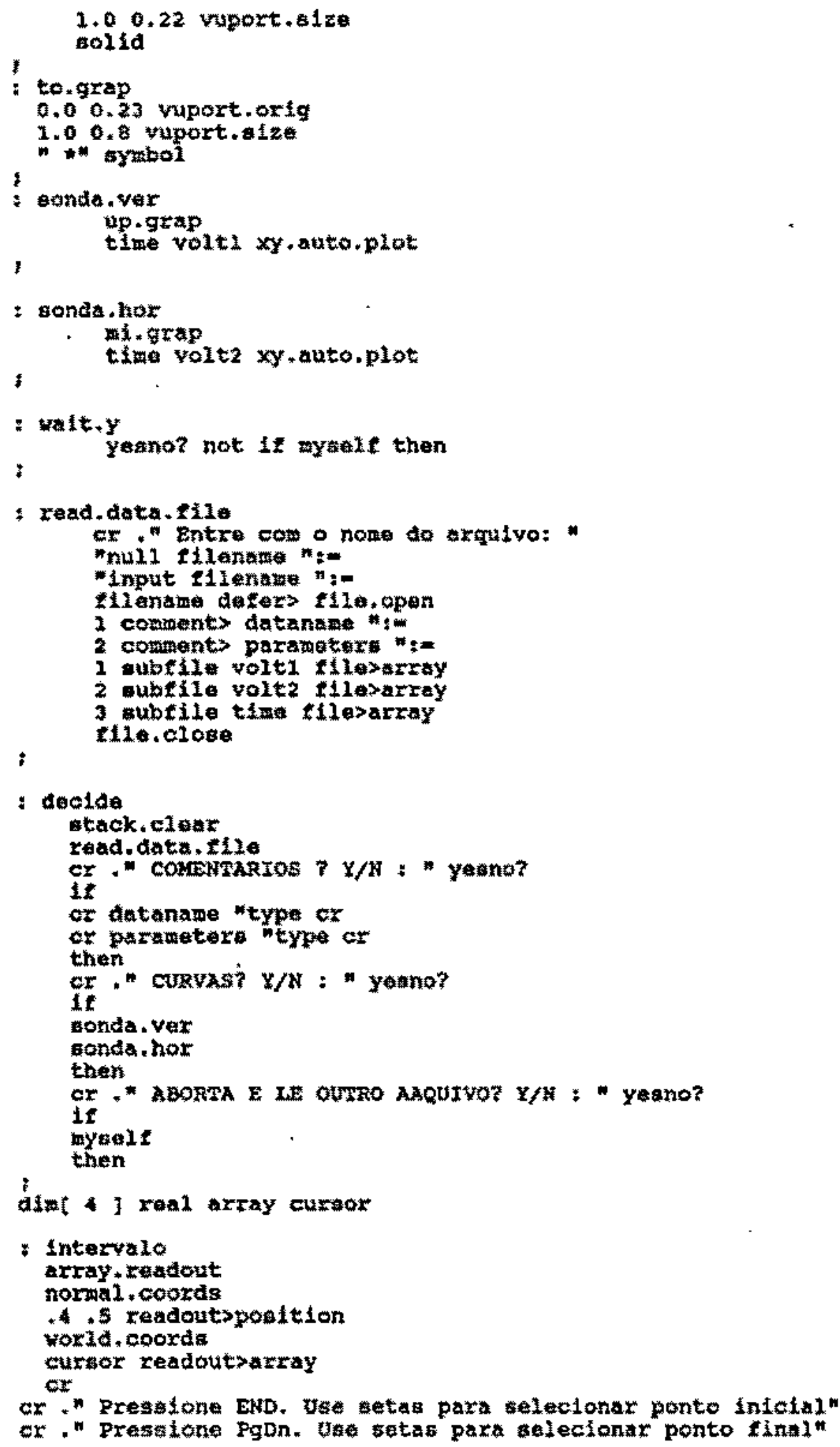




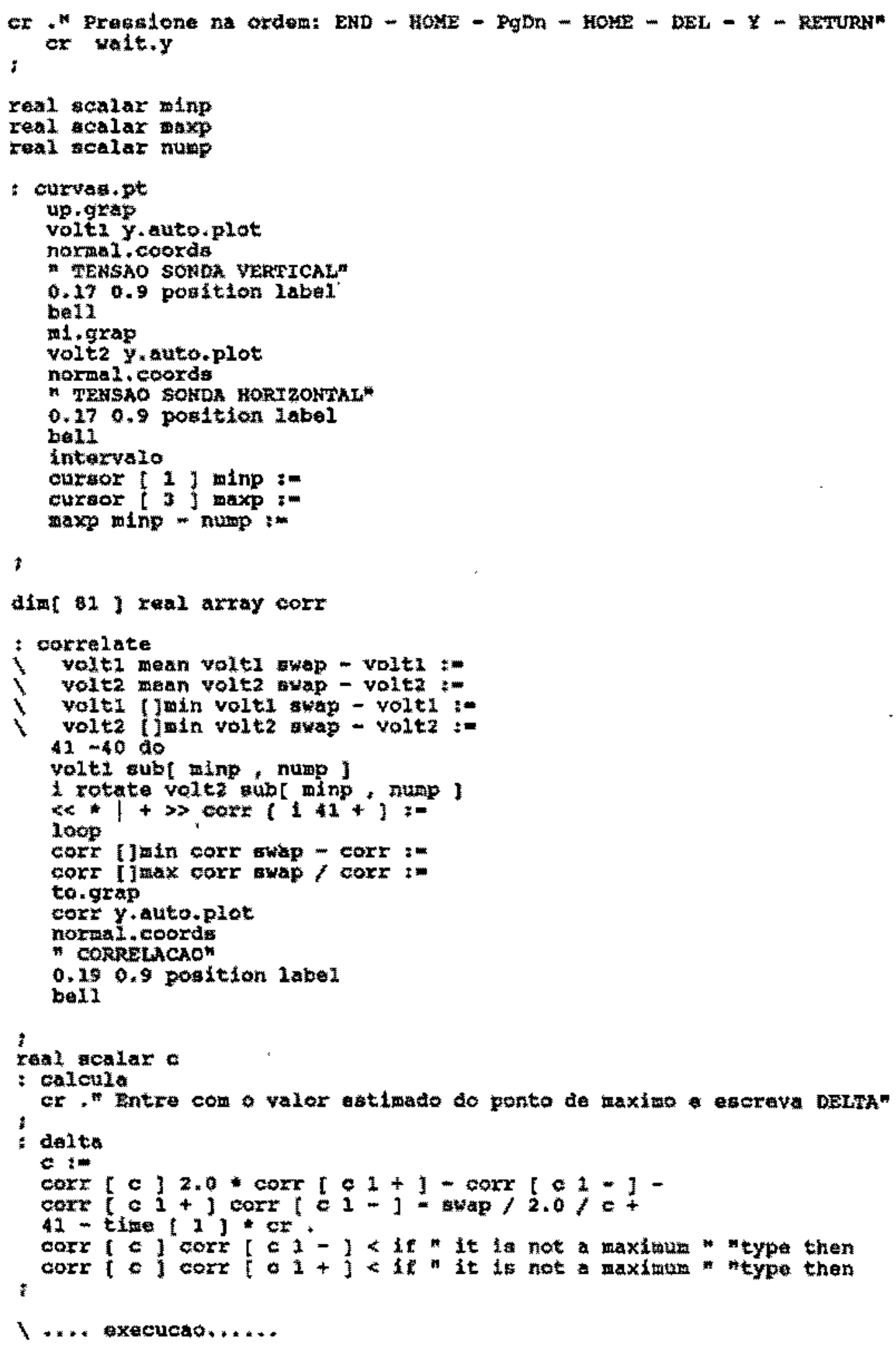


- rotacao

raa. data . Ita

declata

curvata, pt

coxralisto

calcula 


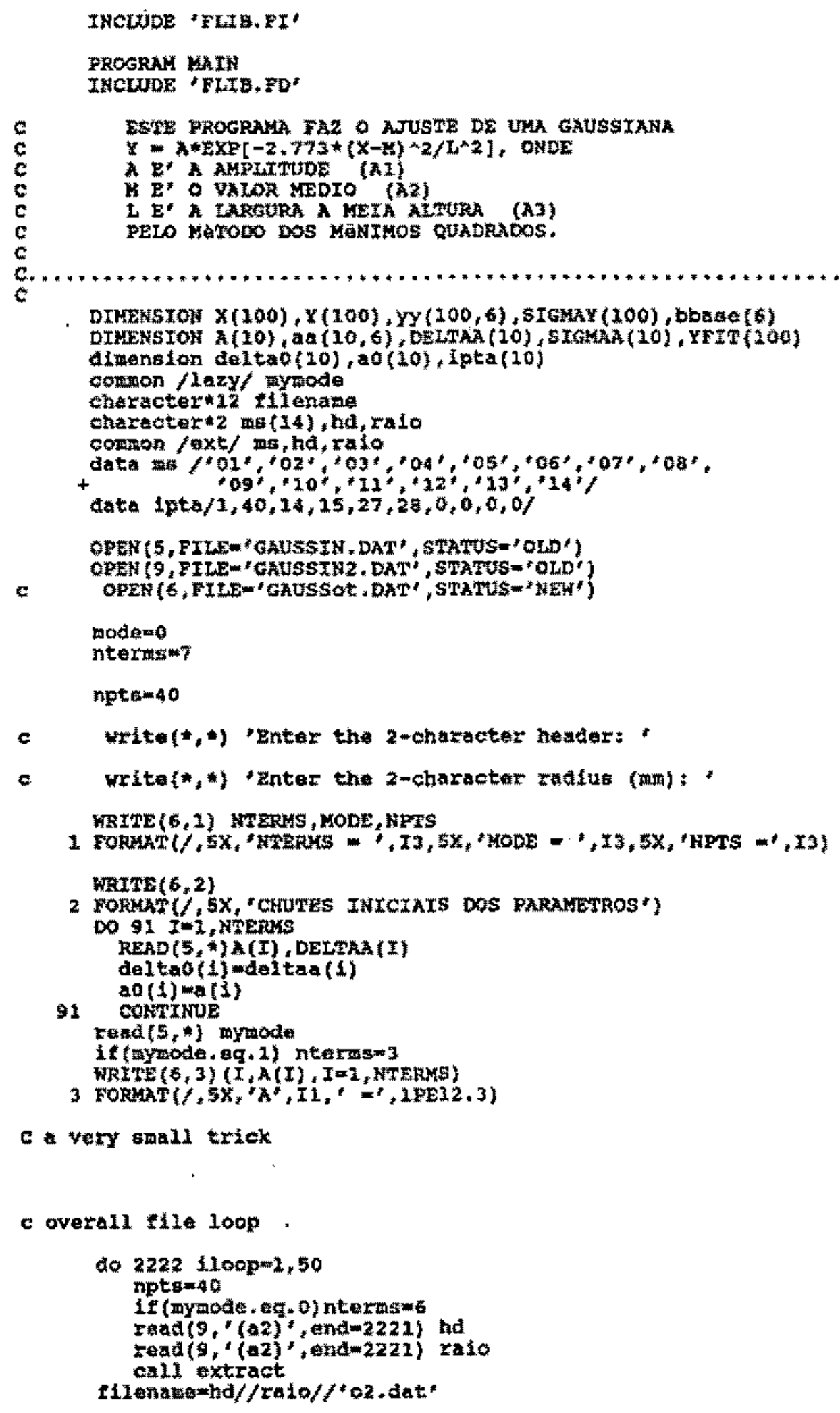




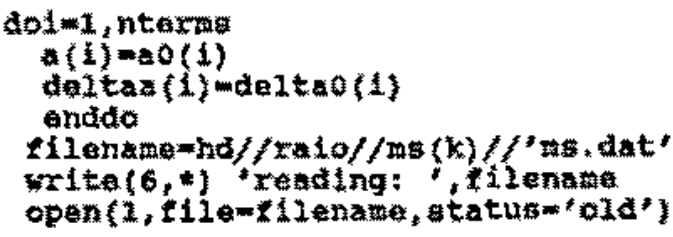

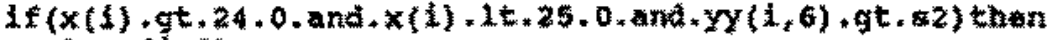
sis-yy $(1,6)$

6

* add more polnts

c cooked to reduce soparation

e

doj $=1,6$ 


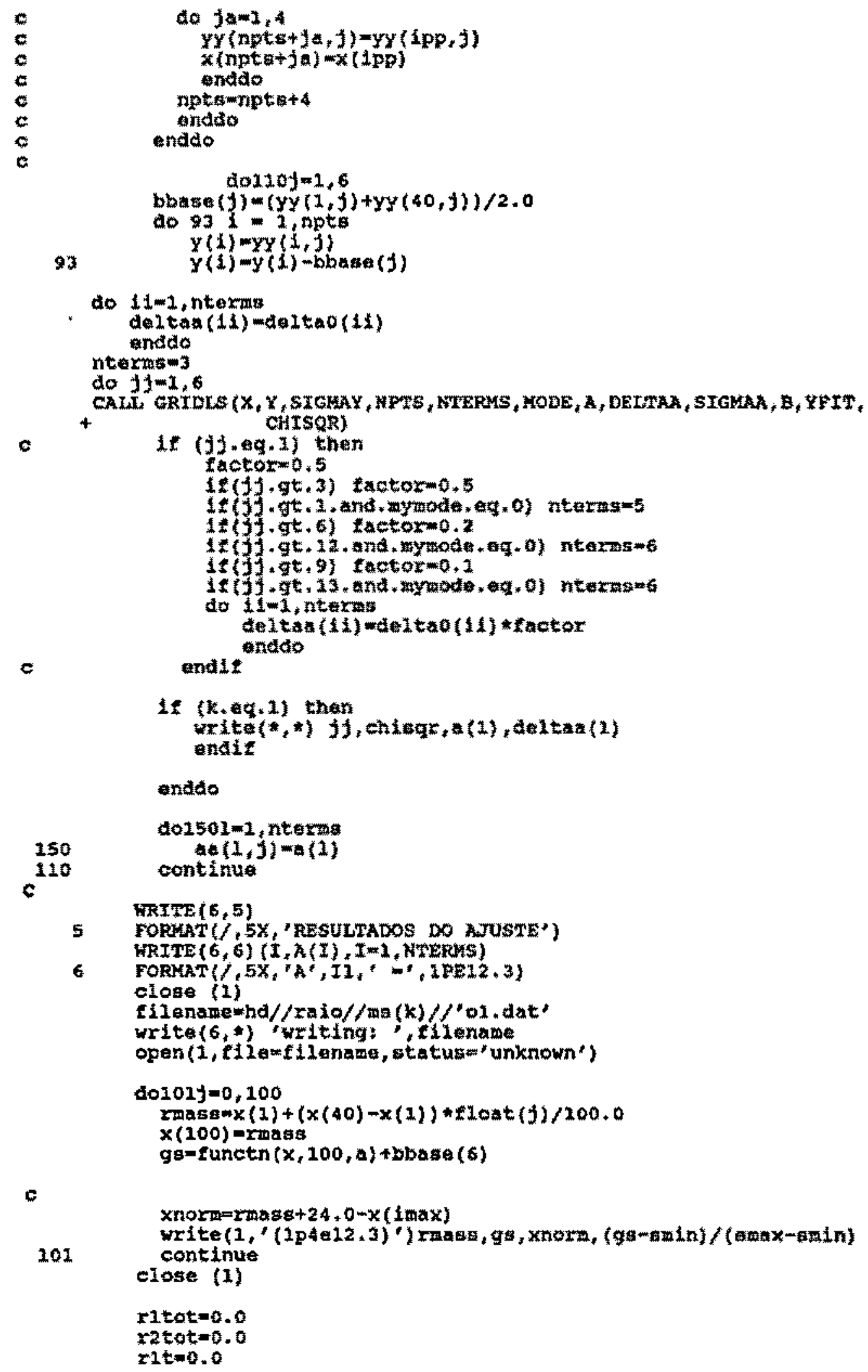


c throw out wort case

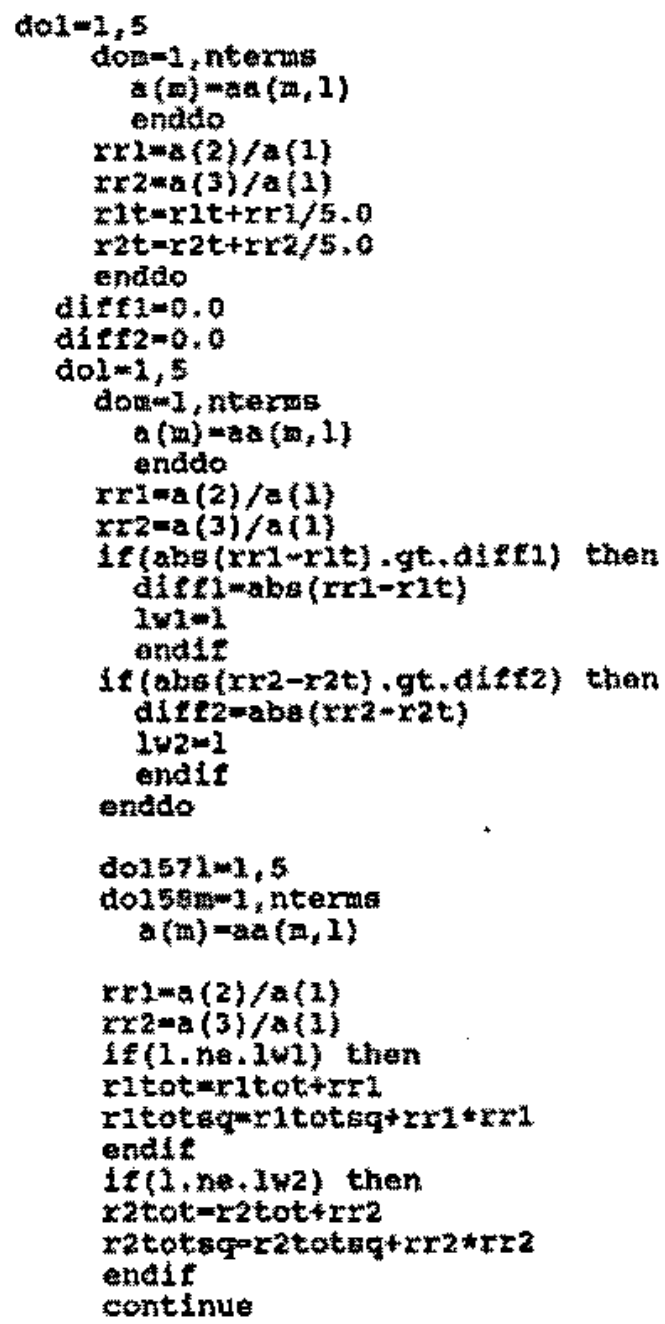

157

adevisget ( (ritotsq-ratot*r1tot $/ 4.0) / 4.0 / 3.0)$

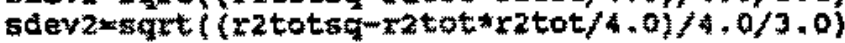
rnor2. $=70.79 / 10.13$ znox ${ }^{\prime}=78.29 / 21.17$ ximedimiteot 4,0 ramentotot 4.0

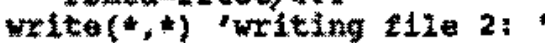
Write(2,'(1pse12*3)' flott(k)

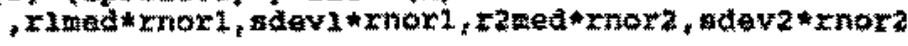

6

Nㅐ

c 


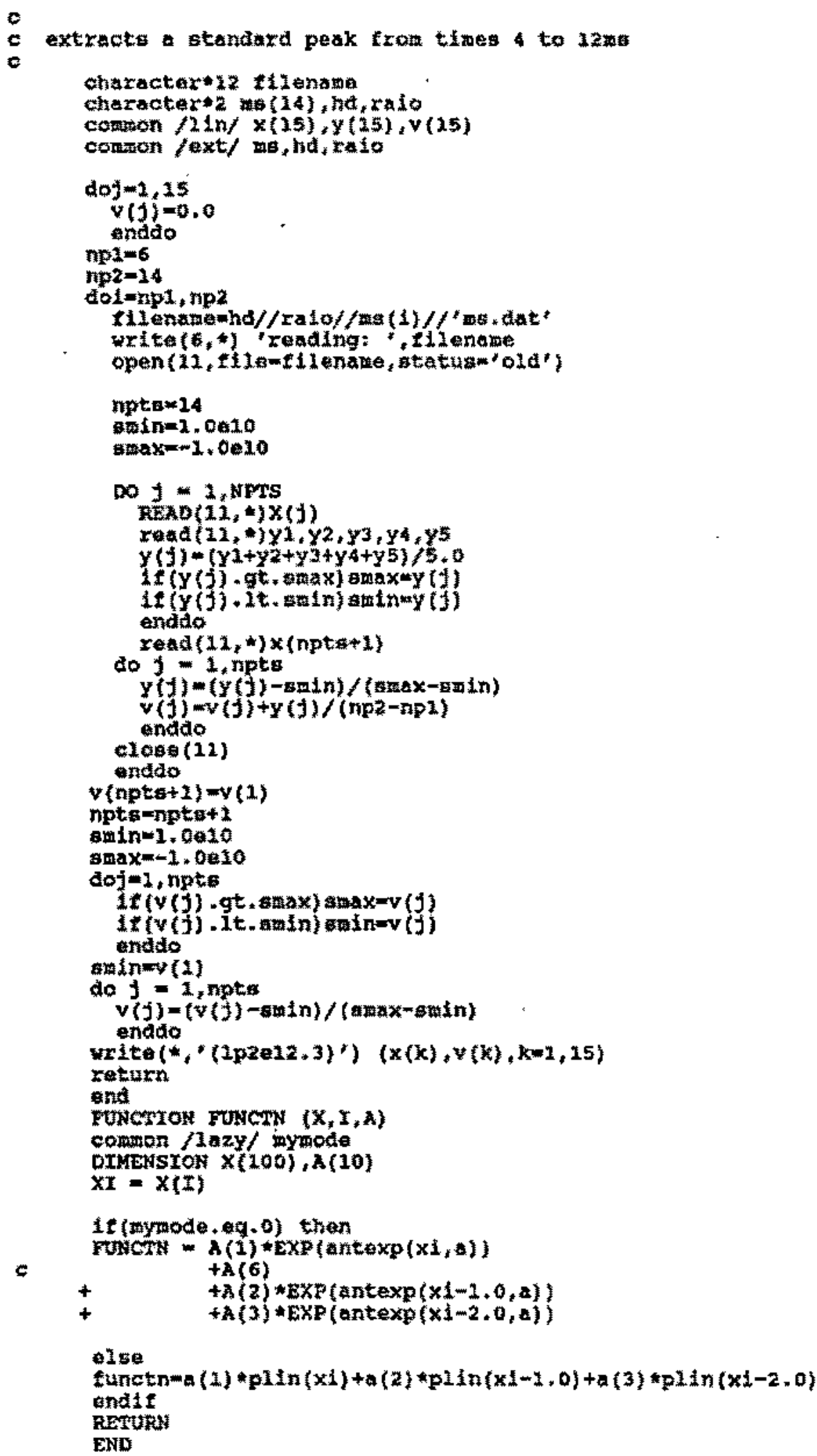




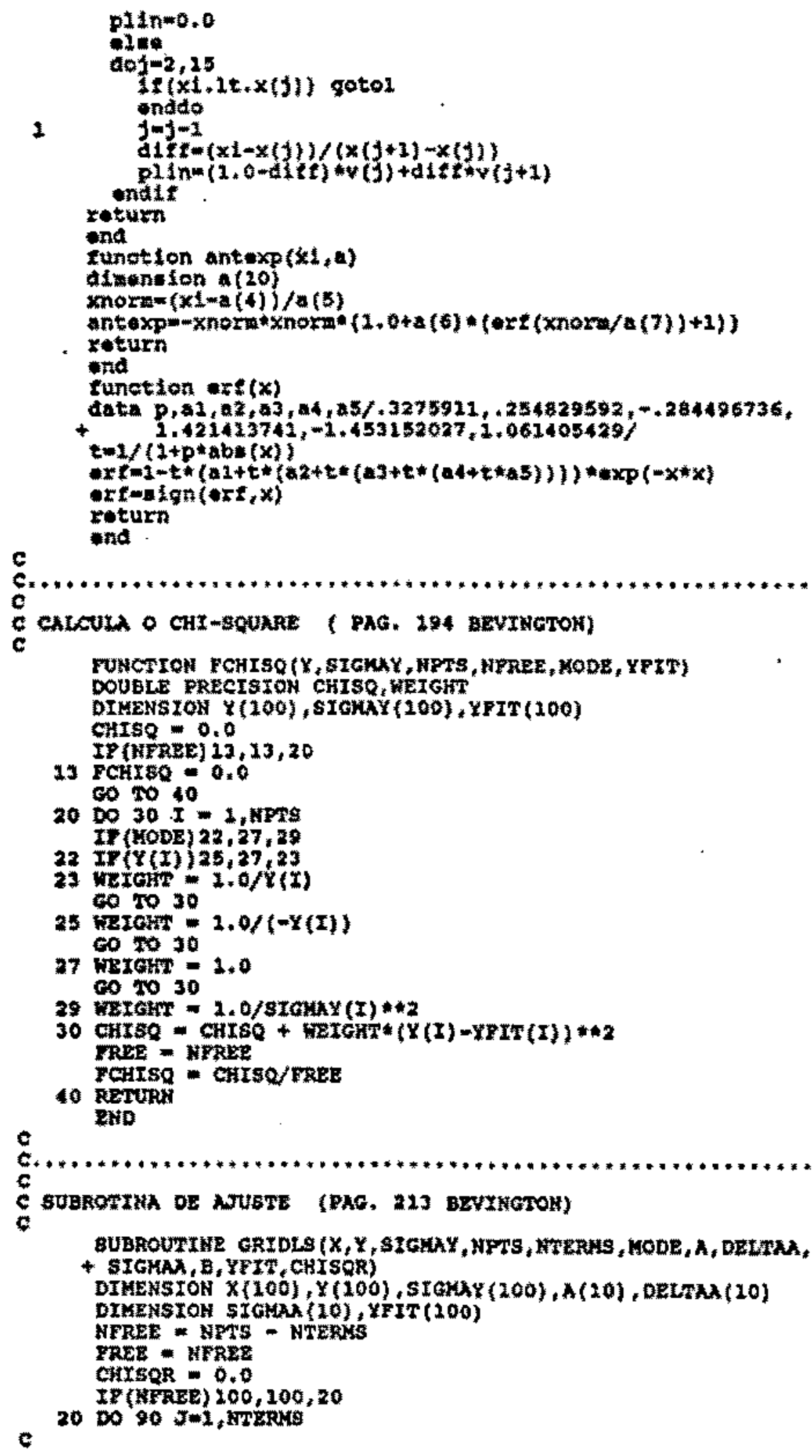

